Book.

Submitted to Open Behavioral Genetics December 25, 2014

Published in Open Behavioral Genetics June 20, 2015

\title{
The Nature of Race: the Genealogy of the Concept and the Biological Construct's Contemporaneous Utility
}

\section{John Fuerst ${ }^{1}$}

Abstract: Racial constructionists, anti-naturalists, and anti-realists have challenged users of the biological race concept to provide and defend, from the perspective of biology, biological philosophy, and ethics, a biologically informed concept of race. In this paper, an ontoepistemology of biology is developed. What it is, by this, to be "biological real" and "biologically meaningful" and to represent a "biological natural division" is explained. Early 18th century race concepts are discussed in detail and are shown to be both sensible and not greatly dissimilar to modern concepts. A general biological race concept (GBRC) is developed. It is explained what the GBRC does and does not entail and how this concept unifies the plethora of specific ones, past and present. Other race concepts as developed in the philosophical literature are discussed in relation to the GBRC. The sense in which races are both real and natural is explained. Racial essentialism of the relational sort is shown to be coherent. Next, the GBRC is discussed in relation to anthropological discourse. Traditional human racial classifications are defended from common criticisms: historical incoherence, arbitrariness, cluster discordance, etc. Whether or not these traditional human races could qualify as taxa subspecies - or even species - is considered. It is argued that they could qualify as taxa subspecies by liberal readings of conventional standards. Further, it is pointed out that some species concepts potentially allow certain human populations to be designated as species. It is explained why, by conventional population genetic and statistical standards, genetic differences between major human racial groups are at least moderate. Behavioral genetic differences associated with human races are discussed in general and in specific. The matter of race differences in cognitive ability is briefly considered. Finally, the race concept is defended from various criticisms. First, logical and empirical critiques are dissected. These include: biological scientific, sociological, ontological, onto-epistemological, semantic, and teleological arguments. None are found to have any merit. Second, moral-based arguments are investigated in context to a general ethical frame and are counter-critiqued. Racial inequality, racial nepotism, and the "Racial Worldview" are discussed. What is dubbed the Anti-Racial Worldview is rejected on both empirical and moral grounds. Finally, an area of future investigation - the politics of the destruction of the race concept - is pointed to.

Keywords: natural division, race, biology

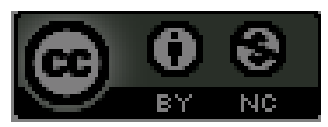

${ }^{11}$ Corresponding author: j122177@ hotmail.com 
Contents

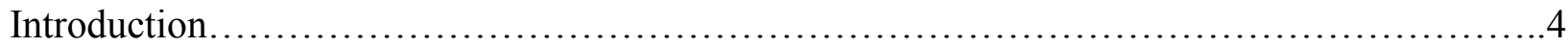

I. Biology - A Philosophical Clarification............................................5

I-A. Existing Views: Confusions Abound

I-B. Biological Concepts in General

I-C. The Validity of Biological Concepts

I-D. Biological Kinds

I-E. Natural Biological Divisions

I-F. Races as Natural Biological Divisions

I-G. The Intraspecific Natural Division as Type of Biological Variation

I-H. The Natural Division as a Taxonomic Unit

I-I. Natural Divisions and Intraspecific Variation with Regards to the Subspecies Category

I-J. Biologically Meaningful Race Concepts

I-K. Biological Reality

I-L. Biologically Important Differences

I-M. Concepts of Biological Race

II. The General Biological Race Concept..........................................25

II-A. The Genealogy of the Concept

II-B. Semantic Complexities and the Evolution of the Race Concept

II-C. Biological Race

II-D. What the Core Biological Race Concept Does Not represent

II-E. Races, Clines, Clusters?

II-F. Clarification on the Meaning of "Arbitrary" and "Objective" in Context to Natural Divisions

II-G. Regarding Different Definitions of Biological Race: What Races Need Not Be

II-H. Genomic-Genealogical Complications

II-I. Estimated Genomic Similarity: Some Ambiguity

II-J. Race: Mixed and Undifferentiated

II-K. Essential and Cluster classes; Fuzzy and Discrete Sets

II-L. Sociological Clarifications

III. The Ontology of Biological Race...

III-A. Other Defenses of Biological Race

III-B. Biological Races and Biological Reality

III-C. Thin Biological Racial Essentialism

IV. The Races of Man

IV-A. A Very Brief Historical Review

IV-B. Human Biological Races and Scientific Consensus

IV-C. Racial Classifications and Biological Race Concepts

IV-D. Traditional human Races

IV-E. THRs and Biologically Objective Races

IV-F. THRs and Migration, Intermixing, and Ancient Admixture

IV-G. THRs and Cluster Discordance 
IV-H. THRs and Taxonomy

IV-I. THRs and Subspecies

IV-J. Are There Human Species?

IV-K. "Significant" Racial Differences

IV-L. Human Biodiversity (HBD) and Society

IV-M. Race and Intelligence

V. Critique of Anti-Biological Race Arguments

126

V-A. Anti-Biological Arguments

V-B. Biological Scientific Arguments

V-C. Sociological Arguments

V-D. Unnaturalistic Arguments and the Numbers Game

V-E. Onto-epistemology Arguments

V-F. Semantic Arguments

V-G. No-True-Race Arguments

V-H. Teleological Argument: The Future of Race

V.I. Can a Good Argument be Made Against (the) Race (concept)?

VI. A Troublesome Inheritance?

VI-A. The Social Destruction of a Biological Reality

VI-B. A Not So New Morality for Race

VI-C. The Moral Critiques: Arguments based on Outcome Differences

VI-D. The Moral Critiques: Arguments based on Racial Classification and Identity

VI-E. The Moral Critiques: Arguments based on Racial Favoritism

VI-F. The Moral Critiques: Arguments based on the "Racial Worldview"

Conclusion

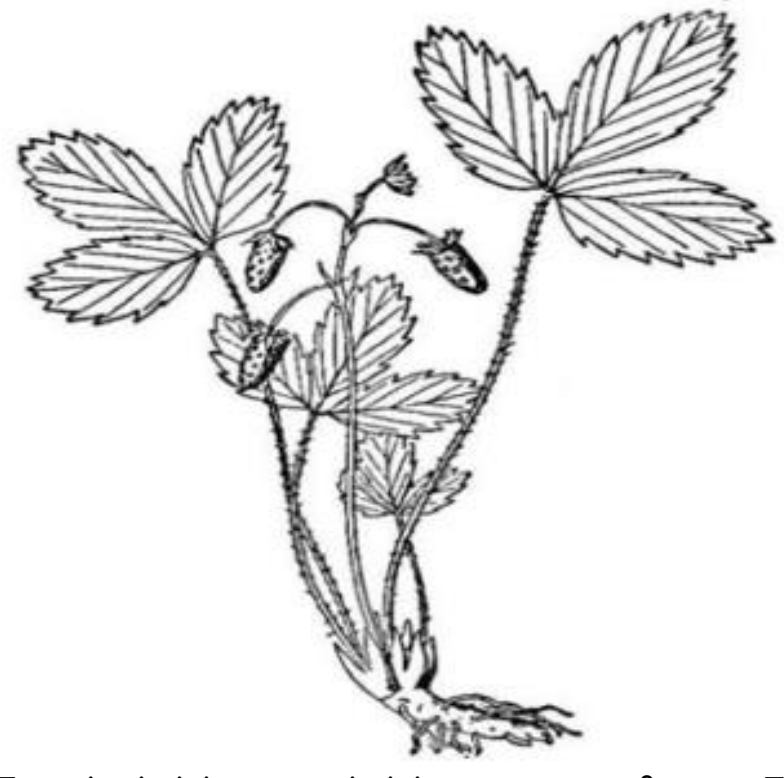

Fragaria virginiana ssp. virginiana
\& $\quad$ Fragaria virginiana ssp. grayana (Britton and Brown, 1913) 
The task for race naturalists, then, is to develop a "biologically informed but non-essentialist concept of race"[.] - Hochman (2013)

\section{Introduction}

It is frequently asserted: firstly, that the word "race" is meaningless; secondly, that races are not, biologically speaking, real; thirdly, that while there do exist biological races in other animal species, there are none in ours; and finally, that any biological differences between the human races are meaningless in the grand scheme of things.

It is infrequently acknowledged that the first through fourth statements can not all be true at the same time: if "race" is meaningless, it makes no sense to say that it is non-biological; if it is nonbiological, it can not exist in nonhuman animals; and so on and so forth. Nevertheless, these four contrary claims, individually flawed as they are, are thought by many to constitute, in composite, an ironclad argument against any attempt to characterize certain divisions of Homo sapiens as biological races. (Presumably it is not yet considered 'scientifically racist' to study biodiversity in other animal species, though we can not be sure. ${ }^{2}$ )

There is, of course, an element of truth to all four of the stated claims: the word "race" indeed has no unique definition; anyone can deem that whatever genetically based differences exist between human populations are unimportant; there are race concepts which are fundamentally non-biological; and there are biological race concepts (frequently made of straw) by which there are no human biological races. All of this is true, and rather trivial, but since the statements are so often taken to mean something true and nontrivial - that there is no robust sense in which human biological races exist - we feel compelled to provide a precise conceptual framework for biological race.

\footnotetext{
${ }^{2}$ We use single quotes to signify that a term is unclear; some of the quoted passages, however, use double quotes to signify the same. We use double quotes to call to attention that we are referring to a term, not a concept.
} 
Still, in the same way as we classify races and degenerations of horses and poultry, of pinks and tulips, so also, in addition, must we classify the varieties of mankind. - Blumenbach (1806)

\title{
I. Biology -A Philosophical Clarification
}

\section{I-A. Existing Views: Confusions Abound}

We must start by carving out a conceptual space for biologically real race. Regarding the panoply of existing views on race (and its biological reality, if any), we must confess to deep confusion. The least bewildering account may be that of philosopher Quayshawn Spencer (2012), which we quote simply to give a sense of the depths into which we are getting:

\begin{abstract}
Historically, "biological racial realism" has been interpreted in either one of two ways. One is "race is a natural kind in biology," and the second is "race is a real biological kind." However, race theorists adopt at least four different views about what a natural kind is. Let me begin with the natural kind views.
\end{abstract}

First, some race theorists - such as Anthony Appiah (1996, 40), Robin Andreasen (2000, S655S657), and Naomi Zack $(2002,4)$ - define a natural kind as an objectively real kind. A paradigm example is Andreasen's view. According to Andreasen (2000, S655), race must be a "natural kind" in order to be biologically real...

Second, some race theorists - such as Edouard Machery $(2005,446)$ and Glasgow $(2009,81)-$ define a natural kind as an inductively useful kind in science. For example, Machery (2005, 445, 446) defines "natural kinds" as "classes about which nonaccidental, scientifically relevant inductive generalizations can be formulated," and Machery and Faucher $(2005,1209)$ go on to require that race must have "inferential power" in order to be biologically real.

Third, some race theorists define a natural kind as a kind that is a useful object of study in a natural science. For example, Haslanger $(2008,58)$ claims that biological racial realism requires that "races are natural kinds," and she goes on to define a natural kind as a kind whose constitutive properties are "natural," where "natural properties of things are... those studied by the natural sciences" (Haslanger 2008, 60).

Fourth, some race theorists define a natural kind using pragmatism. Philip Kitcher is the main proponent of this view. Kitcher $(2007,299,301)$ rejects that there are any objectively real kinds in nature. Instead a kind is natural to the extent that it is... useful for some valuable project $\mathrm{P}$ in some scientific context $\mathrm{C}$, and [its utility] outweighs its "potential damage"[.]

We think readers can appreciate our confusion.

As Spencer's synopsis indicates, there is little agreement among philosophers of science as to what constitutes 'biological reality' or constitutes 'natural kinds. ${ }^{3}$ If our philosophers can not

\footnotetext{
${ }^{3}$ Regarding 'natural kinds' readers are also referred to Hacking (2007): "The work of [Kripke and Putnam] produced a rich sub-discipline of philosophy. There have been endless debates and numerous criticisms. Yet despite the initial enthusiasm, by 2006 we are left with a great many almost unrelated research ideas about natural kinds. I shall not detail here how we got from high noon to here. I shall briefly summarize a situation that will be well-known to many readers... Not an empty add-on, because the term 'natural kind' now carries a lot of baggage with it, and a lot of mutually incommensurable theories that I am about to list." And Hacking (1991): "Many theories of natural kinds
} 
decide what it really means to be 'biologically real,' nor determine the nature of a 'natural kind,' we can not hope to do so, and therefore can not even begin to try to defend the real biological reality or true 'natural kindhood' of race - so we will not.

Instead, we will simply sketch out a biological concept of race, defend its biological validity, explain how this concept applies to human beings, make clear the sense in which race is natural and real, and criticize the usual arguments presented by opponents of biological conceptions of race.

If our conception of biological race is not in accordance with certain philosophers' 'natural' or 'genuine' or 'real' kinds, nothing will be lost, since our account of biological race will at least represent a meaningful biological one and, more importantly, will be the only one that can make sense of the many past and present social and philosophical debates on the reality of race.

\section{I-B. Biological Concepts in General}

Since we mean to sketch out a general biological conception of race, we must start by outlining what exactly a biological concept is. For us, it is a concept employed in, and not peripheral to, the biological sciences. This characterization renders a "biological concept" synonymous with a biologist's concept.

Examples of biological concepts include "predator," "sex," and "deme." Biologists, of course, use these concepts to bring order to their specific domains of knowledge. Examples of non-biological concepts include "criminal," "political party," and "state of residence."

Many concepts belong to more than one field of science; for example, "macro-molecule" and "statistical population." This simply illustrates the unity of knowledge. As such, biologists and physicists, not to mention sociologists and philosophers, focus on overlapping sets of concepts. Nevertheless, certain ones, such as "biome," "organelle," and "gene," can be considered to be primarily biological and not, say, geological. In the same way, "positron" can be considered to be a physical concept; "subculture," a sociological one; and "natural kind," a philosophical one.

\section{I-C. The Validity of Biological Concepts}

are unsatisfactory because they assume there are only one or perhaps two types of natural kinds. But the great tradition of natural kinds need not be not dogmatic, and can adopt thesis (2b) from the beginning of this paper: among types of natural kinds are finite kinds, Mill-kinds, Peirce-kinds and Leibniz-kinds. Undoubtedly many realists who favour natural kinds write as if there were only one type of natural kind. They also subscribe to thesis (4), fantasizing a unique ultimate taxonomy, presumably consisting of inter-related kinds all of the same type. A little examination of the motley of kinds may help us see that there are interestingly different kinds. Those of us who care about other relevant kinds need not be bullied into saying that they are, or are not, just like natural kinds. There is not just one type of kind to be like. One type will be like another type in some ways, unlike in others. We shall also realize that a name denoting natural kinds may on different occasions, and certainly in different eras or when used by different people, denote kinds of different types. Now it may denote a Mill-kind, later, a Peirce-kind, and so on; on many occasions of use, the kind denoted may not be fully specified." See also the discussion of OdrowazSypniewska (2009). 
It is frequently proclaimed, or at least insinuated, that race is not a valid biological concept. Brody and Hunt (2011) remark:

In their informative article, the authors correctly assert that race is not a biologically valid concept and analyze the economic and political motivations for the development of BiDil[.]

And Chollett (2011) asserts:

Since "race" is not a biologically valid concept as applied to human populations, ethnicity is a more appropriate concept for examination of ethnicity-gender-class dialectics.

However, it is rarely explained what it would mean for something to be a 'valid biological concept,' although the phrase has been used in contexts other than race. For example, Lange (2012) argues that a 'biologically valid' concept of autism is needed to advance research on the disorder. Based on how the above mentioned authors use the term, it appears that a 'valid concept,' in whatever field, must be (ns) not self-contradictory and (ck) consistent with the state of knowledge in the field in question. For instance, circle-square would not be a valid mathematical concept, on account of condition (ns), whereas condition (ck) excludes, with respect to biology, spontaneous generation. We see that concepts considered valid can, with further developments in a field, switch from valid to invalid and vice versa; phlogiston may have been a valid chemical concept in the early 18th century, but it was invalidated by the 19th. Likewise, species in the species realist sense of essentialistic taxonomic categories was a valid concept in the 18th century, but it is not now.

\section{I-D. Biological Kinds}

Current usage of the term 'biological kind,' like the philosophers' 'natural kind,' is so confusing that we are forced to invent and use our own definition. When defining "biological kind," we want to do it in such a way that very basic biological things - units of analysis or objects of study in the biological sciences, such as organs, ecosystems, genetic populations, herbivores, and habitats - are all equally biological kinds. To give our biological kind meat, we will stipulate that it is a valid biological concept which both plays a significant knowledge ordering role and is deeply entangled in a research program; as such, a biological concept only becomes a "kind" when it has been well vetted and has become foundational in the sense of being well embedded in a research domain. In this sense, newly introduced or little-investigated concepts would not be considered "kinds""; an example of these might be nanobacteria.

Next, since "kind" in general means "a class or group having characteristics in common" (Collins online dictionary, n.d), we should specify that our biological kinds are groups defined by some shared biological property; that is, the members are related by some biological function or characteristic. Organs are tissues that perform a vital function; herbivores are plant eaters - and so on. This is a necessary but not sufficient criterion for "biological kindhood" as defined here.

\footnotetext{
${ }^{4}$ See Spencer (2012) and Kitcher (2007) for similar approaches.
} 
Our concept of a biological kind is similar to our notion of a valid biological concept, but our biological kinds refer only to groups of things and not to, e.g., processes. By our understanding, then, evolution and reproduction, while both clearly being valid biological concepts, are not biological kinds. So far, our concept of a biological kind is still rather fuzzy; to make it more definite, we provide further examples of what are not biological kinds. Again, biological processes do not qualify; neither do galaxies and irrational numbers on account of not being biological enough.

The situation with regard to other phenomena is not so clear: do the set of all biodomes, for example, form a biological kind? We could define a biological kind to be a group of organisms, but that would include any social group and exclude, for example, genes. We could exclude social groups by clarifying that the shared biological property must be a primary function or characteristic of living organisms. But that also would be problematic, since social groups arise from animal social behavior, which falls under the biological domain of ethology; insofar as "animal social behavior" is a valid biological concept, socialization can represent a significant biological property. It seems we are stuck with a fuzzy, perhaps even porous definition of "biological kind," similar to Kitcher's pragmatic "natural kinds" - minus Kitcher's scientifically arbitrary potential damage clause.

Let us consider Kitcher's position, at least as expressed in Kitcher (2007), so that we may draw an important contrast, and thus more clearly define our biological kind concept. Regarding his biological kinds, Kitcher (2007) states:

Given pragmatism about kinds, it is necessary to point to particular purposes that drawing racial divisions in this way would serve, purposes that can themselves be defended. If no such defensible purposes can be identified, then we should simply acquiesce in eliminativism. Indeed, the criticism can surely be strengthened. Given the immense harm that use of racial concepts has generated in the past, insisting on race as a legitimate biological category, even though that concept is linked to no valuable biological project, can seem irresponsible and even perverse. Moreover, even if the concept of race plays a role in some lines of biological inquiry, the values of those lines of inquiry, and of pursuing them through retention of the concept of human race, would have to be sufficiently great to outweigh the potential damage caused by deploying this concept in the other contexts in which it plays so prominent a role, namely in our social discussions...

... The challenge for someone who intends to defend a biological approach to human races is to develop a similar account for the utility of picking out those inbred lineages that descend from populations once geographically separated, in which, as a result of the separation, there are differences in superficial phenotypic traits, characteristics which, despite their superficiality, are salient for human beings....

... There is a genuine issue about whether the category of race is worth retaining.

Kitcher lays out a theory of pragmatic natural kinds - of which biological kinds are a subtype. According to this theory, a kind is understood to be a pragmatic or useful conceptual tool. Importantly, "useful" is broadly understood to mean both socially and epistemologically valuable. The indistinction between social and epistemological value allows for the epistemic legitimacy of a concept to depend on its broader social utility. Thus, a concept like gene could be potentially epistemologically useful, say to geneticists, but if it was sociopolitically undesirable, say to Lysenkoists, and if the sociopolitical interest was deemed to outweigh the scientific one, the 
concept of gene would be deemed epistemologically (and, so, biologically scientifically) illegitimate. Thus, the question of whether race is an epistemologically legitimate concept would depend, in part, on the concept's overall social utility.

One could define "natural kinds" this way: as concepts that are valuable on average or overall to scientists, philosophers, politicians, or the general population for their various purposes. But that makes "natural kinds" into social constructs by any reasonable definition of the latter. Kitcher might argue that "natural kinds" are all social constructs - but then why call them "natural kinds," rather than, say, "valuable concepts"? Kitcher's notion of a "natural kind" recalls Lewontin's "Science for the People," where science, to be 'true' science, must advance a socialist political agenda. Now, one may certainly choose to embrace this general position; in that case, "fossil" might not qualify as a legitimate biological kind in a creationist society, nor "carnivore" in a vegetarian one.

We do not. We distinguish between social value and epistemic value. Once this distinction is drawn, it becomes clear that social can not directly cancel out epistemic value (as they are different categories); we need only stipulate that a biological kind is a concept that has epistemic value for some program of biological research. To the extent that the concept, or the program itself, works against some political movement or societal ideal, we can call it e.g., "politically or socially undesirable" with respect to that movement or ideal.

To give our concept of a biological kind some philosophical legitimacy, or at least authority, we may note, nonetheless, that it closely resembles Kitcher's (2007) pragmatic kind.

\section{I-E. Natural Biological Divisions}

As races, by any definition, are divisions of a species, we might forgo a discussion of biological kinds and simply concern ourselves with biological divisions. ${ }^{5}$ Since much debate on the scientific validity of the biological race concept revolves around the issue of whether the divisions in question are biologically 'legitimate,' it is essential to clarify which types of divisions in general are biologically 'legitimate.' Do tall people and small people constitute 'legitimate' biological divisions, on account of the respective group members' similarity in a well-defined, highly heritable trait? ${ }^{6}$ Are larvae and imagos 'legitimate' biological divisions? What about sexual dimorphs or other polymorphs (e.g., blonds and brunets)? Or what about New Yorkers and North Carolinians, on the account of these representing different biological populations, as often defined $?^{7}$

\footnotetext{
5In Man's Most Dangerous Myth (1942), Ashley Montagu argued that the term "division" should be used in place of "race"; also "races" were frequently historically described as divisions of a species; thus, referring to "races" as "divisions" seems to be well justified.

${ }^{6}$ The high heritability of height is well established; but strong evidence exists (for example: Marioni et al., 2014a) which also indicates that groups defined in terms of height, at least when dealing with normal variation within a given population, differ also in socially relevant traits such as intelligence and do so for genetic reasons (i.e., owing to pleiotropy).

${ }^{7}$ As will be discussed latter in section II-B, in biology, a "population" is often vaguely defined as e.g., "all the members of a species that occupy a particular area at the same time." "Residents of Iowa City," constitute a
} 
Our answer is "yes"; it seems only logical to conclude that a division is a valid biological one, so long as it is drawn in accordance with a valid biological concept; blonds and brunets, for example, represent morphs and the morph concept is a valid biological one; thus, we have a valid division in some sense. On the other hand, as far as we are aware, "all animals with flies on their nose" versus "all other animals" does not accord with any valid biological concept; thus, we would conclude that this does not represent a valid biological division.

But, of course, races are not morphs. To make sense of what type of biological divisions they are, we must reintroduce two terms so as to distinguish between two general types of biological classifications: natural and artificial. We will base this distinction on that between natural and artificial classifications used in taxonomy and in biology more generally. Natural classifications have traditionally referred to ones based on overall similarity or on some property which causes members of groups to be more overall similar to each other than to members of other groups. Artificial classifications are based on superficial resemblances or on some property which conditions only this. Since evolutionary theory came to be accepted, "natural" classifications or divisions came to be seen as ones based on "propinquity of descent, - the only known cause of the similarity of organic beings" (Darwin, 1859). As Parry and Hacker (1991) note:

The basic classifications that science aims at are those founded on the properties that prove to be most important theoretically. Such a classification was traditionally called a natural classification. In contrast, a classification is a (more or less) artificial classification insofar as the properties on which it is based are relatively thin in invariable relationships with other properties...

With changes in the accepted theories of science come changes in what is accepted as natural classification. After the theory of evolution came to be generally accepted in biology, the basic principles of classification of animals and plants was theoretically simple and objective: species and genera were to be grouped together according to family relationship following supposed line of descent from common ancestors. However, since these relationships are not directly observable, in practice biological classification continue to be based on diverse criteria found empirically to be important.

\section{A typical introductory biology discussion of the concept runs:}

If organisms are grouped according to the way they affect people, edible or poisonous, domesticated or wild, weed or crop, we make an artificial classification. This artificial classification is based on a few, superficial characteristics...

Most existing biological classifications of organisms are based on attempts to show evolutionary relationships between species (phylogeny) based on such evidence as physical characteristics, paleontology, embryology, immunology, biochemistry, cell structure, ecology, behavioral and

biological population in this sense. Not only are some populations not races, but not all races are populations in the typical sense, since to be a member of a race does not necessitate that one shares with other members a locality in physical space. 
reproductive strategies. Classifications which reflect an attempt to show evolutionary origins and relationships are termed natural classifications. (Rowland, 1992)

Shared descent was seen as the property that accounted for overall resemblance in form. Thus, it was seen as a new basis for biological natural classifications. Darwin, though, recognized that descent or genealogy alone did not make for a natural system. For him, a natural system was to be based on "descent with modification" (Darwin, 1859). Descent taken together with modification has been understood by some as representing "genotype." 8 Others have focused exclusively on the genealogical or descent part. Thus, this new theory of natural classification, while decidedly based on "genetic relationship," has lent itself to two major related but not identical interpretations. The two at times lead to discordant classifications (Mayr, 1965). When considering close relatives, the two senses of "genetic," genotypic and genealogical, tightly correspond. For example, the (kinship) coefficient of relationship for half siblings is 0.25 and this closely approximates the relative genotypic similarity between such pairs. Yet when dealing with innumerable generations genotypic similarity and genealogical similarity can disagree substantially.

The difference between these senses has led to some ongoing disagreement as to what precisely constitutes biological natural classifications, especially when it comes to taxonomic categories. ${ }^{9}$ In taxonomy, some (cladists), following Willi Hennig feel that natural classifications should be made only on the basis of relatedness in descent (or genealogy). Others (evolutionary taxonomists), following Ernst Mayr, argue that natural classifications should take into account other evolutionary factors. This entails taking into account genomic similarity due to modification.

In our estimation, Darwin's own position, insofar as it took into account both descent and modification, was closer to the evolutionary taxonomist one than to the cladistic one. ${ }^{10}$ And we agree with Hörandl (2007) that the cladistic position is the more problematic of the two. But this issue is not fundamental to the case being made here regarding race. What is relevant is that the precise nature of biological "natural classifications" is undetermined because there are conflicting meanings of "genetic relationship."

\section{I-F. Races as Natural Biological Divisions}

\footnotetext{
${ }^{8}$ We are unclear about the early evolutionary taxonomic meaning of "genotypic," "genetic similarity," and "genetic program"; so when discussing matters related to evolutionary taxonomy we will ambiguously use "genotypic." To refer to overall genetic similarity, in other contexts, we will use "genomic."

${ }^{9}$ The association between "natural" and "genealogical" was not historically limited to taxonomic categorization.

${ }^{10}$ Readers are referred to Darwin's discussion in "Origin of Species": "Thus, on the view which I hold, the natural system is genealogical in its arrangement, like a pedigree; but the degrees of modification which the different groups have undergone, have to be expressed by ranking them under different so-called genera, sub-families, families, sections, orders, and classes." Or in "Descent of Man": "If we imagine three lines of descent proceeding from a common stock, it is quite conceivable that two of them might after the lapse of ages be so slightly changed as still to remain as species of the same genus, whilst the third line might become so greatly modified as to deserve to rank as a distinct sub-family, or even Order." Darwin clearly indicates that more than descent should be taken into account.
} 
It has been noted by some race critics that if the term "race" merely denotes "biological divisions" or "biological populations" of any sort, then nothing particularly interesting is picked out. "1 Many of these critics, assuming that race in fact denotes no particular type of biological division, proceed to rule races unreal - not, this time, because races are not biological enough, but because they are too biologically generic. We find it odd that these same critics do not claim that, for example, "biological populations" (as commonly defined in biology, see section II) are likewise unreal. Nonetheless, such critics would have a point if "race" did not reference a particular type of biological division.

However, races have long, if not at all times, been seen as divisions in which individuals are arranged by overall genealogical or, more recently, genomic relatedness. Commenting to Huxley on race, for example, Darwin noted:

Grant all races of man descended from one race; grant that all structure [i.e., physical features] of each race of man were perfectly known - grant that a perfect table of descent of each race was perfectly known - grant all this, \& then do you not think that most would prefer as the best classification, a genealogical one, even if it did occasionally put one race not quite so near to another, as it would have stood, if allocated by structure alone. Generally, we may safely presume, that the resemblance of races $\&$ their pedigrees would go together. (Darwin, 1903, letter 204)

These natural divisions are set in contrast to purely phenotypic based ones and to artificial ones, ones which are based on thin resemblance or some property which leads to only thinly related groups.

\section{I-G. The Intraspecific Natural Division as Type of Biological Variation}

The natural division can be treated as a unit of analysis or a conceptual tool in a number of different biological research programs - including population genetics, biological anthropology, taxonomy, conservation biology, and ecology - which have different ways of thinking about it. Taxonomy, which concerns itself with the ordering of organisms by relatedness, deals with classes of natural divisions and treats these classes as units of organization in a hierarchical system extending from Domain/Kingdoms to Subspecies. These classes are called taxonomic categories or, alternatively, taxonomic ranks.

It is sometimes thought that races were and are conceived exclusively as taxonomic categories. This idea is, for example, implicit in the argument made against the existence of human races by Templeton (2003; 2013), who argues that human divisions do not qualify as subspecies in the taxonomic category sense (from now on "taxa subspecies," since subspecies in any other sense would not constitute taxa) and then reasons that human races therefore do not exist. The argument presupposes that race is only understandable as a taxonomic rank. However, this is not the case. Race, initially, matched no taxonomic category. It had no place in the description of natural history. Thus, Doron (2012) cogently notes:

\footnotetext{
${ }^{11}$ At times we refer to "biological divisions" as "populations"; context depending, this is either because we mean "populations" in the statistical sense or because the biological divisions are biological populations in the spatial sense or because the cited authors ambiguously described the divisions in question as populations in some sense.
} 
I believe it is now clear that "race", a notion primarily used, until the eighteenth century, as part of a genealogical rather than taxonomical vocabulary, did not have a self-evident place within the classificatory style of reasoning which dominated natural history. We would be wrong to believe that race and classification are necessarily intertwined. We should rather believe the opposite of this, namely that classical principles of classification were important obstacles to the development of a concept of "race". Between species and variety, or between species and genus, there was no positive space for this concept.

The concept of race was introduced into biology as part of a genealogical approach to making sense of intraspecific biological variation; this approach stood in contrast to the Linnaean one which grouped according to character resemblance. Immanuel Kant, the most prominent philosopher to discuss race, juxtaposed a natural (meaning genealogy based) understanding with a scholastic (meaning phenotypic resemblance based) one and situated the race concept in the genealogy-based perspective:

A scholastic division is based upon classes and divides things up according to similarities, but a natural division is based on identifying lines of descent that classify the animals according to reproductive relationships. The first of these procures a scholastic system for memory; the second, a natural system for the understanding. (Of the Different Human Races)

\begin{abstract}
What is a race? The word is not to be found in a<ny> systematic description of nature, so presumably the thing itself is nowhere to be found in nature. The concept which this expression designates is, however, surely well established in the reason of every observer of nature who supposes a selfpeculiar feature in different animals produced from interbreeding, <that is to say >, a union of cause $<$ that $>$ does not lie in the concept of its species $<$ but was $>$ certainly placed originally in the lineal stem stock of the species itself. $\langle$ The fact $\rangle$ that $\langle$ the $\rangle$ word $\langle$ race $\rangle$ does not appear in the description of nature (but instead, in its place, the word variety) cannot keep <an observer of nature> from finding it necessary from the viewpoint of natural history. (On the Use of Teleological Principles in Philosophy)
\end{abstract}

It was only after Linnaean taxonomic categories were themselves rethought in genealogical terms that race found some place in the hierarchical ordering of life. As the newly genealogically understood categories were not extended down to include all levels of racial differentiation, there was always only an incomplete overlap. Thus, in and out of taxonomy, the existence of races which did not correspond with a taxonomic category was well recognized (Pigliucci, 2013). Their existence was part of the basis of Wilson and Brown's (1953) famous criticism of the zoologist's subspecies category. According to this influential critique, the subspecies category was problematic since it excluded, for conventional reasons, lower level races. The concept of race, then, is not grounded in taxonomic ranks; it is, rather, grounded in genealogical thinking and modern taxonomic categories are also grounded in this thinking. The genealogical (or now, genomic) perspective has been adopted by a number of biological research programs, including population genetics, conservation biology, and taxonomy. Race's grounding in the genealogical perspective, rather than in taxonomic categorization, is what helps establishes the concept as a biological kind.

\title{
I-H. The Natural Division as a Taxonomic Unit
}

Race can be understood as a taxonomic unit - by this we mean a taxonomic classification not limited to a taxonomic category. Generally, taxonomic categories (e.g., genus, species, and taxa subspecies) are a subtype of taxonomic classifications. Taxonomic classifications additionally 
include non-category classifications such as forms, groups, and ecotypes. A morph is a taxonomic unit in this sense. Taxonomic classifications, in turn, are a subtype of biological classifications which additionally include non-taxonomic classifications such as organs and cells. Under the Linnaean approach, morphs often found a place among the taxonomic categories in the form of Linnaean varieties, but now, with the adoption of the genealogical perspective, they no longer do. It would nonetheless be odd to consider the morph concept to not be a taxonomic classification since other formally recognized classes, such as species, are understood in contrast to this. For the same reason, it would be strange to not consider race to be a taxonomic classification of some sort ${ }^{12}$.

To develop and elaborate on a concept of race, in part, as a taxonomic unit - understood either as a taxonomic classification or as a taxonomic category - we must situate our discussion in a general philosophy of taxonomy, a philosophy which itself is based on a theory of what constitutes natural biological divisions. Roughly speaking, historically, there have been four major taxonomic schools: essentialism, pheneticism, cladism, and evolutionary taxonomy (Mayr and Ashlock, 1991). ${ }^{13}$ All of these systems claim to carve out natural biological groupings; and for all of these systems natural groupings are ones where members are grouped by thick or overall relatedness. They differ in the properties used to classify. First, essentialism, in the Aristotelian sense, groups by formal natures which means both manifest - or phenotypic structural similarities and the structural designs (formal natures as mover) which condition these manifest resemblances and which are transmitted across generations. Second, pheneticism groups by overall observed phenotypic similarity, similarity which may or may not be due to shared heritage (Lyman and McKern, 2003). ${ }^{14}$ Third, cladism groups strictly by propinquity of descent (a property which is largely the cause of organic similarity in form). Fourth, evolutionary taxonomy groups by both descent and overall similarity in homologous features (ones shared due to common descent) (Mayr and Bock, 2002).

Currently, there is a consensus in the philosophy of biology against the first two schools (Lewens, 2012a; Lewens, 2012b). Regarding essentialism, Aristotle's formal natures, at least as they have often been interpreted, have been discarded. ${ }^{15}$ Regarding pheneticism, biological natural classifications are now generally understood as ones which are based on evolutionary or genetic relationship, not phenotypic similarity. ${ }^{16}$ This is because, among other reasons, genetic relationship provides an explanation for phenotypic similarity and is able to predict unobserved

\footnotetext{
${ }^{12}$ While the "taxonomic category"/"taxonomic classification" distinction seems obvious and in line with typical systematics, some manage to miss it e.g., Kaszycka et al. (2009).

${ }^{13}$ As testified by the 22 or so species concepts (Wilkins, 2010) many of which could be said to be taxonomic in some sense, it is clear that there are many more than a couple of taxonomic perspectives.

${ }^{14}$ Some consider molecular based classifications to be phenetic ones in a sense (see, for example: Stuessy (2009) and Mayr and Bock (2002)); here, we mean phenotypic-based classifications.

${ }^{15}$ Though, see Henry (2011) for an interpretation of Aristotelian essentialism which is both biologically defensible and applicable.

${ }^{16}$ For a contemporary defense of pheneticism, see Lewens (2012a).
} 
similarity. Insofar as phenotype is used when classifying, it is employed as an index of genetic or evolutionary relationship.

As for the latter two schools, there is intractable and sometimes hostile debate. For both schools, following Darwin, organisms are arranged into groups according to descent. When it comes to ranking and ordering groups, evolutionary taxonomy additionally takes into account overall similarity owing to other evolutionary factors (e.g., divergence within lineages, degree of observable similarity, merging, and absolute time relationships (Hörandl and Stuessy, 2010)). Early on, evolutionary taxonomists stated that grouping by genotypic affinity was the goal (Mayr and Ashlock, 1969; Ashlock, 1974). Mayr (1965b) expressed the position thusly:

In phylogeny, where thousands and millions of generations are involved, thousands and millions of occasions for a change in gene frequencies owing to mutation, recombination, and selection, it is no longer legitimate to express relationship in terms of genealogy. The amount of [genotypic] similarity now becomes the dominant consideration for a biologist ... When a biologist speaks of phylogenetic relationship, he means relationship in gene content rather than cladistic genealogy.

However, in Mayr and Bock's (2002) position paper the familiar phrases "total gene composition" (Mayr, 1965), "genetic program" (Mayr and Ashlock, 1969),and "genetic similarity" (Ashlock, 1974) do not show up. Perhaps the authors wanted to ensure that their classification system was not to be equated with an exclusively genome-based one such as presented by Marakeby et al. (2014). ${ }^{17}$ The latter would seem to represent yet another possible type of genetic or natural classification. Whatever the case, the basic principle of evolutionary taxonomy was outlined by Mayr and Bock (2002): "A Darwinian classification is the ordered grouping of organisms into classes according to their [overall] similarities and consistent with their inferred evolutionary descent." While overall similarities are used, characters are weighted by the degree to which they are seen to be products of "a major and deeply integrated portion of the genotype" (Mayr and Ashlock, 1991). Since the similarities that count are the ones consistent with shared descent, evolutionary classifications are genealogical ones, to use Darwin's phrase, in arrangement.

Cladists, on the other hand, group by descent alone and delineate their taxa ${ }^{18}$ according to lineage branching points; they are uninterested in overall similarity independent of descent (e.g., due to modification). Figure 1.1 below illustrates a situation in which the disagreement between the schools emerges. The cladist, using branching points to delineate divisions, groups Aves and Crocodillia into a cohort called Archosauria which, in turn, is nested in an interclass called Reptilomorpha. Birds are reptiles (or reptilomorphs) since the genealogical branch containing both Crocodiles and other reptiles also includes birds. On the other hand, the evolutionary taxonomist, taking into account relative rates of evolutionary change, groups Crocodiles and other Reptiles in the class Reptilia which is set distinct from the class Aves. From the evolutionary taxonomic perspective, birds are not reptiles since they have evolved to be quite genotypically distinct as reflected by their overall morphological differences.

\footnotetext{
${ }^{17}$ A genomic classification might include non-coding DNA; by "genetic program" or "genotype" Mayr seemed to imply, though it is not clear, coding DNA that was identical by descent (IBD). See the usage in Mayr (2004).

${ }^{18} \mathrm{~A}$ taxon (pl. taxa) is a particular group of organisms that is formally recognized - and so given a formal name (e.g., Hippopotamus amphibious) - and assigned to a definite taxonomic category (e.g. species).
} 
Figure 1.1. An example of a disagreement between the cladistic and evolutionary taxonomic schools

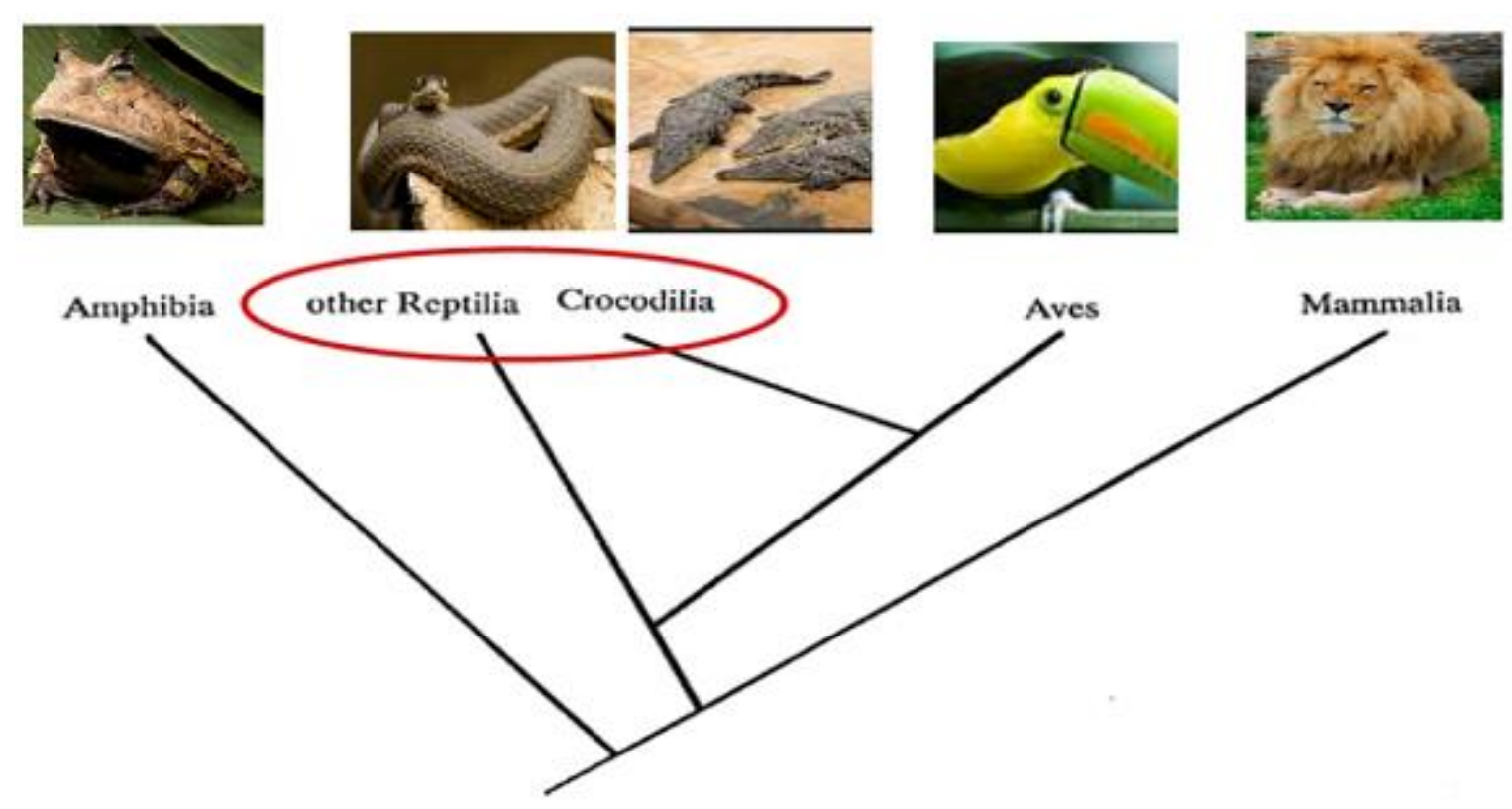

Before proceeding, we first have to clarify some terms. When a group contains some taxa that do not descend from the most recent common ancestral group it is called polyphyletic. When it contains only but not all those taxa that do it is called paraphyletic. The term "monophyletic" is disputed and is used differently by evolutionary taxonomists and cladists. For evolutionary taxonomists, a group is monophyletic so long as all taxa included descended from the nearest common ancestral group - that is, so long as the group is not polyphyletic. For cladists, in addition to not being polyphyletic, to be monophyletic, a group must not be paraphyletic.

That clarified, another way to put the point above is that for cladists a valid taxon must neither be paraphyletic nor polyphyletic. On the other hand, for evolutionary taxonomists, a valid taxon must just not be polyphyletic. Such a taxon can be paraphyletic. When deciding which members to include in a taxon, evolutionary taxonomists take into account overall similarity or, in a sense, similarity in "genetic program"; as such, their taxa index both descent and modification. As will be seen later on, this has some, though not much, bearing on our defense of certain human racial classifications.

\section{I-I. Natural Divisions and Intraspecific Variation with Regards to the Subspecies Category}

For evolutionary taxonomy, higher-order taxa are only valid instances of a taxonomic category if they are monophyletic (in the sense understood by this school). When it comes to intraspecific taxa and the subspecies category, the situation is more complex than monophyletic vs. nonmonophyletic because, as a result of continual gene flow, intraspecific lineages often blur into one another along zones of primary intergradation (due to reduced divergence) and secondary intergradation (due to post-divergence hybridization). An evolutionary taxonomist's cladogram might look as shown in Figure 1.2. In the diagram, there are two species, species 1 and species 2, 
each of which has subspecies. The horizontal lines between subspecies (a) and (b) of species 1 represent zones of intergradation. Subspecies (d) in species 2 is a hybrid.

\section{Figure 1.2. Examples of intraspecific variation in relation to differentiation}

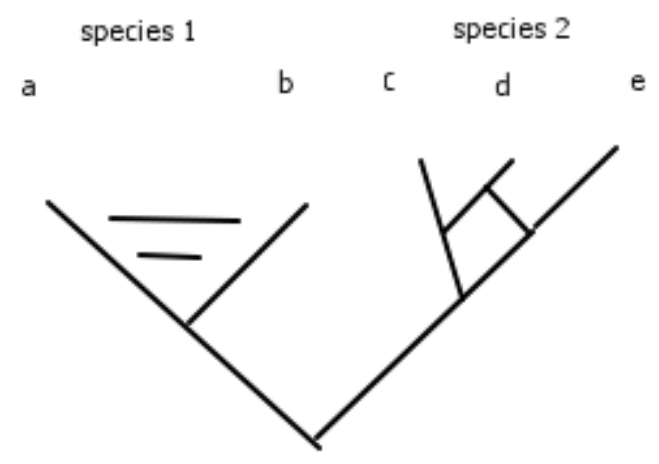

(Based on Figure 5.4 in Haffer (2007).)

Subspecific taxa (a) and (b) in species 1 are more or less phylogenetically differentiated; thus, they are only more or less differentiated lineage branches. ${ }^{19}$ Because the difference is one of degree, these taxa, with their mixed ancestry, can not be delineated on the basis of unique ancestry in the way that Aves and Crocodilia can. ${ }^{20}$ Another problem, from the perspective of the monophyletic requirement, is that subspecific taxa - along with species ${ }^{21}$ - can be and often are hybrids, as is the case for subspecies (d) above. In the case of species 2, although each taxa subspecies is well differentiated in lineage at the end point, subspecies (d), being the product of (c) and (e), is not strictly monophyletic in the evolutionary taxonomic sense of descending from one immediate common taxon; as noted by Mayr and Ashlock (1969), "Taxa that are still crossable, like subspecies, may produce hybrids, which by definition would not be monophyletic." The evolutionary taxonomist's solution to these two problems is to just grant that on the level of lower categories things are messy; as such, on these levels, clear phylogenetic differentiation and strict monophyly is not required. Regarding hybridity and monophyly, Mayr and Ashlock (1969)

\footnotetext{
${ }^{19}$ As with 'monophyletic,' 'phylogenetic' is a disputed term. The different meanings for, respectively, evolutionary taxonomists and cladists parallel those with regards to 'monophyletic.' Thus, the evolutionary taxonomic 'phylogenetic' simply entails common descent. Mayr and Bock (2002) note: "Haeckelian phylogeny is equivalent to Darwinian common descent... [Hennig] introduced an entirely different concept... The Hennigian systematist distinguishes a phyletic branch (clade) containing the stem species and all its descendants, no matter how diverse such a clade may be."

${ }^{20}$ As Velasco (2012) notes, though, strict tree-like models do not fit biological reality in many instances on the species level and above. We might say that on the species level and above, taxa are "much more than less" differentiated. Velasco (2012) notes: "The empirical evidence is clear; there are a great many non-tree-like processes which produce non-tree-like genealogical patterns in nature. The realist is forced to become a realist about networks rather than trees."

${ }^{21}$ Hybridization occurs on the species level also. Mallet (2008) noted that $10 \%$ of animal species, in the wild, formed hybrids with other species.
} 
simply note that, "[M] onophyly is important only at the level of higher categories." Such is the nature of lower level variation (O’Brien and Mayr, 1991).

And what about cladism? The matter is complicated by the number of cladist-based species concepts. Of the 22 concepts discussed by Mayden (1997), at least five have been described by their proponents as being cladistic. ${ }^{22}$ These are shown in Table 1.1.

\section{Table 1.1. A selection of cladistic-grounded concepts from Mayden (1997)}

1. Hennigian Species Concept (HSC). Meier and Willmann (1997): "[R]eproductively isolated natural populations or groups of natural populations [that] originate via the dissolution of the stem species in a speciation event and cease to exist either through extinction or speciation."

2. Internodal Species Concept (ISC). Komet (1993): "[I]ndividual organisms are conspecific in virtue of their common membership of a part of the genealogical network between two permanent splitting events or between a permanent split and an extinction event."

3. Monophyly Version of the Phylogenetic Species Concept (PSC-M). Mishler and Brandon (1987): "A species is the least inclusive taxon recognized in a formal phylogenetic classification. As with all hierarchical levels of taxa in such a classification, organisms are grouped into species because of evidence of monophyly. Taxa are ranked as species rather than at some higher level because they are the smallest monophyletic groups deemed worthy of formal recognition, because of the amount of support for their monophyly [.]

4. Diagnosable Version of the Phylogenetic Species Concept (PSC-D). Wheeler and Platnick (1997): "The smallest aggregation of (sexual) populations or (asexual) lineages diagnosable by a unique combination of character states."

5. Cladistic Species Concept (CISC). Ridley (1989): "[T]hat set of organisms between two speciation events, or between one speciation event and one extinction event, or that are descended from a speciation event."

Of these, the Hennigian Species Concept (HSC) is said by its authors to be identical in practice to the evolutionary taxonomist's Biological Species Concept (BSC). It defines species as intrinsically reproductively isolated populations. Meier (2000) explains that this requirement is necessary as phylogenetic reconstruction "can not adequately deal with nonhierarchical netlike relationships" as in the case of hybridizing groups. While the authors do not discuss a "subspecies" concept, Meier's (2000) discussion implies that, were these entities recognized, subspecies would be seen as more or less phylogenetically differentiated groups. The same can be said in regards to the Internodal Species Concept (ISC) which requires species to be permanently reproductively isolated. For both the HSC and ISC, following Hennig's (1966) position, intraspecific variation is marked by genealogical networks (in Hennig's terms, tokogenic relations). One would expect that, for the authors, the taxa assigned to an intraspecific category would likewise be.

\footnotetext{
${ }^{22}$ Nixon and Wheeler (1990) note: "Species concepts advocated by cladists have included the Biological Species Concept, Simpson's (1961) evolutionary species concept (Wiley, 1978; Ax, 1987), internodal species (Hennig, 1966; Ridley, 1989), autapomorphic species (Rosen, 1979; de Queiroz and Donoghue, 1988, 1990), and "phylogenetic species" consistent with cladistic theory but independent of constraints of autapomorphy (Eldredge and Cracraft, 1980; Nelson and Platnick, 1981 ; Cracraft, 1983; Wheeler and Nixon, 1990)."
} 
Unlike the two concepts discussed above, by both the diagnosable and monophyly version of Phylogenetic Species Concept (PSC), interfertile populations can represent different species. Both concepts require that the species differ constantly in at least one trait. At least for the diagnosable version, hybridization is not seen as a problem since the concept of monophyly is not seen as applicable in context to interbreeding populations. What is notable is that, as seen in their definitions, most proponents of phylogenetic species concepts treat species as the lowest rank. Intraspecific taxa are generally not recognized (Donoghue, 1985). In their review of the subspecies concept, Haig et al. (2006) note: "Under most phylogenetic species concepts... species are the smallest, irreducible, monophyletic units as measured by molecular markers. Any groupings within such species do not warrant taxonomic standing, so subspecies are not recognized." When subspecific taxa are discussed they are so in the manner of Nixon and Wheeler (1990):

Intraspecific taxa (subspecies or botanical varieties) are groups of individual organisms that are centric and not monothetic, in that they are diagnosable only by virtue of part of a broader distribution of one or more traits. Individuals in these populations are not identical for any unique combination of states, and they might or might not be genealogically homogeneous... Our concept of infraspecific "taxa" is consistent with a view that these may be incipient species - populations which exhibit high frequencies or combinations of unique traits that may are some future date becomes "fixed" (constantly distributed).

Nixon and Wheeler's (1990) subspecies, like Groves' (2004; 2012), are groups that are not 100\% diagnosable due to their reticulate relations. These groups, then, when recognized, are akin to the evolutionary taxonomist's (or BSC) subspecies - Groves even employs the evolutionary taxonomist's 75\% diagnostic rule. A key difference between the BSC and PSC's treatment is that the more differentiated evolutionary taxonomist's subspecies are elevated to the status of PSC species. And, at least by Nixon and Wheeler's (1990) concept, less differentiated evolutionary taxonomic subspecies and lesser races seem to be treated as taxa subspecies. ${ }^{23}$ The situation is depicted in Figure 1.3 below.

Finally, for Ridley's Cladistic Species Concept (CISC), species are simply "the set of all the longest possible branches in the phylogenetic tree that do not themselves have splits in them" (Ridley, 1989). By this concept, no character differences are required and groups can be interfertile. For this concept, hybridization is not a theoretical problem in principle; it just changes the taxa. Hybridization does represent something of a philosophical problem though. ${ }^{24}$ Ridley (1989) does not discuss subspecies. Since all of the longest branches without splits, no matter how small, are recognized as species, it seems that subspecies would have to be more or

\footnotetext{
${ }^{23} \mathrm{Cracraft}$ (1997) likewise notes that the continued use of subspecies "might be thought defensible under some circumstances. If one so chose, subspecies names could be applied to populations showing clinal variation and subspecies boundaries could then be determined by sharp gradients in character variation. In this context, however, subspecies are merely descriptors of variation seen in sometimes subjectively chosen, non-diagnostic characters and do not represent taxa having independent ontological status."

${ }^{24}$ For this concept, before the hybridization event that resulted in taxon (d), taxa (c) and (e), from Figure 1.2, represented distinct branches, in which all descendants could be grouped in one or the other. After, there is a branch that contains (c) and (d) and one which contains (d) and (e). Due to the hybridization event, the original branches of species 2 share descendants, violating Hennig's monophyly. The solution proposed by Ridley (1989) and others, is to say that that taxa (c), (d), and (e) were birthed with the hybridization that resulted in (d) and that the taxa that existed prior to this event were extinguished by it. As a result, all existent taxa are Hennigian monophyletic. For a discussion and critique of this solution, readers are referred to Stamos (2003).
} 
less differentiated groups, since there is nothing else which they could be.

\section{Figure 1.3. Comparison of the treatment of species and subspecies under the BSC and PSC}

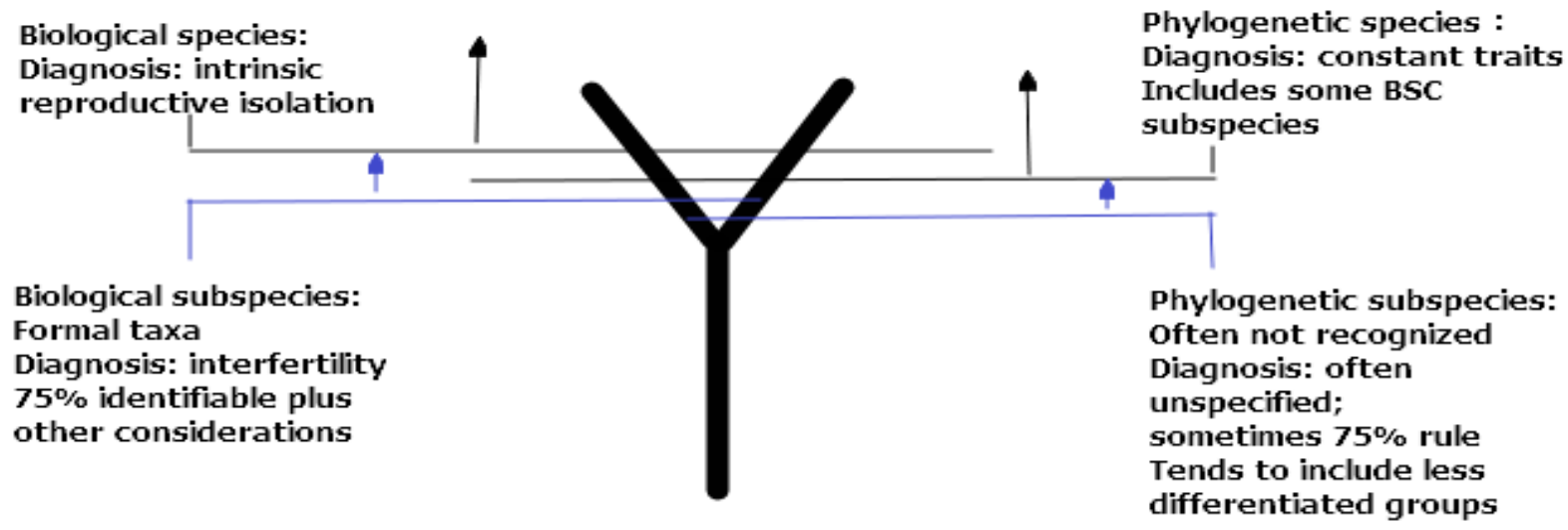

In addition to the concepts discussed above, philosopher Robin Andreasen $(1998 ; 2007)$ has put forth her own cladistic subspecies concept. Something akin to this concept seems to have been advanced by Templeton (1998). ${ }^{25}$ In contrast to the concepts of Ridley (1989) and of the phylogeneticists, and in line with the HSC and ISC, Andreasen (1998; 2007) treats cladistic species as intrinsically reproductively isolated populations. Subspecies for her are potentially interbreeding branch endpoints, or nodes, in a phylogenetic tree. What is interesting is that she interprets differently than us what a HSC and ISC-like subspecies would be. Her subspecies are not more or less differentiated; they do not show reticulate patterns. As such, gene flow abolishes these. They seem to be just interfertile HSC or ISC species. We find this to be an odd conception, since the problem of intraspecific variation for HSC and ISC is reticulate relations. It would seem to follow then that a subspecies concept would accept reticulate relations as part of the definition. Nonetheless, this is a possible way of seeing things. This concept can be contrasted with the understanding discussed by Velasco (2012) in which subspecies, in contrast to species, are characterized by gene flow and more or less phylogenetic differentiation.

Generally, regarding cladistic and related concepts, ${ }^{26}(\mathrm{~m})$ some proponents, at least in principle, treat all distinct lineage branches all the way down as species and do not recognize taxa

\footnotetext{
${ }^{25}$ Templeton refers to an 'evolutionary lineage' race concept. It is not clear how this is distinct from an evolutionary lineage species one. According to Smith et al. (1997), other proponents of the evolutionary lineage concept dismiss taxa subspecies, so it is also not clear how widely accepted Templeton's concept is. Quote: "proponents of the Evolutionary Species Concept dispose of subspecies, for the most part, by disregarding them completely as a component of the biotic classification system (Frost 1995; Frost et al. 1992; Simpson 1961; Wiley 1981, 1992; Wilson and Brown 1953). Typically, in the application of that concept, subspecies are examined critically for their distinctiveness, and those that do not rigorously qualify in that context are not accepted taxonomically." This noted, Templeton's concept seems to roughly correspond with Andreasen's. See Kopec (2014) for a description of the concept.

${ }^{26}$ Cladistic and phylogenetic species concepts are sometimes treated as referring to the same concept. However, depending on how the two concepts are specified, there can be substantive differences between them. The issue is complicated by there being multiple "phylogenetic" species concepts. To give a sense of the divergence and the impact of this on this discussion, consider that Groves (2012) defines phylogenetic species as "populations (or
} 
subspecies as such (e.g., Ridley's (1989) cladistic concept); (n) others treat populations with constant traits as species and do not recognize taxa subspecies (e.g., Cracraft's (1997) diagnosable phylogenetic concept); (o) some treat taxa subspecies as more or less phylogenetically differentiation branches (e.g., Nixon and Wheeler's (1990) phylogenetic concept; also Velasco's (2012) notion); and some (p) treat subspecies as distinct lineage branches/twigs which are interfertile (for example: Andreasen, 1998; 2007). Thus, the answer to our question above, regarding how cladists/phylogeneticists deal with degrees of phylogenetic differentiation, depends on which specific proposed concept we are dealing with. To give an example, Velasco (2012) notes:

[I] thas been argued that there has been so much admixture in human history that the concept of race makes no biological sense (Templeton 1998; but see Andreasen 2004). However, trees of human populations are quite useful for understanding major ancestral migratory events (Soares et al. 2009). Obviously there are migrations between human populations. But whether the amount of migration is "sufficient" to be best represented as collapsing the distinction between different lineages depends on what aspects of the lineages we are focusing on. For different inference purposes, different representations of genealogical history focusing on different aspects of that history are appropriate. Looking at trees of populations at the subspecific level, such as those of humans, is common in the growing field of phylogeography (Avise, 2000). This is a clear example of the superiority of the modeling defense of trees since if there were genetic isolation between these lineages they would represent different species. [Italics added.]

It seems that Velasco (2012) would agree with (o) (at least for some usages) and that Templeton (1998) would agree with (p). It will be noticed, then, that cladistic taxa subspecies concepts, insofar as they are recognized, require two taxonomic decisions and two parallel conventions: (decision 1): how to distinguish species from subspecies when both represent distinct branches? - for (m) all groups, interfertile and not, are species, for (n) and (o) only species are recognized and only when they are $100 \%$ diagnosable based on some constant traits; for (p) species are intrinsically reproductively isolated; (decision 2): what degree of lineage isolation should be required for cladistic species, taxa subspecies, or nothing at all? - for (p), but not (o), taxa subspecies need a very high degree of isolation. Clearly, this often said to be "objective" metaperspective of classification is not free of subjective, conventional decisions!

groups of populations) that are $100 \%$ diagnosable." Elsewhere, the same author explains that there are not a plethora of human species, because humans form a genetic continuum: "Why, they seem to be saying, are there not distinct species of humans or dogs under the PSC? The answer to the first question is that the human species is a genetic continuum. There are no points along this continuum where there are logical breaks with diagnosably distinct populations on either side (Groves, 2013)." And yet elsewhere, the author tells us that taxa subspecies can cut out regions of a continuum: "[With subspecies] their interrelationships are genetically reticulate... they are simply the point along the continuum of population differentiation... at which it becomes worthwhile to give them a scientific name" (Groves, 2004). Taken together, this implies that from Groves' perspective major human populations are phylogenetic taxa subspecies. This conception can be compared with Templeton's as discussed by Kopec (2014): "Recall that cladistic (or 'phylogenetic') subspecies are relatively large groups within a species that form distinct lineages, or, in other words, there is a relatively low level of reproductive... events between these large groups (Templeton 1998)... [T] he groups can still count as distinct taxonomic units so long as they closely approximate distinct lineages. The second model, which Templeton calls the 'trellis' model, holds that all major human populations have been exchanging genes throughout their history, and thus no distinct lineages ever existed." So according to Templeton's cladistic/phylogenetic taxa subspecies concept, human taxa subspecies do not exist because the interrelationships among human populations, to use Groves' term, are genetically reticulate - a defining feature of Groves' phylogenetic taxa subspecies. 
This all clarified, we can answer our question. Insofar as position (o) is adopted, we are dealing with more or less differentiated groups just as in the case of evolutionary taxonomy. And insofar as (n) and (m) is adopted, there is nothing to discuss since there is no subspecies concept. Possibility (p), with taxa subspecies understood as distinct lineage branches/twigs (with little or non-branch-likeness) is interesting on several levels. For example, one has to determine whether these taxa subspecies concepts match with ones envisioned by other proponents of cladism, ${ }^{27}$ both with regards to human and to non-human divisions.

Generally, from the evolutionary taxonomist's and at least some cladist's perspective, intraspecific variation is often messy; taxa subspecies are situated in that mess.

\section{I-J. Biologically Meaningful Race Concepts}

It is frequently asserted that the concept of race is, biologically speaking, 'meaningless.' A 2013 editorial, titled "Dangerous work. Behavioural geneticists must tread carefully to prevent their research being misinterpreted," in the prestigious journal Nature, for example, states:

[I]n light of increasing evidence that race is biologically meaningless, research into genetic traits that underlie differences in intelligence between races, or that predispose some races to act more aggressively than others, will produce little.

Rarely, in these contexts, is it explained what 'biologically meaningless' actually means; one wonders if the authors themselves know.

For clarity, we conceptualize the phrase "biologically meaningful concept of race" in two senses, narrow and broad, in accordance with how the term seems to be used. A biologically meaningful concept of race in the broad sense is a biologically valid concept that has a reasonable claim to the name "race." A biologically meaningful concept of race in the narrow sense is a concept that describes natural biological divisions. Our understanding of a biologically meaningful concept in the narrow sense is based on not uncommon usage, e.g., Wilkins (2011):

"Ape," "monkey" and so on are not terms that have any biological meaning. Here is why: the following [cladistic] diagram indicates the technical names given to primates apart from "monkeys":

...So, goes the argument, "ape" and "monkey" mean nothing useful. They are no more terms of biological relationship than "kind" is a rank in systematics like "species," etc.

For the author, "biologically meaningful" groups are ones that cut out natural divisions. We allow for the more inclusive broad sense because some (e.g., Diamond $(1994)^{28}$ ) have equated races with artificial biological groupings, groupings that could be said to be "biologically meaningful" in some sense. Thus, a concept of race that denotes biological artificial classifications can be said to be biologically meaningful in a broad sense.

\footnotetext{
${ }^{27}$ For example, Levin (2002) advances a cladistic race concept which tolerates a high degree of admixture.

${ }^{28}$ Diamond (1994) entertains the possibility of dividing up the world into lactase positive and negative "races."
} 


\section{I-K. Biological Reality}

In the preceding discussion, the nature of "biological kinds" and the meaning of "biological meaningful" and of "biological valid" were discussed with respect to biological concepts. We did not draw a distinction between a concept and that which it references. We are now moving onto discussion of the meaning of "real" (with respect to the entities in a research program). Since we judge that the term "real" connotes something beyond the epistemic status of concepts, we will now draw that distinction: concepts qua concepts differ from referents.

In our judgment, referents can not be apprehended without a concept, and a concept that references nothing is empty. We roughly agree with Kant's dictum that "a concept without a percept is empty and a percept without a concept is blind." By this understanding, a concept, then, is like a container. What it contains is only thinkable when it is contained.

The container can be valid, meaningful, deeply embedded and well-fitted in a research program (shaped consistently with the overall state of knowledge), but if it is empty, then something is unreal - not the concept per se (the ontological status of concepts is another matter), but rather the complex, thing, or object formed by the concept plus that which it references. One might just say that the concept is empty, or clarify, e.g., "biologically non-real in the sense that the concept is an empty class owing to the nonexistence of the objects of reference." It seems to us that people do refer to concepts and their referents as "things" that can be non-real, so we will allow that these things can be real or non-real.

As discussed above, for a biological thing to be real it must point to a valid biological concept which is not vacuous. Since biology (unlike, e.g., mathematics) is a natural science and since nature is located in the cosmos, the referent must be there too. That which is "biologically real" does not need to be a biological kind. For example, processes such as metabolism and evolution, which are said to not be biological kinds, are nevertheless biologically real. Moreover, biological reality does not require deep, kind-like embeddedness in a research program.

"Biologically real" things include breeding populations, metabolites, the hydra (the animal marked by radial symmetry), and ecosystems. "Biologically non-real" things include humors, the hydra (the many-headed monster), dinosaurs, and Homo floresiensis. Of the latter, the first two are "non-real" because they involve biologically invalid concepts; the latter two are "non-real" because the concepts, while biologically valid, reference nothing currently in existence. Thus we draw a distinction between "biologically valid" on the one hand and "biologically real" on the other.

\section{I-L. Biologically Important Differences}

There is one other sense in which the phrase 'biologically meaningful' is used in a racial context: the sense intended by Lewontin (1972) when he claimed that race was of "virtually no genetic... significance." By this sense, 'biologically meaningful' races are ones which 'importantly' differ.

At times, "biologically meaningful" in this sense of having 'important' differences is conflated with "biologically meaningful" in the sense of being a valid biological classification. To preclude 
confusion, we will simply rephrase the former as "biologically important differences" between races. Doing so clarifies the logical intent of the phrase.

We take it as obvious that races do not need to display "biologically important differences" to represent "biologically meaningful" classifications. Whether races do exhibit "important differences" is an empirical question, given an operational definition of important (e.g., effect size guidelines used in the social sciences). ${ }^{29}$

Readers are referred to the discussion of Hardimon (2013) for further elaboration on the point which we are making - particularly, for a more detailed exposition of the logical and pragmatic reasons for recognizing the distinction between the biological meaningfulness of a race concept and the existence of biologically 'important' differences between races.

\section{I-M. Concepts of Biological Race}

Next, we must clarify what it would mean for a biological concept to be a biological race concept. Such a biological concept need not always be called "race," nor does the term "race" need always refer to the said concept, but any biological race concept must have a reasonable claim to the term.

Obviously, there is a subjective element involved when it comes to assessing what constitutes a "reasonable claim." Nevertheless, examples of biological concepts which qualify (microgeographic race, etc.) and do not qualify (sexual morph, life form, etc.) come readily to mind. Biologists and others who discuss race in relation to biology have frequently referred to the former, but not the latter, as "race." Of course, one could call any biological concept "race," and no term truly belongs to a concept, but some concepts and terms have a history of common or related usage such that using the particular term to describe the particular concept does not seem equivocal or sophistical.

\footnotetext{
${ }^{29}$ For example, for Cohen's d an effect size of 0.2 to 0.3 is conventionally considered to be a "small" effect, of around 0.5, a "medium" effect, and of 0.8 to infinity, a "large" effect (Cohen, 1988).
} 
What is race? - Kant (1788)

\section{The General Biological Race Concept}

\section{II-A. The Genealogy of the Concept}

What is race? The term means many related things and is thus a polyseme. Here, we are not interested in "race" as either a term or a general notion but as a specific concept which picks out a type of biological variation not well captured by other concepts in the domain of biology. We might dispense with the term "race" were it not to appropriately describe the concept of interest and to help facilitate thinking about it. But what is this concept? To ask this question is to request examples of the sort of biological variation that we are trying to describe. Consider the following types of variation: New Yorkers and Parisians, blonds and brunets, East Asians and Europeans in New York, and humans and horses. From the perspective of biology, we would properly refer to the first as "(spatial) populations," the second as "morphs," and the fourth as "species." But what of the third? These are strangely sounding groups. After all, how is someone an 'East Asian' and yet also a 'New Yorker'? Perhaps what is meant is someone who once lived in East Asia - who migrated from the East Asian (spatial) population -and who now lives in New York? Yet what if both our East Asians and Europeans were second or third generation immigrants, ones born in New York? In what way would such groupings be biological? Perhaps, in fact, there is nothing biological to speak of beyond the types of divisions which we have already named. Perhaps our East Asians and Europeans, as such, are nothing at all, biologically speaking.

This is the situation we face contemporaneously, with the rejection of the race concept. We can speak of populations and, within these spatially defined groups, polymorphs but neither concept identifies that which we wish to speak of. A similar situation existed in the 1700s before the development of the race concept. At that time, one could speak of inconstant varieties or species. Yet neither concept seemed to well describe the black Ethiopians born in Europe noted by Carl Linnaeus. These considerations situate us to explore the origin and evolution of the biological race concept. After, we can related this original concept to contemporaneous ones.

Prior to being incorporated into natural history in the 18th century, the term "race" referred to breeds and lineages. "Race" was employed, in a related fashion, in several different discourses. In context to animal husbandry, it was used to describe strains of animals produced through linebreeding. In social discourse, it referred to the genealogical lines of noble families along which prized characteristics were thought to pass (e.g., noblesse de race). In theological context, it signified lineage, a concept which was employed to explain the transmission of original sin; accordingly, all men inherited the sin of Adam due to being of his race; in the same vein, different lineages of Adam, dispersed across the world, were said to represent different races for example, that of Sem (Doron, 2012). Underlying the word usage was a notion of race which involved the idea of genealogy and of the inheritance of traits. This notion was integrated into natural history largely by Comte de Buffon, Immanuel Kant, and Johann Blumenbach to make sense of a particular sort of intraspecific variation, which was sometimes called the "constant variety." This type of variation, with relative constancy, intergenerationally transmitted its form even when reared in non-native lands. While the term "race," being employed by livestock farmers to denote domestic breeds, was already in use to describe "constant varieties" (Ratcliff, 2007) - both the term and the notion it referenced had not yet made its way into natural history. 
It was still an applied scientific notion and not yet a natural scientific concept. "Race" had not yet been naturalized. The conceptual integration took place in context of a paradigm shift occurring in the biological sciences. Biological divisions were beginning to be reunderstood genealogically. As Doron (2012) notes:

Kant first described these two methods in his essay "Of the different races of human beings" (17751777), where he criticized (in accordance with Buffon) a method of thought separating natural beings into "scholastic species"... According to this perspective, natural beings share logical relationships of differences and resemblances; they coexist in collective units that are merely catalogues. Kant systematically contrasts this style of thought with another, through which, according to him, one may obtain a "natural division" of beings "grounded on the common law of propagation"... As Kant puts it, this natural division considers natural beings according to their "strains [Stämme] [and] divide[s] animals according to their kinships [verwandtschaften], with reference to their power of reproduction [Erzeugung]." This is supposed to lead to "the natural science of origins", wherein natural beings would be studied from the point of view of their lineages, original roots and derivations.

Like Darwin later, both Kant and Buffon were critical of non-genealogy, resemblance-based systematics - and Carl Linnaeus's was thought to epitomize this. Regardless of how his systematics was characterized by these and other authors, Linnaeus did have a genealogical understanding of species. ${ }^{30}$ According to this, generation was a matter of the reproduction of the species' form; the laws of generation precluded both spontaneous generation and transmutation (evolution), as these laws ensured that all individuals of a given species were by nature structurally identical, generation on end (Müller-Wille, 2007). His systematics, then, was not bereft of genealogical thinking; rather, genealogy was thought about in a way that left no room for a genealogical understanding of intraspecific variation (and with it evolution) and also in a way which led naturalists to look for the structure marks that defined or characterized species. Under this system, species had created natures or structural designs which were transmitted uniformly across generations, and they were differentiated on the basis of structural resemblance. Intraspecific variation was also organized based on resemblance, but this resemblance was thought to be environmental in origin and so it was not understood genealogically (Sloan, 1973; Doron, 2011). Moreover, the intraspecific groupings were allowed to be artificial, created based on this or that particular deviation from the species type. Both Kant and Buffon juxtaposed with this their more expansive genealogical perspective and therein situated the race concept. These authors were followed by others. For example, after summarizing Kant's approach, Christoph Girtanner wrote that "a new system of classification for the animal kingdom into classes, orders, species, races, variations, and varieties <developed> according to relationships of generation, must be taken up (1796)." And Blumenbach, who originally approached biological variation from a Linnaean perspective, gradually came to adopt the Kantian principle for natural history and with it the Kantian concept of race (Lenoir, 1980).

While Kant criticized the systematics of the day on account of cutting out resemblance, not genealogy, based divisions, Blumenbach, as had Buffon prior, attacked it for being artificial in the sense of cutting out groups based on this or that particular character. Blumenbach criticized "that artificial one of Linnaeus, deduced from comparison of teeth" (Blumenbach, 1795) and

\footnotetext{
${ }^{30}$ Müller-Wille (2002): "If one follows the "laws of generation" referred to by the definition, up to their full explication in the very first two paragraphs of the Systema naturae of 1735, it becomes evident that the substrate of the structural similarity posited between ancestors and descendants is made up of purely genealogical relations."
} 
proposed a classification system in which divisions were "dependent upon all bodily indications alike" (Blumenbach, 1806). Linnaeus himself did not intend for his system, at least on the level of genus and species, to cut out artificial groups. While organisms were often arranged into taxa based on specific characters, species and genus were supposed to pick out Creator-made divisions, ones in which organisms would necessarily be grouped according to their overall structural resemblance. Linnaeus recognized the distinction between natural, Creator-made divisions, ones recognized by their differentia (species and genus) and cultural, human-made divisions, ones which were defined by their character differences (varieties). His species and genus were supposed to be the former; thus, he famously noted, "It is the genus that gives the characters and not the characters that make the genus" (1737). Indeed, Darwin (1859) paraphrased this very statement and noted that with it Linnaeus made clear the importance of using "an aggregate of characters" when classifying organisms. Regardless, Blumenbach saw his natural system, based on overall similarity, as importantly different from that of Linnaeus.

What is of interest to us is that, with regards to intraspecific variation, Blumenbach, unlike Buffon, did not originally conceptualize groupings as genealogical units. This happened only after he came under the influence of Kant (Lenoir, 1980). Thus, Bernasconi and Lott (2000) note that "it was only in 1795" that "Blumenbach's varieties became a part of what Kant had called natural history." Before the middle to late 1790s, Blumenbach's regional varieties would have been phenetic groupings, ones where members were arranged by overall phenotypic similarity. Only after Kant's understanding was incorporated into Blumenbach's system, do we get something akin to Buffon's races - different lineages which were identified using an ensemble of characters - or, for that matter, something similar to Darwin's (1859) natural divisions, where "trifling characters" were important because of "their being correlated with several other characters" and because these correlated characters indexed descent.

Now, while Blumenbach originally thought of his regional varieties as phenotypic-based divisions, Kant, while seeing them as genealogy-based ones, that is, as races, distinguished them not on the basis of overall phenotypic similarity, but on the basis of single characters which were inherited "unfailingly." For Kant (1785), the only character which indisputably was passed on with no exception was skin color. As such, for major human races, color alone was used as a class differentia. From Blumenbach's phenetic perspective (though Blumenbach apparently never commented on the matter), Kant's races would have been artificial, being delineated on the basis of a single trait. To be clear, Kant thought of his divisions as being ones which indexed overall genealogical relatedness. ${ }^{31}$ Nonetheless, from a phenetic perspective, Kant's divisions, distinguished based on singular traits, were artificial. As discussed in section III, when it came to identifying races, Kant seemed not to have considered the possibility of what Darwin later called "correlated variation." Since he conceptualized races in contrast to polymorphs and other inconstant varieties and since he seemed not to have recognized the principle of correlated variation, it was only logical for him to look for uniformly shared and inevitably inherited characters. Whatever the case, Kant did not give us races in the contemporaneous sense of divisions identified using ancestrally informative correlated variation. For that, Blumenbach had to read Kant's race concept through his phenetic-based understanding. Kant's understanding of race, of course, was instrumental to the development of the modern concept as with it "race" was

\footnotetext{
${ }^{31}$ Kant diagnosed races in a way parallel to how contemporaneous proponents of the (diagnosable version) of the phylogenetic species concept diagnose species; the phylogenetic inference would be the same.
} 
neatly situated in a genealogy-based natural system and defined in contrast to both species and inconstant varieties.

To make sense of the race concept, one has to consider how Linnaean varieties were thought of. These varieties were understood in relation to species. While species were thought of as being natural, creator-made categories, varieties were thought of as representing conventional, human contrived ones which were delineated based on accidental, environmentally induced differences. Thus, Linnaeus (1751, quoted in Müller-Wille, 2002) tells us that, "culture is the mother of so many varieties," and Linnaeus (1751, quoted in Stuessy (2009b)) states that a botanical variety is a "plant changed by accidental causes due to the climate, soil, heat, winds, etc. It is consequently reduced to its original form by a change of soil... Species and genera are regarded as always the work of Nature, but varieties are more usually owing to culture." According to the Linnaean system, the differences between varieties - between those "with white, pink, brown, black face; with erect, short, curved, snub, aquiline nose" and between the "fat and thin, straight and bowed, leprosic and lame people" (Linnaeus, 1737, quoted in Müller-Wille, 2002) - were accidental or sportive in that they were not a part of the species' nature, which was passed on in "the unity of generation" (Stamos, 2012). Because the differences were seen as environmental in origin, they were expected to be inconstant across environments. Indeed, Linnaeus instructed that inconstancy of character should be used as an empirical test to distinguish between species and varieties. Müller-Wille (2007) notes:

At the core of Linnaeus's reform stood his distinction between species and variety which was thoroughly based on his theory of generation. In distinguishing between species, Linnaeus advised his fellow naturalists, one should rely exclusively on "constant" characters - that is, not on characters that varied with external conditions like climate or nutrition, but on characters that reproduced in offspring under various external circumstances.

Under this framework, individuals of a species were essentially the same; if reared in the same environment, they would have the same form. Since intraspecific variation was the product of the environment, there was no distinction between the many sorts of variation. The differences between Ethiopian Albinos and Black Ethiopians, between White Europeans and Black Ethiopians, between sun-tanned Europeans and untanned ones were of the same kind: variety.

By the 19th century, the variety concept was expanded to include races and breeds. This led to conceptual confusion and ambiguity. Pointing this out, the English zoologist Edward Blyth noted in 1835 that the "The term "variety" ... is vague in the degree of being alike used to denote the slightest individual variation, and the most dissimilar breeds which have originated from one common stock." Blyth proposed a taxonomy of varieties which included both "breeds" and "true varieties," both of which were brought about through linebreeding. He gave as an example of the latter the "diverse races of mankind." It is evident that, by Blyth's time, intraspecific genealogical thinking, with its breeds and races, had percolated through systematics, thus allowing for the variety concept to be seen as confusing and as conflating importantly different types of variation.

Of course, the matter was more complicated than the discussion above might suggest. After all, Linnaeus himself discovered forms of plants which seemed to be of the same species but which constantly propagated their peculiar forms. And he dubbed these "constant varieties." In Critica 
Botanica (1737), he even related this phenomenon to human populations. He noted: "Who would deny that the Ethiopian is of the same species as we humans... and yet the Ethiopian brings forth black children in our countries." Linnaeus also conducted hybridization experiments, which showed that in hybrids traits were being, somehow, inherited from both parents (Müller-Wille and Orel, 2007); as a result of his experimental findings, he came to entertain the idea that constant varieties were the product of species hybridization (Müller-Wille, 2014).

Yet, despite Linnaeus' recognition of the curious, oxymoronic constant variety and his musings about their origin, they had no place in his systematics, one which became widely adopted. As such, in this Linnaean framework, there was little place for what would later be understood as race. And since there was little, and since certain human geographic groups exhibited relatively constant (across environments) and quite conspicuous differences, it was concluded by some (polygenists) that these regional groups represented different species of man. This tendency to deem as species what we would now call races was not limited to zoology and anthropology; it was fully realized in botany (Stamos, 2012; Ratcliff, 2007). The situation, as noted by Stamos (2012), led Jean Baptiste de Lamarck to complain that "nearly all present day Botanists are multiplying species, at the expense of their variety to infinity." Polygenists were merely treating humans as many botanists treated their objects of study. The genealogically rooted concept of race was introduced by Buffon and Kant to allow for an alternative: a conceptual intermediate, of sorts, between the inconstant variety and the species - one which some polygenists tried to dismiss. As French naturalist Jean Baptiste Bory de Saint-Vincent noted in 1825:

[T] he authors the most convinced of the truths I will try to expose never positively admitted that there may be various species in what was considered as the species par excellence, coming out of a single root. Most of them thought they could escape the difficulty by referring to "races", most likely forgetting that the word "race", synonymous with lineage, is usually used to talk about domestic animals. (Doron, 2012)

To escape the problem of how groups could, without being species, with relative constancy transmit character differences, even when reared in novel environments, these types of groups were understood genealogically as intraspecific lineages. It was allowed that the environment could, acting on a lineage over time, cause heritable character changes which either became fixed (Kant) or became relatively constant (Buffon) in that lineage. In one exceptionally lucid passage, Kant (1777) discussed the process by which something like races could arise:

Those features that belong to varieties - which are, therefore, by themselves hereditary (even if not always) - can through marriages that always take place within the same families, even produce, in time, something that I call family stock. These features ultimately become rooted in the reproductive power so characteristically that they come near to forming a variation in the way that they perpetuate themselves... If nature, when undisturbed (without the effect of migration or foreign interbreeding) can effect procreation everywhere, she can eventually produce an enduring stock at any time. The people of this stock would always be recognizable and might even be called a race, if their characteristic feature does seem too insignificant and so difficult to describe that we are unable to use it to establish a special division.

Referred to were groups of individuals which were linebred sufficiently to exhibit common heritable characters such that could be used to classify them into genealogy-based, or, in Kant's terms, natural divisions. In a subsequent paper, as noted above, Kant argued that races could only be differentiated using characters which were transmitted with "absolutely no exception." He 
noted that hereditary skin color was the only verified trait which met this requirement. ${ }^{32}$ (Though, in a third article, in response to a clever reply by naturalist Georg Forster, he seemed to take a step back, as he suggested that bone structure might be used as another differentia.) Kant's position, at least as developed in his second paper, Determination of the Concept of a Human Race, was out of line with the modern cluster-class understanding. Nonetheless, the basic structure of the modern concept was present. In a manner similar to how Kant described the coming about of his folk stock-races, Buffon, in his Natural History, characterized the emergence of human races:

[T] here was originally but one [human] species, who, after multiplying and spreading over the whole surface of the earth, have undergone various changes by the influence of climate, food, mode of living, epidemic diseases, and the mixture of dissimilar individuals; that, at first, these changes were not so conspicuous, and produced only individual varieties; that these varieties became afterwards specific, because they were rendered more general, more strongly marked, and more permanent, by the continual action of the same causes; that they are transmitted from generation to generation, as deformities or diseases pass from parents to children.

Buffon's races - "constant varieties which perpetuate themselves by generation" (Buffon, 1778) were said to come about through the gradual accumulation of deviations (or degenerations) which became embedded in lineages. Other monogenists argued similarly. ${ }^{33}$ As Buffon's statement above makes clear, he put forth an epigenetic explanation of race differences. A number of others adopted the same position when it came to accounting for the etiology of differences. When not, for example in the case of Kant, who conjectured that environmental factors triggered the expression of adaptive hereditary predispositions which were then genealogically transmitted, the ultimate cause of the differences, or, at least, the cause of the expression of them, was the environment.

Also, to note, with Kant and others there was some ambiguity regarding the conception of races as such; "race" at times described either (1) divisions of organisms which owing to differences in lineage differed relatively constantly in characters or (2) character differences which were transmitted relatively constantly along lines of descent which allowed one to create genealogybased divisions of organisms or (3) lineages which acquired character differences such to allow for a genealogy-based division. ${ }^{34}$ There is a non-trivial conceptual differences here; in the first

\footnotetext{
${ }^{32}$ Kant assumed that darker colored "Whites" such as Spaniards and Arabs were phenotypically dark owing to the environment; this allowed him to classify them as White based on supposed hereditary color. Kant (1788): “Once one sets aside what the sun in a country impresses upon each individual in it, there is no ground for judging that their color is any other than the brunette one among the white human sort."

${ }^{33}$ For example, James Prichard noted: "And in a remote hamlet or district not frequently visited by strangers ... where the population has undergone no changes by the introduction of new occupants, the inhabitants become connected together by intermarriages, and a communication of hereditary varieties takes place, till all become at length more or less alike" (Prichard, 1836).

${ }^{34}$ Doron (2012) notes: "That "race" designates relatively constant characteristics transmitted through generations, so that it can differentiate major lineages among human species, now appears to be clear in the way Buffon contrasts Ethiopians to Nubians." But it is not clear to what extent "race" designated the characters and to what extent the lineages which acquired them, let alone the populations delineated by the lineages. To give two examples: first, in regards to American Indians, Buffon tells us that they "come from the same stem and preserve until today the characteristics of their race without great variation"; here, the characteristics belong to a race as they might to a
} 
case, races as such are seen as divisions of organisms, in the second, as characters which allow for lineage based divisions, and in the third, as lineages based on which organisms could be divided. This ambiguity resulted from races being thought, owing to the concept's pedigree, simultaneously as breeds, as unique types of Linnaean varieties - which were often seen as variations in characters and not as divisions of organisms - and as lineages. The difference, while worth noting, is not fundamental, since either way "race" ended up characterizing, consistent with the contemporaneous understanding, genealogy-based divisions of organisms. Varieties, on the other hand, characterized not only groups of organisms but also individual variations such as, to give some examples of Prichard's (1836) usage, the "varieties of the muscles" or "varieties" which "appear in individuals."

These race concepts, then, differ importantly from modern ones. There are nonetheless substantive and fundamental similarities. First, Buffon, Kant and, by way of Kant, Blumenbach identified races, at least as seen from one angle, with lineage-based divisions of a species, which where distinguishable from one another by the members' inherited characters. Second, relatedly, all three decidedly did not recognize groups such as blonds and brunets or albinos as races since these were not genealogical entities. Third, all three recognized the importance of reproductive isolation in allowing for the formation and maintenance of races. Fourth, these early theorists recognized the gradual accumulation of racial differences, ones resulting from the passing on, along genealogical lines, of heritable individual variations. Fifth, relatedly, in agreement with the idea that intraspecific variation is marked by tokogenic relations, Buffon and Duchesne, who were the first to depict genealogical networks, located races within a species-level phylogenetic network (Morrison, 2012). ${ }^{35}$ Sixth, at least Kant and Blumenbach, who were joined by others such as Antoine Duchesne, ${ }^{36}$ exclusively conceptualized race, when precisely understood, as a type of intraspecific variation.

We see then the epistemic role that the race concept played in the $18^{\text {th }}$ and $19^{\text {th }}$ century. It allowed one to speak of groups that were neither species nor inconstant varieties. And it also allowed one to explain how different groups of organisms reared in the same environment could with intergenerational constancy differ without being different species. Race also played a

lineage - they are not the race; second, regarding Tartars and Chinese, Buffon notes, "In their features, and form, however, there is so striking a resemblance, as to leave a doubt whether they did not spring from the same race." Features and forms are clearly being used to evidence the "race" from which Tartars and Chinese sprung; race here is understood to mean lineage. Similarly regarding Kant, we are told that race is a "radical peculiarity," indicating a character which allows for a natural classification. But also that "this stock... might even be called a race," indicating that a race is a group of individuals. And, additionally, that the "human species... could be divided in a system of nature into a line (or lines) of descent, races, or deviate forms (progenies classificae)," indicating that race is simultaneously a line of descent, characters which allow for a natural classification, and a division of organisms ( progenies classificae $=$ classifiable offspring).

\footnotetext{
${ }^{35}$ For example, see Buffon's genealogical network of races of dogs ("Table de L'Ordre des Chiens") in volume V of Histoire naturelle. This can be contrasted with branches in a phylogenetic tree.

${ }^{36}$ Ratcliff (2007) notes: "According to Duchesne [1747-1827], this term needed "to be introduced into the history of vegetables," to designate objects in the territory between botanists and cultivators. He considered race to be a better word for "constant variety," which was an "improper denomination" in his view... Duchesne's claim was that, although both races and species were constant, races were not the same as species."
} 
leading role in an expanded genealogical framework, one in which natural history was understood in terms of networks of filiation.

\title{
II-B. Semantic Complexities and the Evolution of the Race Concept
}

Had the term "race" consistently been used to refer to intraspecific lineages, much contemporaneous confusion about the concept would have been precluded. On the other hand, if so, the concept which we now know as "race" might be called something else. Conceptual confusion arose because the term "race," especially after it was popularized by Buffon and Kant, was often used to describe population-lineages of either the intraspecific or specific (species) sort. Thus, in reply to Kant, the renowned naturalist Georg Forster (1786) wrote:

\begin{abstract}
We have borrowed <the term> [race] from the French; it seems very closely related to <the words> racine and radix and signifies descent in general, though in an indeterminate way. For one talks in French of the race of Caesar <in> the same <way> as of the races of horses and dogs, irrespective of the first origin, but, nevertheless, as it seems, always with tacit subordination under the concept of a species... <The word $>$ should mean nothing more than a mass of men whose common formation is distinctive and sufficiently at variance with their neighbors <such that they> could not be immediately derived from them. <They are> a lineage whose derivation is unknown, and consequently, one which we cannot easily count under one of the commonly accepted human varieties because we lack knowledge of the intermediary link.
\end{abstract}

Forster advocated using the term "race" in a way that could be applied to either specific or intraspecific divisions. This inclusive sense of race was used at times by Buffon, who wrote of both the "human race" and the "white race." We also see it employed by polygenists such as Voltaire, Josiah Nott, and those who argued that the races of man represented separate species. When, for example, John Aktins said, "I am persuaded the black and white race have, ab origine, sprung from different-colored first parents" (Horsman, 1981), he was proposing that the said races were different species. Additionally, we see this more general sense deployed by monogenists such as Prichard (1836), who tells us that "races are considered specifically different" if the evidence leads us to conclude that the groups "have not descended from the same original stock."

It is worth considering Prichard's understanding since, when juxtaposed with Kant's, it sheds light on the evolution of the race concept. Kant, we said previously, understood races both as unfailingly transmitted hereditary particularities and as the genealogy-based divisions which these particularities allowed one to identify. He stipulated that races were intraspecific divisions and used interfertility as a diagnostic tool to distinguish between races and species. Kant helped establish race, in the intraspecific sense, as a type of entity in natural history. With the concept established, the term "race" could later be used to refer either to constant varieties or to species.

Contra Kant, polygenists rejected the view that species were necessarily intrinsically reproductively isolated; they argued that species (defined as distinct creations) should be diagnosed, instead, on the basis of character constancy (in line with Linnaeus' instruction). Polygenists, then, were using race to mean both lineages and genealogy-based divisions, regardless of character constancy. Accordingly, races needed not exhibit generationally constant characters, since they needed not be species. And they were not characters but were rather population-lineages which characteristically differed. 
While Prichard argued against the polygenist view, he agreed that species should be evidenced by constancy of character (and he added that they should also be evidenced by character discontinuities). He then emphasized the inconstant transmission of human racial characters pointing, for example, to reports of exotic cases in which Black Africans bore white colored children. What we see happen is that the concept of intraspecific "race" sheds the understanding of being a hereditary character variation, one which marks out divisions, and becomes more directly identified with genealogy-based divisions as such. This was a subtle shift, but it allowed intraspecific race to eventually be understood as it is now.

The dual usage of the term, race, to either refer exclusively to constant varieties or to refer inclusively to constant varieties or species, in conjunction with the $20^{\text {th }}$ century use of the term (to refer exclusively to intraspecific divisions), has led to much confusion and mischief. It has led many to conclude or at least imply that races as constant varieties were once thought of as representing distinct ancestries or permanent types. Insofar as this was thought about "races," these races were thought of as species and not as the races of Buffon, Kant, and Blumenbach. This said, a couple of important points are worth highlighting. First, irrespective of whether the term was used inclusively or exclusively, "race" cut out a type of variation unlike Linnaeus's (1737) "fat and thin, straight and bowed, leprosic and lame people." "Race" allowed one to specify and to think about lineage-based divisions of creatures. It cut out constant varieties and/or species as generative-based classifications in contrast to morphs, individual peculiarities, and other types of biological variation. Second, and relatedly, the concept of race in the inclusive sense had the effect of grouping species and constant varieties together as genealogical entities in contrast to variations of other sorts. This inclusive sense was, then, able to conceptually bridge some of the chasm between the intraspecific and the specific. The inclusive usage of "race" thus paved the way for the recognition of the continuity between (intraspecific) race and species.

Regarding semantics, since race was used in an inclusive sense, the question of the day was often phrased as one of whether races were varieties or species, a phrasing which, with the use of the term "race," implied with respect to "variety" something other than the Linnaean type, something which incorporated intraspecific genealogical thinking. The important point here is that the conceptual distinction between race as species and race as constant variety was recognized after Buffon, Kant, and Blumenbach had popularized the term "race" with reference to the latter. After this, it was possible to debate whether or not groups were (1) varieties in the inconstant sense or (2) intraspecific races (alternatively, races as varieties) (3) or species (alternatively, races as species). That is, there was a conceptual, if not semantic, trichotomy.

In short, "race" came to be used dually to describe "species" and "constant varieties," the latter which we now know of as "race." This usage brought about some semantic confusion. But it also allowed "constant varieties" to be thought about as a type of biological entity similar to species: population-lineages.

Another level of confusion has resulted from the use of the term "race" to describe both taxa subspecies and intraspecific lineages not formally recognized. The term "subspecies" was first defined by German entomologist Eugen Esper (1782). Esper equated subspecies with "pure varieties (meras varietae)" and contrasted them with both "accidental varieties" and species. The 
subspecies of his species shared a common origin and did not differ in essential characteristics; they did, though, transmit their distinct characters across generations. ${ }^{37}$ As examples of different human subspecies, which he also parenthetically referred to as races, Esper noted Europeans and Africans and their differences in skin color, hair shape, thickness of lips, and so on. A couple of years later, Swiss botanist Jakob Ehrhart (1784) offered a similar definition. Subspecies, for Ehrhart were varieties which passed on their slight character differences through their seed. Ehrhart (1784) noted:

Halbarten, Scheinarten, Subspecies.

In this way I term plants which agree in essentials almost completely with each other, and are often so similar to each other that an inexperienced person has trouble in separating them, and about which one can conjecture, not without reason, that they have formally had a common mother, notwithstanding that they now always reproduce their like from seed. They are in a word, Varieties constantes, or an intermediate between species and Spielarten [inconstant varieties]. They are separated from species in that they differ from one another in small particulars of little importance; and they differ from Spielarten in that they reproduce themselves unchanging by seed and always beget their like. (Cited in Chater, Brummitt, and Ehrhart (1966).)

As with Buffon's races, Esper's and Ehrhart's subspecies both described constant varieties and gave a more or less genealogical account of these. The relation between race, subspecies, and constant varieties did not go unnoticed by others. Thus, Rorn (1810) equated subspecies with both races and "permanent varieties" (Fuchs, 1958). Notably, in contrast to how Buffon, Kant, and Blumenbach dealt with their intraspecific races, Ehrhart, foreshadowing future usage, consistently assigned trinomina to his subspecies; he treated them as taxa. Over the course of the 19th century, the term "subspecies" increasingly came to be used to refer to the taxonomic rank under species. For example, when, in 1844, Hermann Schlegel created the concept of conspecies, he included an intraspecific rank designated as "subspecies" or "local races" (Johnson, 2012). As noted by Haffer (2003), ornithologist Christian Brehm also placed "subspecies" in a hierarchical system. In the early 20th century, "subspecies" was officially recognized by the International Commission on Zoological Nomenclature as a zoological taxonomic rank. (The International Botanical Congress of 1867 had already recognized it as a botanical one.) Initially, there were no even informal conventions for the recognition of zoological taxa subspecies. Over time, informal conventions were developed and were tightened up, leaving us with the zoological subspecies we have today, which represent major and 'significant' divisions in a species. In contrast, in zoology, "race" did not come to officially describe a taxonomic category. This was partly owing to the term's legacy of being, somewhat confusingly, dually used to refer to both specific and intraspecific lineages. While, in the $19^{\text {th }}$ and $20^{\text {th }}$ century, "geographic race" was often used as a synonym for taxa subspecies, it was generally recognized that taxa subspecies referred to races

\footnotetext{
${ }^{37}$ Esper (1782) writes: "Subspecies (untergattungen, Races) quae vulgo annumerantur varietatibus, plane ab his sunt separandae. Originem ex speciebus duxisse, perfectus in iis declarat partium essentialium similitudo. Characteríbus autem pariter sunt distinctae, quamvis minus essentialibus, caussa qua fuere mutatae eadem manente, sive sit externa sive interna. Ad procreandam sobolem eamque ipsis aequalem aptae, differunt hac virtute a varietatibus quibus ea denegata est."
} 
which were thought to be deserving of formal taxonomic recognition. Thus, for example, Hubbs (1943) noted: "Unlike races, subspecies are animal kinds which are sufficiently clear-cut as to be thought worthy of a place in the nomenclatorial system."

As noted prior, the dual $19^{\text {th }}$ and $20^{\text {th }}$ century use of "race" to describe both taxa subspecies and other intraspecific natural divisions has led to some confusion. This is especially the case in context to contemporaneous philosophical debates concerning the validity of the race concept. However, the common original use of the terms to refer to constant varieties should make clear the absurdity of at least some historic usage based criticisms of the (intraspecific) race concept, as such criticisms work just as well against a now formally recognized taxonomic rank.

Box 2.1. Semantic confusions

Some of the disagreement on the status of the race concept is a product of historic terminological inconsistency. Originally, in the Linnaean framework, the lowest taxonomic category was "variety." Varieties were understood to be environmental deviations from the species type. Sometimes the term "race" was informally used to describe species, but in applied scientific discourse "race" referred to (intraspecific) breeds of animals. Natural historian Comte de Buffon popularized the term in the middle of the $18^{\text {th }}$ century and used it mainly to refer to "constant varieties." The eminent philosopher Immanuel Kant picked up both the term and the idea from him and contrasted "race" with both species and varieties. Kant's definition was later adopted by Johann Blumenbach. This concept of race was used by some to argue that human groups were not separate species as maintained by polygenists. Polygenists, though, turned around and appropriated the term. They used it to mean either species lineages or intraspecific ones.

This situation necessitated the use of another term to stipulate the intraspecific sense when this was meant. Often the ambiguous term varieties was reemployed but increasing, in the middle of the 19th century, the term "subspecies" was used. In "Descent of Man," Darwin, for example, noted that "some naturalists have lately employed the term "sub-species" to designate forms which possess many of the characteristics of true species, but which hardly deserve so high a rank." Darwin went on to argue that it would be more fitting to consider major human regional groups to be different subspecies than to be different species.

At this time, "subspecies" was still not infrequently used to describe geographic (intraspecific) races in general. It was not used exclusively in the taxonomic category sense. When the concept was first developed by entomologist Eugen Esper and botanist Jakob Ehrhart, in the $18^{\text {th }}$ century, it referred to the same thing that Buffonian races did: constant varieties. After Darwin's theory was adopted, the monogenist versus polygenist debate largely died down. With the cessation of this dispute, "race" was used in the intraspecific sense. In zoology, during the 20th century, the term "subspecies" began to be exclusively used to denote the taxonomic category below species and with it only formally recognized races.

Both in zoology and botany subspecies replaced variety as the category immediately below species. In botany, a taxonomic category named "variety" is still recognized by the International Code of Botanical Nomenclature; but differences between varieties are understood to be genetically caused. Regarding taxa subspecies, originally, there were no conventional standards for recognizing them. This led to a proliferation of formally recognized races. In the early to middle 20th century, some informal rules were, for pragmatic reasons, adopted in zoology to limit the number of subspecific taxa. Only races which met some conventional criteria were then dignified with a trinomen and recognized as taxa subspecies.

No criteria were ever formally agreed upon and the rules of thumb in use were often and continue to be both loosely employed and interpreted differently. Thus, to this day, formal racial recognition standards vary wildly. In some quarters of biology the term "subspecies" retains its looser meaning of intraspecific race in general. In popular discourse, the term "race" is still used at times to describe species as in the case of the phrase "the human race." 


\section{II-C. Biological Race}

The semantics are undoubtedly confusing. But the core notion of race is not difficult to identify. Our bridge between these early concepts and contemporaneous ones is Darwin, who reasoned that members of races should be arranged by overall genealogical similarity, who grasped the importance of 'correlated variation' when it came to delineating natural divisions, ${ }^{38}$ and who understood, unlike many of his predecessors, that intraspecific races were way stations to, not degenerations of, species. How this Darwinian understanding relates to the original ones, at least as developed by Buffon, Kant, and Blumenbach but employed by others, should now be obvious. Among other things: like Buffon, Kant, and Blumenbach's race concept, Darwin's was natural in the sense of being genealogy-based; like Buffon's and Blumenbach's concept, Darwin's was also natural in the sense of being defined by overall relatedness indexed by an ensemble of characters; finally, like Kant's concept, race differences were seen as adaptive. How this understanding relates to the diversity of 20th and 21 st century concepts needs now to be discussed. Undoubtedly, a plethora of race definitions have been offered. ${ }^{39}$ Some of these are shown below in Table 2.1.

\section{Table 2.1. A selection of definitions of race from the 20th and 21st century}

\section{Genetic Population Based}

Boyd (1950): "Dobzhansky and Epling (14) propose to define races as (different) populations which are characterized by different frequencies of variables genes and/or chromosome structures... In the ideal case, one would take account of all the variable genes and chromosome structures in order to describe a given race."

Hulse (1962): "Races are breeding populations which can be readily distinguished from one another on genetic grounds alone. They are not types, as are a few of the so-called races within the European population, such as Nordics and Alpines. It is the breeding population into which one was born which determines one's race, not one's personal characteristics."

Dobzhansky (1970): “A race is a Mendelian population, not a single genotype; it consists of individuals who differ genetically among themselves ... This is not to deny that a racial classification should ideally take cognizance of all genetically variable traits, oligogenic as well as polygenic."

Garn (1971): "Races, moreover, are natural units and not artificial assemblages created by selecting 'types' out of a population." "Members of such a breeding population shared a common history and a

\footnotetext{
${ }^{38}$ For example, in chapter 13 of Origin of Species, Darwin notes: "We may err in this respect in regard to single points of structure, but when several characters, let them be ever so trifling, occur together throughout a large group of beings having different habits, we may feel almost sure, on the theory of descent, that these characters have been inherited from a common ancestor. And we know that such correlated or aggregated characters have especial value in classification."

${ }^{39}$ Generally, a concept organizes instances of experience into units; and a definition elaborates a concept. When a concept's definitions vary, one might say that specific definitions imperfectly elaborate the concept or that they perfectly elaborate sub-concepts, that is, qualified versions, of the concept in question. Wilkins (2010) does the former with regards to species concepts, we do the latter with regards to race ones. Thus, our many race definitions are treated as elaborations of qualified versions of a more general concept. And we use the term 'definition' and 'concept' more or less synonymously.
} 
common locate. They have been exposed to common dangers, and they are the product of a common environment. For this reasons, and especially with advancing time, members of a race have a common genetic heritage."

Hartl and Clark (1997): "In population genetics, a race is a group of organisms in a species that are genetically more similar to each other than they are to the members of other such groups. Populations that have undergone some degree of genetic differentiation as measured by, for example, Fst, therefore qualify as races."

Vogel (1997): "A large population of individuals that have a significant fraction of their genes in common and can be distinguished from other races by their common gene pool."

Crow (2002): "Groups that split and became separated, typically by a geographical barriers, and gradually diverged genetically."

Molnar (2002): "Geographically and culturally determined collection of individuals who share a common gene pool."

Leroi (2005): "Populations that share by descent a set of genetic variants in common that are collectively rare in everyone else."

\section{Biological Anthropological}

Hooton (1926): "[A] great division of mankind, the members of which, though individually varying, are characterized as a group by a certain combination of morphological and metrical features, principally non-adaptive, which have been derived from their common descent."

Pearson (2002): "[A]n inbreeding descent group" or "a large extended family that inbreeds to a sufficient extent that its members share distinctive identifying biological characteristics."

Sarich and Miele (2004): reasonably discrete groups differentiated based on phylogenically related characteristics.

\section{Zoological and as a Zoological Taxonomic Category}

Mayr (1963): "A race that is not formally designated as a subspecies is not recognized in the taxonomic hierarchy. However, the terms subspecies and geographic race are frequently used interchangeably by taxonomists working with mammals, birds, and insects. Other taxonomists apply the word race to local populations within subspecies."

Cavalli-Sforza and Bodmer (1976): "[R]aces could be called sub-species if we adopted for man a criterion from systematic zoology. The criterion is that two or more groups become sub-species when 75 percent or more of all individuals constituting the groups can be unequivocally classified as belonging to a particular group."

Mallet (1995): "Under the genotypic cluster definition [in which groups are identifiable genomic clusters], subspecies are not very different in kind from species, differing only in their tendency to produce intermediates when they overlap. Except in zones of overlap, subspecies are often as objectively definable as some species."

Mayr (2002): "A geographically defined aggregate of local populations which differ taxonomically from other subdivisions of the species." 
Groves (2004): "Populations, geographic segments of a species, that differ from each other on average, not absolutely."

Allaby (2010): "An interbreeding group of individuals, all of whom are genetically distinct from the members of other such groups of the same species. Usually these groups are geographically isolated from one another, so there are barriers to gene flow. Examples include island races of birds and mammals, such as the Skomer vole and the St. Kilda wren."

Coyne (2012): "Races of animals (also called "subspecies" or "ecotypes") are morphologically distinguishable populations that live in allopatry (i.e., are geographically separated)." Coyne (2014). "To a biologist, races are simply genetically differentiated populations, and human populations are genetically differentiated. Although it's a subjective exercise to say how many races there are, human genetic differentiation seems to cluster largely by continent, as you'd expect if that differentiation evolved in allopatry (geographic isolation)."

King, Mulligan, and Stansfield (2013): "[A] phenotypically and/or geographically distinctive subspecific group, composed of individuals inhabiting a defined geographical and/or ecological region, and possessing characteristic phenotypic and gene frequencies that distinguish it from other such groups. Homo sapiens can be subdivided into five races on the basis of the geographic origin..."

\section{Ecological}

Gregor and Lang (1936): "A population distinguished by morphological and physiological characters, most frequently of a quantitative nature; interfertile with other ecotypes of the ecospecies, but prevented from freely exchanging genes by ecological barriers." Gregor (1944): "The ecotype as defined by Turesson is any assemblage of organisms which genotypically reflects the selective action of environment, and may represent anything from a small colonial community to a large regional race."

King and Stansfield (1990): “A phenotypically and/or geographically distinctive subspecific group, composed of individuals inhabiting a defined geographical and/or ecological region, and possessing characteristic phenotypic and gene frequencies that distinguish it from other such groups. The number of racial groups that one wishes to recognize within a species is usually arbitrary but suitable for the purposes under investigation."

Similarly, there is a diversity of species (Wilkins, 2010) and of population (Waples and Gaggiotti, 2006) definitions. This is unsurprising as the basic concepts can be approached from different research programs (e.g., ecology versus population genetics) and with different aims (e.g., taxonomic classification versus analysis of population differences). Underlying the diversities, though, are common conceptual cores. In the case of race, this is the general biological race concept (GBRC). According to this, races are organismic groups which differentiated from one another as a result of historic patterns of filiation; they are groups, which due to histories of sufficient linebreeding, form intraspecific natural divisions, ones which can be identified based on the correlations between the organisms' inherited characters.

Some specific definitions do not explicitly stipulate that these groups are natural divisions, though that they are is more or less implied. For example, some zoologists, as discussed by Mallet (1995; 2001), define subspecies as identifiable "genotypic" or "genomic" clusters which hybridize in zones of overlap; these necessarily would be delineated in terms of genomic similarity and thus would be natural divisions. Others, such as Coyne (2012; 2014a; 2014b), define races as morphologically and/or genetically distinguishable populations that live in 
allopatry or that evolved differences because they once did. At the same time, they note that such groups are identified with an "assemblage of genes" or by "aggregating data from many genes across the genome" (Coyne, 2014a). Thus, these race concepts turn out to match up with the GBRC.

As another example, Dobzhansky (1970), after approvingly quoting Immanuel Kant on the matter, states: "A race is a Mendelian population, not a single genotype; it consists of individuals who differ genetically among themselves." Later, after citing Boyd (1950), ${ }^{40}$ he notes that this "is not to deny that a racial classification should ideally take cognizance of all genetically variable traits, oligogenic as well as polygenic." He does not, along with many other population geneticists, explicitly state that races are natural divisions, but if races are populations - not forms or morphs - which differ genetically, and if classifications are based on all genetically variable traits, then races must be natural divisions.

Generally, granting that races are intraspecific groups that differ genetically/genealogically on average, which is what they are now invariably said to be, they could be: (1) artificial divisions such as morphs or forms, (2) natural divisions, (3) spatiotemporally defined populations, like Iowans and North Carolinians, which, while differing genetically on average, do not cut out genealogical/genomic divisions, or (4) genealogy-defined divisions which are not so linebred that members are more overall genetically similar to other members of the same division than to members of other divisions. This is the manifold of possibilities. Proponents of the race concept have made it abundantly clear that "race" does not reference (1); these wild breeds, as noted above, were purposely introduced into biology in the 18th century to allow for the thinking of a different kind of intraspecific grouping, a grouping understood in terms of ancestry and filial relation and which provides information about both parents' lineage; since, it has been reaffirmed repeatedly that races are not polymorphisms or the like (Hulse, 1962; Dobzhansky, 1970; Garn, 1971). (Polymorphisms, of course, are genetic based, but not being based on genomic similarity they often do not index propinquity of descent.) While many have also made it clear that "race" does not refer to (3), by including references to common "genetic heritage," "descent," "ancestry," "phylogeny," some definitions have, in this regard, lacked precision. Hulse (1962), for example, tells us simply that, "Races are breeding populations which can be readily distinguished from one another on genetic grounds alone." When one considers that the multiracial US and UK can both be said to be breeding populations which differ genetically (on account of differences in heterogeneous composition), one can see that this definition is unclear. It could refer to (2) or to both (2) and (3), despite (3) being inconsistent with the original usage of the term. Yet Hulse's (1962) discussion of race makes the matter less opaque:

Genetic differences between these groups have accumulated throughout the thousands of generations during which they have shared only a minute portion of their ancestry. Certain constellations of characteristics have become typical of the peoples of East Asia, others have become just as typical of Europeans...

\footnotetext{
${ }^{40}$ For reference, Boyd (1950) noted: "Dobzhansky and Epling (14) also point out that it would be equally fallacious to define race as a group of individuals having some single gene in common, or some chromosome structure in common... In the ideal case, one would take account of all the variable genes and chromosome structures in order to describe a given race." [Emphasis added.]
} 
It is the breeding population into which one was born which determines one's race, not one's personal characteristics... One cannot change one's race, but, by mating with someone of another race, one can produce offspring who may fall into a different classification: only the future can tell.

We are told that between races less ancestry is shared than within and that relative reproductive isolation has led different races to evolve different constellations or clusters of characteristics. And we are informed that one's race is fixed; and that for one's descendants to be of a different race one must outbreed. This makes sense only if race is conceptualized as (2). If (3), one could simply change one's race by transplanting oneself to a different spatiotemporally defined population. Were some population geneticists to understand race in the sense of (3) this would not be in line with the historic biological race concept, which was lineage based, and which was employed to explain why transplanted organisms retained their region of origin characteristics ${ }^{41}$ - for example, why Ethiopians born in Europe retained their parents' dark pigmentation.

Some discussants of race might mean (4); however, this conception does not well make sense of the common stipulations that races have some relatively constant character (e.g., the whole idea of constant varieties) or that races have a significant fraction of genes in common (e.g., as with Leroi (2005) and Vogel (1997)), stipulations which are met when groups are sufficiently linebred. Additionally, many proponents of biological races have either noted, concurred, or specified that races should be delineated in terms of overall genetic similarity (e.g., Darwin (1903), Dobzhansky (1970), Hartl and Clark (1997)); and many others have implied this. We imagine that few to no researchers have conceptualized biological races so loosely as to include

Box 2.2. From inconstant varieties to species: another continuum

One way or another, race is situated in a continuum. Spatial continua are often noted, but there are other important ones, such as degree of lineage entwinement. As recognized early on by race theorists such as Buffon, races are the product of linebreeding. With linebreeding, networks of filiation within populations become thicker relative to those between and inherited variations accumulate in the population-lineages. When linebreeding is sufficient, we no longer have individual differences but we have recognizable natural divisions. In "Origin of Species," Darwin recognized the continuum being discussed:

Certainly no clear line of demarcation has as yet been drawn between species and subspecies... or, again, between sub-species and well-marked varieties, or between lesser varieties and individual differences. These differences blend into each other by an insensible series; and a series impresses the mind with the idea of an actual passage.

Certainly, there is no clear line of demarcation in nature. Yet, the concept of race can be understood such to allow for a clear distinction in the mind. Understood as intraspecific natural divisions, races are divisions of organisms that are sufficiently linebred such that each member is more genetically similar to other members of the same division than to members of other ones but not so linebred that members of different divisions can not readily produce viable offspring.

\footnotetext{
${ }^{41}$ For example, Doron (2012) notes: “[As Buffon saw it] climate and life conditions act over time. They are transmitted through generations and inscribed in the body through genealogy. For instance, «the germ of blackness is transmitted to children by their fathers and mothers so that in any country where a Negro may be born, he will be as black as if he were born in his own country.» (p. 523) Over time, relatively "constant races" are created this way. It means that, according to Buffon, history, kinships and transmission of characters over generations creates relatively constant varieties transmitted over time."
} 
mtDNA lineages or all descendants of Genghis Khan, even though doing so would be consistent with the historic extra-scientific usage of the term, as expressed by the phrase "the race of Caesar." This said, we grant that some researchers might conceptualize biological race such to include, at least on the periphery, lineages with intermediate degrees of entwinement, something akin to folk stocks. It makes logical sense to us to understand races to be divisions which are linebred enough such that members are more overall genetically similar to other members of the same division than to members of other divisions (of the same classification scheme) but not so linebred that members can not readily produce viable hybrids with members of other divisions and, further, to classify other lineage based divisions either as folk or regional stocks when less linebred or as species or above when more linebred. Nonetheless, we grant that it might make biological sense, given the messy nature of biological reality, to use the term in a less defined manner. ${ }^{42}$ Regardless, we are confident that few would consider extended families which are so little linebred that many members could not be, based on propinquity of descent, assigned exclusively to this or that division to make for good biological races.

Above, race was said to imply a lineage based concept, specifically one that cuts out genealogybased divisions. Races then represent, in a sense, distinct lineages. Since, at least on the intraspecific level, divisions where individuals are arranged by genealogy correspond with ones where they are arranged, via cluster analysis, by genomic similarity, these latter also represent, in the same sense, distinct lineages. This genomic-genealogical correspondence allows for a general concept of race.

We say distinct lineages "in a sense," since that phrase is at times imprecisely used. For some it means "distinct lineage branches" which implies genealogical discontinuities. Understood this way, 'distinct lineages' are inconsistent with both genealogical and genomic continua. We do not see a logical problem with genealogical continua, though. One can imagine a case of perfect isolation by distance which occurred over numerous generations. This would result in a genealogical network which could be represented as a cross-temporal stack of genomic continua. Just as how out of a genomic (or population) continuum one can cut out natural divisions, out of a genealogical one, one can cut out distinct lineages in the sense of ones which do not overlap. Distinct lineages, then, do not require lineage branching. Nor do they require an absence of admixture, at least when by lineage we mean overall descent or full pedigree. When taking into account full pedigree, individuals of one lineage can be more genealogically similar overall to other individuals of the same despite sharing lines of descent with members of other lineages.

This discussion recalls an imaginative passage by Darwin, found in The Various Contrivances by which Orchids are Fertilized by Insects, regarding an evolutionary continuum brought about by the resurrection of forms long past:

To make a perfect gradation, all the extinct forms which have ever existed, along many lines of descent converging to the common progenitor of the order, would have to be called into life. It is due to their absence, and to the consequent wide gaps in the series, that we are enabled to divide the existing species into definable groups. If there had been no extinction, there would still have been

\footnotetext{
${ }^{42}$ For example, Harvey (2011) states: "Therefore, and for the sake of simplicity I have chosen to lump together several different levels of division as races. I will use the term to mean any division larger than the clan where there is a reasonable possibility that average group characteristics may have developed."
} 
great lines, or branches, of special development ... but ancient and intermediate forms, very different probably from their present descendants, would have rendered it utterly impossible to separate by distinct characters... one great body from [an]other. [Emphasis added.]

Likewise, in Origin of Species, Darwin notes:

Extinction has only separated groups; it has by no means created them; for if every form which has ever lived on this earth were suddenly to reappear, though it would be quite impossible to give definitions by which each group could be distinguished from other groups, as all would blend together by steps as fine as those between the finest existing varieties, nevertheless a natural classification, or at least a natural arrangement, would be possible. [Emphasis added.]

Phylogenetic disjunctions enable, or give one the authority, to divide by distinct character biodiversity into definable evolutionary groups. But in absence, the lineages still exist, just submerged in a continuum, like a statue yet chiseled out of a block of stone. Opponents of the artistic project of cutting these out would note that delineations are necessarily arbitrary - not authorized by a pattern of extinction. Yet, despite only cut in the mind, they still represent concrete reality, natural divisions even if artistically divided.

Now, this all said, we are in position to explicate the correspondence of biological race concepts. Grant, on the intraspecific level, that genomic divisions correspond with genealogy ones: our (Darwinian) natural divisions correspond with genomic ones. Grant that Mayr's evolutionary taxonomy is based on similarity in genotype ("genetic program"): our evolutionary taxonomy races correspond with Darwinian natural divisions ${ }^{43}$ Grant that cladistic races cut out a type of Darwinian natural division: our cladistic races represent a type of genealogical races and cut out the same type of thing that evolutionary taxonomy races do. Grant that Mayr was more or less correct that all ecological races are at least microgeographical races: our ecological races cut out a type of the same thing. Grant that population genetic races are generally delineated in terms of overall genetic similarity: these, then, are genomic races. Grant that biological anthropology concerns itself, when dealing with biological race, with ancestry based divisions in which, owing to common descent, members share an ensemble of characters which differentiate them from members of other divisions: we are dealing with something very similar to Buffonian and Blumenbachian races. Grant that, when we have such divisions, members of a given division are more genealogically similar to each other than to members of other divisions: our biological anthropological and 'old school' races more or less correspond with Darwinian natural divisions. Grant that Darwinian natural divisions represent distinct lineages whether or not they are lineage branches: evolutionary-lineage races correspond with the others mentioned.

\section{II-D. What the Core Biological Race Concept Does Not represent}

1. Biological races are natural divisions, not artificial ones. As such, they are not "forms" or "morphs." Štrkalj (2006), discussing the distinction between natural and artificial classifications, notes:

\footnotetext{
${ }^{43}$ As noted in section I, for Mayr and Bock (2002), it is based on overall similarity in homologous characters (morphological, molecular, and otherwise); this, though, corresponds with (identity-by-descent) genotype.
} 
[An artificial classification] is defined by Mayr and Ashlock (1991: 409) as "classification based on convenient and conspicuous diagnostic characters without attention to characters indicating relationship; often a classification based on a single arbitrarily chosen character instead of an evaluation of the totality of characters". As defined in The Cambridge Dictionary of Human Biology and Evolution, artificial classification is "any classification system in which the members of a group resemble each other in the defining characters only, and show no similarity in non-defining characters".

Artificial classification schemas include, for example, all lactose intolerant people and all members of a certain mitochondrial lineage.

These classifications are artificial in that the classes are not delineated by overall genetic relatedness. Frequently, with these classifications, the defining characteristics are unrelated to other phenotypic and genetic characters. It is worth noting that Štrkalj (2006), a crusader against biological race, goes on to mischaracterize Dobzhansky, claiming that his races represented artificial classifications and, therefore, that they should be called "forms," not "races." Yet Dobzhansky was quite clear that his races were not morphs or forms. Thus Dobzhansky (1944) noted:

It would be fallacious to define a race as a group of individuals having a given gene allele or a given chromosomal structure in common. Since in most species there are many variable genes and chromosome structures, and since different genes and chromosome structures are capable of forming a variety of combinations, an individual or a population might belong to one 'race' as far as the gene A is concerned, to a different 'race' with respect to the gene B, to a still different 'race' with respect to C, etc.

And Dobzhansky and Dobzhansky (1970) clarified:

A race is a Mendelian population, not a single genotype... Blue-eyed individuals are not a race distinct from brown eyed individuals, yet eye color is one of the traits that distinguishing races.

2. Biological races are also not clusters of genetic characters. Rather, they are divisions of organisms whose alleles cluster as a result of common ancestry. Biological races are groups of organisms; the genes of the members of these groups cluster together; as such, genetic clusters index biological races but are not themselves races.

That distinction made, it should be noted that the term "genetic cluster" is often used as a euphemism for "biological race." As Kitcher (2007) notes (emphasis added):

\footnotetext{
Although contemporary research may speak of "clusters" rather than "races," it is relatively easy to foresee that the old, loaded word will often substitute for the aseptic scientific terminology...

... When such occasions arise, the obvious tactic is to try to find ways of insulating the research so that potentially damaging consequences do not occur. Precisely this sensible tactic is prefigured in the use of the term 'clusters' by the researchers on human migrations. Unfortunately, the pressure on science journalism, even in the most apparently respectable media, to sensationalize recent findings, led quickly to the demolition of the barrier that the investigators had hoped to erect.
}

We, however, recognize the distinction between a cluster of genetic characters, per se, and a biological group (see below). This is important since clusters as indexes of natural divisions can 
be discordant when markers are unreliable with respect to true ancestry. Natural divisions can not be.

3. Biological race is not synonymous with "biological population." In biology, a "population" is frequently loosely defined as, for example, "all the members of a species that occupy a particular area at the same time" (Wells, Richmond, and Milo, 1995) or "a group of conspecific individuals inhabiting a given area" (Camus and De Ciencias, 2002). Waples and Gaggiotti (2006) provide a representative sample of definitions, shown below in Table 2.2.

It is readily obvious that many of these groupings do not necessarily describe classes where individuals are arranged by overall genetic similarity. And it is readily obvious that members of the same race do not need to "occupy a particular area at the same time." As discussed above, one of the purposes of the race concept was to explain why transplanted organisms, ones moved to a different location, retained and transmitted across generations their region of origin characters.

\section{Table 2.2. Population definitions given by Waples and Gaggiotti (2006)}

\section{Ecological Paradigm}

A group of organisms of the same species occupying a particular space at a particular time.

A group of individuals of the same species that live together in an area of sufficient size that all requirements for reproduction, survival and migration can be met.

A group of organisms occupying a specific geographical area or biome.

A set of individuals that live in the same habitat patch and therefore interact with each other.

A group of individuals sufficiently isolated that immigration does not substantially affect the population dynamics or extinction risk over a 100 -year time frame.

\section{Evolutionary Paradigm}

A community of individuals of a sexually reproducing species within which matings take place.

A major part of the environment in which selection takes place.

A group of conspecific organisms that occupy a more or less well-defined geographical region and exhibit reproductive continuity from generation to generation.

A group of individuals of the same species living close enough together than any member of the group can potentially mate with any other member.

\section{Statistical Paradigm}

An aggregate about which we want to draw inference by sampling. 
The totality of individual observations about which inferences are to be made, existing within a specified sampling area limited in space and time.

While races are biological populations in some sense clearly not all populations are races, nor are all races spatially defined populations. ${ }^{44}$ There is, of course, an obvious probabilistic causal relationship between being a spatial population, a deme, and a race. ${ }^{45}$

4. Biological races are not demes. The term "deme" was originally coined by Gilmour and Gregor (1939) to refer to "nothing beyond, simply, a group of individuals of a specified taxon" (Gilmour and Heslop-Harrison, 1954). It was supposed to be a neutral term. To describe a "breeding population," Gilmour and Gregor (1939) coined the term "gamodeme," which was defined as a "more or less isolated local intrabreeding community." Zoologists, to both Gilmour's displeasure and frustration, adopted the term "deme" and employed it to mean, basically, what Gilmour and Gregor (1939) intended by "gamodeme" (Winsor, 2000).

Generally, demes (or gamodemes) are defined in terms of the probability of sharing descendants, while races are defined in terms of shared ancestry. While the two concepts are related, as demes which are isolated to a sufficient degree for a long enough time become races (a point recognized by early race theorists), the concepts are distinct. Thus, one can not change one's race by changing one's deme (that is, by joining another breeding community). Conversely, by forming a more or less isolated breeding community one can not immediately form a race; and by dissolving the barriers to exogamy that define a deme, one can not make members of a once deme-race, not members of a race. This is a nontrivial conceptual distinction and it is one which stands at the core of the original race concept, one which attempted to explain why transplanted organisms kept their region (and often deme) of origin characteristics and yet were capable of interbreeding with organisms in the destination region (and often deme).

Since races are not demes, they also are not "genetic populations" in this sense. Regarding this point, in population genetics, the term "genetic population" is often ambiguously used to refer to both breeding populations and to divisions delineated by common ancestry. Aulchenko (2010), discussing these two conceptions, notes:

Therefore a definition of a genetic population should be based on the chance that different alleles, present in the individuals in question, can mix together; if such chance is zero, we may consider such groups as different populations, each described by its own genotype and allelic frequencies and their dynamics. Based on this consideration, a genetic population may be defined in the following way:

\footnotetext{
${ }^{44}$ Ernst Mayr characterized races as spatiotemporally located populations. While we agree that races are typically these in the wild, we do not consider spatiotemporality to be a requirement. For one, a spatial requirement does not make sense of the historic concern related to migration. For another, this is not logically necessary given a genetic understanding. To put this point in context, we would consider a Black African living in Guangzhou to be a member of a race other than the Guangzhou Han majority. This said, "biological population" can mean a "collections of individuals that share some biological attributes" (Waples and Gaggiotti, 2006). Races would necessarily be "biological populations" in this sense.

45"Population" is, of course, also used as an euphemism for race. Thus Duedahl notes: "Dobzhansky on the other hand argued that it would make sense to categorize humanity according to the frequency of different genes but preferred to replace the politically loaded race concept with the concept of "populations"."
} 
Two individuals, I1 and I2, belong to the same population if (a) the probability that they would have an offspring in common is greater than zero and (b) this probability is much higher than the probability of I1 and I2 having an offspring in common with some individual I3, which is said to belong to another genetic population.

Here, to have an offspring in common does not imply a direct offspring, but rather a common descendent in a number of generations.

However, in gene discovery in general and GWA studies in particular we are usually not interested in future dynamics of allele and genotype distributions. What is a matter of concern in genetic association studies is potential common ancestry - that is, that individuals may share common ancestors and thus share in common alleles, which are exact copies of the same ancestral allele. Such alleles are called "identical-by-descent," or IBD for short.

Thus for purposes of gene discovery we can define genetic population using retrospective terms based on the concept of IBD:

Two individuals, I1 and I2, belong to the same genetic population if (a) their genetic relationship, measured with the coefficient of kinship, is greater than zero and (b) their kinship is much higher than kinship between them and some individual I3, which is said to belong to another genetic population.

In short, the term "genetic population" can mean both deme and race. Races then are not necessarily "genetic populations."

5. Biological races are linebred groups (essentially, wild breeds); they are not individual organisms or sibships. An individual could be the last member of a race delineated at a prior time; but, when initially delineated, since races are divisions in which members, owing to endogamy, are more related to other members of the same division than to members of other ones, each division would have to originally be comprised of more than one organism.

\section{II-E. Races, Clines, Clusters?}

When discussing biological race, often the term "cline" is coughed up as a sort of retort. The American Anthropological Association even has a module called "Races or clines?" (Italics added). The term "cline" was introduced by Julian Huxley (1939). Huxley introduced it in order to correct for what he saw as deficiencies arising from the practice of focusing solely on subspecific group differences. He noted:

Some special term seems desirable to direct attention to variation within groups, and I propose the word cline, meaning a graduation in measurable characters. This, being technical, seems preferable to such terms as characteristic-gradient or phrases such as 'geographical progression of characters', used by W. F. Reining in his recent book "Elimination und Selektion" ...

Clines may be of inter- or intra-group nature. Intergroup clines connect the mean values of the subspecies of a polytypic species (or of the species of a geographical subgenus or Artenkreis) ... Intragroup clines concern continuous variation within a population ...

It is in no way intended that specification by clines should replace any of the current taxonomic methods. It would constitute a supplementary method which, it is suggested, would correct certain defects inherent in that of naming areal groups notably in stressing continuity and regularity of 
variation as against mere distinctiveness of groups. It is important to note that clines for different characters may run in different directions (shrikes, fox-sparrows, lincoln sparrows, etc.).

Huxley did not see clines and races as antithetical, hence he allowed for intersubspecies clines. More to the point, his cline concept describes a character gradient. As such, a "cline is an arrangement of characters, not of organisms or of populations" (Simpson, 1961). As a result, a race can belong to as many different clines as it has characters; if it belongs to more than one, it is no less a race.

As we noted above, with races, individuals are grouped based on their overall genetic similarity. This similarity is evidenced by similarity in concordant specific characters. That is, relatedness in clusters of specific characters, phenotypic and genetic (e.g., specific genetic loci) are used to infer overall relatedness. Clines do not even describe divisions of organisms; they describe characters. The juxtaposition of clines (characters) with races (divisions of organisms), then, represents a categorical confusion. Properly understood, there is no "cline versus race" debate.

But there is a substantive issue that we have not touched upon immediately above. When the "clines, not races" argument is not altogether conceptually confused - when it is only semantically so - it raises an issue that we must address. Sometimes natural divisions are such that they form a smooth genetic population continuum, across which character clines would tend to run in the same way. (This is not the case, though, for human continental divisions (Weiss and Fullerton, 2005; Rosenberg et al., 2005).) In zoology, these are simply known as population continua and are distinguished from population isolates. If we take "cline" to mean population continuum, then we might rephrase the American Anthropological Association's question as: "Races or population continuums?" But this begs the question: "Races: not population continuums?" As defined above, and as consistent with zoological practice, races can exist in and be cut out of a population continuum. The existence of a population continuum is not even inconsistent with the formal zoological recognition of biological races (Mayr and Ashlock, 1991). As Albrecht, Gelvin, and Miller (2003) note:

Population structure refers to the geographic arrangement of local populations across the species' range. Population structure can be described in terms of three phenomena: the population continuum, geographic isolates, and zones of secondary intergradation (hybrid zones) (e.g., Mayr and Ashlock, 1991). The population continuum is that part of the species' range where there is continuity of contact among local populations, some of which may be recognized as subspecies if sufficiently differentiated. [Emphasis added.]

This is not to say that population structure has no relevance to discussions of biological race. If the genetic structure of a species formed a perfect population continuum, it would be impossible to empirically delineate natural divisions in an objective way. In relation to natural divisions in general, this point was noted by Simpson (1961):

The point will be discussed later, but even here it is advisable just to mention that such arbitrary subdivision does not necessarily produce taxa that are either 'unreal' or 'unnatural,' as has sometimes been stated. A simple but, at this point, sufficient explanatory analogy is provided by a piece of string that shades continuously from, say, blue at one end to green at the other. Cutting the string into two is an arbitrary act, but the resulting pieces are perfectly real section of the string that existed as natural parts of the whole before they were severed. 
Simpson (1961) was correct that dividing a perfect continuum would result in empirically arbitrary delineations. But rarely are we faced with perfect continua. As a result, non-arbitrary or objective delineations of groups can be had (e.g., using unsupervised cluster mapping programs). So long as the underlying natural divisions exhibit "small discontinuous jumps in genetic distance" between them (Rosenberg et al., 2005), clusters can be identified objectively at a given grain of focus. These clusters can then be used to infer objectively delineated races.

"Grain of focus," "grain of analysis," or "level of genetic analysis" refer to the fact that one can look at different degrees of genetic relatedness when dealing with natural divisions. The analogy is to a microscope where one can zoom in and out for, respectively, finer and coarser grains of focus. A coarser grain would mean looking at larger degrees of genetic differentiation. When racial divisions are cut out at a coarser grain, there would be fewer of them - they would represent the major racial divisions of a species. At a finer grain, more divisions can be cut out one would, effectively, subdivide or split those divisions identified at a coarser grain. The "grain of focus" issue is also known as the lumper and splitter issue, which refers to the fact that one can aggregate and divide natural populations into, respectively, larger and smaller groupings. This issue exists on all levels when it comes to natural divisions. In taxonomic hierarchy, for example, family represents a coarser grain of focus than genus, genus than species, and species than subspecies. It is impossible to objectively define a "true" grain of focus - class, for example, is not a more true level of genetic analysis than species - but given a grain of focus, one can objectively delineate races, so long as there are small genomic discontinuities between them.

As this is an issue which many get confused, we will clarify it thusly: The structure of a population is either continuous (continua), discontinuous (isolates), or once discontinuous but since reconnected (zones of intergradation); when there are continua there will be innumerous character clines running the same way like a bundle of wires. Races are determined by the past population structure of a species. Races that are deemed to be sufficiently interesting are recognized formally as taxa subspecies. Neither continua nor zones of intergradation past or present are inconsistent with the presence of subspecies, let alone lesser races. Continua, as discussed in section IV, nonetheless argue against the formal recognition of races. Since continua are not inconsistent with races and since along continua many clines will run concordantly, clines, per se, are not either; though, clines, insofar as they evidence continua, argue against the formal recognition of races. Cluster is an ambiguous term; it can mean "bundles of correlated characters" or "the statistical output from a cluster analysis program." Clusters as bundles of correlated characters evidence natural contra artificial divisions, since natural divisions are based on overall genetic similarity, which entails concordant characters. When there is a continua, clines "cluster" in the sense that they tend to run in the same direction and thus form "bundles of correlated characters" viewed cross-sectionally. Clusters, as bundles of characteristics, then are not necessarily inconsistent with clines. Unsupervised cluster analysis programs can identify natural divisions when there are small genetic discontinuities; that is, they can identify isolates. These identified divisions have been called "clusters"; thus "cluster" has come to mean also "isolates," that is, discontinuous natural divisions. While isolates, insofar as they are natural divisions, are races, race is a broader concept, one which includes natural divisions cut out of a continuum. 


\section{II-F. Clarification on the Meaning of "Arbitrary" and "Objective" in Context to Natural Divisions}

In pre-Darwinian times, it was commonly held that species had Creator-given formal natures. These natures - which were, basically, structural designs - were such or at least the generational reproduction of them was such to preclude the transmutation or evolution of species. This meant that species were unchanging and "permanent" (so long as they reproduced). As Charles Lyell put it in 1830, "species have a real existence in nature, and that each was endowed, at the time of its creation, with the attributes and organization by which it is now distinguished." This view was called "species realism" and it was juxtaposed with the idea that species were, from a crosstemporal perspective, "arbitrary" divisions, ones which, to quote Lyell, "are capable, as some naturalists pretend, of being indefinitely modified in the course of a long series of generations." Since, from our contemporary perspective, species realism - and taxonomic realism in general is false, one could say - and it sometimes is said - that all natural divisions are arbitrary. They are just points along an evolutionary continuum. This being the case, though, does not entail that natural divisions are empirically arbitrary in the sense of made willy-nilly. If some criteria are specified, if the criteria are empirical, and if we consistently group according to these, groupings are by definition empirically non-arbitrary.

When it comes to groupings, there are two major issues: how individuals are arranged into divisions and how the border-lines between divisions are drawn. In the case of natural divisions, arrangement is based on propinquity of descent. Since by definition members are so arranged, natural divisions are necessarily non-arbitrary in arrangement. Darwin made this point, noting: "From the first dawn of life, all organic beings are found to resemble each other in descending degrees, so that they can be classed in groups under groups. This classification is evidently not arbitrary like the grouping of the stars in constellations" (Darwin, 1859). When the arrangement is based on objective measures of ancestry, the arrangement can also be said to be objective.

As for border-line drawing or delineation, again, this is empirically non-arbitrary if groups are divided consistently according to some criteria. In regards to natural divisions, the delineations can, for example, be said to be biologically non-arbitrary and objective if they are made on the basis of biological or genetic data alone (e.g., using multilocus genetic clustering or unsupervised genetic clustering). If the delineations are made partially on the basis of biological or genetic data, they can be said to be biologically objective along some dimension.

Now, as discussed earlier, there is no necessary contradiction between non-objective delineations and the existence of races. Regarding humans, one could, for example, out of genomic space cut an indigenous West West-Eurasian race and compare it to an indigenous East West-Eurasian one. Even if these divisions were objectively unidentifiable on the basis of genetic data, even if they were culturally delineated, they would constitute different natural biological divisions so long as the members of each population were arranged by overall genetic affinity.

\section{II-G. Regarding Different Definitions of Biological Race: What Races Need Not Be}

We have noted that there are a number of different concepts of "biological race" and that most share a common conceptual core, which we call the general biological race concept. Specific 
race definitions differ in how they qualify this more general concept. In the most inclusive sense, all intraspecific natural divisions can be called races. Championing a view similar to this, Dobzhansky (1946) noted:

\begin{abstract}
One may perhaps question the desirability of applying the term 'racial differences' to distinctions as small as those that can be found between populations of neighboring villages and as large as those between populations of different continents. Might one modify the definition of race by specifying that the differences in gene frequencies be above a certain minimum magnitude? Such a modification is undesirable for two reasons. First, since all magnitudes of difference are found among populations, any specified minimum can be only arbitrary. Second, it is most important to realize that the differences between the 'major' human races are fundamentally of the same nature as the relatively minute differences between the inhabitants of adjacent towns or villages.
\end{abstract}

Others (seemingly) accept the core concept but qualify it differently, creating more exclusive groupings. For example, Mayr's biological race concept describes geographically circumscribed races, e.g., microgeographic and geographic races. Vogel and Motulsky's (1986) concept describes broad intraspecific divisions, presumably excluding microgeographic races. Sarich and Miele's (2004) and Pearson's (2002) definition describes divisions which differ "significantly" in genetically conditioned phenotypic traits.

These concepts of biological race overlap, and, in principle, do not (seem to) conflict in terms of the core concept as we understand it; they simply qualify this concept in different ways, for example: Hulse (1963) - being "readily distinguished"; Vogel and Motulsky (1986) - "a large population" with "a significant fraction" of genes in common; Leroi (2005) - having "collectively rare" variants; Pearson (2002) - "a large extended family" sharing "distinctive identifying biological characteristics"; Sarich and Miele (2004) - being "reasonably discrete." As Dobzhansky noted, such qualifications are arbitrary in the sense that they do not modify the underlying biological reality being described; they simply tax it with unnecessary criteria.

We take the above as obvious. But as it is commonly argued that "Race really means ..." and subsequently concluded that "Because there are no such divisions, races do not exist," we offer the following clarifications:

1. Races need not be taxa (groups formally assigned to a specific taxonomic category). Why was explained in section I: races were never originally such; race never fully corresponded with a taxonomic category; race has a history of nontaxonomic category use.

2. Races need not be few in number or represent the major divisions of a species. Why is explained in section IV and elsewhere. While "major," "base," and "continental" races were recognized, so were subdivisions of these - so called "micro," "derivative," and "local" races. Buffon, for example, managed to have a European race embedded within a White race and to have groups as small as the Tartar race.

3. Races need not exhibit significant discontinuities. It was always the case that some allowed races, in the intraspecific sense, to flow "seamlessly" into one another. In fact, many such as Prichard and Darwin regularly cited the apparent lack of 
discontinuity in the case of man as evidence that human races were not species. That is, continuity was often seen as - and still at times is (for example: Groves, 2013) - a diagnosing character of intraspecific race; continuity distinguished (intraspecific) race from species.

4. Races need not largely differ. Originally they were thought of as relatively minor deviations from the species type, like Ehrhart's (1784) subspecies which agreed "in essentials almost completely with each other, and are often so similar to each other that an inexperienced person has trouble in separating them". Eventually, taxa subspecies did come to refer to divisions which differed from one another significantly enough to warrant formal recognition. The same does not hold for race, which has a more general meaning.

5. Races need not be unadmixed. Even those who once argued that the races of man were species acknowledge pervasive intermixing; they merely argued that this was not inconsistent with groups being species (which were, at that time, defined in terms of a lack of common ancestral origin).

Now, in the above, one might see deep conceptual inconsistency - "some saying this, some that." We see sub-conceptual variability unified under a broad concept.

\section{II-H. Genomic-Genealogical Complications}

As discussed above, we do not see much practical distinction between genealogical conceptions of race and genomic ones. However we recognize a conceptual and a technical one.

In biology, individual organisms are arranged into natural divisions according to pedigree, since, on the level of the individual, genealogical similarity explains genomic - and with it concordant phenotypic - similarity. When it comes to populations (which is what taxonomy concerns itself with), factors other than descent come into play in explaining similarity. While not cladists, evolutionary taxonomists take these into consideration when organizing taxa. Evolutionary taxonomists more or less follow Darwin's prescription, expressed in Descent of Man:

This system, it is now generally admitted, must be, as far as possible, genealogical in arrangement that is, the co-descendants of the same form must be kept together in one group, separate from the co-descendants of any other form; but if the parent-forms are related, so will be their descendants, and the two groups together will form a larger group. The amount of difference between the several groups - that is the amount of modification which each has undergone - will be expressed by such terms as genera, families, orders, and classes. [Emphasis added.]

Accordingly, the hierarchical ranking of groups is to be based on descent plus modification. Organisms are arranged into taxa genealogically; taxa are given a rank based on both descent and differences owing to the degree of evolutionary change that the taxa experienced. Because groups are so classified, they can be, as discussed in section I, paraphyletic. 
Now regarding the level of the individual organism, it is generally assumed that pairs of individuals from the same division, defined in terms of pedigree, will be more overall genomically similar to each other than will be pairs of individuals from different divisions.

However, this basic evolutionary intuition has been challenged. For example, Barbujani, Ghirotto, and Tassi (2013) argued that the genomic similarity between two individuals from the same pedigree defined population can frequently be less than that between two individuals from two different pedigree defined divisions. They state:

Today, developments in DNA sequencing technology allow us to compare completely sequenced genomes. Ahn et al. (54) observed that two US scientists of European origin, namely James Watson (11) and Craig Venter (2), share fewer SNPs $(461,000)$ than either of them shares with a Korean scientist, Seong-Jin Kim (569,000 and 481,000, respectively) (Figure 2). Of course, this does not mean that, on average, people of European origin are genetically closer to Asians than to other Europeans. However, it does show that patterns of genetic resemblance are far more complicated than any scheme of racial classification can account for. On the basis of the subjects' physical aspect, a physician would consider Venter's DNA, and not Kim's, a better approximation to Watson's DNA. Despite ideological statements to the contrary $(55,56)$ racial labels are positively misleading in medicine, and wherever one is to infer individual genome characteristics.

Likewise, Keita et al. (2004) have argued:

Arguments against the existence of human races (the taxa "Mongoloid", "Caucasoid" and "Negroid" and those from other classifications) include those stated for subspecies and several others. The within- to between-group variation is very high for genetic polymorphisms (85\%; refs. 16, 17). This means that individuals from one "race" may be overall more similar to individuals in one of the other "races" than to other individuals in the same "race".

In line with the above arguments, Witherspoon et al. (2007) found that for closely related and admixed populations - but not for distant ones separated by geographic barriers (e.g., Europeans, East Asians, Sub-Saharan Africans) - pairs of individuals from the same pedigree defined populations were not always more similar to each other with respect to 10,000 genetic loci than were pairs of individuals from different populations. This suggests that, on the individual level, genealogical and genomic similarity need not always correspond. However the results are not clear cut. Tal (2012), discussing the example of James Watson, Craig Venter, and Seong-Jin Kim, noted:

Our model also facilitates the assessment of results from analysis of complete genome sequences. The study of Ahn et al. (2009) suggests that the pairwise distances among three individuals, a Korean ("SJK"), Craig Venter and James Watson, measured by multilocus ASD, are roughly similar despite the distinct geographical origin of SJK in relation to Venter and Watson (see also their Fig. 2 E). These results are surprising in light of our model for $\mathrm{n}$, which predicts that for worldwide distant populations (FST > 0.13) the probability for such an occurrence is virtually zero given as little as 200 independent and informative SNPs (Appendix F, Fig. F.1). In fact, with roughly 3.5 million SNPs sequenced in each individual genome, the pairwise distances Venter-Watson and Venter-SJK (or Watson-SJK) must show substantial discrepancy, since the ratio of average pairwise distances RAD is above 1.3 already at FST $=0.10$ (see Fig. 5A). The paradoxical result is most likely an artifact of the high error rate and low coverage in Watson's SNP calling (Yngvadottir et al., 2009). 
In short, it seems quite unlikely that Venter actually shares more genetic information with Kim than with Watson. Tal (2012) found the following, based on a hypothetical infinite number of slightly informative loci:

The probability that a random pair of individuals from the same population is more genetically dissimilar than a random pair from distinct populations is primarily dependent on the number of informative polymorphic loci across genomes from the total population pool. This probability asymptotically approaches zero with a sufficiently large number of informative loci, even in the case of close or admixed population.

The reason for the disagreement between the results of Tal (2012) and Witherspoon et al. (2007) concerning close and admixed populations is not clear. Tal's (2012) results fit with those of Gao and Martin (2009) who found almost complete differentiation between populations when using a large number of loci. Whatever the case, we have to take into account possible instances of such discordance. When/if this occurs what does one do? There are two possibilities:

Pedigree + genomic races: individuals are members of one of a set of races if and only if they are, due to individual pedigree, more genomically related to members of that race than to members of different races. As such, if Watson is, in fact, more genomically similar to Mongoloids than to Caucasoids, we would not classify him as Caucasoid despite his presumed pedigree, and we would not classify him as Mongoloid due to his presumed pedigree. He would be unclassifiable in principle.

Genomic or Pedigree races: individuals are members of one of a set of races if and only if they are more genomically/(genealogically) related to members of that race than to members of different races. As such, if Watson is, in fact, more genomically/(genealogically) similar to Mongoloids/(Caucasoids) than to Caucasoids/(Mongoloids), we would classify him as a Mongoloid/(Caucasoid), despite his supposed pedigree/(genome).

Since we are advancing a general race concept, we will not decide which is the better method of defining "overall" genetic similarity in the case of genomic and genealogical discordance. We would suggest going with genomic similarity, though. If two horses begat, in the natural way, a genomic and phenotypic human, most people would probably classify the genealogical horsegenomic human as a human. That is, we imagine that most people would classify by genomicphenotypic similarity, and not pedigree, in cases of discordance. So, when it comes to racial groups, doing the same would seem to be reasonable. Whatever the case, we leave the issue undetermined. These are just different formulations of a basic conception. In practice, this is not a pressing matter since, on the individual level, the correspondence between the two forms of genetic relatedness is extremely high when dealing with non-trivially-differentiated populations.

\section{II-I. Estimated Genomic Similarity: Some Ambiguity}

Two issues, one practical and one theoretical, arise when it comes to estimating genomic similarity. First, practically speaking, how is genomic similarity indexed? Witherspoon et al. (2007) outline several methods, e.g., dissimilarity fraction, pairwise genetic distance, and centroid classification rate. We will assume that, using the same information, there will be a very high concordance between methods and so we need not endorse any particular one. 
Second, how is similarity conceptualized? Both theoretical and empirical results indicate that individuals can be classified into divisions with a higher rate of accuracy than the probability of pairwise similarity would suggest. This situation has been illustrated by Witherspoon et al. (2007), Strauss and Hubbe (2010), and Tal (2012). Tal (2012) noted:

\begin{abstract}
Witherspoon et al. rightfully suggest that classification methods typically make use of aggregate properties of populations, while $\mathrm{w}$ [dissimilarity fraction] merely reflects properties of pairs of individuals. Expanding on this insight, we note that allele-sharing distances, whether used in individual pairwise comparisons or distances of individuals to population centroids, do not take into account the shape of the distributions (i.e., the variance-covariance matrices of the within-population genotype distributions). This explains why the slow decline of $\mathrm{n}$ is most prominent with closelyrelated populations and rare alleles: the low MAF [i.e., minor allele frequency] of rare polymorphisms induce low variances (with frequency $p$ the variance is $p(1-p)$ ), such that populations are 'flatter' in the dimension corresponding to these loci in the multidimensional space of multilocus genotypes. When populations are close, between-population pairs of individuals are then liable to be closer than many within-population pairs.
\end{abstract}

The discordance entails that one can understand genomic similarity to mean similarity to the population as a whole, an understanding which takes into account the average and/or aggregate properties of the population; or, one can understand similarity to mean pairwise genomic similarity to all other members of the population. With the former method, one can use the distance from the centroid or center-point of the genetic distribution to classify with or without taking into account the variance-covariance matrices. With the latter method, one only uses the distance from every member of the set of individuals to do so. The latter method has a more essentialist quality. Both allow for discrete categorizations and one could define the membership of a race either way. Thus, we have another pair of formulations: classification genomic races and pairwise genomic races.

Figure 2.1 attempts to illustrate a situation in which the two methods produce divergent results. Circles B and D represent classification genomic races. Membership in these races is defined with respect to, respectively, center-points 1 and 2 . Since the distance between individual Y and center-point 1 is less than the distance between center-point 1 and any point in classification race $\mathrm{D}$, individual $\mathrm{Y}$ would be grouped into race $\mathrm{B}$. Circles $\mathrm{A}$ and $\mathrm{C}$ represent pairwise genomic races. Membership in these races is defined such that all members of race $\mathrm{A}$ are closer in distance to all other members of the same race than to any member of Pairwise Genomic Race C. Y would not fall in pairwise race $\mathrm{A}$ since the distance between $\mathrm{Y}$ and some points in race $\mathrm{C}$ would be less than that between $\mathrm{Y}$ and some points in race A. Given this simplified treatment, one in which we are using only two dimensions, $\mathrm{Y}$ and $\mathrm{X}$ would fall in the same pairwise race yet a different classification race.

The point is that one can understand "genetic similarity" in a number of overlapping ways. Generally, we prefer pairwise genomic races, which follows Aulchenko's (2010) (retrospective genetic population) conception, as this gives us a more essentialist concept of race - in the sense that all members in a race share a commonality with each other instead of only with respect to the population as a whole. 
To put this preference into perspective, Michael Levin, a well-known racial hereditarian and defender of biological race, tells us:

Finally, it may be required that any two members of one race resemble each other genetically or phenotypically more than either resemble any member of any other race, as when it is objected that within-group variances greatly exceed group mean differences or constitute a large portion of total variance. These constraints create an easily dispatched straw man but are no part of the ordinary connotation of "race" or of any serious scientific or normative controversy. (Levin, 2002)

We do not believe that this formulation of race can be easily dispatched, but we agree that the pairwise similar understanding of racial membership is a relatively strict one - though, in practice it is often met as a result of the high multi-dimensionality of genomic space (Tal, 2012). To be clear, though, we are not saying that this is how race membership must be assigned; this is just the formulation that we prefer.

\section{Figure 2.1. Classification genomic races versus pairwise genomic races}

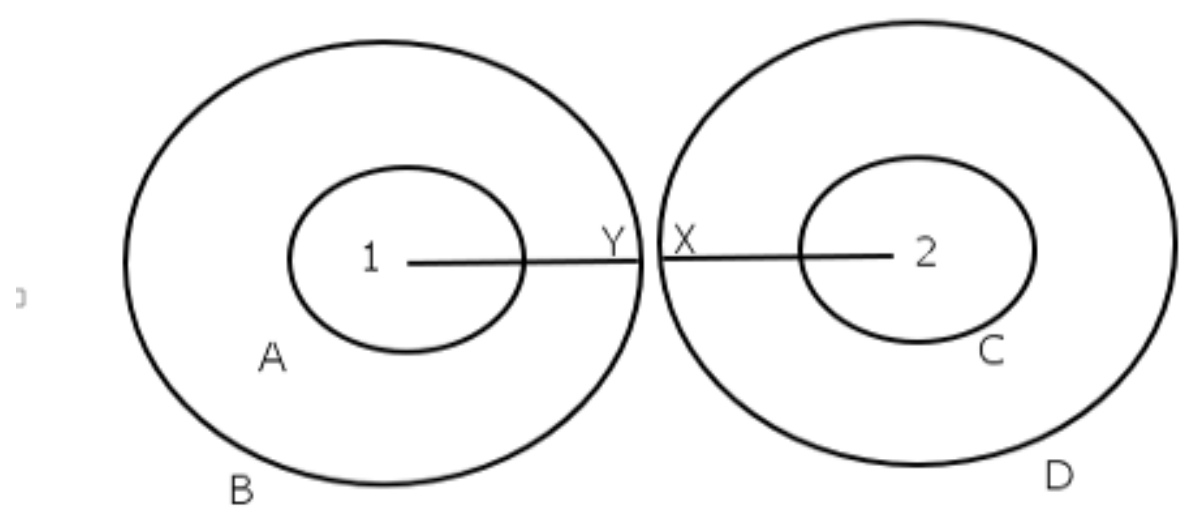

\section{II-J. Race: Mixed and Undifferentiated}

As implied in the above discussion, under unusual circumstances, some individuals may not in principle be assignable to a race due to a discordance between individual pedigree and genome. Others may not be assignable in practice simply on account of the degree of genomic relatedness involved. There are two broad ways in which this latter situation might occur.

First, when dealing with closely related or admixed races, some individuals may not be assignable to any one of a set of races, especially given our pairwise conception. The likelihood of such occurrences seems to be undetermined (see: Tal (2013) vs. Witherspoon et al. (2007)).

Second, members of close or admixed races might not be assignable to races at a coarser level of focus: for example, continental races (e.g., Caucasoids and Mongoloids) are comprised of numerous regional races, also known as "ethnic groups"; but some regional races fall in zones of intergradation (e.g., in central Asia) such that neither the regional races nor their members can be assigned to a continental-level race. 
We do not find it problematic when, due to admixture or a lack of differentiation, individuals can not be assigned to a race at some grain of focus. These individuals can be assigned to statistical populations labeled "undifferentiated race" or "mixed race." Nothing pertaining to our conceptualization precludes it, and in zoology, situations such as this are common.

At this point, it needs to be emphasized that the concept of "race" is relativistic. It parallels, in many respects, that of "population." In both cases, divisions are defined in relation to one another. It follow from this consideration that the divisions identified depend on the meta-population under consideration. From the perspective of natural history and zoology, the meta-population would be the global one (at a certain time) since of concern is the natural history of the species as a whole. This is how most people understand the concept. However, one need not look at the global population and thus one can speak of groups locally racially differentiated with respect to each other. The upshot is that "mixed races" on the global level can be "full races" on the local one. Mestizos and Mulattos in Mexico represent two "mixed" races from the perspective of the global meta-population. From the perspective of the Mexican meta-population, they likely represent two different "full" races.

\section{II-K. Essential and Cluster classes; Fuzzy and Discrete Sets}

Individuals can form either essential character or cluster classes. With essential character classes members must possess each and every qualifying characteristic e.g., red hair, freckles, and a pug nose. These classes are necessarily discrete sets; one is either a member or not. With cluster classes, no character is individually necessary for membership; rather, membership is determined by an individual's similarity to a class as judged based on a joint assessment of characters. Cluster classes can form either fuzzy or discrete sets. With fuzzy sets, an individual is assigned a degree of membership based on their relative similarity to a class. With (cluster class) discrete sets, membership is either yes or no, dependent on whether an individual meets a qualifying level of similarity. ${ }^{46}$

Biological races have at times been described as being fuzzy sets (e.g., Jensen in Miele (2002)). As we are characterizing them, they primarily represent cluster class discrete sets; individuals either are or are not a member of a given race. We allow, though, for a fuzzy set conceptualization layered on top of our primarily discrete set one. One can view our discrete set races as regions in multidimensional genetic space with boundaries drawn such that members of a race are more genomically similar to other members of the same division than to members of other divisions. Some individuals, owing to admixture or to a lack of differentiation, will fall in between races. These individuals can be given a relatedness value, indicating relative similarity with respect to the various discrete races. Additionally, individuals within each discrete set can be given a relatedness value with respect to other discrete divisions, indicating their relative similarity to other divisions. To illustrate, we can take the case of modern humans and Neanderthals, groups which we presume to have been different semi-species. Imaginably nearly all contemporaneous modern humans are more related to each other than to the Neanderthals of 20 kya. Thus, they could be dichotomously classified as modern humans contra Neanderthals. Nonetheless, some modern humans are more Neanderthalish. And imaginable there were, at

\footnotetext{
${ }^{46}$ Readers are referred to Stamos (2005) for a similar discussion.
} 
some time, mixed individuals who could not be assigned to one of our two groups and who could only be given a relatedness value.

Understood this way, we have two overlapping senses of biological race: the primary sense, in which biological races represent cluster class discrete sets and a secondary sense in which biological races represent cluster class discrete-plus-fuzzy sets. Having clarified this point, we can now address a common critique concerning racial admixture such as that made Jorde et al. (2004). The authors, highlighting an apparent incongruence between race and mixed ancestry, note:

[It] might be tempting to conclude that genetic data verify traditional concepts about races. But the individuals used in these analyses originated in three geographically discontinuous regions: Europe, sub-Saharan Africa and East Asia. When a sample of South Indians, who occupy an intermediate geographic position (see also Fig. 1) is added to the analysis (Fig. 3b), considerable overlap is seen among these individuals and both the East Asian and European samples, probably as a result of numerous migrations from various parts of Eurasia into India during the past 10,000 years. Thus, the South Indian individuals do not fall neatly into one of the categories usually conceived as a 'race'...... Ancestry, then, is a more subtle and complex description of an individual's genetic makeup than is race. This is in part a consequence of the continual mixing and migration of human populations throughout history.

The solution is simple: putting aside the fact that Jorde et al. used a relatively small number of markers when conducting their cluster analysis, that is, treating the results as if they were the results found when using the totality of genetic data, we would (taking a continental perspective) classify our South Asian Indians into an undefined discrete "major race." If we wanted to, we could characterize them as being either mixed or undifferentiated and so as representing part of either, respectively, a zone of secondary intergradation or a zone of primary intergradation. We could then describe their relatedness to each major discrete race - which is basically what Jorde et al. do when they discuss the relative amount of "continental ancestry" of the various groups.

This discrete-plus-fuzzy set conception allows us to integrate race as understood as a cluster class with some of the conceptually fuzzier understandings of race as a population, where what exactly qualifies an individual as a member of a given population is left unstipulated. We can then readily move back and forth between discussing races as discrete classes and race as populations with non-discrete borders.

As suggested above, we might further conceptualize biological races as representing overlapping ancestrally defined groups. For example, in the case of humans, the set of individuals descended from Charlemagne and that descended from Confucius could be said to represent two overlapping biological races, with membership assigned on a hypodescent basis. These divisions would overlap because while many individuals share only one or the other lineage many share both. Though membership would overlap, the divisions taken as wholes would differ. While such undoubtedly constitute meaningful biological divisions of a sort, they do not constitute, as we are characterizing them, natural divisions, since they are not being defined in terms of overall genetic similarity. Such divisions could be said to represent artificial biological races proper. 


\section{II-L. Sociological Clarifications}

\section{(a) Sociological, Biological, and Socially Constructed Races}

In sociology, race is sometimes defined as "a category of people who perceive themselves and are perceived by others as distinctive on the basis of certain biologically inherited traits" (Calhoun, Light, and Keller (2001), quoted in Morning (2014)). It is obvious that this sociological concept and the classifications based on it could, but need not, correspond with a biological one and the classifications based on that. Sociological races may or may not reasonably coincide with biological races. To the extent that they do not, the former can be said to represent non-biological scientific classifications.

Some equate "socially constructed" classifications (which we distinguish from "sociological classifications") with non-biological scientific ones. This equation is problematic, as it presupposes that biological classifications can not themselves be "social constructs" - in this case, that biological races necessarily are, in philosophical jargon, "natural kinds," the converse of "social constructs." But, as we have seen, "natural kinds" have been defined in a myriad of ways, and under many definitions biological groupings such as species, subspecies, and demes are not these.

If we grant the equation of "socially constructed" with "non-biological," by many understandings of what it is to be "socially constructed" numerous groupings which are generally understood as being biological (e.g., species) cease to be so: reductio ad absurdum.

\section{(b) Sociological Races versus Sociologically Significant Traits}

Regardless of whether and to what extent sociological races correspond with biological ones, any given difference between them might possibly be congenital. The same holds with regards to all sociological (and socially constructed) groups. For example, some of the differences between social classes, such as cognitive ability, have been shown to have a substantial congenital basis (Rowe, Vesterdal, and Rodgers, 1998; Trzaskowski et al., 2014; Marioni et al, 2014b). Generally, since outcome variance within sociological races and within the meta-populations containing them can often be attributed in part to genes, outcome variance between any two sociologically defined races can often reasonably be hypothesized as being genetically conditioned. The questions which one must ask are: Are there relevant phenotypic difference between these sociological races? To what extent are the differences genetically conditioned? How did these genetic differences arise?

With regards to these questions, the debate about "biological race" is largely orthogonal: sociological races might not correspond with biological races; if the two correspond, the members of the former might not be representative of the latter; biological race does not necessitate specific genetically conditioned differences; and a lack of correspondence between sociological and biological races does not preclude genetic differences between sociological ones.

In some instances, biological race might be relevant in that it might offer a conceptual framework for understanding why differences exist between sociological races. Yet there can still 
be differences between sociological races independent of differences between biological ones. A realistic scenario is as follows: in country $\mathrm{A}$, members of sociological race 1 express trait $\mathrm{P}$ to a lesser extent than do members of sociological race 2 simply on account of differential migrant selection; membership in sociological race 1 and sociological race 2 correspond perfectly to membership in biological race 1 and biological race 2, respectively; but biological race 1 and biological race 2 do not differ genetically in trait $\mathrm{P}$. This illustrates the indirect relation between biological race and congenital differences.

Referring to such a scenario, Nisbett et al. (2012), dedicated racial environmentalists, note the following in regards to East Asian performance in the US:

Matters in the United States have changed since the passage of immigration laws in the late 1960s that encouraged the immigration of highly skilled workers. That change resulted in a huge inflow of talented East and South Asians. These people bring on average very substantial educational and cultural capital and undoubtedly some genetic advantage over the general U.S. population.

A perusal of the "Database on Immigrants in OECD Countries (DIOC)" shows that the same logic must hold for other groups, ${ }^{47}$ some being more genetically selected, others being less so. These points are obvious and trivial - or at least they should be. But this obviousness has not prevented legions of academics and pundits from arguing against the existence of congenital differences between sociological races on the grounds that the said races do not perfectly correspond with biological races. For example, Alland (2004) reasons that:

[Levin (1997)] should instead say that the social group referred to as "black" or "African American" consistently scores lower on IQ tests than do members of the social group referred to as "white." On the other hand, if he does wish to test the proposition that IQ and race are correlated in a biologically causal way he needs to test a different null hypothesis. The proper null hypothesis would state that there is no biological causal relationship between IQ and membership in a biological population. This null hypothesis has never been disproved.

To be absolutely clear let me state this another way. Any null hypothesis must deal with real variables. Since I have already shown that biological race is a false category (or false variable), Levin's null hypothesis can neither be proved nor disproved.

The author fails to consider that one can have genetically caused differences between nonbiological scientific classes. Alland's argument is doubly strange because he would undoubtedly agree that there is a biological basis to the average differences in skin pigmentation between the "black," "white," and "Hispanic" groups. Anyone who recognizes differences in color must concede that a sociological understanding of race does not preclude genetic differences. This author, and many others, make what we might call the social construct fallacy, according to which the social construction of groups somehow implies that all group differences must be nongenetic in origin - as if groups could not be socially constructed around genetic differences! (Consider, again, the tall and the small.)

This point deserves more development. Showing or claiming that sociological races do not correspond with biological ones provides no leverage in arguing that there are no significant

${ }^{47}$ Accessible at: http://www.oecd.org/migration/mig/databaseonimmigrantsinoecdcountriesdioc.htm 
genetic differences between them. This is because there obviously are socially important genetic differences between many socially constructed groups, such as social classes. "Social construction," then, necessarily can not be inconsistent with "genetic differences." Groups obviously can be socially constructed around genetic differences. Knowing nothing else, one would treat socially constructed groups as arbitrarily constructed ones. The a priori probability that any differences between arbitrarily constructed groups is a function of the heritability of the trait in the population (see Tal (2009) for proof concerning individual differences). This is merely a restatement of the behavioral genetic default according to which group differences should be, knowing nothing else, assumed to have a genetic basis since genes condition differences between individuals within the population at large. To argue against this probabilistic reasoning, one must provide evidence that the said groups are not arbitrarily constructed - that they are constructed in a manner such that there are no such differences or such that the existence of such differences is a priori implausible.

Were we to socially construct groups and then select pairs between which there are appreciable differences in some highly heritable trait, it would be more likely than not that the betweengroup differences were partially congenital. In the case of skin color: Argentinians versus Colombians, North Hemispherians versus South Hemispherians, Theravada Buddhists versus Mahayana Buddhists, wealthy Mexicans versus poor Mexicans. In some instances the group differences would be completely unrelated to genetics. Whether genes explained differences between the majority of the groups would depend on the precise population heritability estimate of the trait in question. But it is clear that social constructionism per se is not inconsistent with between-group genetic differences. Thus, when it comes to "race," what is the argument? It can not merely be that races are socially constructed. It would have to be that races are socially constructed only around non-behavioral differences. But this begs the question.

\section{(c) Sociological Race in the United States}

In the United States, commonly defined sociological races, such as Asians, Caucasians, Blacks, Native Americans, and Pacific Islanders correspond somewhat with historic continental-level races - respectively, Mongoloids, Caucasoids, Negroids, Amerindians, and Pacific Islanders. The correspondence is far from perfect. For example, the Asian classification includes both South Asian Caucasoids and Mongoloids, and the African-American population largely represents a hybrid Caucasoid-Negroid population, one with a variability in admixture such that members overlap, genomically, with both European Caucasoids and Western African Negroids.

Nonetheless, the genomes of those who identify as e.g., East Asian, White, and Black American tend to cluster with those of the respective continental-level natural divisions (Lao et al., 2010).

Correspondence with historic continental-level race is not, of course, a prerequisite for constituting different biological races. What is is that groups cut out different natural divisions with respect to each other. An analysis by Tang et al. (2005) suggested that "white, African American, East Asian, and Hispanic" ethno-racial groups in the U.S. more or less do - that is, they cut out distinct genomic divisions. As the authors noted, though, the Hispanic group in their sample was based on a Mexican-American sample. When using a more diverse Hispanic sample, another research group (Lao et al., 2010) found that the Hispanic ethnic groups did not form a discrete cluster but rather overlapped with the other groups (in this case, Europeans, East Asians, 
and Africans). This is not unexpected since, across Latin America, there is substantial heterogeneity in historic continental-level racial admixture. Given the genomic heterogeneity in their region of origin, it is probably better to understand U.S. Hispanics as representing a cultural group. If they are called a "race," they would be a non-biological, sociological one. More generally, it is probably best to understand U.S. sociological races (and ethnic groups) as overlapping with - to some degree or another - not constituting biological races.

Obviously, as noted above, whether or not sociological racial, ethnic, and cultural groups are better understood as being non-biological says little about the etiology of phenotypic differences. For example, no one would argue that the mean skin color differences between sociologically defined Whites, Hispanics, and Blacks in the United States are entirely non-genetic on account of Hispanics being a socially constructed group. The same should hold true with regards to other polygenic traits.

In general, the utility of biological race in a sociological context comes from its ability to explain patterns of differences in gene frequencies between sociological racial, ethnic, and cultural groups. For example, one would explain the differences in skin color between Whites, Hispanics, and African Americans in part by noting that there are skin color differences between Caucasoids, Amerindians, and Negroids and by noting that Whites, Hispanics, and African Americans differ in their Caucasoid, Amerindian, and Negroid admixture. 
Nature makes species and genus, culture makes varieties - Linnaeus (1737)

\section{The Ontology of Biological Race}

\section{III-A. Other Defenses of Biological Race}

In recent years, a number of theoretical and philosophical defenses of the biological race concept have been articulated. Consistent with historic usage, with these, race is conceptualized in terms of lineage and/or overall genetic relatedness. Insofar as one is interested in a very general concept and an expansive discussion, these apologia have been wanting. While, as noted by Woodley (2009), conceptual differences between concepts largely come down to ones of "descriptive emphasis," there are some substantive issues:

Sailer (1998) put forth a concept of race as a linebred extended family; by this, races represent different genealogically delineated groups. Unfortunately, Sailer (1998) was not specific as to how much endogamy was needed for an intraspecific lineage to constitute a race. As discussed in section II, linebred extended families need not form natural divisions; and they can be rather unlike biological races as typically conceived. Thus, this concept is potentially too permissive.

Building off of Kitcher (1999), Hardimon (2012; 2013) educed and defended a population conception in which races as populations represent endogamous biological lineages. Insofar as Hardimon's populations correspond with the population geneticists' retrospectively defined genetic ones we have no complaints, since we are then dealing with natural divisions. There is potentially discord, though, between some population concepts of race and a natural division one. In zoology, for example, races are at times imprecisely defined as geographic "populations which differ taxonomically from other subdivisions of the species" (Mayr (1940), cited in O'Brien and Mayr (1991)). When this definition is literally read, such groups need not be natural divisions; they could be collections of ancestrally dissimilar subpopulations which happened to coincidentally inhabit a common locale - for example, a zoo space - and which happened to differ on average from other such collections. More precise zoological definitions stipulate that members share "phylogenetically concordant" characters and a "unique natural history" (O'Brien and Mayr, 1991). These qualifications specify that members of one race are relatively more similar to other members of the same race owing to common ancestry. Thus, we are left with something akin to natural divisions.

There are, though, two potential areas of disagreement between such conceptions and a natural division one. First, when members of a zoological population-race are said to have "shared a geographic range" this could be taken either descriptively or prescriptively. Insofar as it is taken as the latter, as a membership criterion, we are dealing with a narrow form of a natural division and with a curious type of race, given the genealogy of the concept, one which attempted to explain why relocated organisms retained their region of origin characteristics. As we understand things, races are not defined in terms of geographic relationship; rather, such relationship is an explanation for the breeding patterns which brought them about. Second, in discourses where races are said to be "populations," as opposed to classes or divisions, the exact degree of genetic similarity that is needed for an individual to qualify as a member of a specific race is often not clarified. We are left with a fuzzy conception which lends itself to a fuzzy set concept reading, 
one in which the boundaries of races are left indiscrete. Races as populations then potentially represent fuzzy sets, while natural divisions as we primarily understand them represent discrete sets. Of course, as noted in section II, a fuzzy set population concept of race can be incorporated into a discrete set natural division one; a distinction nonetheless exists. Generally, Hardimon's (2012; 2013) population-race concept, and related ones for that matter, might perfectly correspond with the natural division one presented here. Before we can determine, we will have to wait for proponents of these concepts to clarify their meanings.

Levin (2002a) and Andreasen (1998; 2000; 2003; 2004; 2005; 2007) developed and defended cladistic concepts. Accordingly, races represent different clades or lineage branches. Both argued that races only exist if mixed-race populations are relatively small. ${ }^{48}$ Why Levin (2002a) required this eludes us. In a paper subsequent to the one in which he elaborated his concept, Levin defended the idea of races cut out from a continuum due either to primary or secondary intergradation:

Swedes may be grouped with Swedes and Bantus with Bantus so long as the mean Swede differs from the mean Bantu, despite the existence of intermediate individuals or fertile Swedish/Bantu matings ... Appeal to continuity as a disproof of race needs the added assumption that races must be discontinuous ... it is not clear why populations must be biometrically or psychometrically or genetically discrete to count as races. (Levin, 2002b)

Since, under this circumstance, there is no problem with intermixing per se, it is not clear why there would be one with most individuals being intermixed. As for Robin Andreasen, she apparently sees a lack of historic isolation as a problem; accordingly, races have to exhibit a high degree of genealogical discontinuity and reproductive isolation. While such intraspecific lineage branches (or twigs) would constitute biological races - assuming that they did not, as discussed in section I-I, form cladistic species - we do not see that races need be these. For one, approaching the matter from a cladistic perspective, there is no established convention concerning a degree of impermissible lineage admixture for races, formally recognized or not. Applying Andreasen's apparent strict branched-ness criterion to other species would result in the elimination of many recognized subspecies, as admixture and continual gene flow is common on the intraspecific level. Since many cladists (when they grant the existence of taxa subspecies) simply adopt the evolutionary taxonomist's formal races, and since many of these subspecies exhibit continual gene flow, we can infer that continual gene flow is not felt by many cladists to be inconsistent with the existence of even formally recognized races. Andreasen (2007) justifies this isolation requirement by saying that it is necessary for groups to be monophyletic; but she fails to explain why her cladistic races require monophyly, in the sense she understands it, given that many prominent cladists consider monophyly to not be applicable on the intraspecific level (Hennig, 1966; Nixon and Wheeler, 1990). Arguably, a proper "cladistic" race concept, should define races and subspecies not in terms of monophyly but in terms of tokogenic relationships, which is to say pedigree. (Readers are referred back to our discussion in section I-I.)

\footnotetext{
${ }^{48}$ Levin (2002) stated, for example: "[Continental] races exist so long as most individuals can trace their ancestry to one of a small number of continental clades." Andreasen (1998): "These data, in conjunction with the fact that there has been reduced reproductive isolation in modem times, indicate that races are fading out of existence. Ever since the voyages of discovery, colonization and immigration have been blurring racial distinctness."
} 
For another, approaching the matter from a non-cladistic perspective, substantial admixture between populations is consistent with the presence of natural divisions. Thus, despite the known historic admixture in humanity, one can divide by genomic propinquity humans into classes (e.g., Tal (2012)). There is no inconsistency between lineage admixture and natural divisions because what matters for the latter is overall genetic similarity, not lineage purity. There is, of course, nothing special about a genomic versus genealogy-based race concept that allows for such admixture. Just as individuals can be, in degree, more genomically similar to one group than to another, they can be more genealogically so. For example, an ethnic Hui individual might have a ratio of one South Asian to 511 Han ancestors. In pedigree, as in genome, this Hui individual would be more related to Han than to South Asians. By virtue of pedigree collapse, due to linebreeding, more of the Hui person's ancestry paths would trace back to some Han centuries prior than to some South Asian.

Finally, approaching the matter from a historical perspective, it was always recognized that races, in the intraspecific sense, intermixed. Thus Kant had his half and admixed races, Buffon his Tartars with their Muscovite admixture, Huxley (1870) his Melanochroi who were part Australoid, Hooton his secondary races, and so on. The idea that races were lineage-branches between which there was little admixture was never generally held; thus it is difficult to see how such could be said to be only what races are. Andreasen's concept, then - and also Levin's - is best treated as a specific version of a cladistic concept which itself is a specific type of a more general race one.

Shiao, Bode, Beyer, and Selvig's (2012) "clinal class" concept, in which groups are defined in terms of ancestry-indexing clusters of genetic characters, is also a lineage-genomic one. Importantly, it is conceptualized in contrast to genomic/population continua (or "clines" in the authors' terms). ${ }^{49}$ The concept we are discussing, however, is not at odds with genomic/population continua, insofar as natural divisions can be carved out of these; rather, it is with a view of biological races as artificial biological divisions. Shiao et al.'s (2012) concept then is possibly too exclusive insofar as it possibly excludes natural divisions which are 'arbitrarily' - in the sense of not enabled by the global population structure present in the species - cut out of a genomic continuum.

Spencer (2011) presented an apologia for human races as continental genetic meta-populations; this is also a genomic concept. Being a meta-population concept, it seems to exclude micro intraspecific natural divisions and thus is also too exclusive.

In other cases, we do not see obvious problems with the concepts articulated, just with the incompleteness of the defenses:

Woodley (2009) outlined a consolidated concept in which biological races were said to be "populations expressing a composite number of traits whose distributions intercorrelate in such a way so as to give rise to a particular, distinct correlative structure"; he noted that this implied a

\footnotetext{
${ }^{49}$ In a subsequent paper (Shiao, 2014), the lead author writes: "In sum, the best theoretical description of human genetic variation includes both isolation by distance (clines) and modest discontinuities (clinal classes)." His "clinal classes" seem to require modest (historic) discontinuities.
} 
lineage concept. It is obvious from the discussion that it also implied a genomic similarity one. Sesardic (2010) defended a genomic similarity concept: "Research has shown that, indeed, groups of people of significantly different geographical ancestries do differ from one another genetically, when compared on many genetic loci these groups have different frequencies of different alleles." Wade (2014a) articulated the same: "A necessary approach to studying racial variation is to look not for absolute differences but at how the genomes of individuals throughout the world cluster together in terms of their genetic similarity." Unfortunately, these authors, left much undeveloped.

The commonality among these concepts is obvious: genomic similarity indexes genealogical. Thus races delineated in terms of (overall) genomic similarity are races delineated in terms of (overall) pedigree: natural divisions either way. Sesardic (2010), Wade (2014a), Shiao et al. (2012), Woodley (2009), and Hardimon (2012; 2013) end up discussing some variant of the genomic cluster/similarity race concept, which is the intraspecific corollary of the genomic species concept (e.g., Mallet, 1995; 2001) in zoology and a doppelganger of the population geneticists' retrospective genetic population concept (e.g., Hartl and Clark (1997)). As discussed in section II, this is a derivative of Darwin's (genealogical) natural division formulation which ties it to Sailer's linebred extended family concept - genomic similarity being the product of sufficient endogeneity - and to Andreasen-like cladistic concepts, which merely add some conventional criterion of sufficient branchedness. For all of this human biological diversity, there is an embarrassing lack of the conceptual variation!

To approach this topic more generally: races, in general, are classes, the members of which are thought to be arranged by propinquity of descent. With strictly non-biological concepts, members of the same races do not, in fact, share more ancestry relative to members of other races. For example, were we to construct a Human South Hemispherian race, which included individuals whose ancestors predominately lived in the South Hemisphere between 10,000 B.C. and 1500 A.D., we would not have constructed a biological scientific race of any sort. With artificial biological race concepts, members are arranged by ancestry, but not overall ancestry. Hypodescent defined races would be an example of such. They can, insofar as the defining genealogies are accurate, be said to be no less biological than morphs or forms; yet the groups described would frequently not be natural in the sense of describing overall genetic relatedness. When lines of descent are sufficiently endogenous, that is, when our extended families are sufficiently linebred, natural division races emerge from artificial. These races have five dimensions, two causal, two essential, and one consequential. Races are the product of extrinsic reproductive barriers and of the historic breeding patterns that these barriers have shaped. They are lines of descent, ones sufficiently linebred to allow for class distinctions, which over the course of generations have accumulated modifications. Owing to their common ancestry, members of a race share phenotypic patterns which can be used to distinguish them from members of other races. Different biological research programs varyingly emphasize, sometimes to the neglect of others, these different dimensions e.g., zoology and allopatry, population genetics and breeding patterns, phylogenetics and descendancy, ecology and adaptations, and biological anthropology and phenotypic similarity.

\section{III-B. Biological Races and Biological Reality}


Not infrequently is it professed that races have been discovered to be "unreal"; in a 2013 New York Times editorial, philosopher Justin Smith, for instance, avers:

Since the mid-20th century no mainstream scientist has considered race a biologically significant category; no scientist believes any longer that "negroid," "caucasoid" and so on represent real natural kinds or categories [1] ... footnote [1]: What it does mean to say that race is no longer a legitimate scientific category is that this limited, contextual helpfulness tells us nothing about a natural kind or real subdivision of the human species. (Smith, 2013)

By this narrative, once-upon-a-time races were thought to represent "real natural kinds," but it turned out that there were no such kinds and so mainstream scientists later rejected the concept. ${ }^{50}$ In actuality, close to the opposite occurred, at least insofar as we are referring to intraspecific divisions.

Let us clarify this latter point, first. As noted in section II, in context to natural history, the term "race" was used both exclusively to refer to a sort of intraspecific division and inclusively to refer to this in addition to species. The latter usage allowed for the question: "Are the races of man species?" Insofar as race was used to describe intraspecific variation it referred to "constant varieties," genealogically understood. In the $20^{\text {th }}$ century, the indiscriminate concept of varieties was retired and terms such as "polymorph" and "race" were employed to describe different sorts of intraspecific variation. "Race" gained an exclusively intraspecific denotation - though, outside of the natural sciences it was and is still often used in the inclusive sense, for example, when people refer to the "human race" and mean the "human species" or when fantasy fiction novels speak of different separately created races such as the elves and dwarves of Middle Earth. Since the term "race" had this dual meaning there is a sense in which some scholars believed that the races of man were natural kinds in the species realist sense - after all, some believed that races were species and that species were separate creations. Thus one has to interrogate the specific meaning of the claims. Smith (2013) makes it clear that he is speaking about races as "subdivision of the human species," so we will frame our discussion in terms of this understanding.

As noted prior, many biologists of the 1600 to 1800 s were species realists. Generally, species realists thought that different species were the product of separate creations. Species were thought to have unique structural designs (alternatively, formal natures or essences) which were such or were transmitted such to preclude the intergenerational transmutation (i.e., evolution) of the species' form. As a result, consistent with the Aristotelian perspective, the realist's species were thought of as permanent - that is, they did not change their form across generations. Being so, they were considered, unlike, for example, inconstant varieties, to have extra-mental reality. As Stamos (2005) and others have pointed out, the majority of 17th to 19th century thinkers were not realists with respect to higher taxonomic categories (e.g., classes or orders). Rather, they were nominalists. Stamos (2005) notes:

\footnotetext{
${ }^{50}$ To be fair, in his later published and eloquently written book, "Nature, Human Nature, and Human Difference: Race in Early Modern Philosophy," Smith concludes that races as subdivisions of a species were not in fact thought to be Millian "real natural kind." The opinion expressed in his 2013 editorial nonetheless represents a not uncommon misconception.
} 
Darwin (1859) would shortly afterward second this judgment, not only when he says "Several of the best botanists, such as Mr. Bentham and others, have strongly insisted on their [higher taxa from genera to orders] arbitrary value" (419), but especially when he informs us that many naturalists "admit that genera are merely artificial combinations made for convenience" (456). If (assuming it is safe to say) the great majority of pre-Darwinian naturalists and taxonomists did not believe that higher taxa are real, then why did they even bother to group species into higher taxa? The answer is because of practical necessity. As Stevens (1994) puts it, "it should not be forgotten that all naturalists had to describe groups, whatever their opinion of their ontological status" (462).

This was because these higher taxa were not Creator made entities. Rather, they were collections of species grouped according to coincidental resemblance. Stamos (2005) could also have noted, but did not, that nominalism reigned too when it came to intraspecific groupings. This is why Blumenbach, for example, described his human varieties as "arbitrary kinds of divisions." In a sense, then, it is true that few to no mainstream scientists presently consider race or any other biological grouping to represent real natural kinds in the species realist's sense; as such, few to no biologists currently believe that "humans" and "horses" and so on represent extra-mental, permanent, and intrinsically essentialist entities.

Box 3.1. 18th century conceptions of intraspecific race and subspecies

While it has been asserted that both early subspecies and intraspecific race concepts were essentialistic in a species realist sense, an examination of early definitions shows that both concepts were employed to describe constant varieties, genealogically understood. These subspecies and races as constant varieties were originally understood in contrast to the species realists' species. They were seen as superficial cuts of biological variation as compared to the realists' species, which, conceived as independent creations, were thought to sever biological nature at its joints. A collection of early definitions are listed below:

Duchesne (1766): "It is certain today that, if all species are stable, there are also races whose distinctions are constant, although belonging to the same species. The Versailles strawberry that I saw born, and which became the head of a race, puts that fact beyond doubt. Cultivation and other accidental causes do not produce new species, but changes in certain individuals do occur that are perpetuated in their posterity, constituting new races."

Buffon (1778): "The races in each species of animal are only constant varieties which perpetuate themselves by generation."

Esper (1782): "Subspecies (untergattungen, Races) which are generally called varieties, are to be clearly separated from them. That they originated from species is clearly revealed by the perfect similarity of the essential parts... they are equally capable of producing offspring, an ability which varieties are denied."

Kant (1788): Race is "a radical peculiarity that both indicates a common descent and grants several such persistently transmitting characters to the same line of descent... they are not really different kinds but deviate forms, even though they are still so distinct and persistent that they justify a class distinction. According to these preliminary ideas, the human species... could be divided in a system of nature into a line (or lines) of descent, races, or deviate forms (progenies classificae); and different human stock (varietates nativae)."

Ehrhart (1784): Subspecies are "plants which agree in essentials almost completely with each other, and are often so similar to each other that an inexperienced person has trouble in separating them, and about which one can conjecture, not without reason, that they have formally had a common mother, notwithstanding that they now always reproduce their like from seed. They are in a word, Varieties constantes, or an intermediate between species and Spielarten [inconstant varieties]." 
Yet few to no realists of the 17th to 19th century endorsed intraspecific realism in the first place. In Fundamenta Botanica (1737, quoted in Stamos (2005)), Linnaeus characterized the metaphysics of the systematics of his day thusly: "Nature makes species and genus, culture makes varieties, art and nature makes classes and orders." At this time, intraspecific variation was frequently chalked up to degenerative environmental factors since formal natures, which were seen as what allowed for the intergenerational consistency of form, were seen as species/genus level properties.

From the perspective of this intellectual paradigm, the phenomena of "constant varieties," conspicuous varieties which retained their peculiar forms even when reared in foreign environments and which in these new environments propagated these peculiarities across generations, was a curiosity (Doron, 2011; 2012). Some polygenists had fun with this problem: if not different species, whence the apparent hereditary nature of the notable differences between populations? If because these groups represented "constant varieties," how does one make sense of such an oxymoronic concept?

The monogenist Buffon had a response. He conceptualized species as physical networks of historical filiation (Sloan, 1979) and, in turn, constant varieties as character differences which were transmitted along intraspecific lineages or, alternatively, lineages along which character differences were transmitted. He tells us: "[I]n animal species, races are simply constant varieties that propagate through generations" (Ratcliff, 2007). He also notes: "The germ of blackness is transmitted to children by their fathers and mothers so that in any country where a Negro may be born, he will be as black as if he were born in his own country" (Doron, 2012). He introduced the concept of race into the study of natural history, in part, to account for the constancy of differences between regional varieties. He proposed that environmental factors left imprints on genealogical lines - an idea not too dissimilar from the modern one of epigenetics. Accordingly, members of races shared relatively constant, across environments and generations, patterns of traits owing to the imprint which the environment, acting long across generations, left on their particular lineage.

This pattern repeats itself with other racial theorists. For example, in On the Use of Teleological Principles in Philosophy (1788), Kant, a monogenist like other well-known racial theorists, distinguished between "races" and "varieties" as he defined them. By his understanding, varieties characterized groups of individuals whose trait differences were failingly hereditary; Kant gave the example of blonds and brunettes. Races, on the other hand, characterized intraspecific groups whose trait differences were unfailingly hereditary. Regarding the latter, Kant gave the example of skin color in context to gypsies and old Europeans. He notes:

[W] now have a decisive example in the <Asian> Indian skin color of a band of people who have been reproducing in our northern lands for several centuries, namely, the gypsies... nature remains so persistent in preserving <their skin color> that, if we can indeed follow their presence in Europe back twelve generations, they still come to light so perfect that, had they grown up in India, no difference at all would, in all probability, be found between them and those native born <in India>.

He went onto distinguish thusly between races and species:

Just in this way, race, or deviate form, is an invariable, heritable peculiarity that, to be sure, authorizes divisions into classes but is certainly not specific because the invariably half-breed resemblance 
(hence, the fusing together of the characters of their difference) makes it at least not impossible to regard their inherited differences - even from the very beginning in their line of descent - as unified in simple endowments and gradually developed and separated only in reproduction. For we cannot make an animal group into a particular species if it belongs with another in one and the same generative system of nature. Species type and species would, consequently, in natural history, signify one and the same thing, namely heritable peculiarity which is not compatible with common descent. (Kant, 1788)

Kant adopted the species realist position that species did not evolve from a common stock. For him, races differed from species in that they descended from a common stem and that they were interfertile. This fertility diagnostic criterion had been proposed by others; Kant, himself, cited Buffon. Generally, species were often thought to be characterized by intrinsic reproductive isolation, a lack of common descent, and constancy of character, while varieties were thought to be characterized by both inconstancy of character and interfertility. From this perspective, groups which were interfertile and which exhibited constancy of character were an oddity. As Ratcliff (2007) notes in context to botany: "[T]he lack of the term race in botany had confusing consequences; botanists were unable to differentiate between varieties that interbreed and vary, and races that interbreed but do not vary." The intrinsic isolation diagnostic criterion for species, of course, was rejected by others; polygenists, for example, argued that species could be interfertile if they were not very different in form. ${ }^{51}$ The innovative aspect of Kant's concept and similar ones was that groups were conceptualized as being interfertile, as having a common phylogenetic origin, and yet as exhibiting differences in characters with constancy (across environments). Since races were seen as having differentiated from a common stem and since it was allowed that they could blend back together, for Kant, as with others, these intraspecific divisions were not seen as real in the species realist sense. Kant, nonetheless understood races to be natural divisions, which, anticipating Darwin, he conceptualized as divisions based on genealogical relationship.

The species/race/variety distinction, or lack thereof, is apparent in the paper in reply to which Kant's On the Use of Teleological Principles in Philosophy (1788) was written. In, Something More about the Human Races, the notable naturalist and ethnologist Georg Forster situated the question of the day as one of species or varieties, where a variety was characterized by the inconstancy of its characters. He then argued that the conspicuous differences between Whites and Blacks exhibited some degree of intergenerational constancy and heretically suggested that, therefore, the groups represented different species. We are told:

How much, then, is it to be hoped for a decisive ruling on the <previous> question? Is the Negro a variety or a species in the human genus [Menscheneschlect]? If <the ruling $><$ in this matter $>$ depends upon proving the descent of all varieties from an original, common parental couple, which cannot be demonstrated without indisputable historical evidence, there will be no definite solution; for such evidence is nowhere to be found. If, on the other hand, we are satisfied by the Linnaean ruling

\footnotetext{
${ }^{51}$ The disagreement about whether species should be expected to exhibit intrinsic isolation, or something akin to this, persists today. The debate has a different flavor to it, though. Prior to the acceptance of evolutionary theory, species (contra varieties) were defined in terms of having distinct phylogenetic origins; it was argued by some that this distinctness should be diagnosed or evidenced by a lack of interfertility, as it was thought by them that separateness of origin precluded interfertility. Since the acceptance of evolution, it has been recognized that different species share a common origin; those who now argue that species should exhibit intrinsic reproductive isolation generally define species (contra subspecies) this way. Accordingly, species are races which have acquired intrinsic isolation mechanisms. It has been pointed out by a number of authors (e.g., Baker (1974)) that this is a problematic definition since a number of recognized species can and do produce hybrids with closely related species.
} 
[Bestimmung], <that> a variety differs from a species simply through the inconstancy of its characteristic feature, then a little provisional investigation is required <to find out> to what extent the definition [Definition] fits the various human lines of descent...

There are obvious differences of <skin> colors in each of the human lines of descent, the white as well as the black. Whites becomes black-ish in Africa <and> Negroes becomes olive-colored in the land of the Kaffirs. But no experiment up to now teaches us if this variability might be able to take place up to a full transformation of the white into the black color, and, the other way around ... Now, I will show with some probability that the color of whites, like that of the Negro, is alterable only up to a certain point, but after this is transmitted uniformly in mixed generations without exception.

As with others, Forster addressed and tried to dismiss the proposed race concept, which attempted to make epistemic space for "constant varieties." He noted that the term "race" generally connoted intraspecific lineages of some sort, argued that it should be used to merely refer to phenotypically differentiated lineages (either specific or intraspecific), and then criticized Kant's formulation:

$<$ The word > should mean nothing more than a mass of men whose common formation is distinctive and sufficiently at variance with their neighbors <such that they> could not be immediately derived from them. <They are> a lineage whose derivation is unknown, and consequently, one which we cannot easily count under one of the commonly accepted human varieties because we lack knowledge of the intermediary link... If we wish in the future to keep this definition when talking about human beings, we can continue to use the word. Where <this is $>$ not $\langle$ the case>, we can conveniently dispense <with it>. Kant's definition, on the other hand, seems to be much less acceptable the more uncertain and improbable it is that, among animals, one and the same lines of descent could always produce and invariably heritable difference.

Rhetorically, Forster's criticism of Kant's formulation allowed him to reduce the issue back to one of species versus inconstant varieties and then to provide evidence in defense of the polygenist position. The exchange between Forster and Kant provides us with a sense of the role that the concept of race, in the intraspecific sense, was playing. Monogenists were employing it to offer an alternative to the Linnaean paradigm which led, if not logically then rhetorically, to the empirically untenable conclusion that regional groups were different inconstant varieties or to the morally objectionable (to some) one that they were different species.

Returning to our main point, one can not say that the unreality of races was uncovered. One might say that races were discovered to not be species as maintained by polygenists, but polygenists were a heretical minority and, moreover, the species of both polygenists and monogenists were discovered to be unreal anyways - that is, to paraphrase Darwin, to be just a variety of varieties. This last point is important. Post-Darwin species were, in a sense, ontologically demoted. The result is that all lineage segments are now conceived of as unreal in the species realist sense and, hence, not "real natural kinds" understood thus. At the same time, though, what it is to be biologically natural was reconceptualized in a genealogical sense without the "natural kind" presumptions; hence: biological natural divisions. We see this meaning shift play out in Darwin's writing. Darwin stated that species both were and were not arbitrary groupings. On the one hand, we are told:

From these remarks it will be seen that I look at the term species, as one arbitrarily given for the sake of convenience to a set of individuals closely resembling each other, and that it does not essentially differ from the term variety, which is given to less distinct and more fluctuating forms. The term 
variety, again, in comparison with mere individual differences, is also applied arbitrarily, and for mere convenience sake. (Darwin, 1859)

Yet, on the other:

[F]rom the first dawn of life, all organic beings are found to resemble each other in descending degrees, so that they can be classed in groups under groups. This classification is evidently not arbitrary like the grouping of the stars in constellations. (Darwin, 1859)

For Darwin, as indicated in the first quote above, species as with intraspecific divisions were arbitrary in that they did not carve out real or natural divisions in the species realist sense. They were not Creator-made divisions. They were, nonetheless, as indicated in the second quote, natural in the sense meant by Kant and current thinkers. The upshot of these considerations is that races can now be said to be as real - or unreal, meaning depending - as species. Relatively speaking, then, the ontological status of "Negroid," "Caucasoid," and so on has moved up quite a bit since the age of the Enlightenment! Of course, Darwin recognized this. In Descent of Man, having noted that the distinction between species and intraspecific race was fundamentally arbitrary, he pointed out that human geographical groups could be considered to be either. ${ }^{52}$ This is because, with his theory, the ontological gulf between specific and intraspecific variation vanished. With this erased, the debate between monogenists and the polygenists largely lost its meaning. Thus Darwin noted:

So again, it is almost a matter of indifference whether the so-called races of man are thus designated, or are ranked as species or sub-species; but the latter term appears the more appropriate. Finally, we may conclude that when the principle of evolution is generally accepted, as it surely will be before long, the dispute between the monogenists and the polygenists will die a silent and unobserved death.

To be clear, some still currently use the phrase "biologically real" to mean "mind independent." Those who do often do not realize the historically close tie between the notion of "mind independent" and the species realist view. They do not grasp the meaning shift. Since the meaning of "biologically real" changes over time, what "real" once generally meant does not necessarily correspond with what it does now or will mean in the future. Given the shifting nature of understandings, explicitness of meaning is necessary for coherence. If one proclaims that "races are unreal" where "unreal" is used in the archaic sense of permanent or extra-mental, one should make one's meaning clear. ${ }^{53}$

\footnotetext{
${ }^{52}$ Darwin does not use the term "intraspecific race" but in the passage being discussed he uses the term "race" intraspecifically. Thus, he notes: "[The forms of Cebus] would be ranked by most naturalists as mere varieties or races; and thus the greater number of naturalists have acted with respect to the races of man. Nevertheless it must be confessed that there are forms, at least in the vegetable kingdom, which we cannot avoid naming as species." Elsewhere, he notes that the term "sub-species" might be preferable to "race" because it clearly indicates intraspecific status. He notes: "Some naturalists have lately employed the term "sub-species" to designate forms which possess many of the characteristics of true species, but which hardly deserve so high a rank... The term "subspecies" might here be used with much propriety. But from long habit the term "race" will perhaps always be employed."

${ }^{53}$ There certainly are different usages floating around. For example, in his critical review of Nicholas Wade's “A Troublesome Inheritance," biologist Allen Orr notes: "In this statistical sense, races are real." (Orr, 2014). Yet other maintain that human races are not real, based on other sense of "real."
} 
In section I, we defined "biologically real" in a simple commonsense manner that allows us to make sensible claims such as "demes are real." We did not favor other more metaphysical understandings because we wished to define "reality" in a metaphysically neutral manner. This said, we are not opposed, per se, to other conceptions of what-it-is-to-be-biologically-real. If one wishes to define "biological reality" in other manners, fair enough. But the definition should be applied consistently. And examples of which biological things are and are not real by the said definition should be offered for context.

Per our definitions in section I, the race concept here discussed is a biological concept which (a) is biologically valid; (b) is biologically meaningful in both the broad and narrow senses; (c) represents a biological kind; (d) describes natural biological divisions; and (e) has a strong claim to the term "race." Additionally, (f) there are biologically real human races in our commonsense sense of biologically real. Of course, one could define "valid," "meaningful," "biological kinds," "natural biological divisions," "real" and "biologically objective" in other ways. Preferably, the definitions would allow one to make sensible statements such as "forests are ecologically real" or "a breeding population, the basic unit of evolution, is a biologically meaningful concept." That is, one's ontology of biology should be coherent and sensible - like ours.

At very least, terms should be consistently applied. Thus, for example, if one is going to maintain that for something to be 'biological real' it needs to be uniquely distinct from related things, one should, for instance, either grant that the Krebs Cycle is not molecularly biologically real because it is not distinct enough from stage 2 Glycolysis or one should explain why these metabolic processes are, in fact, distinct enough (to be biologically real) given some pan biological criterion of "sufficient distinctness." This all said, as we are not disposed to feud over words, we offer the following qualified position: biological races, here defined, are both "real" and "unreal," "valid" and "invalid," "meaningful" and "meaningless," "biological kinds" and "social constructs" in the way that kingdoms, species, ecologies, character clines, demes, morphs, omnivores, local populations, ecosystems, Köppen climatic zones, and habitats are. On the other hand, they are not biologically real in the way that species were once thought to be. To better make sense of the issue, it would be helpful if, in the future, biological race anti-realists offered examples of the types of biological things that, by their understanding, are "really" biological real.

\section{III-C. Thin Biological Racial Essentialism}

It is also frequently argued that races, in the intraspecific sense, are not real or that they do not exist for the simple reason that no candidate groupings have biological essences and that, historically, race was conceived - and so should still be - in a now untenable essentialistic way. These 'race was historically an essentialistic concept' arguments pop up time and time again. For example, the 2011 version of the Stanford Encyclopedia of Philosophy article on race states:

The concept of race has historically signified the division of humanity into a small number of groups based upon five criteria: (1) Races reflect some type of biological foundation, be it Aristotelian essences or modern genes; (2) This biological foundation generates discrete racial groupings, such that all and only all members of one race share a set of biological characteristics that are not shared by members of other races... 
This historical concept of race has faced substantial scientific and philosophical challenge. ... Others defend the concept of race, albeit with substantial changes to the foundations of racial identity, which they depict as either socially constructed or, if biologically grounded, neither discrete nor essentialist, as the historical concept would have it. (James, 2012; emphasis added.) ${ }^{54}$

As will be discussed later on, races in the modern sense do have essences, ${ }^{55}$ or features which establish what it is to be one of them - just not intrinsic ones. They have relational essences and genes, either in the molecular or the genealogical sense, form the biological foundation of these. Because they have relational essences they can be discrete sets. Of course, "all and only all members of one race" do not share with each other a collection of specific hereditary characters; they do not form a character-essentialist class. Rather, they form a molecular character-cluster class; "all and only all members of one race" share a collection of overlapping genes which jointly defines their membership in one as opposed to another race. This granted, the concern can only regard how races were conceived in the 18th and 19th century - specifically, whether they were conceived in an implausibly essentialistic way. Two implausible, given current understandings of biological variation, forms of essentialism have been suggested: Aristotelian essentialism and character essentialism. Let us first consider the claim about character essentialism.

As for strict character essentialism, as noted in section II, Kant's formulation would probably best qualify. We quote from his paper, Determination of the Concept of a Human Race (1785):

The character of the class is passed on invariably in heterogeneous interbreeding, and there exists absolutely no exceptions to this. Those who say they have found exceptions base their claims on a misunderstanding, as they have taken the albinos or kakerlak (both monstrosities of nature) for whites...

Physical characters by means of which human beings (irrespective of gender) distinguish themselves from one another - but, to be sure, only those that are heritable - come into question in order to establish the division of the species into classes. These classes, however, are to be called races only when that character is passed on invariably ( $<$ both $>$ within the same class as in interbreeding with every other).

Kant recognized that one needed some criteria which would allow one to assign individuals to their respective natural divisions. The possibility of trait clusters apparently did not dawn on him. This left, as classificatory criteria, specific congenital characters which were unfailingly transmitted and in which divisions did not overlap. ${ }^{56}$ Thus, his classes were hereditarian character essentialist ones. Since he recognized "mixed" and "incipient" races (Kant, 1777), ones which, respectively, were the products of hybridization and incomplete differentiation, he clearly recognized the overlap of races. He just could not allow for an overlap in the specific differentia of different races, since he was not using character clusters. For Kant, the differentia used to distinguish one pair of races did not need to be the same as that used to distinguish all pairs. For

\footnotetext{
${ }^{54}$ For the unrevised 2008 version see: http://isteve.blogspot.com/2010/07/stanford-encyclopedia-of-philosophyon.html

${ }^{55}$ Aristotle used the phrase "to ti ên einai" which translates to "what-it-was-to-be-that-thing" or, in Latin, "essence."

${ }^{56}$ It is worth noting that Kant's race concept is remarkably similar to the diagnosable version of the Phylogenetic Species Concept discussed in section I-I and IV-J.
} 
example, Abyssinians and Kaffirs could be distinguished from whites by color and from each other by bone structure. Thus, his character essentialism was not inherently biologically implausible. To get a situation where one could identify lines of descent this way, one would just need several traits which well tracked lineage and for which the between group variance was high, that is, for which the distributions of the traits did not overlap (outside of the zones of intergradation). The problem with regards to human races is, of course, that there are a dearth of such traits. Some molecular characters such as SNP rs3827760 allele G of the EDAR gene, which conditions Mongoloid typical phenotype (for example, thick hair and shovel shape upper incisors) runs high in East Asian populations and low in many others. But using such characters singularly would end up misclassifying many individuals with respect to how they would be if classified according to overall genetic similarity. It is now clear that individual traits do not make for good differentia. But this is not a new discovery. It was recognized by Buffon, Blumenbach, Darwin, and the many others who argued that one should simultaneously take into account similarity in numerous traits. We imagine that Kant would have had no problem with using character clusters if he understood the technique. Thus, we do not see Kant's concept as principally or foundationally character essentialist. It was just contingently so; he did not grasp the possibility of cluster classes.

Blumenbach did, though. He was highly critical of artificial systems of classification, ones based on one or a few characters. And he understood a natural classification to be one "dependent upon all bodily indications alike" (Blumenbach, 1806). Blumenbach applied this understanding to regional groups first understood as varieties and, later, as races. As such, in, On the Natural Varieties of Mankind, he tells us that "one or two [characters] alone are not sufficient" to delineate varieties and that we "must take several joined together." Blumenbach's position did not change in this regards when he adopted Kant's race concept, a concept which Blumenbach cited in the fifth - or 1797 - edition of his Handbook of Natural History. As such, in Contributions to Natural History (1806), in the subsection "Division of Man into Five Principle Races," he tells us that there is "not a single one of the bodily differences in any one variety of man, which does not run into some of the others by such endless shaded of all sorts [.]" Speaking of Africans, he states that he is "acquainted with no single distinctive bodily character which is at once peculiar to the Negro, and which can not be found to exist in many other and distant nations." Giving examples to make his point, he writes that the color of Africans can be found in New Guineans and that "curly woolly hair is well known not to be common to all the Negroes." Blumenbach's groups, whether characterizes as varieties or as races, were quite unlike the entities discussed by the Stanford Encyclopedia of Philosophy.

Since we consider Buffon to be one of the primary innovators of the race concept, we might consider his position, specifically that which was presented in his Natural History. As with Blumenbach, Buffon was critical of artificial systems. In his "Initial Discourse," he faults Linnaeus for creating arbitrary divisions and then praises Aristotle for, before delineated groups, first establishing "general differences and resemblances," which take into account "form, color, size, and all the exterior qualities of the whole animal," and for not instead dividing animal groups "on the basis of small special characteristic such as the Moderns do." Since he starts off with a denunciation of artificial classifications, we should anticipate that he will not delineate his races in a character essentialistic manner. And he does not. Let us consider a series of passages: 
The blood of the Tartars is mixed on one side with the Chinese, and, on the other, with the oriental Russians. But the characteristic features of the race are not entirely obliterated by this mixture; for, among the Muscovites, the Tartarian aspect is very frequent; and, though the former have sprung from the common European race, we still find many individuals with squat bodies, thick thighs, and short legs, like the Tartars. But the Chinese have so great a resemblance to the Tartars, that it is uncertain whether they be not of the very same race: The most remarkable difference arises from a total disparity in their dispositions, manners, and customs... In their features and form, however, they have a great resemblance to the Tartars...

Most of the Dutch voyagers agree that the Chinese, in general, have broad faces, small eyes, flat noses, and hardly any beard; that the natives of Canton, and all along the southern coast, are as tawny as the inhabitants of Fez in Africa; but that those of the interior provinces are mostly white. Now, if we compare the descriptions of the Tartars and Chinese given by the different authors above quoted, we cannot hesitate in pronouncing, that the Chinese, though they differ a little in their stature and in the form of their countenance, have a greater relation to the Tartars than to any other people, and that all the differences between them proceed entirely from climate and the mixture of races...

The Japanese are so very similar to the Chinese, that they may be regarded as the same race of men; their colour is indeed darker, because they live in a more southern climate. In general, their complexion is vigorous; their stature short; their face and nose broad and flat; their eyes small; their beard think; and their hair black...

All these nations, it is apparent, differ little from the Chinese, and resemble the Tartars in the smallness of their eyes, their flat visages, and their olive colour. But, in proceeding southward, the features begin to be diversified in a more sensible manner...

The people of Malacca, of Sumatra, and of the small adjacent islands, though they differ between themselves, differ still more from the Chinese, Tartars, \&c. and seem to have originated from a different race; yet the natives of Java, who are in the neighbourhood of those of Sumatra and Malacca, have no resemblance to them, but are similar to the Chinese, excepting in colour, which, like that of the Malays, is red mingled with black...

The discussion of the Tartarian aspect in Muscovites, the indecision as to whether Tartars were of a different race than Chinese (given the relative overall similarities between these groups) and the discussion of and weighing of degrees of overall differences between Chinese and Japanese and between Chinese and the people of Malacca all strike us as being non-character essentialistic. It can not be denied that Buffon at times referred to uniform difference - for example, regarding Tartars: "[A]ll these people, even in their youth, have large wrinkled foreheads; their noses are thick and short, and their eyes small and sunk" - but such essential characters were not required. Moreover, for Buffon shared characters did not define races, rather they identified them. Thus, as with Kant and Blumenbach, Buffon did not consider morphs such as albinos to constitute races. For Buffon, to be a member of a race is to share a common lineage with other members of the same race, not to just share common phenotypic characteristics. Thus, regarding Chacrelas and Bedas, two Albino groups, we are told:

"If, however, these white people actually proceed from copper-coloured parents, we must allow that the Chacrelas and Bedas have also been produced by tawny progenitors, and that all the white men, whom we find at such great distances from each other, form not a particular race, but are only individuals who have accidentally degenerated from their original stock." 
Unlike Kant, Buffon had no problem with using non-hereditarian traits such as customs and language to evidence the genealogical relations between groups. He had no problem concluding, for example, that "[these] are the same race of men; because they resemble one another in figure, in stature, in colour, in manners, and even in singularity of customs." Races here, of course, are not being defined in terms of, for example, customs, rather they are being defined in terms of lineage and similarity in customs are being used to index similarity in lineage.

Now, we might examine other early (intraspecific) race theorists. And in the process we might uncover irredeemable character essentialists. But since a number were manifestly not, we can conclude that race concepts were not generally conceptualized this way. Generally, we have a situation in which some race concepts were formulated character essentialistically (Kant) but for which character essentialism seems to not have been logically necessary, in which some race concepts were formulated in an explicitly non-character essentialistic manner (Blumenbach) and in which some concepts were formulated in a way that, at very least, did not require character essentialism (Buffon). This situation does not well support the charge that character essentialism was a foundational part of the historic race concept - or even that it was consistently a part.

And what of Aristotelian essences? As historian James Lennox has noted, Aristotle's essentialism "is at once sophisticated and remarkably unlike what passes for "Aristotelian essentialism" in modern philosophy" (Lennox, 2009). Since Aristotle's version diverges from many contemporary accounts of it, to answer the question we need to first clarify what is meant. Unfortunately, Michael James does not do this in his 2012 Stanford Encyclopedia entry, so we must turn to the contemporary literature. In sociology, some equate "biological essentialism" with the position of genetic determinism or even hereditarianism. ${ }^{57}$ In more rigorous discourse, biological essentialism, in a supposed Aristotelian sense, refers to something else - what is not without ambiguity. Whatever it is, as Devitt (2008) notes, there is a consensus against it. But what precisely is being repudiated? Okasha (2002) tells us:

What concept of essentialism is at work in such claims? Ernst Mayr (1982) describes the essentialist or "typological" species concept of pre-Darwinian biology as the view that each species is constant through time, and consists of similar individuals which share a common, unchanging essence (p. 260). Clearly, if we accept Mayr's characterisation, then essentialism about species is flatly incompatible with the theory of evolution - for the latter asserts that current species have evolved from ancestral ones and thus that species are not constant through time.

A better characterisation of essentialism, and one that would be accepted by nearly all philosophers of biology, is David Hull's: "each species is distinguished by one set of essential characteristics. The possession of each essential character is necessary for membership in the species, and the possession of all the essential characters sufficient" (Hull 1994, 313). So characterized, essentialism is not immediately refuted by the mere fact of evolution, but is it true?

...It simply is not true that there is some common genetic property which all members of a given species share, and which all members of other species lack.

\footnotetext{
${ }^{57}$ As an example of the latter, in their "Dictionary of Media and Communication," Chandler and Munday (2011) define Biological essentialism as: "The belief that 'human nature', an individual's personality, or some specific quality (such as intelligence, creativity, homosexuality, "masculinity," "femininity," or a male propensity for aggression) is an innate and natural 'essence' (rather than a product of circumstances, upbringing, and culture)."
} 
Okasha (2002) describes two broad understandings of essentialism which have been characterized as being Aristotelian. The first, mentioned by Mayr (1982), corresponds, more or less, with species realism; the second, articulated by Hull (1994), corresponds with something akin to character essentialism. As we have already noted, intraspecific races were not conceptualized in the species realist manner and they were not consistently understood in a character essentialist way.

What about other proposed forms of Aristotelian essentialism? Sober (1980), after criticizing the idea that Aristotle's essentialism was of the character type, characterizes the position as the view that "there exists some characteristic unique to and shared by all members of H. sapiens which explains why they are the way they are" and which is a "causal mechanism which works on each member of the species, making it the kind of thing that it is." Here, the essence is explanatory; it explains why the members belong to the groups which they are said to and why they have the characteristics which they have. In explaining the problem with this form of essentialism, Sober (1980) tells us that it involves a "Natural State Model," according to which groups have a natural tendency which, when not interfered with, regulates their form across generations:

In the biological world... [d]iversity was to be accounted for as the joint product of natural regularities governing how organisms reproduce themselves... The Natural State Model constitutes a powerful tool for accounting for variation. Even when two species seem to blend into each other continuously, it may still be the case that all members of one species have one natural tendency while members of the others species have a quite different natural tendency. Interfering forces, in varying degrees, deflect individual in both species from their natural states.

This interpretation is not too far off. As Lennox (2001) notes, Aristotle held that species had formal natures of a sort which, while allowing for degrees of intraspecific variation, prevented the transmutation of one species into another, thus allowing species to be permanent, at least so long as they reproduced. These formal natures did not exist independent of the species but represented the structural designs of the different groups, designs which were realized in one generation and then transmitted to the next. There is some debate as to the precise mechanism by which these structural designs were thought to remain stable across generations, but generally the idea was that substantive deviations from the species form were maladaptive relative to the species' way of life; thus, such deviations were eliminated across generations, allowing for a constant refreshing of the species form (Lennox, 2001; Henry, 2006).

This, of course, is quite similar to the 18th and 19th century species realist position, according to which, as discussed by Stamos (2012), there was a generational return to the species type, one which precluded transmutation. As we have said, though, races, in the intraspecific sense, were not understood this way. Rather, prior to the acceptance of evolutionary theory, they were seen as representing deviations from or degenerations of the species realist's species form. To explain why these constant varieties persisted and did not readily revert to the stem species form, early racialists had to devise theories of hereditary degeneration (e.g., Buffon) or deviation (e.g., Kant) (Doran, 2011). Importantly, the factors thought to induce intraspecific constancy were quite different from those thought to induce species constancy. Intraspecific race, then, was never conceived in an Aristotelian species essentialistic sense - at least in the manner formulated by most contemporary philosophers. 
But what about Aristotle's actual meaning or something close to that? As said, insofar as we are referring to Aristotle's species-like formal natures, the answer is "No." But what about other senses? There is continual debate as to whether Aristotle allowed for intraspecific essences (Henry, 2009; Gelber, 2010). He did recognize hereditary variants which run in family lines (Henry, 2006; Henry, 2009). The hereditary variants were a result of the particular movements of the reproductive fluids of the parents (Gelber, 2010). These movements of the reproductive fluids were what caused Socrates to have blue eyes and the grandson, but not daughter, of the white woman from Ellis and her Ethiopian spouse to have a dark complexion. ${ }^{58}$ Some argue that this implies that Aristotle recognized some sort of intraspecific essences; others disagree. Whatever the case, the possible essences in question are quite different from Aristotle's species ones and are not the type which have been rejected.

Now, we might go back and reformulate Aristotle's position. In his system, at least on the level of species, the same principle which explained why offspring had the same characteristics as their parents - why man begot man and horse begot horse - explained why lines of descent had the same form across generations. We might split his position into what we could call "classificatory nature essentialism" which purports to explain why the group form is "fixed" and "unchangeable" across generations and what we might call "explanatory nature essentialism" which explains why individuals belong to the group that they are said to and why they manifest the particular group typical characters which they do. It is clear that intraspecific races were not thought to have classificatory essences. We might ask, though, if $18^{\text {th }}$ and early $19^{\text {th }}$ century races were thought to have Aristotelian-like species explanatory natural essences. The answer would depend on what we meant. The answer would be "Yes" in the sense that individuals were said to belong to a particular race and to exhibit the phenotypic characteristics typical of that race on account of their genealogical line. But it would be "No" in the sense that very different types of factors were recruited to explain differences between lineages within species and differences between species. It was only after the Darwinian revolution that it was understood that horses begot horses essentially, so to speak, for the same reason that Ethiopians begot Ethiopians.

In sum, the position that historic concepts of race were essentialistic in an Aristotelian species or a species realist sense is difficult to defend. This conclusion stands in stark contrast with a common view, rehashed by Andreasen (1998), according to which in "the spirit of Aristotle, subspecies were first defined as types - as natural kinds defined in terms of an essential property possessed by all and only the members of the same subspecies." This all noted, a thin form of racial essentialism can nonetheless be constructed. Conceptualizing the most basic version of explanatory biological essentialism as a position which explains in terms of some property: ${ }^{59}$

(1) why some particular individuals belongs to a race and

(2) why the race exhibits the characters it does

We can state that the essence or to ti ên einai of a race is its relative location in multidimensional genetic space. Our natural divisions are located in a unique region of space on account of the

\footnotetext{
${ }^{58}$ These examples are given by Aristotle in reference to biological heredity.

${ }^{59}$ For a similar conception, see, for example, Walsh's (2006) defense of biological essentialism.
} 
unique gene pool of the sets of individuals which constitute them; since the membership of these classes, at least when discretely conceptualized, is defined in terms of relative genetic similarity, the same property which explains why individuals belong to a division also explains the specific characters of the population and explains why the individuals tend to exhibit these specific characters. In a sense, then, races do have a whatness - they have a what-makes-them-what-theyare-and-gives-then-the-phenotypic-form-which-they-have. Is this thin kind of "essentialism" a meaningful one? It depends on how one wishes to construct the meaning of "essentialism." As noted above, different people understand the term differently. That said, in the philosophy of biology, relational essentialism, which the above formulation is version of, has currency. Indeed, Okasha (2002) notes:

And in fact, on the most popular accounts of the species concept found in contemporary evolutionary biology, organisms are assigned to species on the basis of relational properties... These considerations suggest that instead of saying that Darwinism shows species not to have essential properties, we should really say that Darwinism shows the essential properties of species to be relational rather than intrinsic.

We can, then, reasonably say that races have essences - in a relational sense. We would go further and argue that this sense of essentialism captures one core part of the Aristotelian one. ${ }^{60}$

Some might wonder how we managed to defend the concept of race from the charge of indefensible essentialism. After all, the traditional concept of race was supposedly refuted. Both supporters and opponents seem to agree. For example, though they defend a revamped race concept, Shiao et al. (2012) tell us:

We argue that the recent research in genetics demonstrates that certain racial, and also ethnic, categories have a biological basis in statistically discernible clusters of alleles rather than in the traditional notions of human races as arising from categorically distinct ancestries or as possessing categorically unique essences (Marks 2006; Spickard 1992).

And Caspari (2009), who is hostile to race concepts, informs us that:

Both Linnaeus and Blumenbach were 18th century figures cited by Hrdlicka (1918a) for placing man within the natural history tradition ... The races defined by the western race concept were codified by Linnaeus and by the definitive 10th edition of Systemae Naturae (Linnaeus, 1758); he described five subspecies of humans listing both morphological and behavioral characteristics of each type that were considered a part of the essence of the category and were implicitly (and explicitly) understood to be part of the intrinsic biology of the race... The essence of the categories, believed to be stable and unchanging, was defined by science.

We, of course, agree with Shiao et al. (2012) and Caspari (2009) that notions of races which arose from "categorically distinct ancestries" or which possess "categorically unique essences"

\footnotetext{
${ }^{60}$ Some have argued that Aristotle adopted pluralistic realism with regards to natural kinds and that his natural kinds were simply biological groups whose shared phenotypic similarities were underwritten by a common cause (for example: Henry, 2011). Employing this natural kind concept, in the most stripped down fashion, we can say that our natural division races, as they have weak explanatory essences, constitute such kinds. Thus, while we agree with Justin Smith that biological races are not real natural kinds in the typical 17th to 19th century species realist sense, they can yet be said to be ones in a far older Aristotelian sense, as least as interpreted by e.g., Henry (2011).
} 
or which have traits that were "a part of the essence of the category" are indefensible. Yet, as said, indefensible also is the notion that historic concepts of race, in the intraspecific sense, entailed these positions. We already explained the problem with Shiao et al.'s (2012) criticism. Contra Caspari (2009), Linnaeus discussed the category of varieties, which, on account of a lack of species-like essence, was characterized by inconstancy; later race concepts attempted to make sense of "constant varieties," and, thus, indeed, described and explained constancy of form, but not in specific types of characters, such as behavioral ones, since the concepts applied across species, for example to Tulips. And while the racial characteristics were said to be stable and relatively unchanging, that is, constant, the divisions themselves, which diverged from a common stem and could fuse back together, were not.

How did this bizarre situation - in which historic race is revised and contemporary race is deconstructed on the account of not being faithful to the so-said historic concept - come to pass? Surely poor historiography. Possibly duplicity: the concept of race being retroactively revised into an implausible position - a historic straw race constructed - so to delegitimize contemporaneous formulations. There is something else, though. Essentialism of an implausible sort is clearly being projected onto race concepts. We surmise that the concept of race is seen to be implausibly "thick," because to see it as realistically thin would leave unexplained some of the thickish descriptions of some actual human races. If the race concept is not inherently thick, essentialist, and value-laded, in the manner often said, and if it is not true that the race concept entailed thick essentialism, then what possibly could explain the frequent and intergenerationally stable perception of certain races and of certain race differences? These perceptions must be informed and stabilized by something. If not pre-existing stereotypes and hard to refute essentialistic concepts, what - barring reality experienced? Sociologist Catherine Bliss has argued that race is a "belief system that produces consistencies in perception and practice at a particular social and historical moment" (Bliss, 2012). We imagine that many anthropologists adopt a similar view because they simply can not accept that it is reality which is conditioning the said perceptual stability. ${ }^{61}$

\footnotetext{
${ }^{61}$ Caspari (2009) is explicit about this: "It is a hallmark of essentialism that refutation of stereotypes and other assumptions does not easily dispel them; neither does logic. Hence, inconsistency often goes unrecognized when hypodescent is practiced in society, and also when racial assumptions are undermined by science."
} 
Recognizing races is only recognizing a biological fact. - Mayr (2002)

\section{The Races of Man}

\section{IV-A. A Very Brief Historical Review}

The natural scientific concept of race was developed as a conceptual tool to make sense of constant varsities of, for example, strawberries. ${ }^{62}$ By it, these oxymoronic varieties were understood as lineages of a species which had gradually acquired, over the course of generations, patterns of genealogically transmittable character differences. These differences allowed for a genealogy-based classification of organisms. With regards to humans, specifically, there had long been three strands of 'race-like' thinking, including: the cognizance of regional human phenotypic differences, the recognition of the inheritance of characters, and the genealogical understanding of nations and ethnic groups.

Firstly, regional morphological differences were recognized and used, at times, to classify populations. As noted by Sarich and Miele (2004), crude race-like classifications were depicted in Egyptian, Chinese, Islamic, and Greco-Roman art and literature. Egyptians, for example, divided humans into four color groups: Egyptian, Negro, White Libyan, and Asiatic (Middle Easterners). Chinese historians differentiated between barbarians of the Caucasoid and Mongoloid type. Islamic writers distinguished between black Sub-Saharan Africans and white North Africans. And in "Moretum," the Roman poet Virgil characterized the Sub-Saharan African phenotype (dark skin, tightly curled hair, puffy lips, broad shoulders) little different from how modern anthropologists have. Generally, regional phenotypic differences had long been noticed. Secondly, a number of classical Greco-Roman writers deduced that regional characters were biologically inherited. Thus, for example, Aristotle used the case of an Ethiopian's color to illustrate a principle related to biological inheritance. ${ }^{63}$ While differences, and the inheritance of them, were often attributed to the direct effects of the environment or to cultural practices,${ }^{64}$ not a few classical writers held epigenetic views, according to which environmental factors left imprints on genealogical lines (Isaac, 2006), ${ }^{65}$ or held other views according to which character differences, once acquired by a people, were biologically passed on. Thirdly, nations of people were often understood genealogically. For example, in the Christian literature, national peoples

\footnotetext{
${ }^{62}$ Refer to Duchesne's (1766) Histoire naturelle des fraisiers.

${ }^{63}$ See the relevant discussion in Henry (2006).

${ }^{64}$ Müller-Wille (2007) notes: "In this premodern perspective - which prevailed, as we will see, well into the seventeenth century - specific and individual similarities between ancestors and descendants result from similarities in particular constellations of climatic, economic, political, and social factors... The phenomenon of heredity - that "like begets like" was thus as trivial as it was precarious: it was trivial insofar as it was stabilized and reinforced by municipal rules; it was precarious insofar as it always remained open to transgressions against such rules." However, others such as Isaac (2006) suggest that epigenetic/Lamarckian views, ones which involve biological inheritance, were not uncommon.

${ }^{65}$ Isaac (2006) notes: "In summary, the heredity of acquired characters is a concept generally accepted in Greece and Rome and explicitly formulated by several authors. It is found in several Hippocratic treatises, Aristotle, Strabo, Pliny, and others and implicitly in many more authors."
} 
were categorized genealogically in terms of descendants of Noah's sons, who were referred to as the races of Shem, Ham, and Japheth.

During the Age of Discovery, when exploring distant lands, Europeans encountered various peoples who exhibited conspicuous phenotypic differences. The dogma at the time was that all of these many peoples along with Europeans descended from the biblical Adam and Eve several thousand years prior. Some prominent thinkers conjectured that these different peoples represented different human species, where species were understood to be distinct creations. This position was condemned by the spiritual authorities as heretical, but, it did not disappear, as it had a face plausibility. First according to the reigning paradigm, inconstancy of form evidenced differences between varieties while constancy evidenced differences between species; and differences between human groups were recognized as being more or less intergenerationally constant. Second, the origins of life on earth was often understood from a young earth creationist perspective, according to which species were relatively recently created. From this perspective, it was more plausible that human groups were separately created in different locations around the world than that they spread, from one common source, across the globe and then somehow acquired their many conspicuous differences.

Some opponents of this polygenist view (e.g., Buffon, Kant, and Blumenbach) counter-argued that these different peoples, instead, represented different lineages of the same species which developed or acquired differences that became more or less rooted in their lineage: race. They employed the race concept, which was created to explain "constant varieties," to defend the position that human groups were of the same species. As these early race thinkers were species realists, they saw their races as intraspecific lineages which had acquired or developed, over time, degenerations or deviations from a primitive species type; these deviations were conceptualized as either being adaptive (Kant) or as being a sort of pathology which had become second nature (Buffon and Blumenbach) (Doron, 2011).

Was this concept new and invented? The prerequisite ideas had been thought of prior and could be found in the common literature. But before the mid to late 1700s, no concept which unified them occupied a space in natural history. Thus to the extent that something like race (e.g., breed in context to animal husbandry) was thought, it was not so as a modern scientific idea, one which purported to describe an aspect of the natural world. Moreover, prior to the introduction and later popularization of this concept in the field of natural history, intraspecific variation was understood in non-genealogical terms and was primarily attributed to the direct effects of the environment.

This concept still had to evolve some before it became akin to what we now think of. This was only possible after Darwin inaugurated an intellectual revolution which led to a re-understanding of the nature of species, which intraspecific races, were, in part, conceptualized in contrast to. Following this paradigm shift, individual species were no longer understood as being Creatormade entities; rather they were seen as the product of descent with modification from a common stock. In turn, races, or constant varieties, were understood as being the lineages that could evolve into species ones. These constant varieties were no longer the degenerations of and deviations from an essential species type; rather they were modifications of one species potentially on the way to becoming another. Both species and races were, then, understood as 
being a part of the same network of filiation. With the discovery of DNA, the molecular form of genes, genealogy was re-understood genomically. Races and species have begun to be understood likewise.

\section{IV-B. Human Biological Races and Scientific Consensus}

Unquestionably, there are human biological races given the concept which we have laid out. This statement might seem surprising to those who have come to believe in some sort of scientific consensus regarding the nonexistence of human races. That there is such a concord has been persistently claimed. For example, physical anthropologist Robert Wald Sussman recently asserted that " $[\mathrm{t}]$ oday, the vast majority of those involved in research on human variation would agree that biological races do not exist among human" (Sussman, 2014). Since our understanding of race might not correspond with that of others, the claim that human races undoubtedly exist need not stand logically at odds with claims such as Sussman's. However, if Sussman is correct, one might reasonably wonder if our concept, by which there surely are human races, grasps at a biological concept which actually has currency. It is, then, worth investigating the matter.

The issue of scientific opinion on "race" is complicated since people who use the term often reference different, albeit overlapping, concepts. When researchers are surveyed, they are typically not asked whether human races in this or that biologically plausible sense exit but whether human races do as the researcher understands them. Regarding this method, Lieberman, Kirk, and Littlefield (2003b) noted, "After centuries of study and discourse there is no consensual agreement on what is meant by race, therefore the participants should be asked about what they mean by 'race,' and whether they believe their definition is valid and useful in research." While we feel that researchers should be queried about specific concepts, Lieberman's approach has routinely been taken. As such, most currently published survey-based studies can not directly answer the questions of interest. Specifically, they can not confirm that researchers both agree that there are necessarily human races by our concept and agree that this concept can reasonably be and is often referred to as "race." These survey results could only indicate that our concept is not accepted by nearly all relevant researchers, as would be the case if Sussman (2014) was correct.

Regarding expert views, Lieberman et al. (2003b) reviewed studies from six regions (Englishspeaking nations, Spanish language areas, Poland, Europe, Russia, and China). The authors concluded that the rejection of the concept (as understood by the experts in question) "varies from high to low with highest rejection of race occurring amongst physical anthropologists in the United States, other English speaking nations (mostly Canada), and Poland; moderate rejection of race in Europe; and sizeable, though quite low, rejection of race evidenced in Poland and Cuba." After conducting a review of articles published in the People's Republic of China's leading journal of anthropology, Acta Anthropologica Sinica, Wang, Strkalj, and Sun (2003) concluded that race-like concepts were "alive and well" in Chinese anthropology. Kaszycka, Štrkalj, and Strzałko (2009) found that a majority of European anthropologists agreed that there were races either in the sense of taxa subspecies or in some other sense. The authors found that anthropologists from Eastern bloc countries were more likely than those from Western bloc ones to view human biodiversity in racial terms. After reviewing the research, Strkalj (2007) concluded: 
Research shows that there is as yet no consensus on the status of the concept among biological anthropologists. It also suggests that the reasons (which we are only beginning to understand more fully) for differences in biological anthropologists' attitudes towards race are to be sought in a variety of scientific, social and professional factors as well as "the vagaries of chance."

Generally, the results do not seem to support Sussman's (2014) claim except as understood as the parochial perspective of an American physical anthropologist. To get a better sense of the matter, we scrutinized the responses reported in all available studies. A summary of the results is shown in Table 4.1 below.

Table 4.1. Survey results concerning the existence of human biological races

\begin{tabular}{|c|c|c|c|c|c|c|c|c|}
\hline Author & $\underline{\text { Year }}$ & & & Question & $\underline{N}$ & \% Yes & $\%$ No & \% Undecided \\
\hline Anthropologists & & & & & & & & \\
\hline $\begin{array}{l}\text { Lieberman et al. } \\
\text { (1992) }\end{array}$ & $\begin{array}{l}1983- \\
1984\end{array}$ & Physical & US & $\begin{array}{l}\text { "There are biological } \\
\text { races in the species } \\
\text { Homo sapiens" }\end{array}$ & 147 & 50 & 43 & 7 \\
\hline $\begin{array}{l}\text { Lieberman, Kirk, } \\
\text { and Corcoran }\end{array}$ & 1985 & Physical & AAA [1] & "" & 101 & 50 & 41 & 10 \\
\hline & 1985 & Cultural & AAA [1] & "" & 421 & 30 & 53 & 17 \\
\hline & 1999 & Physical & AAA [1] & "" & 267 & 24 & 69 & 7 \\
\hline & 1999 & Cultural & AAA [1] & "" & 190 & 14 & 80 & 6 \\
\hline Fuertes (2000) & 1999 & Biological & Inter. [2] & $\begin{array}{l}\text { "Are there biological } \\
\text { races among } \\
\text { human beings?" }\end{array}$ & 105 & 31 & 66 & 3 \\
\hline $\begin{array}{l}\text { Kaszycka and } \\
\text { Strzałko (2003) }\end{array}$ & 2001 & Physical & Polish & $\begin{array}{l}\text { "Are there subspecies } \\
\text { or human races" }\end{array}$ & 100 & 75 & 25 & 0 \\
\hline Subsample [4]: & 1999 & Physical & Polish & $\begin{array}{l}\text { "Are there human } \\
\text { subspecies?" }\end{array}$ & 55 & 31 & 62 & 7 \\
\hline $\begin{array}{l}\text { Kaszycka et al. } \\
(2009)\end{array}$ & 2002 & $\begin{array}{l}\text { Physical/ } \\
\text { Cultural }\end{array}$ & EAA [3] & "" & 125 & 50 & 48 & 2 \\
\hline $\begin{array}{l}\text { Morning (2011) } \\
\text { Anatomists }\end{array}$ & $2001 / 2$ & Unspecified & US & "Race is biological" & 19 & 32 & 68 & 0 \\
\hline $\begin{array}{l}\text { Strkalj et al. } \\
(2008)\end{array}$ & 2003 & Anatomy & & $\begin{array}{l}\text { "There are biological } \\
\text { races within the } \\
\text { species Homo sapiens" }\end{array}$ & 56 & 52 & 30 & 18 \\
\hline Biologists & & & & & & & & \\
\hline $\begin{array}{l}\text { Lieberman et al. } \\
\text { (1992) }\end{array}$ & $\begin{array}{l}1983- \\
1984\end{array}$ & $\begin{array}{l}\text { Animal } \\
\text { Behavior }\end{array}$ & US & "" & 147 & 73 & 15 & 12 \\
\hline Morning (2011) & $2001 / 2$ & Biology & US & "Race is biological" & 22 & 45 & 55 & 0 \\
\hline $\begin{array}{l}\text { N-Weighted } \\
\text { [1] American Anth } \\
\text { [4] Subsample of }\end{array}$ & $\begin{array}{l}\text { Assoc.; } \\
\text { szycka a }\end{array}$ & $\begin{array}{l}\text {; [2] Inter. Su } \\
\text { and Strzałko ( }\end{array}$ & $\begin{array}{l}\text { Irvey; [3] E } \\
\text { (2003) not }\end{array}$ & $\begin{array}{l}\text { European Anthro. Assoc.; } \\
\text { included in average }\end{array}$ & 1700 & 39 & 52 & 9 \\
\hline
\end{tabular}


Based on the results, we can infer that the "vast majority" of anthropologists and biologists do not reject the existence of human biological "races" (in some sense). As said, this only tells us so much. But what accounts for the substantial rejection of this polyseme? After all, far fewer people accept the existence of human races than we would predict given our concept, one which we claim is a very general one. The following seem to be the main reasons:

(1) There is simply a disavowal of the term "race." As Lieberman et al. (2003b) noted, the "American practice of using ethnic groups was advocated by Huxley and Haddon Montagu, and Lieberman and Reynolds, in order to refer to biological divisions without the baggage of the race concept." The authors suggested that this practice was taken up. If so, this accords with the eminent biologist Ernst Mayr's statement that there "is a widespread feeling that the word 'race' indicates something undesirable and that it should be left out of all discussions" (Mayr, 2002).

(2) Race is conceptualized by some in a biologically unrealistic way. Lieberman, Kirk, and Littlefield (2003a) provide some information on how AAA members understand race and why many reject the concept as they understand it. This is summarized in Table 4.2.

\section{Table 4.2. Survey results concerning reasons for the rejection of biological race}

Of those who agree with the following criticisms of the race concept, what $\%$ agree/disagree that there are human biological races?

\begin{tabular}{|c|c|c|c|}
\hline & Agree & Neutral & Disagree \\
\hline & $\%$ & $\%$ & $\%$ \\
\hline $\begin{array}{l}\text { 1. Human biological variation is best understood in terms of continuous } \\
\text { gradations (clines) not races. }\end{array}$ & 13 & 8 & 79 \\
\hline $\begin{array}{l}\text { 2. Pure races, in the sense of genetically homogeneous populations, do not } \\
\text { exist in the human species today, nor is there evidence that they ever existed } \\
\text { in the past. }\end{array}$ & 15 & 7 & 78 \\
\hline $\begin{array}{l}\text { 3. There is more variation within traditional conceived biological races than } \\
\text { among them. }\end{array}$ & 13 & 7 & 80 \\
\hline 4. Gene flow between populations invalidates them as distinct races. & 6 & 6 & 88 \\
\hline
\end{tabular}

The table lists four criticisms of the position that there are human races. It also lists the percent of people who agreed with these positions and who agreed/were neutral/or disagreed that there were human races. The data suggest that human races were rejected on account of the mentioned criticisms. If so, many AAA members feel that biological race (1) precludes population continua, $(2,3)$ requires high levels of genetic homogeneity, and (4) is at odds with gene flow. Obviously, this notion of race is rather unlike the concept which we have been discussing. Many of these anthropologists seem to not even be considering a biologically realistic or historically grounded concept. To be clear, we agree that such human AAA races do not exist. Such races, though, are caricatures; they do not correspond with races as generally understood by actual employers and proponents of biological race concepts.

(3) When not understood in an unrealistic way, the race concept is conceptualized in an overly restricted fashion. For example Sussman (2014) parrots Templeton's (1998) argument against human taxa subspecies. Both authors conflate races and formally recognized races. As discussed 
later on, one can reasonably maintain that no human races deserve formal recognition and trinomia. To conclude from this that there are no human races is to make an ignoratio elenchi.

(4) Also, there seems to be a mental refusal by some to think in terms of human genetic divisions. Antagonists of race thinking are not difficult to locate. For example, Kaszycka et al. (2009), cited above, conclude: "Hence, the struggle against the concept of 'race' - in all of its connotations is bound still to be long and arduous. Nonetheless, it is one eminently worthwhile to continue to undertake." We presume that researchers who are dedicated to the "struggle against the concept of race - in all its connotations" will not approach the matter with a perfectly open mind.

(5) Finally, as noted by Wang et al. (2003), Štrkalj (2007), and Kaszycka et al. (2009), politics is a major factor in the rejection or acceptance of the biological race concept. The authors mentioned generally interpret the acceptance of the concept as being motivated by political concerns - e.g., reinforcing the idea of the nation - and see the rejection of it as the natural state of affairs. The argument, though, runs both ways and one's evaluation ultimately hinges on one's interpretation of the biological utility and validity of the concept. Contrary to the above authors, we would interpret the rejection of the concept as playing an important social and political function - e.g., facilitating the multicultural and post-national projects.

The reasons suggested above likely account in full for the rejection of "race." Overall, the results of the surveys cited above do not tell us much about which race concepts are being rejected and which are being accepted. Importantly, they do not tell us to what degree the concept elaborated here would be accepted as one that reasonably could (and should) be called "race."

\section{IV-C. Racial Classifications and Biological Race Concepts}

Here we define a racial classification (RC) as a race-based classification that is commonly employed by some people somewhere. We emphasize that a RC is not a racial concept. A RC represents a specific grouping created in line with a specific racial concept; a race concept represents a conception about what makes races what they are. We see two important reasons for making this classification versus concept distinction: (a) a given RC might identify divisions that fail to meet the basic criteria for what-it-is-to-be-a-race as stipulated by a given race concept; (b) a given racial concept may lend itself to multiple correct non-identical RCs. As an example of (a), a RC which included as one division "North Hemispherians" and as another "South Hemispherians" would misidentify divisions with respect to the natural division concept discussed above. As an example of (b), we recall Aulchenko (2010): "In human genetics literature you may find references to a particular genetically isolated population, population of some country (e.g., "German population," "population of the United Kingdom"), European, Caucasoid or even general human population." A race concept can lend itself to many nested race classifications similar to how the concept of "statistical populations" can.

That clarified, it goes without saying that some RCs misidentify groups with respect to the biological race concept which we are discussing. In the US, for example, the federal government, as of 2012, recognizes the following racial groups: "Whites," "Blacks," "Asians," "American Indians," and "Multiracials." As for "Asians," the US department of Labor, states: "The definition used for "Asian or Pacific Islander" in Directive No. 15 refers to a person having 
origins in any of the original peoples of the Far East, Southeast Asia, the Indian subcontinent, and the Pacific Islands." There is no "Asian" evolutionary natural division that we are aware of which includes both South Asians and North East Asians and yet excludes West Eurasians. This $\mathrm{RC}$ is incongruent with the natural division concept. As such, the "Asian" class is biologically meaningless in the narrow sense.

\section{IV-D. Traditional Race Classification}

We could discuss any RC but we will focus on the one frequently discussed - the traditional RC which describes the traditional race of man. This classification has been characterized varyingly as "the traditional races" (Keita and Kittles, 1997), the "the classic" races (Risch, Burchard, Ziv, and Tang, 2002), "the continental races" (Wade, 2014), "folk races" (Kaplan, 2010), and "the Blumenbach partition" (Spencer, 2012). We will call the classification, per se, the "traditional RC" (TRC) and the groups classified the "Traditional Human Races" (THRs). The primary races based on this classification include Negroids (Sub-Saharan Africans), Caucasoids (West Eurasians), and Mongoloids (East Eurasians). Other groups, such as Amerindians (Native Americans) and Australoids (Indigenous Australians, Papua New Guineans, and Melanesians), are often also recognized. Described are the major continental-level human populations, which have existed from roughly $10 \mathrm{kya}$ (depending on which groups are being discussed) to modern times. (Obviously, one could refer to a different time and derive different continental races, e.g., modern humans versus archaic humans, but, if so, one would no longer be dealing with the TRC and the THRs.)

\section{Figure 4.1. Traditional races of man}

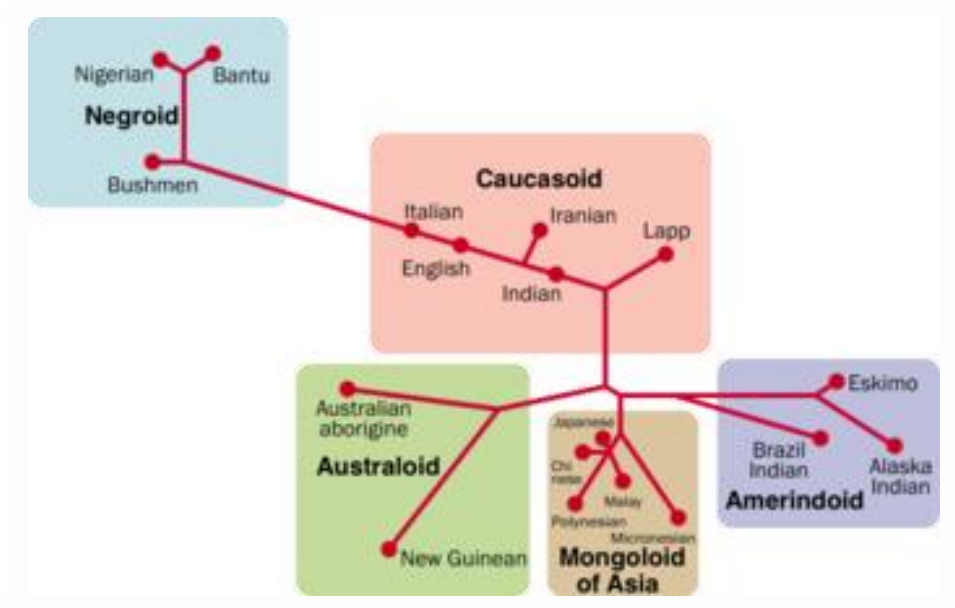

(Modified from: 遺伝的近縁図 http://ja.wikipedia.org/wiki/\%E4\%BA\%BA\%E7\%A8\%AE)

One might compare the validity of the TRC to that of traditional continental classifications. Currently, the number of continents is said to range from 5 to 7 , depending on how one divides up the land masses. At a different time, the range would have been different. And the delineated continents represent neither a "true" characterization of the Earth's geographic diversity, nor a metaphysically "privileged" level of analysis. As such, a Martian geographer might very well make no distinction between large and small land masses (continents and small islands). 
The origin of this classification scheme can be traced to the works of Bernier (1688), Linnaeus (1735), and Blumenbach (1775). These classifications were not necessarily conceived of as being racial, as such - for example, Bernier described "species or races," seemingly equating races with species and Linnaeus described Linnaean varieties, a kind of division which lacked a necessary genealogical dimension. ${ }^{66}$ Regardless of how groups were conceptualized - as varieties, races, or species - the ones picked out were understood to represent the major geographical divisions of human biological variation. For our present purposes, this is all that matters, since the concern here is with the cross-temporal recognizably of the groups in question.

In his essay, "A New Division of the Earth," Bernier (1688) attempted to create "a new division of the earth, according to the different species or races of men who inhabit it." He derived "four or five species or races of man." The first included Europeans, North Africans, Middle Easterners, and most South Asians. Interestingly, in the four "species or race" model, he also added Americans to this first group, noting, "As far as the Americans are concerned, they are really mostly olive-skinned and their faces have a rather different shape from ours. Nevertheless I do not consider that that difference is so large as to warrant making them a special type distinct from our own." Bernier's second division was comprised of Sub-Saharan Africans. The third included South and North East Asians along with many Central Asians. The fourth was comprised of Lapps. In the five division model, the fifth was comprised of Americans. The divisions were made on the basis of differences in morphological traits (not limited to color) that were, in part, presumed to have a congenital basis. ${ }^{67}$ In the tenth edition of his "Systems Naturae (1735)," Carl Linnaeus divided up H. sapiens into four major geographic varieties: "Europæus albus" (Europeans), "Americanus rubescens" (Native Americans), "Asiaticus fuscus" (East Asians), and "Africanus niger" (Sub-Saharan Africans). These divisions were based on phenotypic differences which were presumed to be of environmental origin. After referencing these two just-mentioned authors and others, in the third (1795) edition of his treaties, "The Natural Varieties of Mankind," Johann Blumenbach proposed five major varieties: Caucasians (including Europeans minus Lapps, North Africans, Middle Easterners, and South Asians as far as the Obi river, Caspian Sea, and Ganges), Mongolians (including East Asians and Lapps, etc.), Ethiopians (including all Sub-Saharan Africans), Americans, and Malaysians (including Pacific Islanders, Indonesians, Malaysians, and Filipinos).

As can be seen in retrospect, these early divisions cut out ones which happened to roughly match with major natural divisions. Now, it is not being argued that there was perfect consistency between early classifications. Regarding this point, readers are encouraged to read Blumenbach's summary of various other proposals. And it is not being argued that any of the early classifications just mentioned stand in perfect accords with the natural division race concept. None perfectly do. It is maintained that these early classifications did not completely misidentify populations with respect to the race concept being propounded here. Moreover, it is claimed that these early classifications form the basis of the TRC and that there is reasonable consistency

\footnotetext{
${ }^{66}$ Bernier calls his human, or rather global, divisions "species or races" but does not specify concepts for these terms.

${ }^{67}$ For example, when talking about the beauty of the women of different peoples, he says that it "arises not only from the water, the diet, the soil, and the air, but also the seed which must be peculiar to certain races and species."
} 
between these and more recent continental-level classifications such to allow one to speak of the TRC. The following is a sampling of more recent continental-level RCs, that is, of more recent versions of the TRC:

Nei and Roychoudhury (1974) have shown that the differences among negroids, caucasoids, and mongoloids in the protein and blood group loci are slight compared with those between individuals within any one of them. There is disagreement on the number of major races that should be recognized. At a minimum, the Australoids are added to the three referred to above. (Wright, 1978)

In this paper, we have attempted to identify the major groups of human populations and to infer their evolutionary relationships. The major groups identified here are more similar to those recognized by classical anthropologists than to those by Cavalli-Sforza et al. (1988). That is, human populations can be subdivided into five major groups: (A) negroid (Africans), (B) caucasoid (Europeans and their related populations), (C) mongoloid (East Asians and Pacific Islanders), (D) Amerindian (including Eskimos), and (E) australoid (Australians and Papuans). (There are intermediate populations, which are apparently products of gene admixture of these major groups, but they are ignored here.) However, the evolutionary relationships of these major groups are hierarchical rather than parallel, and some groups apparently originated from a population belonging to some other groups (e.g., australoid). (Nei and Roychoudhury, 1993)

So, among the six geographic races of the world described by Campbell (1992), Gill and Rhine (1990), and other - black (Negroid), white (Caucasoid), East Asian (Mongoloid), Melanesian/ Australian (Australoid), American Indian and Polynesian - four are well described metrically and anthroposcopically, while two (Polynesians and Australoid) are not. (Gill, 1998)

Effectively, these population genetic studies have recapitulated the classic definition of races based on continental ancestry - namely African, Caucasian (Europe and Middle East), Asian, Pacific Islander (for example, Australian, New Guinean, and Melanesian), and Native American. (Risch et al., 2002)

Indeed, a 2002 study by scientists at the University of Southern California and Stanford showed that if a sample of people from around the world are sorted by computer into five groups on the basis of genetic similarity, the groups that emerge are native to Europe, East Asia, Africa, America and Australasia - more or less the major races of traditional anthropology. (Leori, 2005)

The argument made here is that since there is a rough continuity between some of the early classification schemes and some of the more recent ones, it is meaningful to speak of the "traditional RC" as if it described a somewhat cross-temporally coherent classification, one which has been and is still subject to alteration but not to fundamental revision. But is this not obvious? Well, whether or not it is, some claim that there has only been classificatory confusion with respect to the TRC. Barbujani and Colonna (2010), for example, claimed: "On the contrary, no two racial catalogs proposed are entirely consistent." The authors purport to show this by listing thirteen classifications, two of which are sociological and another five of which describe local, not continent-level, divisions.

Table 4.3 shows, in bold, the major divisions described in Barbujani and Colonna's (2010) referenced sources. A number of other influential classifications are shown. We notice, firstly, that all of the classifications include some version of the big three: Caucasoid, Negroid, and Mongoloid - groupings which do not simply reflect continental ancestry. That is, these delineations are not drawn geographically, rather they are drawn biologically. As such, in no 
instance are North Africans grouped into a "pan-African race" along with Sub-Saharan Africans, and in no instance are South Asians grouped into a "pan-Asian" race along with East Asians.

\section{Table 4.3. Major racial classifications}

\begin{tabular}{|c|c|c|c|c|c|c|c|}
\hline Author & Criteria & Caucasoid & Negroid & Mongoloid & Amerindian & Australoid & Other \\
\hline Bernier (1688) [1] & Morph. & First species & Second species & Third species & $\begin{array}{l}\text { (First species } \\
\text { or fifth species) }\end{array}$ & & $\begin{array}{l}\text { Fourth } \\
\text { species }\end{array}$ \\
\hline Linnaeus (1735) [2] & Morph. & Europaeus & Afer & Asiaticus & Americanus & & \\
\hline Buffon (1749) [3] & $\begin{array}{l}\text { Morph. } \\
\text { \& Culture }\end{array}$ & $e^{\text {European }}$ & Negro & $\begin{array}{c}\text { East Asian Other S. E. Asian } \\
\text { with Polynesian }\end{array}$ & American & & Lapp \\
\hline Kant (1775) [4] & Morph. & Hindustan & $\begin{array}{l}\text { Negro } \\
\& \text { Negrito, NG }\end{array}$ & Mongol & $\begin{array}{l}\text { (American, as a } \\
\text { Mongol sub-race) }\end{array}$ & & \\
\hline Blumenbach (1795) [5] & Morph. & Caucasian & Ethiopian & Mongolian Malay & American & & \\
\hline Cuvier (1828) [6] & Morph. & Caucasoid & Negroid & Mongoloid & & & \\
\hline Huxley (1870) [7] & Morph. & Xanthrachroid & $\begin{array}{l}\text { Negroid } \\
\text { \& S.E.A Negrito) }\end{array}$ & Mongoloid & & Australoid & \\
\hline Coon and Garn (1955) & Morph. & Caucasial Indian & S.S. African & East Asian Polynes. & American & Mico-Melane & lesian \\
\hline Coon (1962) [8] & Morph. & Caucasoid & Congoid Capoid $* *$ & Mongoloid & & Australoid & \\
\hline Garn (1965) [9] & Morph. & European Indian & African Khoisanid & Asiatic Polynes. Melanes. & Native American & Australian & \\
\hline Baker (1974) & Morph. & Europid & Negrid & Mongolid & Indianid & Australasid & \\
\hline Wright (1978): & Genes & Caucasoid & Negroid & Mongoloid & & Australoid & \\
\hline $\begin{array}{l}\text { Nei and } \\
\text { Roychoudhury (1993) }\end{array}$ & Genes & Caucasoid & Negroid & $\begin{array}{l}\text { East Asian } \\
\text { \& Pacific Islander }\end{array}$ & Amerindian & $\begin{array}{l}\text { Australian } \\
\text { \& Papuan }\end{array}$ & \\
\hline Gill (1998) & Morph. & Caucasoid & Negroid & Mongoloid Polynes. & American & Australoid & \\
\hline Risch et al. (2002) [10] & Genes & Caucasian & African & Asian & American & Pacific Islander & \\
\hline Leori $(2005)$ & Genes & Europe & Africa & East Asia & America & Australasia & \\
\hline Rosenberg et al. (2011) & Genes & $\begin{array}{l}\text { Europe } \\
\text { \& West Asia }\end{array}$ & S.S. Africa & East Asia & Americas & Oceania & \\
\hline
\end{tabular}

[1] These groups were ambiguously described as "species or races."

[2] These were Linnaeus' four geographic varieties of "Homo sapiens."

[3] Buffon's major geographic races were: European, American ("Thus, the whole continent of America contains but one race of men"), East Asian (our term) (Chinese, Japanese, south Asians - e.g., "inhabitants of the kingdoms of Pegu and Aracan differ not from those of China and Siam"), Malay (Austronesians: "The people of Malacca, Sumatra, and the small adjacent islands"), Negros (S.S. Africans excluding Ethiopians), and Tartars/Lapp (all extreme northern peoples e.g., Danes and Siberians).

[4] Kant considered American Indians to be a race derived from Mongoloids; he felt that they were not differentiated enough to be classed as a base race - Amerindians, we are told, "appear to be a Hunnish race that is not fully acclimated." Kant's base races were: White (West Eurasians excluding South Asians), Negro (S.S. Africans and Negritos), Hunnish or Mongolish (East Asian), Hindustani (South Asian).

[5] In his third edition, Blumenbach includes Lapps with Mongolians. The Malay race included: "Pacific Archipelago ... the New Zealanders ... The other who inhabit New Caledonia, Tanna, and the New Hebrides ..." [6] These are Cuvier's (1828) primary races as noted in Barbujani and Colonna (2010).

[7] Huxley's four great types were: Australoid (Australian Aborigines), Negroid (S.S. Africans, Bushmen, and Negritos), Xanthrachroid (fair Europeans), Mongoloid (Laplanders to Siamese along with non-Negrito S.E. Asians). He criticized the classification of "Caucasian" on the grounds that it lumped his Xanthrachroid with his Melanchroid. Melanchroid - or "dark whites" - were thought to be Xanthrachroid- Australoid hybrids.

[8] Coon's Capoids are Khoe-San/Bushmen.

[9] Garn's 1965 races were: European (West Eurasians, minus South Asians), Indian (South Asians), African (S.S. Africans), Australian (Australians), Asiatic (East Asians), Micronesian, and Polynesian.

[10] The pacific Islanders of Risch et al. (2002) included "for example, Australian, New Guinean, and Melanesian." 
Secondly, the areas of disagreement are generally sensible in light of the current morphological and genetic data. For example, at times, South Asians were treated as a major biological division separate from other West Eurasians; and it so happens that this is the first major West Eurasian group to separate out at a finer grain of genetic analysis. Likewise, there has been continual disagreement as to the status of Pacific Islanders (these various peoples being classified as a major race separate from the big three, grouped with Mongoloids or at times Australoids, or treated as several major races, etc.); part of the disagreement reflects terminology, much of it reflects discordance between genetic and morphological (e.g., craniometrical) differentiation, and much of it reflects actual biological ambiguity produced by a combination of continual East Asian gene flow into the region and reduced gene flow between subregions.

Other areas of disagreement are likewise biologically sensible. For example, Ethiopians were considered sometimes Caucasoid and sometimes Negroid - and they happen to be rather admixed. The point here is that much of the classificatory confusion parallels actual population complexity. If so, Barbujani and Colonna's argument is valid: classifications are confused when populations are not well separated or when they are admixed. Yet the classifications show a striking degree of coherence. Barbujani and Colonna's (2010) modus tollens, then, seems to be our modus ponens.

Regarding these classifications, molecular evidence requires a modification of them, but no fundamental revision. Based on this genetic evidence, we infer the following THRs: Negroids (Sub-Saharan Africans), Caucasoids (West Eurasians), Mongoloids (East Asians), Australoids (Oceanians), and Amerindians (Native Americans). This is not to say that these are the only races of man; rather, these are - or, at a certain time, were - major races. One can always lump or split groups; nonetheless, one can infer, from the clustering of genes across geography, that these groups represent major human natural divisions. As noted by Rosenberg (2011):

We also found that in an unsupervised cluster analysis, individuals grouped into geographical clusters largely corresponding to sub-Saharan Africa, Europe and the part of Asia west of the Himalayas, the part of Asia east of the Himalayas, Oceania, and the Americas. These observations are compatible with serial sampling, assuming that major geographic barriers such as oceans, the Sahara desert, and the Himalayas were not frequently crossed during human migrations.

Likewise, McEvoy et al. (2011) note:

The matrix of pairwise interpopulation genetic distances (FST values) was used to construct a neighbor-joining (NJ) phylogenetic tree that summarizes the relationship of the 52 populations to each other (Figure 1A). The tree divides the populations into five broad groups: African, East Asian, West Eurasian (European, Middle Eastern, and Central and South Asian populations), American, and Oceanic. This continental division of the human species reflects the result of different historic migratory paths that humans took during the last 100 thousand years (see, for example, Prugnolle et al. (2005).

Now, regarding the genetic evidence, we are not here suggesting that cluster analysis always and at every time identifies, at $\mathrm{K}=5$, the continental races mentioned above. We presume, though, that cluster analysis would identify these divisions if the maximum amount of genetic information possible (whole genomes) was used. If not, we would have to modify our rendition of the TRC. 


\section{IV-E. THRs and Biologically Objective Races}

It has been argued that the THRs represent divisions imposed on human genetic variation and that they have no genetically objective basis. For example, Marks (1994) states: "The racial categories with which we have become so familiar with are the result of our imposing arbitrary cultural boundaries in order to partition gradual biological variation."

When carving out natural divisions from multidimensional genetic space, one necessarily needs to select a time period (e.g., 200,000 years ago) and a degree of genetic relatedness. As discussed in section II-F, strictly speaking, these two boundary dimensions can not be objectively defined. If one is dealing with a perfect genetic/population continuum, then regions of genetic space can also not be biologically objectively defined. In that circumstance, one would have to "arbitrarily" pick out non-overlapping regions just as is done when defining electromagnetic regions (e.g., "visible light," "ultraviolet," and "X-rays"). For humans, to the extent that there are such perfect genetic/population continuums, racial delineations are, in a sense, biologically arbitrary, which is not to say artificial. We do not see arbitrariness in this sense as fundamentally problematic, because as Darwin noted (see: e.g., Darwin (1962) p. 262), when looked at across both time and space all natural divisions are so. That is, were one to take into account all life forms, living and extinct, one would find a genetic continuum. There is a deep sense, then, in which natural divisions are intrinsically non-objective - they are not like the species realist's Creator-made divisions; they exist in a continuum and appear only when the full range of biological diversity, past and present, is hidden from view.

Regardless, it so happens that, on the inter-continental level, there is no human genetic continuum. As a result, one can not carve out pan-African, North Eurasian, and South Eurasian natural divisions. One can not strictly geographically define races. And one can use unsupervised genetic cluster analysis to biologically objectively define continental races (given some time period and grain of focus).

Moreover, while one can not predetermine, based on genetic data, a grain of focus - that is, a degree of genetic relatedness to focus on - to some extent one can use genetic data to make a case that certain grains are preferable to others. As discussed by Rosenberg et al. (2005), for example, certain grains of focus exhibit higher levels of clusteredness; as discussed by Herráez et al. (2009), certain grains exhibit less cluster discordance; as discussed by Witherspoon et al. (2007), certain grains exhibit a lower dissimilarity fraction. Since opponents of biological race often argue that "race fails" because human natural divisions do not cluster enough or because differences between divisions are not different enough, one might - though we do not - take the degree of clusteredness and the dissimilarity fraction as an index of race idealness. Since the grain of focus on which the TRC exists objectively shows higher clusteredness, higher cluster concordance, and a lower dissimilarity fraction than many other grains of focus there are empirical reasons to prefer, relative to many other possible classifications, the TRC: less discordance of character, more clusterability, and a lower dissimilarity fraction.

On the basis of genetic data alone, then, the THRs of the TRC can be biologically objectively picked out to a large extent. Given the genetic data and some idealized sense of race, the TRC can also be preferred over many other natural division based RCs. There are, then, empirical 
reasons to privilege this classification scheme. As such, it is not true that there is no objective basis for picking out the TRC. And it is not true that the "racial categories with which we have become so familiar with are the result of our imposing arbitrary cultural boundaries in order to partition gradual biological variation." In any case, as discussed, we do not see a conflict between gradual biological variation and natural biological divisions. So, even if it were true that we were dealing with a continuum, as is often the case on the intra-continental level, it would be of no matter (to us).

\title{
IV-F. THRs and Migration, Intermixing, and Ancient Admixture
}

It has been argued that the idea of human races has somehow been rendered incoherent because of recent migrations. Discussing this view, Crow (2002) noted:

\begin{abstract}
Because of this mixing, many anthropologists argue, quite reasonably, that there is no scientific justification for applying the word "race" to populations of human beings... Unlike those anthropologists who deny the usefulness of the term, I believe that the word "race" can be meaningfully applied to groups that are partially mixed.
\end{abstract}

This argument usually arises in context to discussions of the THRs. Until recently, major human geographic populations were isolated enough to racially differentiate, as demonstrated by cluster analysis. However, recent innovations have increased human mobility to the point that geographic races are homogenizing. As a result, the question arises as to whether traditional continental classifications are still coherent given the recent deracination.

Racial homogenization per se is just one of the many fates to which races and subspecies are potentially subject. Mayr and Obrien (1991) tell us:

In our view an allopatric subspecies has four possible fates; it may: (i) go extinct; (ii) exchange genes with another subspecies and become a new "mixed" subspecies; (iii) by genetic drift, selection, subdivision, or other demographic processes change its genetic character over time to become one or more new subspecies; and (iv) if effectively isolated, become a new species by acquiring genetic isolating mechanisms.

With respect the humans, it is expected that all continental races will follow path (ii) and merge into one raceless global population. But how does this affect the epistemic and biological status of these races?

First, let us consider the epistemic issue. The human geographic races circa 10,000 BC to 1,500 $\mathrm{AD}$ differ from the human geographic races circa 200,000 to 100,000 BC. Both of these racial classifications are biologically valid and meaningful, since race describes temporally specific natural divisions. Hence, for example, it makes sense to speak of modern and archaic human semispecies, ${ }^{68}$ even though the latter class is presently empty. As such, it is intelligible to note that many modern human races have varying amounts of archaic admixture. In dwindling, then, races do not become, in some way, incoherent; they become unpopulated; and, by our concept of

\footnotetext{
${ }^{68}$ There is continual debate as to whether Neanderthals and other archaic groups represented, relative to modern humans, different human races, semispecies, or species. Recent research has suggested a high degree of intrinsic genetic isolation, suggesting that these groups were closer to being separate species. They can reasonably be considered to be semi-species.
} 
biologically real, they become non-real at a given time (e.g., Neanderthals represent a presently non-real human semispecies). The upshot of these considerations is that the issue of migration and intermixing is largely irrelevant to the epistemology of race in the sense that racial extinction, transformation, hybridization, or speciation only alters the question at hand from "Which races exist presently?" to "Which races existed in the past?" - and from "Which individuals belong to which present races?" to "Which individuals descended (and to what extent) from which past races?"

As for the biological issue, there are no clear rules for determining when the extinction, merging, or transformation of biological races occur. For example, in the world, there are only a handful of the northern subspecies of the white rhinoceros (Ceratotherium simum). And there is only one male. Imagine that for conservation purposes they were transported to a southern white rhinoceros preserve. Imagine also that the remaining members of the northern subspecies bred freely with the members of the southern. When precisely would the white rhinoceros cease to have two traditional subspecies? When the last of the northern race died? When no full-blooded northern rhinoceros could be born? Currently, since there are so few of the northern subspecies? It is the sorties paradox applied to natural populations. No attempt to answer these questions will be made here (though it will be noted that conservationists do speak of the last of a race or subspecies). We ask them simply to illustrate the ambiguity of the situation.

An argument conceptually related to that above would be that present day human divisions represent a fusion of ancient lineages; thus, they never represented deep clades as, say, a simple serial founder effect model would suggest. There is indeed a growing body of evidence that indicates that ancient admixture was prevalent (Pickrell and Reich, 2014). Figure 4.2 shows a more recent model of population flows, one that can be contrasted with the simplified cladogram presented in Figure 4.3. The colored lines represent different population flows at different time periods.

Figure 4.2. Historic population movements across time in modern humans

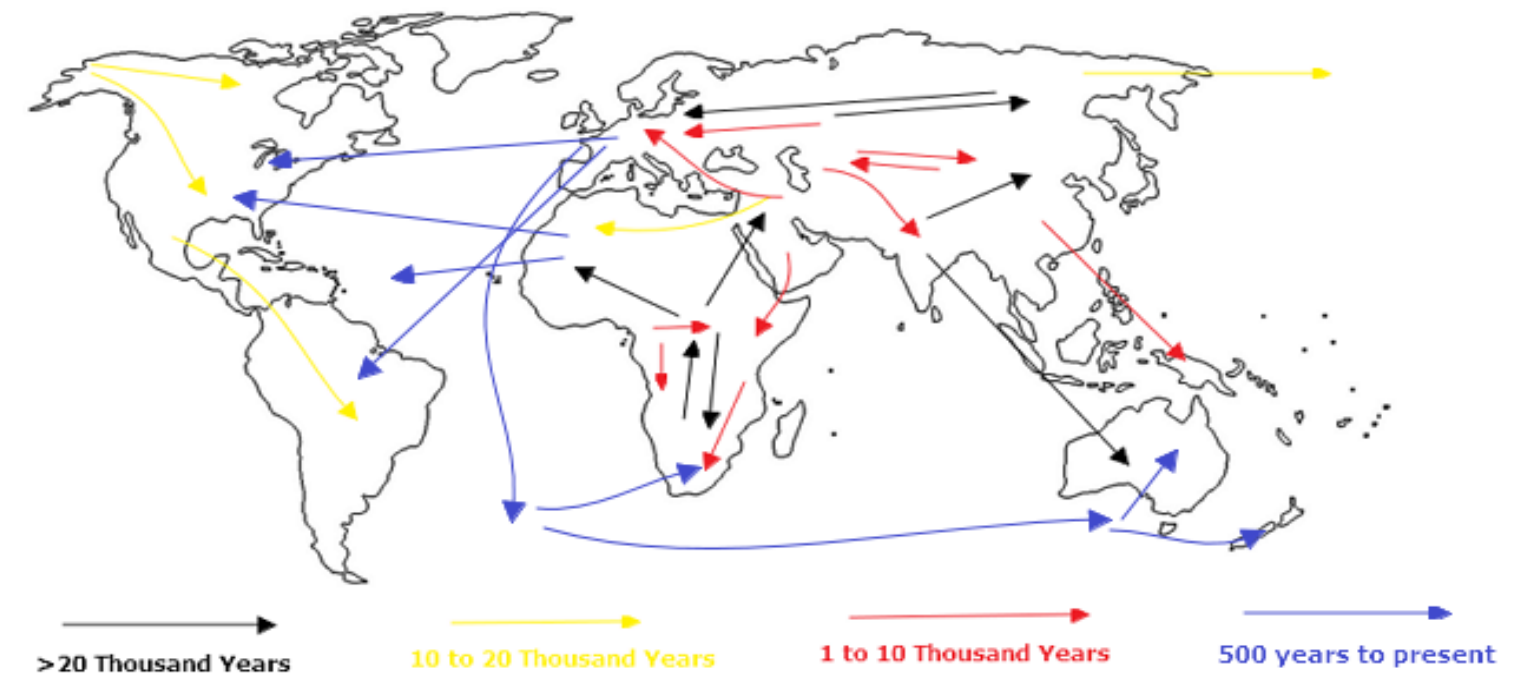

(Based on Figure 3 in Pickrell and Reich (2014).) 
This history of admixture might be fatal to a deep clade concept such as advocated by Templeton $(1998 ; 2013)$ and Andreasen $(2007) .{ }^{69}$ But, as we have noted elsewhere, we do not see much theoretical, let alone historical, justification for such a concept. For one, by many phylogenetic/cladistic conceptions, deep clades represent species; intraspecific relations, by definition, are seen as mainly tokogenetic and reticulate (for example: Hennig, 1966). For another, early (intraspecific) race theorists were not oblivious to historic population flows and admixture. Buffon, for example, discussing South East Asians, noted:

From these descriptions it appears, that the islands and coasts of the Indian ocean are peopled by men widely different from each other. The natives of Malacca, of Sumatra, and of the Nicobar islands, appear to drive their origin from those of the peninsula of Indus, and those of Java from the Chinese...

Relatedly, in a discussion of humans in context to the affects of climate, he noted:

As migrations have often happened, as whole nations have intermixed, and as men have traveled and dispersed themselves through every quarter of the globe, it is not surprising that the human races are less subject to the influence of climate, and that strong, handsome, and even ingenious men are to be found in every country.

As seen in the first quote, he reasonably accurately described the flows of peoples into South East Asia, as shown in Figure 4.3; of course, as with other early race theorists, Buffon's time frame would have been greatly compressed. ${ }^{70}$ As seen in the second quote, Buffon was not unaware of population flows. The point is that races were not historically equated with deep clades, in the sense of groups long isolated from each other.

\section{IV-G. THRs and Cluster Discordance}

Some have argued against meaningful biological races on the grounds of genetic cluster discordance. For example, Barbujani et al. (2013) state:

However, further attempts to identify major human groups by clustering genotypes have yielded inconsistent results. Different numbers of groups and different distributions of genotypes within such groups, were observed when different datasets were analyzed $(30,41-44)$. The inconsistencies in these results reflect a well-known feature of human diversity, that is, different genetic polymorphism are distributed over the world in a discordant manner (44)... It comes as no surprise, then, that if we look back at the many racial catalogs compiled since the 17th century, and at more recent genomic analyses (compare Refs 19, 32, 34, Figure 1), the only point they seem to have in common is that each of them contradicts all the others $(49,50)$.

The logic of Barbujani et al.'s (2013) argument is not clear. The authors seem to suggest that natural divisions do not exist because "different genetic polymorphism are distributed over the

\footnotetext{
${ }^{69}$ Andreasen (2007) notes, for example, that because it must be monophyletic "a population must be reproductively isolated over a significant portion of evolutionary history before it can be designated a cladistic race." As we noted in section I, though, a number of cladists, including Hennig, do not consider monophyly to be applicable on the intraspecific level.

${ }^{70}$ Buffon wrote that the earth was 70,000 years old and that humans came around in the last 10,000 (that is, the seventh epoch); a number of other pre-Darwinian race theorists, agreeing with the young earth model, considered the earth to be only several thousand years old. Either way, population movements and admixture was thought to have been relatively recent.
} 
world in a discordant manner." Yet, it is trivially true that individuals are more overall genetically related to some than to others. Thus, one can cut out natural divisions. The question is: do such and such racial classifications do this? Genetic cluster analysis can provide evidence that classifications, in fact, cut out natural divisions.

With regards to their discussion of contradictory classifications, we presume that Barbujani et al. (2013) are restricting discussion to a specific grain of focus, specifically to a continental one. That is, we assume that they, being population geneticists, appreciate that nested classifications are not contradictory ones, that there is no contradiction inherent, for example, in being both human and mammal or Irish and Caucasoid. As such, we interpret Barbujani et al. (2013) as arguing that the "many racial catalogs" on the continental-level conflict. As discussed in section IV-D, we do not see this. To illustrate our point further, in Table 4.4 we show the results from 8 studies which identified continental-level clusters (at $K=5$ or $K=6$, where $K$ is the number of divisions). The studies used different clustering methods (PCA, Structure, Frappe, and TIPS), different loci, and different numbers of loci but managed to produce fairly consistent genetic clusters.

Table 4.4. Clusters at the continental-level as determined in eight studies

\begin{tabular}{|c|c|c|c|c|c|c|c|}
\hline & & & & & & & \\
\hline Author & & $\begin{array}{l}\text { (1) } \\
\text { McEvoy et al. } \\
2010\end{array}$ & & $\begin{array}{l}\text { (2) } \\
\text { Rosenberg et al. } \\
2005\end{array}$ & $\begin{array}{l}\text { (3) } \\
\text { Jensen }\end{array}$ & $\begin{array}{l}\text { (4) } \\
\text { Nei a }\end{array}$ & $\begin{array}{r}\text { nd Roychoudhury } \\
1993\end{array}$ \\
\hline Method & & Structure & & Structure & PCA & NJ $n$ & nethod \\
\hline Trait & & whole genome & & microsatellites & $\begin{array}{l}\text { Protein } \\
\text { blood group } \\
\text { loci }\end{array}$ & 29 loc & \\
\hline & 1 & African & 1 & African & Negroid & 1 & Negroid \\
\hline & 2 & $\begin{array}{l}\text { West Eurasian } \\
\text { including most } \\
\text { S. Asian }\end{array}$ & 2.1 & $\begin{array}{l}\text { (West) Eurasian } \\
\text { including most } \\
\text { S. Asian }\end{array}$ & Caucasoid & 2 & Caucasoid \\
\hline & & & 2.2 & Kalash & & & \\
\hline & 3 & East Eurasian & 3 & East Asian & $\begin{array}{l}\text { North East } \\
\text { Asian }\end{array}$ & 3 & $\begin{array}{l}\text { East Asian and } \\
\text { Pacific Islander }\end{array}$ \\
\hline & 4 & American & 4 & American & Amerindian & 4 & Amerindian \\
\hline & 5 & Oceanian & 5 & Oceanian & $\begin{array}{l}\text { Australian/ NG } \\
\text { Pacific Island \& } \\
\text { South East } \\
\text { Asian }\end{array}$ & 5 & Australoid \\
\hline
\end{tabular}




\begin{tabular}{|c|c|c|c|c|c|c|c|}
\hline & & (5) & & (6) & (7) & (8) & \\
\hline Author & & $\begin{array}{r}\text { Cavalli-Sforza } \\
1994\end{array}$ & & $\begin{array}{l}\text { Herráez et al. } \\
\qquad 2009\end{array}$ & Zhang & Li et & 2008 \\
\hline Method & & $\begin{array}{l}\text { PCA } \\
\text { (based on } \\
\text { world map) }\end{array}$ & & Frappe & TIPS & Frap & \\
\hline Trait & & Various & & SNPs & microsatellites & & SNPS \\
\hline & 1 & African & 1 & S.S Africa & Africa & 1 & Africa \\
\hline & 2 & Caucasoid & 2.1 & $\begin{array}{l}\text { Europe } \\
\text { Middle East }\end{array}$ & $\begin{array}{l}\text { Europe } \\
\text { Middle East }\end{array}$ & 2.1 & $\begin{array}{l}\text { Europe } \\
\text { Middle East }\end{array}$ \\
\hline & & & 2.2 & $\begin{array}{l}\text { Central } \\
\text { South Asia }\end{array}$ & $\begin{array}{l}\text { Central } \\
\text { South Asia }\end{array}$ & 2.2 & $\begin{array}{l}\text { Central } \\
\text { South Asia }\end{array}$ \\
\hline & 3 & Mongoloid & 3 & East Asia & East Asia & 3 & East Asia \\
\hline & 4 & American & 4 & America & America & 4 & America \\
\hline & 5 & Australian & 5 & Oceania & Oceania & 5 & Oceania \\
\hline
\end{tabular}

*Clusters at $\mathrm{K}=5$ and $\mathrm{K}=6$. If author(s) reported or showed both $\mathrm{K}=5$ and $\mathrm{K}=6$, clusters were presented as $\mathrm{K}=5.1$ and $\mathrm{K}=5.2$ )

We grant, of course, that genetic clusters based on different methods and using different loci are not always perfectly concordant with each other at a given grain of focus. But we reiterate that this is not a problem, since biological races are not genetic clusters; rather, they are natural divisions which are inferred based on clusters of phenotypic and genetic data. If one desired the most accurate classification scheme possible, one would apply cluster analysis using whole genomes. This would eliminate cluster discordance resulting from the use of discordant sets of genes. Such results seem to vindicate the TRC and the THRs discussed above (for example: McEvoy et al., 2010).

\section{IV-H. THRs and Taxonomy}

It has further been argued that the TRC does not represent a valid taxonomic classification scheme. Long, Li, and Healy (2009), for example, argued:

Although it is logically consistent to group populations by relationship, the nested pattern of genetic diversity in the EHM [Expanded Hierarchical Model] disagrees with the traditional anthropological classifications that placed continental populations at the same level of classification (i.e., race). A classification that takes into account evolutionary relationships and the nested pattern of diversity would require that Sub-Saharan Africans are not a race because the most exclusive group that includes all Sub-Saharan African populations also includes every non-Sub-Saharan African population (Figs. $2 B$ and $4 B$ ). 
The claim seems to be that certain THRs, to the extent that they can be treated as clades, are nested within each other and that this nestedness precludes the placement of these races together in the same taxonomic categorization scheme. The situation is illustrated in Figure 4.2. Four major traditional groups split off of one of several African lineages, the descendants of which along with those of other African lineages are said to form a major "Sub-Saharan African race." Another way to say this is that our THRs are paraphyletic.

\section{Figure 4.3. Major human clades}

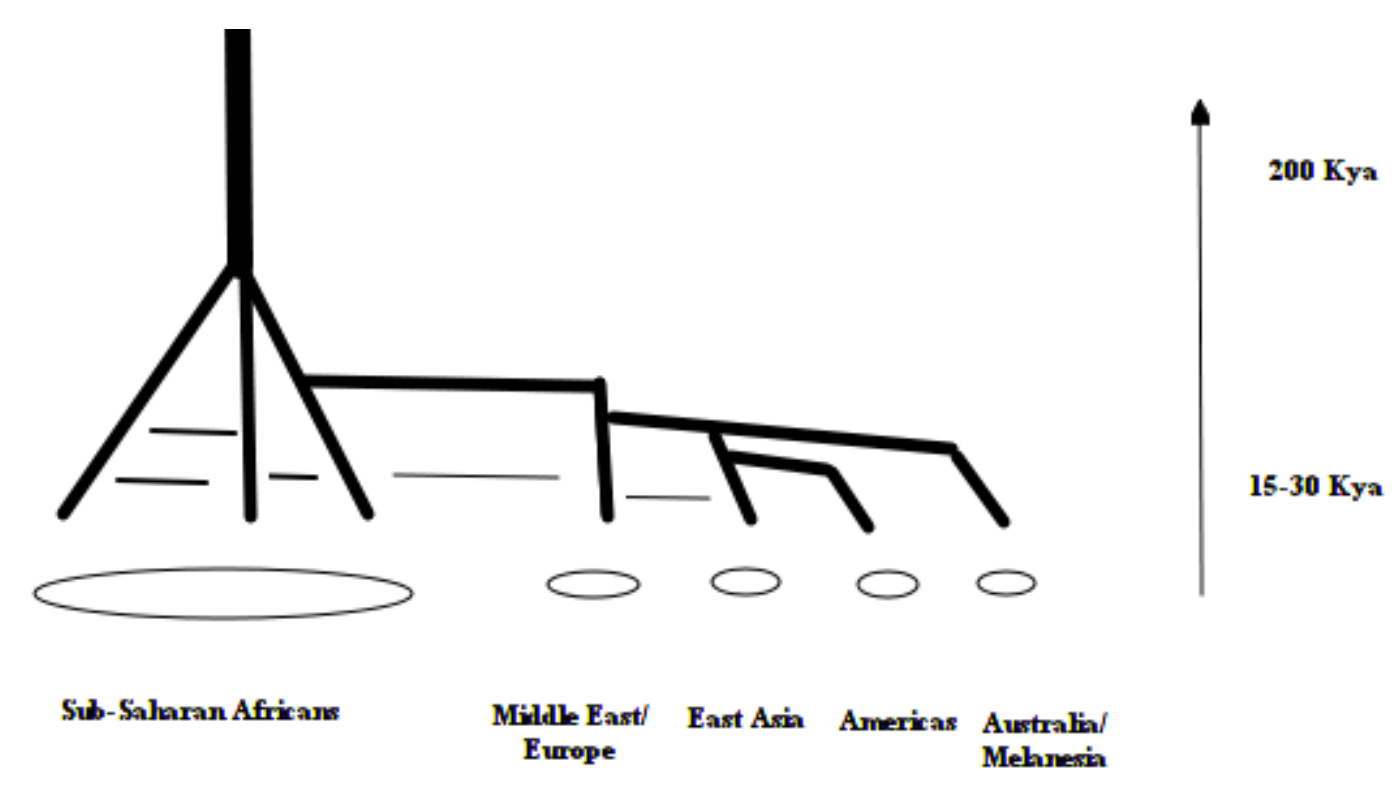

(Based on Figure 2 in Campbell and Tishkoff (2010).)

In relation to this type of argument we make three points:

(a) As noted in section I, race is not exclusively a taxonomic classification. It need not be understood from the perspective of taxonomy, let alone hierarchical taxonomic categorization; properly understood, races need not be taxa.

(b) From the perspective of the evolutionary classificatory school, taking into account "evolutionary relationship" (as defined by this school (e.g., Mayr and Bock (2002)) is what allows paraphyletic taxa to be given the same category rank. This is in accords with Darwin's position. Readers are referred back to section I-H.

(c) From the perspective of the cladistic school, the situation is unclear, because there are a plethora of different understandings. For example, Ridley (1989) explains that the species rank includes the "set of all the longest possible branches in the phylogenetic tree that do not themselves have splits in them." (See similarly: Nixon and Wheeler, 1990). Nestedness is not an issue for species, which for Ridley includes at least some evolutionary taxonomic subspecies. By this type of understanding, nestedness would presumably not be a problem for subspecies were they recognized. 
A related argument runs: there is more genetic diversity in Africa than out, so Sub-Saharan Africans can not be grouped into a coherent biological race. Conley, Fletcher, and Dawes (2014) make it, saying:

Meanwhile, a deeper look at race shows that genetic analysis does not reify our racial categories but instead destroys them: thanks to the population bottleneck coming out of Africa, we Caucasian authors of this article are most likely more genetically similar to Eskimos than are two Ugandans 200 miles apart (Tishkoff et al., 2009). The vastly greater genetic diversity within African descended populations does not just mean that race as we knew it is a mirage.

Our diagram above shows the flaw with this line of reasoning. In the diagram, the ovals below the lineage branches express the degree of genetic similarity. (Note that these ovals and the distances between them were not drawn to scale.) The Sub-Saharan African oval encompasses more space than do the other ones, indicating that within this groups there is a relatively high degree of genetic heterogeneity. Regardless, since the Sub-Saharan African oval does not overlap with the others, the individuals within are more similar to each other than they are to members of other divisions; thus they comprise a natural division. The reason that the descendants of the African lineages are more similar to each other than to descendants of out-of-African ones is that there was more linebreeding within Sub-Saharan Africa than between Sub-Saharan Africans and out-of-Africans. Readers are referred to Spencer's (2014) lucid and more patient discussion of this issue.

Box 4.1. Critiques of unsupervised cluster analysis

A number of critiques have been made against the use of unsupervised cluster analysis to objectively delineate racial classifications. One is that cluster-analyses can not establish a correct level of genetic granularity; thus any level of analysis must be subjectively chosen. Another is that global genetic and morphological data bases such as 1000 Genomes, HapMap3, and W.W. Howells' Craniometric Data Set are based on biased samples, ones which were collected with traditional racial classifications in mind. A third is that cluster analysis outputs heavily depend on the population data inputted; when one inputs data from different sets of populations one gets different results. Regarding the first, it is correct that cluster-analyses can not establish a correct level of genetic analysis. This is as one would expect since there is no such level. One can look at genetic propinquity on a broad continental-level or on a small regional one. In context to race, this has always been recognized. The same consideration holds with respect to taxonomic categories. For example, the level of genetic analysis that corresponds to "genus" is no more correct than that which corresponds to "species." Nonetheless, unsupervised cluster-analyses can provide objective grounds for preferring one level of intrapecific analysis to another given some notion of what makes for an ideal race, for example: degree of clusteredness, amount of genetic differentiation, and the genetic coherence of the divisions picked out. When unsupervised cluster analysis is run which automatically picks out a "best" level of analysis (e.g., using fineSTRUCTURE and DAPC) or which generates results which allow one to do so (e.g., STRUCTURE), the TRC has generally been shown to cut out divisions which are preferable given these pre-specified criteria (Dienekes, 2005; 2014). Regarding the second argument, one can not directly refute a hard form of this, according to which subtle and difficult to detect biases inevitably shape sampling decisions. One can only ask those who make the argument to apply it equally to other scientific endeavors. If done, this would unveil the epistemic nihilism on which it is based. In response to a moderate version of the same argument, it can be pointed out that multiple data bases developed by different research teams for different purposes generate similar results. Moreover, the results are as one would expect given known historic geographic barriers to movement, for example, the presence of large deserts, mountain ranges, oceans, and so forth. The third point is superficially correct; the population data which one inputs into a cluster analysis program flavors the results. But this point only works as an argument against the TRC insofar as one maintains, in accordance with the second argument, that global data bases are riddled with sampling-bias. As discussed above, there are good reasons for concluding otherwise. 


\section{IV-I. THRs and Subspecies}

In biology, the term subspecies is frequently used to refer both to ecotypic races, an ecological concept, and to taxa subspecies. As discussed prior, the term "subspecies" is also sometime used in a more general sense to refer to races both formally recognized and not. Also, in some instances, the groups designated as taxa subspecies are potentially not races. This is the case with polytypic subspecies, which represent aggregates of geographically separate but phenotypically similar - due to convergent evolution - populations (Mayr and Ashlock, 1969). Polytypic subspecies are only recognized when there are no races in a species which can be dignified with a trinomen. ${ }^{71}$

The THRs correspond with ecotypic races/subspecies when ecotypes are broadly understood as environmentally adapted subdivisions of a species. Since virtually all geographical races are, as aggregates, adapted to the regions in which they evolved, they fit this definition. This broad formulation was expressed by Mayr (1970), when he noted that "not a single geographic race is known that is not also an ecological race" and by Dobzhansky (1970) when he wrote, "Is there a difference between a geographic race and an ecotype? To a large extent the two terms are synonymous." As some envision the ecotype concept more narrowly, whether the THRs constitute ecotypic subspecies depends on the specific concept employed. This issue is discussed more in section V-B. In a sense, then, the THRs represent human subspecies. But the question in this regards is often: do the THRs represent taxa subspecies? Since no human races are formally recognized, strictly speaking, the answer is "No." What is often really meant, though, is: could the THRs be formally recognized as taxonomic category subspecies? Or: would they be recognized if there was no social pressure against doing so? As noted in section I, race historically found no place in taxonomic categorization; thus, the interest in races as taxa strikes us as odd. Nonetheless, we will consider the matter.

As noted in section I, one must approach this question from the perspective of a specific taxonomic school. As discussed, we are uncertain about the cladistic perspective. Many proponents of cladism or similar positions, calling all distinct lineage branches species, simply do not recognize taxa subspecies as such (Haig et al. 2006). For them, the question would be: do the THRs represent taxa species? Others, such as Nixon and Wheeler (1990) and Wheeler and Platnick (2000) who advance a diagnosable version of the Phylogenic Species Concept, grant species status to many of the evolutionary taxonomists' subspecies and treat less well defined populations as subspecies. Nixon and Wheeler (1990) note, for example:

\footnotetext{
Intraspecific taxa (subspecies or botanical varieties) are groups of individual organisms that are centric and not monothetic, in that they are diagnosable only by virtue of part of a broader distribution of one or more traits. Individuals in these populations are not identical for any unique combination of states, and they might or might not be genealogically homogeneous ("monophyletic" in the sense of de Queiroz and Dogoghue, 1988, 1990). Our concept of infraspecific "taxa" is consistent with a view that these may be incipient species - populations which exhibit high frequencies or combinations of unique traits that may are some future date becomes "fixed" (constantly distributed).
}

By such a weak taxa subspecies concept, it would seem likely that the THRs would qualify. But

\footnotetext{
${ }^{71}$ This is at least Mayr and Ashlock's interpretation. But see also the usage in e.g., Archer (1988): "I find the polytypic subspecies unacceptable as it brings together populations with different evolutionary histories."
} 
not considering subspecies to be of much importance, the authors of these concepts do not provide conventions for determining which populations qualify. ${ }^{72}$

Thus, insofar as we are interested in determining the matter based on accepted conventions, it seems that we can only approach it from the evolutionary taxonomic perspective. From this, since the formal recognition of all biological races would result in taxonomic chaos, only the ones that are deemed taxonomically significant enough are formally recognized (Mayr and Ashlock, 1969; 1991). When it comes to deciding if races should be formally recognized, Mayr and Ashlock offer the following advice:

\begin{abstract}
Degree of difference is only one of a number of considerations in the recognition of a subspecies (Chap. 3). A yardstick such as the CD will help to achieve more uniform standards, but other information, such as degree of isolation, presence or absence of clinal variation, presence or absence of a checker-board type of distribution, or discordant variation of different characters, must be equally taken into consideration.
\end{abstract}

Of the five criteria mentioned, the only one for which there is a semi-accepted quantitative standard is the one pertaining to a sufficient degree of differentiation. The standard is called the $75 \%$ rule. By this rule, taxonomic sufficiency depends on the ability to correctly classify or, alternatively, to correctly distinguish, on the basis of selected diagnostic characters, members of biological races. This rule has been characterized as being only "a rule of thumb" (Groves, 2004). Indeed, it seems that it often is not applied. For example, Remsen (2010) notes that in ornithology its "application has been erratic at best." Remsen (2010) goes onto state:

It is not possible to tell how many of the subspecies currently recognized in such sources would qualify as subspecies under the $75 \%$ rule, but it is certain that many subspecies, especially in North America, would not qualify as valid taxa under this rule, particularly those defined by menstrual differences. From personal experience in attempting to use subspecies diagnoses, such as the keys in the Birds of North and Middle America series (Ridgway and Friedmann 1901-1950), I predict that more than $75 \%$ of North American subspecies taxa delimited by menstrual data would not survive application of the $75 \%$ rule.

When it comes to employing this rule, there are a few points to note: (1) There is no set number of characters to use; the characters, though, are often weighted by "phylogenic information content" or "information concerning ancestry," with those characters which have a higher weight deemed to be more suitable. (2) Given a set of 3 races A, B, and C, the characteristics used to differentiate race $\mathrm{A}$ from race $\mathrm{B}$ need not be the same characteristics used to differentiate race $\mathrm{A}$ from race C. Pertaining to this point, Mayr and Ashlock (1969) note that a "characteristic by which members of two taxa agree but differ from a third taxon is a taxonomic character." (3) This rule has numerous, often discordant, interpretations; when applying it, results depend on the specific interpretation employed.

Now given some frequently cited interpretations (e.g., the multivariate interpretation discussed by Smith, Chiszar, and Montanucci (1997) or the correct classification interpretation - which also employs multivariate analysis - mentioned by others), the THRs clearly meet the degree of difference criteria. Referring to the most lackadaisical interpretation of the $75 \%$ rule, CavalliSforza and Bodmer (1976) noted:

\footnotetext{
${ }^{72}$ The exception is Groves (2004) who simply uses the $75 \%$ rule and apparently nothing else.
} 
[R]aces could be called sub-species if we adopted for man a criterion from systematic zoology. The criterion is that two or more groups become sub-species when 75 percent or more of all individuals constituting the groups can be unequivocally classified as belonging to a particular group.

Likewise, Wright (1978) noted:

There is also no question, however, that populations that have long inhabited separated parts of the world should, in general, be considered to be of different subspecies by the usual criterion that most individuals of such populations can be allocated correctly by inspection ...

It is, however, customary to use the term race rather than subspecies for the major subdivisions of the human species as well as for minor ones. The occurrence of a few conspicuous differences, probably due to selection for adaptation to widely different environmental conditions, does not necessarily imply much difference in general. Nei and Roychoudhury (1974) have shown that the differences among negroids, caucasoids, and mongoloids in the protein and blood group loci are slight compared with those between individuals within any one of them. There is disagreement on the number of major races that should be recognized. At a minimum, the Australoids are added to the three referred to above.

Simply, human individuals can be very reliably classified - above the $75 \%$ threshold - and the THRs can be differentiated using multivariate techniques given a sufficient number of characters. For applications of multivariate techniques to human continental-level races, readers are referred to, e.g., Irish (1998), Hubbe, Hanihara, and Harvati (2009), and Relethford (2009). ${ }^{73}$ For a discussion of characteristic differences between selected races, readers are referred to, e.g., Baker (1974), Brues (1990), and Gill (1998). Finally, readers are referred to the Sesardic's (2010) discussion:

Indeed, a quick look into the literature confirms this. For instance, a study that covered 17 populations over the world and that relied on 34 different measurements managed to assign $98 \%$ of the specimens to their correct major racial group (Brues 1990,6 ). Another more recent study had a success rate of $80 \%$ in distinguishing between American Whites and Blacks, although it used just two variables. With seven variables, however, it reached the reliability of $95 \%$, and with 19 variables the probability of correct classification rose to $97 \%$ (Ousley et al. 2009). Also, estimating generally the reliability of attributing a given data point to one of the five racial categories, another team of experts calculated that under some realistic conditions it is sufficient to use as few as 13 characteristics to have the posterior probability of the correct classification attain the value of $99 \%$ (Konigsberg et al. 2009).

There have been some attempts to tighten up the 75\% rule; for example, Ramey, Liu, Epps, Carpenter, and Wehausen (2005), discussing a 90\% version, note:

The critical test of the original subspecies description was two-fold. First, the hypothesis of Z. h. preblei being a unique, smaller subspecies relative to Z. h. campestris would be rejected if the skulls of Z. h. preblei were not significantly smaller for the majority of skull measurements. Second, we used LDA to test uniqueness with the distinguishability criterion that $\geq 90 \%$ of the specimens be correctly classified to subspecies at jackknifed posterior probabilities $\geq 0.95$ (Wehausen \& Ramey, 2000). This unambiguous criterion requires that specimens be correctly classified with a high degree of certainty using a multivariate analysis of shape.

\footnotetext{
${ }^{73}$ To be clear, these authors do not call the human populations analyzed "races." It is not claimed that they do, rather it is claimed that their results show that the populations meet the (multivariate version of the) $75 \%$ criterion.
} 
Still, by this more stringent reading, the THRs would most likely, unlike many of the unfortunate races of the Preble's meadow jumping mouse, meet this criterion. What about other interpretations? One such is the univariate one discussed by Mayr and Ashlock (1969). By this, the $75 \%$ in the $75 \%$ rule is interpreted as implying a $90 \%$ non-overlap in the group distributions of the diagnostic characters (since at the point of intersection between two distributions in which $75 \%$ of the members of one is separated from $97 \%$ of the members of the other, $90 \%$ of one group will be separated from $90 \%$ of the other). This $90 \%$ non-overlap is translated into a Coefficient of Difference (CD) of 1.28, where:

$\mathrm{CD}=(\mathrm{Mb}-\mathrm{Ma}) /(\mathrm{Sda}+\mathrm{SDb})$

where:

$\mathrm{M}=$ mean

$\mathrm{SD}=$ Standard Deviation

$\mathrm{a}$ and $\mathrm{b}=$ groups

This CD of 1.28, in turn, is equivalent to a Cohen's d, or standardized difference, of about 2.58 (assuming normality and equal variances). When dealing with more than two groups, one must naturally select sets of diagnostic traits such that, for example, group 1 and 2 can be differentiated on the basis of trait A, group 1 and 3 can be differentiated on the basis of trait B, et cetera. As for the THRs, one probably could create diagnostic sets were one to look hard enough for characteristics. For example, Table 4.5 presents the diagnostic standard offered by Mayr and Ashlock (1969) - in addition to alternative quantifications of this standard - along with CD values for the traits reported by Keita (1993).

Table 4.5. Mayr and Ashlock's (1969) proposed differentiation level

\begin{tabular}{|c|c|c|c|}
\hline Percent & Joint nonoverlap & Cohen's d & Coefficient of Difference (CD). where: \\
\hline \multirow[t]{5}{*}{$75 \%$ from $97 \%$} & (about) $90 \%$ & (about) 2.58 & 1.28 \\
\hline & & & $\mathrm{CD}=(\mathrm{Mb}-\mathrm{Ma}) /(\mathrm{Sda}+\mathrm{SDb})$ \\
\hline & & & $\mathrm{M}=$ mean \\
\hline & & & $\mathrm{SD}=$ Standard Deviation \\
\hline & & & $\mathrm{a}$ and $\mathrm{b}=$ populations \\
\hline
\end{tabular}

$\begin{array}{lllll} & \text { Negroid (af) } & \text { Mongoloid (as) } & \text { Amerindian (am) } & \text { Caucasoid (s) } \\ \text { Negroid (af) } & & & & \\ \text { Mongoloid (as) } & \mathbf{1 . 5 6 / 2 . 1 7 / 1 . 7 9 / 1 . 5 7} & & & \\ \text { Amerindian (am) } & \mathbf{0 . 4 2 / 1 . 8 6 / 1 . 2 0 / 1 . 2 7} & 1.12 / 0.48 / 1.02 / 0.44 & & \\ \text { Caucasoid (s) } & 0.48 / 1.22 / 0.77 / 0.77 & 1.15 / 1.21 / 0.94 / 0.86 & 0.03 / 0.74 / 0.06 / 0.48 & \\ \text { Australoid (au) } & 0.57 / 0.62 / 0.01 / 0.35 & \mathbf{1 . 9 6 / 1 . 6 5 / 1 . 7 0 / 1 . 2 5} & 1.14 / 1.23 / 0.79 / 0.91 & 1.01 / 0.55 / 0.73 / 0.43\end{array}$

Since there are five groups, there are ten pair-wise comparisons. On the basis of these five traits, three group pairs more than meet Mayr's CD criterion; another three nearly meet it. If one wanted to, one undoubtedly could sort through all characters and construct diagnostic sets for 
these groups such that the 1.28 CD criterion was met for each of the ten group comparisons. There is no shortage of typically used diagnostic characters to look at; Gill (1998) lists some. On average, though, the THRs' character differences fall far below the univariate standard. For example, we looked at the W.W. Howells Craniometric Data Set and found, based on 71 cranial measures, an average Caucasoid-Negroid CD of less than $0.5 .^{74}$ Of the traits, only $15 \%$ had a CD above 1.0; these results were consistent with those reported by Sarich and Miele (2004), who ended up emphasizing the largeness of these differences relative to those between other primate intraspecific groups. It is worth noting that other craniofacial traits, such as soft tissue ones, show much larger differences (for example: Guo et al., 2014).

So can the THRs qualify as taxa subspecies? It is difficult to adjudicate given the ambiguous nature of the formal racial recognition criteria. As it is, there are no formal formal recognition criteria. Despite substantial disagreement with regards to the standards, there does seem to be a general feeling both in taxonomy and in conservation biology that some subdivisions of a species make for bad subspecies while others do not.

In "Ungulate Taxonomy," Groves and Grubb (2011) playfully contrast subspecies that are "Bad" with those that are "Ugly" (by which they really mean "good" or "acceptable," given the intrinsically "Ugly" nature of sub-specific divisions):

\begin{abstract}
These subspecies may be differentiated into the Good, the Bad, and the Ugly... The Good subspecies are $100 \%$ diagnosable, hence they are actually distinct species masquerading as mere subspecies...The Bad subspecies are points along a cline, or are differentiated at very low frequency levels, or simply are based on one or two individuals that seemed outstanding at the time. The samples that they represent may be interesting for population genetics or in some other respect, but they have no taxonomic standing... The Ugly subspecies are the ones which are left over. Subsequent studies have shown that they can be differentiated from other subspecies (i.e., from other geographic segments of the same species) at high frequencies, but they are not absolutely differentiated or diagnosable. The dilemma is, what to do with them? There does seem to be some advantages in dignifying them with a trinomial, especially for conservation purposes, but as these Ugly subspecies are arbitrary and unfalsifiable, one cannot insist upon it. Nonetheless, this is what we have in mind when we recognize subspecies in this book, unless we specifically state that they are provisional.
\end{abstract}

The question which we must ask, then, is: do the THRs qualify as Ugly or just plain Bad subspecies? We can attempt to answer this using Mayr and Ashlock's five considerations: (a) degree of difference, (b) presence or absence of clinal variation, (c) presence or absence of checker-board type characters, (d) discordant variation of different characters, (e) and degree of isolation. With regards to (a), as noted above, the THRs meet the 75\% rule criterion by at least some interpretations. (Readers can decide for themselves; for various interpretations of this rule, they are referred to the discussions of Amadon (1949), Mayr and Ashlock (1969), and Smith et al. (1997).) This said, when it comes to Mayr's (multiple) univariate method, one has to fish around for sufficiently differentiated characteristics. As such, the THRs do not indisputably meet this criterion. Moving on, the THRs also show a relative lack of clinal variation in some characters which have high phylogenic information content e.g., craniofacial morphology (see, for example: Relethford, 1994; 2009); additionally, while it is frequently imputed that these divisions form a population continuum, this is not true, as the genetic data demonstrates (see, for example: Rosenberg, 2011). This all noted, it is not clear how to assess the overall degree of

\footnotetext{
${ }^{74}$ This data set is freely available at: http://web.utk.edu/ auerbach/HOWL.htm
} 
clinality in terms of taxonomic significance. As for the third consideration, the THRs do not have checker-board types of trait distributions. Regarding discordant (i.e., disagreement in) variation of different genetically conditioned phenotypic characteristics, some characteristics show substantial discordance and yet some do not; the latter allow for, as a result of the correlation between characters, accurate classifications, despite relatively low between population divergence.

Did our THRs once show a sufficient degree of isolation? We were unable to locate a quantification of 'sufficient' and so were unable to determine this matter. If we adopt the Fst statistic as a measure of isolation, since Fst is inversely proportional to gene flow (given various assumptions) (Hawks, 2011), we can say, given the interpretive standards proposed by Sewall Wright, that the amount of isolation between the THRs was moderate. ${ }^{75}$ We can put the amount of the THRs' isolation - or at least the Fst values - into cross-species context. Templeton (1998) did this using mtDNA data for non-human species (between subspecies) and microsatellite and RFLP data for humans (between continental populations). The Fst values ranged from about 0.095 to 0.95 . Of the 13 species, he presented, humans came in 11th place in terms of interpopulation Fst values. Using Templeton's (1998) method in conjunction with Lorenzen, Arctander, and Siegismund's (2008) mtDNA Fst values for 17 ungalate species we found similar results. Of the 17 ungalate species plus humans, humans placed 14th.

There is a problem with Templeton's (1998) analysis, though; he made a zebras to lions comparison. MtDNA Fst values were used for non-humans, while autosomal microsatellite and RFLP Fst values were used for humans. This is problematic for two reasons: (1) mtDNA Fst values are generally higher than autosomal values, and (2) male based dispersal, common in many species, can elevating mtDNA Fst. With regards to the former point, Merriwether et al. (1991), Stoneking, Jorde, Bhatia, and Wilson (1990), Jorde, Bamshad, and Rogers (1998), Jorde et al. (2000), Wilder, Kingan, Mobasher, Pilkington, and Hammer (2004), and Wang, Jin, and Li (2013) report human mtDNA Fst or Gst values ranging from 0.14 (Wilder et al.) to 0.46 (Merriwether et al.) with a mean of about $0.23 .^{76}$ These estimates are substantially higher than the autosomal based one used by Templeton (1998).

With regards to the second point, a number of authors have warned about the influence of malebiased dispersion (for example: Melnick and Hoelzer, 1993) on mtDNA Fst values. For humans there is no evidence of such dispersion (if anything, dispersion was more prominent amongst females). ${ }^{77}$ Whatever the case, cross-species differences in sex related migration makes mtDNA (and Y-chromosome) comparisons problematic. In addition to MtDNA, autosomal microsatellite diversity is commonly studied in species. As such, we can compare autosomal microsatellite Fst values. To do this, we conducted a literature search and located studies on 24 species in which

\footnotetext{
${ }^{75}$ See, though, Whitlock et al.'s (1999) cautionary note about using Fst values to assess the degree of gene flow between populations within species.

${ }^{76}$ This was when using the average of the values given by Merriwether et al. (1991).

${ }^{77}$ Hence, Seielstad et al. (1998) reported a Y-chromosome continental Fst value of 0.65 versus an mtDNA Fst of 0.19 and Wang et al. (2013) report a Y-chromosome continental Fst of 0.36 versus an mtDNA Fst of 0.17 ; though, see Wilder et al. (2004).
} 
the autosomal microsatellite genetic differentiation between the species' subspecies was reported. The results are shown below in Table 4.6. The authors' opinion concerning subspecies status is noted.

\section{Table 4.6. Autosomal microsatellite Fst/Gst values by level of expected heterozygosity for various subspecies}

\section{Species}

Red-Winged Blackbirds (5 subspecies) [18]

Plain Zebra (6 subspecies) [1]

African Wild Cat/Domestic Cat

(2 sp. CT+ Pretoria versus F. lybica) [23]

Jaguars (4 populations/subspecies) [2]

Ocelot (Scheme A: 6 subspecies) [22]

Warthog (3 subspecies) [3]

Harbour Seal (5 subspecies) [4]

Bison (2 subspecies Plains and Wood) [25]

Mexican White Tailed Deer (6 subspecies) [24]

Orangutans (3 subspecies) [5]

Spotted Owl (3 Subspecies) [20]

NA Caribou (3 subspecies) [6]

Kob (2 subspecies) [7]

Roan (6 subspecies) [11]

Waterbuck (2 subspecies) [21]

American Puma (6 subspecies groups) [8]

Impala (3 Subspecies) [9]

European Mountain Hare (4 subspecies) [10]

Ostriches (subspecies: australis,

molybdophane, syriacus, massaicus) [12]

Mountain Zebra (subspecies: CMZ versus HMZ) [13]

Idaho ground squirrels [19]

Giraffe (6 Subspecies) [14, 15]

Tigers (5 Subspecies) [16]

Leopards (7 subspecies) [17]

\author{
Authors' Opinion on \\ subspecies status
}

Not Questioned

Not Questioned

Not Questioned

Challenged

Questioned

Not Questioned

Not Questioned

Challenged

Not Questioned

Not Questioned

Not Questioned

Suggests Reordering

Not Questioned

Not Questioned

Not Questioned

Not Questioned

Not Questioned

Not Questioned

Not Questioned

Not Questioned

Not Questioned

Not Questioned

Not Questioned

Not Questioned

Microsatellite
F/Gst (CT)

Hs(CT)

(average)

0.01

0.03

0.05

0.72

0.76

0.69

0.06

0.74

0.07

0.84

0.07

0.08

0.72

0.73

0.09

0.48

0.09

0.74

0.09

0.73

0.11

0.74

0.11

0.45

0.11

0.66

0.13

0.46

0.14

0.68

0.17

0.65

0.67

0.53

0.2

0.26

0.28

0.46

0.29

0.51

0.3

0.52

0.31

0.58

0.36

0.62

(The mean of the pairwise subspecies values was used when a subspecies divergence statistic was not reported. When there was a choice, we used Fst values, as opposed to analogs. The references are given below.)

[1] Lorenzen et al. (2008); [2] Eizirik et al. (2001); [3] Muwanika et al. (2003); [4] Burg et al. (1999);

[5] Kanthaswamy et al. (2006); [6] Cronin et al. (2005); [7] Lorenzen et al. (2007); [8] Culver et al. (2000);

[9] Lorenzen, Arctander, and Siegismund (2006); [10] Hamill et al. (2006); [11] Alpers et al. (2004);

[12] Miller et al. (2011); [13] Moodley and Harley (2005); [14] Brown et al. (2007); [15] Lorenzen et al. (2012);

[16] Luo et al. (2004); [17] Uphyrkina et al. (2001); [18] Williams et al. (2004);

[19] Garner et al. (2005); [20] Funk et al. (2008); [21] Lorenzen, Simonsen, Kat, Arctander, and Siegismund

(2006); [22] Ruiz-García et al. (2012); [23] Wiseman et al. (2002); [24] Xochitl et al. (2012); [25]

Cronin et al. (2013) 
Next, we reviewed the data concerning human continental populations. The results are shown below in Table 4.7. The number of loci used, the sample sizes, and the number of human continental races compared are noted for reference. The values range from 0.040 to 0.14 ; the nweighted average was about 0.065 . Based on the two most representative samples it was 0.053 .

Table 4.7. Human autosomal microsatellite Fst

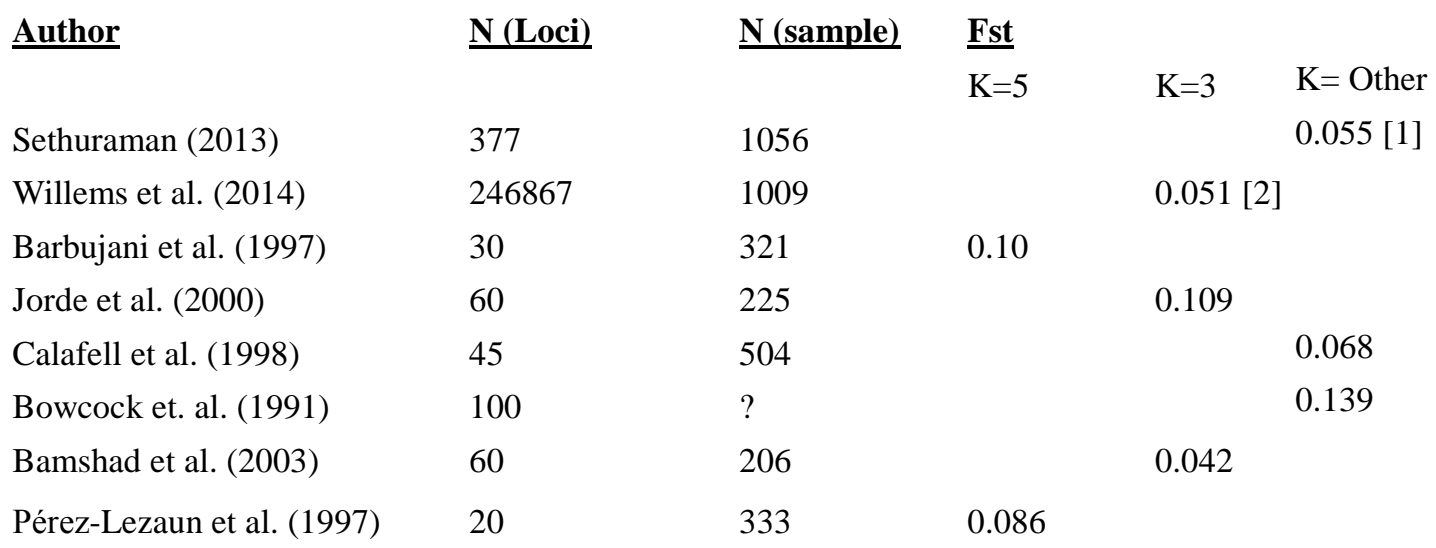

[1] This is based on Rosenberg et al.'s (2002) sample using Nei's (1973) Fst at K=7; the Fst values are higher than the AMOVA values; see Table 4.8 below. [2] These are the n-weighted average Rst values from the authors' Suppl. Table 9; the sample was 1000 Genomes.

For continental races, Humans came 21 or 22 out of 25 in terms of genetic differentiation. ${ }^{78}$ These results, then, are quite similar to those found by Templeton (1998) and found when applying Templeton's (1998) method to Lorenzen et al.'s (2008) data. It seems that the differentiation between human continental races falls around the $15^{\text {th }}$ percentile in a cross-species comparison. The 15 th percentile, of course, is typically considered to be low average (9th to 23rd) as opposed to borderline (2nd to 8th).

The situation, however, is complicated since, as Meirmans and Hedrick (2011) among others have noted, common measures of population differentiation such as Fst can be misleading when it comes to making cross-species comparisons concerning population structure because Fst and Fst analogue values are dependent on and constrained by intra-population heterogeneity (genetic diversity). Simply:

$$
\mathrm{Fst}=\left(\mathrm{HT}_{\mathrm{T}}-\mathrm{Hs}\right) / \mathrm{HT}
$$

where $\mathrm{Ht}$ is the total genetic diversity and $\mathrm{Hs}$ is the within population genetic diversity (or expected genetic diversity); therefore: Fst < 1-Expected Heterozygosity (Hs).

The Fst values between populations in a species are limited by the within population expected genetic diversity. For our 24 species with recognized subspecies, the correlation between Fst and expected genetic diversity was $r=-0.57$. This relation is very similar to that reported by Heller

\footnotetext{
${ }^{78}$ The Fst for African Wild Cats came out to 0.0465 .
} 
and Siegismund (2009) and by Meirmans and Hedrick (2011), though neither research team limited consideration to species with formally recognized races. Concerning the relationship between Fst values and heterozygosity, Meirmans and Hedrick (2011) noted:

\footnotetext{
Notice that the observed range of FST is always less than HS and that the range of FST becomes very small when HS is large. For example when HS $=0.9$, a value that is commonly encountered for microsatellite markers, the maximum possible value of FST is 0.1. Such a value of FST is generally interpreted as representing a rather weak population structure. However, here it represents the case with maximum differentiation among the populations, meaning that the populations do not share any alleles at all.
}

In short, species with high within population diversity will necessarily show low between population Fst and Fst analog values, regardless of the actual between population diversity as indexed by the number of shared alleles. (Readers are referred to Jakobsson, Edge, and Rosenberg (2013) for a discussion of this matter with regards to human populations.) For humans there is indeed high within continental race genetic diversity. Based on Pemberton, DeGiorgio, and Rosenberg's (2013) list of microsatellite Hs values for 267 populations, we can compute continental Hs values along with the average of them. These are shown in Table 4.8. The average Hs value was 0.72 (and so the maximum possible Fst would be 0.28 ). When Hs is plotted by F/Gst for the sample of 24 species, a Hs value of 0.72 predicts a F/Gst value of 0.05 . Using Heller and Siegismund's (2009) regression line based on 43 species the same result is found. Thus, the low microsatellite Fst value between major human races is about what one would expect to find were one dealing with the subspecies of a species which had a heterozygosity value similar to that of the human species.

Table 4.8. Human microsatellite $\mathrm{Hs}(\mathrm{CT})$ based on Pemberton et al. (2013)

$\begin{array}{lr}\text { Caucasoid* } & 0.725 \\ \text { Amerindian } & 0.677 \\ \text { Oceanian } & 0.700 \\ \text { Negroid } & 0.754 \\ \text { Mongoloid** } & 0.726 \\ & \\ \text { Average } & 0.717 \\ * \text { (Europe, Middle East, Central/South Asia) } & \\ * * \text { North/South East Asia } & \end{array}$

Another way to look at this is to compare microsatellite genetic differentiation values based on statistics designed to take into account Hs (e.g., Jost's D) and those not so designed (e.g., AMOVA, Nei's Fst, and Weir and Cockerham's Fst). Below, in Table 4.9, are estimates from Sethuraman (2013), based on the HGDP-CEPH data set, using a seven population model. As can be seen, by taking into account Hs either Jost's D is inflated or the others are deflated. Whatever the case, the interpretation of the divergence statistic values is not straightforward. 
So, what conclusion should we draw? A reasonable one is simply that the situation is not clear cut. Whether or not the THRs once showed a "sufficient" degree of isolation to meet this criterion, given post 1950 s standards, is debatable.

Table 4.9. Human microsatellite divergence values reported by Sethuraman (2013)

$\begin{array}{ll}\text { AMOVA } & 3.60 \% \\ \text { Nei (1973) } & 0.055 \\ \text { Weir \& Cockerham (1984) } & 0.053 \\ \text { Jost (2008) } & 0.207\end{array}$

More generally, based on Mayr and Ashlock's five criteria, taken together, we are incapable of ruling against the formal recognition of the THRs. (For references, Mayr, himself, concluded that the THRs represented taxa subspecies - or, at least, "geographic races" - on the account that they "agree in most characteristics with the geographic races of animals" (Mayr, 2002)). To help advance this debate, we might add another dimension to Groves and Grubb's (2011) Bad or Ugly dichotomy, one that describes the classifier's disposition: conservative or liberal. In our opinion, the THRs qualify as acceptable taxa subspecies when taxonomically liberal interpretations of the various criteria are applied. We judge this to be the case, because we were able to locate a number of recognized subspecies that less well met the various discussed criteria. ${ }^{79} \mathrm{We}$ also feel that by a more taxonomically conservative reading of the criteria the THRs would have no chance. We imagine, also, that they probably would not qualify as "evolutionarily significant units" (ESU) as defined by Ryder (1986), who notes that not all subspecies are created equal or are equally deserving of conservation efforts - at least, given available funding. Would they qualify as Management Units (MU)? Possibly.

In the future, new conventions or new interpretations of old ones might be established. And interpretative rules might be tightened up such that even by liberal standards, no human races past or present could qualify for formal racial recognized. But, as it stands of 2015, at least by liberal interpretations of the existing conventions, the THRs can qualify. Regardless, it should be clear that such criteria and rules for formal recognition - while fun to debate - are arbitrary in the sense discussed by Wilson and Brown (1953). Given this arbitrariness, tax subspecies, by most technical usages of the term, are not "natural kinds"; rather, they are, "social constructs" in the most constructive manner.

\section{IV-J. Are There Human Species?}

While human groups were once thought, by some, to be Linnaean species, neither they nor any other division of organisms could have been these Creator-made entities. However, with the acceptance of Darwin's theory of evolution, the ontological distinction between intraspecific races and species has been erased. Species have become just another variety of varieties, with the distinction between the two conventionally defined. This situation opens up the possibility that certain human groups can represent species in a conventional post-Darwinian sense. Since there

\footnotetext{
${ }^{79}$ In our estimate, based on the overall fit of currently recognized mammalian subspecies, human continental divisions would come in at the lower 10th to 15 th percentile, a percentile rank which normally would be considered to be (at the bottom end of) "low average."
} 
is no fundamental distinction between intraspecific races and species, whether there are different human species depends on the particular species concept employed.

While he felt that major human regional groups were best characterized as being subspecies, Darwin granted that one could, not without reason, describe them as constituting separate species (given an implied morphological concept). In Descent, he noted that "a naturalist might feel himself fully justified in ranking the races of man as distinct species" because they are "distinguished by many differences in structure and constitution" and because the "mutual fertility of all the races... would not be an absolute proof of their specific identity". For Darwin the admixture between groups argued against, but did not rule out, the treating of them as species, as a lack of interfertility and admixture were not necessary characteristics of species. During the 20th century, the evolutionary taxonomist's Biological Species Concept (BSC) came to dominate. With this, species were defined as being intrinsically reproductively isolated populations; by this, modern human populations necessarily could not represent different species. However, in the last several decades there has been a push back against this and others concepts which require intrinsic reproductive isolation. ${ }^{80}$ As noted in section I, some of the newer concepts which have been put forth are rather permissive. Both proponents and opponents of these often note that the acceptance of these concepts would lead to the elevation of many of the evolutionary taxonomist's subspecies to the status of species.

Discussing their diagnosable Phylogenic Species Concept (PSC-D), Wheeler and Platnick (2000) note that by it, since intrinsic reproductive isolation is not a criterion, some human populations could possibly constitute separate human species. They argue, though, that due to the recent history of admixture this is unlikely:

Given the vast extent of interbreeding among current human populations, it is unlikely (although not impossible) that any geographically restricted sample of humans is diagnosable [as separate species] today... [P]rior to the advent of intercontinental travel in the past few hundred years, it does appear probable that character distributions would have suggested more than one species of human on the planet...however...the obvious contemporary pattern of increasing introgression among previously allopatric human populations suggests that we are or soon will become on global polymorphic species[.]

Their diagnosability criterion for separate species is a "unique combination of constantly distributed characters." As Davis and Nixon (1992) and Coyne and Orr (2009) note, for this concept, a combination of variable traits (e.g., alleles at a particular loci), analyzed jointly, can be treated as a 'constant character.' Coyne and Orr (2009) point out that this condition would seem to allow for at least some contemporaneous human populations to meet the diagnosability criterion. ${ }^{81}$ Whether they could then be recognized as species would depend on how one conceptually dealt with intermediate populations and with intergradation. By a strict reading of the PSC-D concept - though not a more liberal one - when there is extensive secondary intergradation even once distinct PSC-D species are treated as one species, since they end up

\footnotetext{
${ }^{80}$ See, for example, the evaluations in Mayden (1997).

${ }^{81}$ Genomic analysis indicates that between some major regional races such as Europeans, East Asians, and West Africans there are at least a few fixed allelic differences (e.g., 1000 Genomes Project Consortium (2010)), so there might be some constant differences in single traits between certain races. If not, one could just combine traits as in multivariate analysis.
} 
being connected by a character gradient (Nixon and Wheeler, 1990). However, proponents of this concept have also stated that the existence of "hybrids does not negate the existence of parent species" (Platnick and Wheeler, 2000) and have suggested that "significant introgression" is only a problem insofar as it leads to a lack of constant differences between parent species. Since traits can be combined into characters, ${ }^{82}$ whether or not certain regional groups could constitute species by a liberal reading of this concept, one which allows for extensive hybridization, would depend on whether the groups in question at one time formed more or less distinct clades, that is, whether there was a 'sufficient' lack of primary intergradation. That there was is probably well defensible regarding primary human divisions such as between Africans and Eurasians. Some human natural divisions might then constitute PSC-D species, at least given a liberal reading of the concept.

A more permissive concept has been recently put forth by Kevin de Queiroz (1999; 2003; 2007; 2011). de Queiroz developed a general or unified species concept by which species are said to be the end points of "separately evolving metapopulation lineages". Specific criteria such as the Morphological Species Concept's phenotypic difference one, the PSC's constant character one, or the BSC's intrinsic reproduction isolation one are not considered to be a part of the general definition (de Queiroz, 2007). "In other words," we are told, "lineages do not have to be phenetically distinguishable, diagnosable, monophyletic, intrinsically reproductively isolated, ecologically divergent, or anything else to be considered species." As a result the concept is radically more inclusive than other species concepts. As de Queiroz (2003) notes:

One consequence of adopting a unified species concept is that all separately evolving population level lineages are species... Thus, not only reproductively isolated lineages are species, nor only ecologically differentiated ones, nor only diagnosable ones, nor only phenetically distinguishable ones. Even undifferentiated and undiagnosable lineages are species. As long as a lineage exists, which is to say as long as it is (or was, in the case of an extinct lineage) evolving separately from other lineages, it is a species... A corollary of this consequence is that there are many more species on Earth than biologists have been prepared to accept under traditional views. [Italics added]

And as de Queiroz (2011) points out:

If varieties are incipient species, then, in an important sense, varieties are species. Varieties are simply species at an early stage in their existence... Darwin's reasoning can be extended further. Just as varieties are incipient species, less modified and therefore unranked earlier segments of lineages can be seen as incipient varieties (i.e. species at a yet earlier stage of their existence). Thus, the segment of a lineage that is conceptualized as a species can be pushed all the way back to its initial separation from other lineages, as it is under the unified concept. [Italics added]

This concept is radically inclusive even compared to Darwin's, which, by removing the ontological species-intraspecific race distinction, allowed for the possibility that human races could be viewed as separate species. de Queiroz's concept seems to additionally remove the expectation that "species" should be seen as necessarily importantly different from one another. ${ }^{83}$

\footnotetext{
${ }^{82}$ See also Cracraft (1997) Table 16.1: "Extensively hybridizing, diagnosably distinct populations recognized as separate species?" "Almost Always."

${ }^{83}$ For a rather different and in our opinion erroneous reading of the concept see Braby et al. (2012). Compare their Figure 2 to de Queiroz's (2007) Figure 1 and discussion.
} 
As a results, his "species" ends up being nearly equivalent to 18th century inclusive sense "races". Imaginably this concept (properly understood) will not gain much currency - so we need not fret about the eruption of a new human species/constant variety debate. The existence of de Queiroz's general species concept (and of the PSC-D) does call to attention the contemporaneous conventionality of the species/subspecies/race distinctions.

\section{IV-K. 'Significant' Racial Differences}

It is frequently argued that there can be no socially important congenital differences between human biological races because there is too little genetic variation between them. For example, Brown and Armelago (2001) state:

[T] he evidence against genetically mediated differences in behavior along racial lines is overwhelming (Table 1). First of all, a host of studies, beginning with those by Lewontin in 1972 and most recently by Barbujani and colleagues in 1997, have shown that the amount of human genetic diversity that is attributable to race is only about $5 \%$ to $10 \%$. Following this, any particular "population" includes roughly $85 \%$ or more of the total human genetic diversity.

And Ossorio (2009) notes:

Finally, it is crucial to reemphasize that the amount of genetic variation between groups is very small compared to the 85 to 95 percent of variation found within human groups. ... The vast majority of human genetic variation is between individuals, including individuals who can be assigned to the same racial, ethnic, or national group. Because humans have high within-group genetic variation, genes are unlikely to explain average differences in IQ test scores of different racial groups.

Since we draw the obvious distinction between the existence of biological races and the existence of socially important differences between these, arguments like the two above would be of no interest to us were they not, for some reason, incorporated into ones against the existence of races themselves. One relatively sophisticated version runs: belief in human biological races is potentially dangerous, so we should only recognize these races if there are really important genetic differences between them; no such differences could possibly exist, since the variation between human races is very small; therefore, we should not recognize the existence of race, and we should instead assert that they do not exist. Though bizarre, this argument, if not in so many words, is common. Kitcher (2007), for example, elegantly states:

The challenge for someone who intends to defend a biological approach to human races is to develop a similar account for the utility of picking out those inbred lineages that descend from populations once geographically separated, in which, as a result of the separation, there are differences in superficial phenotypic traits, characteristics which, despite their superficiality, are salient for human beings... as the researchers point out, 93 to 95 percent of human genetic variation is found within the clusters (rather than between clusters); each cluster, then, is itself genetically quite heterogeneous...Yet here we should tread carefully, for the emphatic disavowal of racial essences already signals the fact that the clusters demarcated on the basis of genetic similarity are not going to play a significant role in the explanation of shared phenotypic features or susceptibilities to various types of disease[.]

Of course, one can only argue against the existence of socially important genetic differences between biological races if one recognizes and defines biological race. The next step is to 
actually show that the said differences do not exist. Some try to skip this step, though. They argue that such differences could not exist. Of course, it was not preordained that different human populations would not diverge in traits contemporaneously seen to be valuable. Even the radical egalitarian Stephen Jay Gould (1984) would have agreed: "Equality is a contingent fact of History." It is argued, though, that there is too little genetic variation between groups for there to be any such differences. This argument is so confused and fallacious that it is difficult to know where to begin when discussing it. We will briefly explain why it is unsound and why, if the validity of the argument is granted, it leads to the opposite conclusion drawn by those who make it.

As for the soundness of the argument:

A-1. When it comes to discussions of genetic contributions to phenotypic differences between groups, what is of relevance are the differences in the specific genes associated with specific traits, not the average genetic differences between groups. Regarding racial groups, genetic variation at a typical locus will have no functional consequence since a typical locus is selectively neutral. As such, average genetic variation will tend to measure neutral mutations and so index the time of divergence and the degree of isolation between populations (Sarich and Miele, 2004). The upshot is that the average genetic variation across loci does not allow one to predict the amount of differentiation in loci that were under selection - the very ones that are typically relevant when it comes to discussions of behavioral genetic and many other socially significant differences, ones which presumably were and are subject to selective pressure. With regards to these, one must look at differentiation in specific genetic regions (for example: $\mathrm{Wu}$ and Zhang, 2011) and the specific genes that code for the differences. To give a concrete example in which overall genetic differentiation is unindicative of differentiation with respect to a specific trait which has been under selection, at their extremes, northern and southern Europeans differ in height by approximately one standard deviation (Turchin et al., 2012; supplementary data). These height differences are substantially genetically determined (Turchin et al., 2012). Yet average European interpopulation SNP Fst values are trivial at 0.001 to 0.01 (Tian et al., 2009).

A-2. Measures of genetic differentiation based on fixation (e.g., Fst and $\Phi$ st) are often poor measures of true genetic differentiation. As Bird, Karl, Smouse, and Toonen (2011) remind us: "Using fixation indices will systematically underestimate genetic differentiation, especially when using highly polymorphic markers such as microsatellites (Hedrick 1999)." This is because maximum Fst values are limited by heterozygosity. To give an example of this underestimation, Long and Kittles (2003) found a between-population microsatellite Fst of 0.11 based on a sample of human populations; when they added chimpanzees to the set of human populations, the between-population Fst rose only to 0.18 . There were several reasons for the results, one of which was that the maximum possible Fst value, given the markers used, was well below the theoretical maximum of 1 both in the case of the human comparisons and in the case of the human and primate comparisons. The take away is that, as Mountain and Risch (2004) noted after citing this example in relation to their discussion of genetic contributions to phenotypic differences among ethnic and racial groups, "a low Fst estimate implies little about the degree to which genes contribute to between-group differences." 
A-3. The above noted, with caution genetic variability as indexed by Fst and Fst analogs can be and often is used to index the expected variation in quantitative traits owing to genetic drift (neutral variation) (Leinonen, McCairns, O'Hara, and Merilä, 2013). That is, researchers sometimes make comparisons between Fst and an index of heritable quantitative trait variability called Qst. This comparison is made to help evaluate if the quantitative trait variation found between populations is larger or smaller than would be expected based on neutral variation (i.e., if the traits under question were under selection). Whitlock (2008) explains the measure Qst:

\begin{abstract}
The calculation of QST for a trait requires two quantities: the additive genetic variance of the trait within a population (V A, within) and the genetic variance among populations ( V G, among). For diploids, QST is calculated as

Qst $=$ V G, among / (V G, among + 2V A, within)

For haploids, the same equation applies, but without the ' 2 ' in the denominator. [That ' 2 ' for the diploid case comes from the fact that the quantitative genetic variance among populations is proportional to two times FST (Wright, 1951).]
\end{abstract}

What is particularly relevant to the present discussion is Whitlock's last statement, since we are interested in predicting quantitative genetic variance from Fst, not comparing Qst to Fst. Amongst diploid populations, the predicted quantitative genetic trait variance is equal to $2 \mathrm{Fst} /(1$ + Fst) (Leinonen et al., 2013). ${ }^{84}$ The 2 in the equation comes from the fact that roughly half of the genetic variation within diploid populations is within individuals.

A-4. The point immediately above is often missed even by respected population geneticists, so it is worth elaborating on. It is not infrequently erroneously claimed that, in context to human races, 85 to $95 \%$ (for example: Barbujani and Colonna, 2010) or "the vast majority" (for example: Feldman, 2014) of the total genetic variance is between individuals within populations. This is incorrect since among diploids a large chunk of the total genetic variance is captured within individuals (Harpending, 2002; Sarich and Miele, 2004). The between population variance values given by Fst and Fst analogs is out of the summed variance between populations, between individuals within populations, and within individuals (e.g., Weir and Cockerham (1984)). Roughly half of the total within population variance for diploid populations is expected to be intra-individual. As such, the ratio of genetic variance between populations to that between individuals within populations (but not within individuals) is Fst/(Fst $+1 / 2(1-F s t)$ ), which is mathematically equivalent to $2 \mathrm{Fst} /(1+\mathrm{Fst})$, the predicted amount of quantitative genetic trait variance owing to drift.

Nishiyama et al. (2012) give an example which illustrates the flaw in deducing from low between population Fst values that the overwhelming portion of variance is between individuals. The authors decomposed the SNP genetic variance for various Japanese populations into interpopulational, inter-individual, and intra-individual variance. They found that between 96.7 and

\footnotetext{
${ }^{84}$ Cole et al. (1986), alternatively, note: "Wright $(1943,1951)$ showed, using a model of additive gene effects at a single locus, that variation among populations in the value of a selectively neutral quantitative character is, in expectation, $\mathrm{O}_{\mathrm{B}}^{2}=2 \mathrm{Fst} \mathrm{o}^{2}{ }_{0}$, where $\mathrm{o}^{2}{ }_{0}$ is the genetic variance expected under panmixia with the same gene frequencies, and FST is the correlation among uniting gametes relative to the total population."
} 
$99.6 \%$ of the variance was located within individuals. When intra-individual variance was partitioned out, roughly the same percent of genetic variance was located between subpopulations as between individuals within subpopulations. Interestingly, when decomposing variance between major human races using 1000 Genomes phase 3, Piffer and Dall'Olio (2015) also found that most variance was located within individuals. The decompositions are shown in Table 4.10 below.

In both cases, most of the variance was still "intrapopulational" in the sense of inter-individual plus intra-individual. It just was not mostly inter-individual in the sense of exclusively between individuals. Does this matter? Well, it casts the oft-referenced genetic variance ratios in a different light. And it is relevant if one's argument is that quantitative genetic differences between individuals between groups can not be substantial because there is "too little" between group genetic variation (relative to that between individuals within groups).

It should be noted that the empirical results mentioned are at odds with theory, which predicts that only roughly one half of the variance will be within individuals. ${ }^{85}$ It is possible that inclusion of relatives in the samples deflated the between individual variance.

Table 4.10. Total genetic variance partitioned into variance between subpopulations, among individuals within subpopulations, and within individuals in a Japanese sample and in1000 Genomes

\begin{tabular}{|c|c|c|c|c|}
\hline \multirow[t]{2}{*}{ Japanese Sample } & & Between & Among individuals & Within \\
\hline & & & & \\
\hline \multirow[t]{2}{*}{ Amami vs. Mainland } & Variance component & 0.03 & 0.02 & 2.13 \\
\hline & Relative proportion & $1.2(\%)$ & $1.1(\%)$ & $97.7(\%)$ \\
\hline \multirow[t]{2}{*}{ Okinawa vs. Mainland } & Variance component & 0.04 & 0.03 & 2.12 \\
\hline & Relative proportion & $1.9(\%)$ & $1.4(\%)$ & $96.7(\%)$ \\
\hline \multirow[t]{2}{*}{ Amami vs. Okinawa } & Variance component & $<0.01$ & $<0.01$ & 2.2 \\
\hline & Relative proportion & $0.2(\%)$ & $0.2(\%)$ & $99.6(\%)$ \\
\hline \multicolumn{5}{|c|}{ (Based on Table 4 in Nishiyama et al. (2012).) } \\
\hline \multirow[t]{2}{*}{1000 Genomes } & & Between & Among individuals & Within \\
\hline & & Population & within subpopulations & Individuals \\
\hline \multirow[t]{2}{*}{ European vs. African } & Variance component & 0.0049 & 0.0000 & 0.0353 \\
\hline & Relative proportion & $12.27(\%)$ & $0.06(\%)$ & $87.67(\%)$ \\
\hline \multirow[t]{2}{*}{ East Asian vs. African } & Variance component & 0.0060 & 0.0000 & 0.0346 \\
\hline & Relative proportion & $14.81(\%)$ & $0.02(\%)$ & $85.17(\%)$ \\
\hline \multirow[t]{2}{*}{ European vs. East Asian } & Variance component & 0.0033 & -0.0001 & 0.0290 \\
\hline & Relative proportion & $10.34(\%)$ & $-0.17(\%)$ & $89.83(\%)$ \\
\hline
\end{tabular}

\footnotetext{
${ }^{85}$ Several researchers who had written on the topic were contacted about the matter, but they either failed to reply, did not have an explanation, or stated that they were not familiar with the specific issue.
} 
A-5. Getting back to the main point, if we wish to estimate expected quantitative genetic trait variation it is often advised to avoid using low mutation rate genetic markers such as microsatellites, which, as discussed, have high Hs values and thus necessarily exhibit low Fst values. It is often advised instead to use SNPs, both because these markers do not tend to have very high Hs values and because SNP variation codes for typical quantitative trait variation (Edelaar and Björklund, 2011). ${ }^{86}$ Another way to look at this is to consider that the magnitude of (fixation index estimated) genetic differentiation varies by the class of loci analyzed, with part of this variation being attributable to loci variation in Hs (Jakobsson et al., 2013); for example, for humans, continental microsatellite, SNP, and mtDNA Fst values are typically around, respectively, $0.05,0.12$, and 0.20 . Were one to try to infer the magnitude of genetically conditioned phenotypic variation from typical indices of fixation (e.g., Fst values), it would make sense to use the class of loci that most likely underpins the relevant trait variation. For example, since variation in single-nucleotide polymorphisms (SNPs) explains variation in many interesting polygenetic traits such as height and intelligence (for example: Yang et al., 2010; Davies et al., 2011), it would make more sense to attempt to infer magnitudes of genetic differentiation in these traits from SNP Fst values than from microsatellite or mtDNA ones. ${ }^{87}$

Now, these five considerations set up the problem for the "too little variance" argument, with its implicit premise that the ratio of genetically mediated phenotypic variability in socially significant traits is roughly concordant with the ratio of average genetic variability. As will be seen, the argument lends itself to the opposite of the conclusion drawn by biological race antagonists. This is for the following reasons:

B-1. The magnitude of average genetic differentiation depends on the biological divisions in question. It makes no sense to argue that differences between regional biological races (e.g., Europeans and West Africans) can not be genetically conditioned on the account of supposedly small differences between continental races (e.g., Caucasoids and Negroids). The magnitudes of the genetic differentiation in SNPs between some regional races are shown below in Table 4.11.

Table 4.11. Intercontinental autosomal genetic distance based on SNPs for 1000 Genomes (below diagonal) and HapMap3 (above diagonal)

$\begin{array}{llll} & \text { YRI (Yoruba) } & \text { CHB (Chinese) } & \text { CEU (European) } \\ \text { YRI (Yoruba) } & & 0.183 & 0.156 \\ \text { CHB (Chinese) } & 0.161 & & 0.11 \\ \text { CEU (European) } & 0.139 & 0.106 & \end{array}$

(From: Bhatia et al. (2013), Table 2. Based on recommended ratio to average method.)

\footnotetext{
${ }^{86}$ Edelaar and Björklund (2011) note: "[W]e would like to promote the use of neutral single-nucleotide polymorphisms (SNPs; reviewed in Brumfield et al. 2003; Morin et al. 2004). We feel that these provide us with a closer approximation to the genomic mechanisms driving quantitative trait evolution and to the presumably low mutation rates of underlying QTL than do highly variable markers such as microsatellites."

${ }^{87}$ For a breakdown of SNP variance by classes (e.g., coding, non-coding), readers are referred to supplementary Table 2 of Barreiro et al. (2008).
} 
B-2. The magnitude of SNP differentiation, as indexed by Fst, is not small, even between continental races, according to population genetic and social scientific standards. The median continental race SNP Fst value is said to be around 0.12 (Li et al., 2008; Campbell and Tishkoff, 2008; Elhaik, 2012; Bhatia, Patterson, Sankararaman, and Price, 2013), with the estimated magnitudes varying somewhat due to the choice of specific loci, the method of aggregation employed, the Fst estimators used, and so on (see: Bhatia et al. (2013)). With regards to population genetic standards, the difference would be moderate by Sewall Wright's (1978) not infrequently cited scale. ${ }^{88}$ By this:

0 to 0.05 indicates little genetic differentiation; 0.05 to 0.15 indicates moderate genetic differentiation, 0.15 to 0.25 indicates great genetic differentiation, 0.25 indicate very great genetic differentiation.

Now, with regards to social scientific standards, if we naively treat our Fst statistic as indexing the proportion of the total genetic variance lying between groups we can interpret it in terms of eta-squared. A between group variance of 0.12 would be moderate. Alternatively, treating the SNP Fst $=0.12$ as an index of between group variance, one can convert the value into standardized differences, a metric in which, in the social sciences, group comparisons are often made. The formula is shown below:

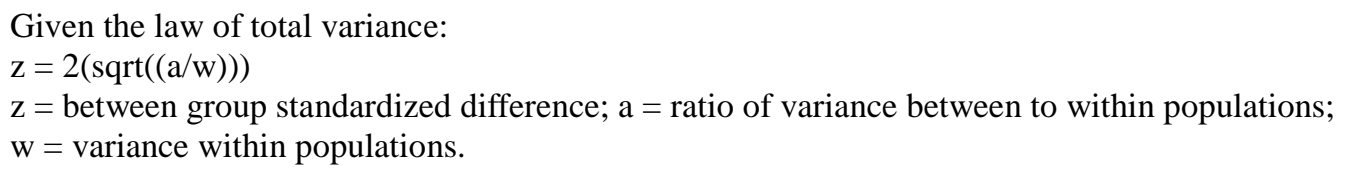

If one assumes normality and equal variances, a $12 \%$ between-population variation is equivalent to a $d$-value of $\sim 0.74$, which is typically said to be "medium" to "large." For illustration, the relationships between percent variance between populations and various statistics are shown in Table 4.12 (from Cohen (1988)).

Table 4.12. Interpreting and comparing effect sizes in the social sciences

$\begin{array}{lllll}\text { Size of Effect } & \text { Cohen's f [1] } & \text { \%Variance (eta-squared) [2] } & \text { Cohen's d [3] } & \text { Pearson's r } \\ \text { Small } & 0.1 & 1 & 0.2 & 0.1 \\ \text { Medium } & 0.25 & 6 & 0.51 & 0.25 \\ \text { Large } & 0.4 & 14 & 0.81 & 0.38\end{array}$

[1] Cohen's $\mathrm{f}=$ Square Root of eta-squared / (1-eta-squared). [2] Eta-squared is interpretable as the variance that lies between groups relative to the total variance (Cahan and Gamliel, 2011). [3] Cohen's $d$ is the mean difference between populations divided by the pooled standard deviation.

Of course, as noted, contrary to what is sometimes stated (e.g., Fish (2013)), unlike eta-squared, Fst values are rarely out of 1 in practice. For example, in their Table 1 and 2, Xu, Huang, Qian, and Jin (2008) give expected heterozygosity (Hs) values for Japanese (JPT), Chinese (CHB),

\footnotetext{
${ }^{88}$ See for example: Oliveira et al. (2007) and Zhang and Tier (2009). Note, Wright (1978) noted that the scale was somewhat arbitrary.
} 
Uyghurs (UIG), Europeans (CEU), and Yorubi (YRI) based on 20177 SNPs. The average Hs came out to about 0.30 , meaning that the maximum possible SNP Fst value - the value that would be found if populations had no alleles in common - would be 0.7. Treating Fst as something akin to eta-squared is therefore problematic.

B-3. But all of this neglects the points made in A-3 and A-4. As said, our Fst value is relative to total variance, which includes the irrelevant, in this context, intra-individual variance. Instead of the expected (simply owing to neutral variation) between group quantitative genetic variation being proportional to Fst, it is proportional to roughly 2(Fst). Solving Fst= V G, among / (V G, among $+2 \mathrm{~V}$ A, within) for a between group quantitative genetic variance value $\left(\mathrm{V} \mathrm{G}_{\mathrm{G}}\right.$ among $)$, when Fst $=$ 0.12 , gives us $V_{G}$, among $=0.22$. This value can then be inputted back into the equation given in B.-2. When done so, we find that more than a little quantitative genetic variance is expected to lie between groups.

Can the "too little variance" argument be salvaged? It can not. To avoid a racial-hereditarian conclusion, it must be discarded - but how? One could, citing the points made in A-2, argue that, in general, there is little correlation between average genetic variability and genetically mediated phenotypic variability. But this is not the case at least with regard to many classes of character differences. Relethford (2009), for example, notes:

Several studies have looked at estimates of FST based on the global craniometric dataset originally collected by Howells $(1973,1989,1995,1996) \ldots$ Using an average heritability of 0.55 , Relethford $(1994,2002)$ found that estimates of FST based on all 57 traits ranged from 0.11 to 0.14 depending on the number of geographic regions sampled. These FST values are similar in magnitude to those estimated in a number of studies of classical genetic markers and DNA markers.

Relethford's (2009) "craniometric Fst" values approximate Qst ones - and, in this case, they also happen to be roughly equivalent to human (genetic) Fst ones. When we grouped Howells' 28 populations into six major continental races - West Eurasians, East Eurasians, Australoids, Negroids, Amerindians, and Pacific Islanders - and ran an ANOVA using the first principle component we found a (phenotypic craniometric) eta-squared of between 0.10 and 0.14 (depending on the specific method used), which is in line with Relethford's (2009) findings. Assuming a heritability of about 0.55 , as Relethford does, we get a craniometric quantitative genetic variance value of around 0.22 , as predicted based on the considerations in B-3. ${ }^{89}$

Similar results have been reported in context to dental traits (e.g., Hanihara (2008)). Taken together, the theory and evidence suggests that, between continental races, Fst values are roughly half of the size of the between group quantitative genetic ones - at least for traits varied due to drift - and are roughly proportional to the phenotypic variance values when the narrow heritability of the traits is modest (e.g., 0.5). Yet, as we noted above, Fst values are medium to large as judged by social scientific standards. So if one grants the premise of the "too little variance" argument, that between population genetic variance indexes variance in behavioral genetic or other socially relevant traits, one is left with medium to large genetically conditioned differences. Instead of Lewontin's conclusion, one is left with the early Franz Boas's deduction:

\footnotetext{
${ }^{89}$ The phenotypic variance between populations is lower than the quantitative genetic variance in proportion with the heritability (i.e., variance in phenotype owing to genes). When $\mathrm{h}^{\wedge} 2=1$, the phenotypic variance is equal to the quantitative genetic variance.
} 
It does not seem probable that the minds of races which show variations in their anatomical structure should act in exactly the same manner. Differences of structure must be accompanied by differences of function, physiological as well as psychological; and, as we found clear evidence of difference in structure between the races, so we must anticipate that differences in mental characteristics will be found. [...] (Boas, 1974).

Of course, one could try to argue that differentiation in the genes that underlay interesting physiological and neurological functions is trivial - but the empirical evidence speaks against such an argument. As an example of such evidence, in the context of regional (European, East Asian, and West African) population differences, Wu and Zhang (2011) conclude:

[W] find that genes involved in osteoblast development, hair follicles development, pigmentation, spermatid, nervous system and organ development, and some metabolic pathways have higher levels of population differentiation. Surprisingly, we find that Mendelian-disease genes appear to have a significant excessive of SNPs with high levels of population differentiation, possibly because the incidence and susceptibility of these diseases show differences among populations.

Another way to escape the reverse of the "too little variation" argument would be to reiterate a version of Loring Brace's (1999) argument. According to this, since each population has an equal ability to use language and to develop culture, they must not differ in behavioral traits such as intelligence. This type of argument, of course, is (logically) ridiculous when applied in context to normally distributed traits because within each and every population innumerous subpopulations exist which do differ in these traits. If these subpopulations which differ can exist then populations which exist can differ. Worse, it is already known that human populations do differ in the said traits; the debate is over "why," not "whether."

Ultimately, the way around the early Boas' deduction is to reiterate our point A-1. However, numerous philosophers of science and population geneticists have deemed the "too little variance" argument to be valid (for example: Kitcher, 2007; Brown and Armelago, 2001; Barbujani and Colonna, 2010), so perhaps its reversed version can not be so easily dismissed. Such an argument could never establish a genetic basis for specific differences; but, perhaps, as suggested by Boas and others, it provides probabilistic support - a baseline expectation - for the existence of some behavioral genetic differences. Whatever the case, to the extent that the "too little variance" argument is deemed to be valid it clearly fails to support the position in defense of which it has been enlisted.

\section{IV-L. Human Biodiversity (HBD) and Society}

The considerations above lend themselves to the conclusion that there are at least some interesting behavioral genetic differences between certain races. On the individual level, these differences do not typically seem to be large, at least by social scientific standards. This, though, does not imply that some of the known large cultural, national, and regional differences are not explainable in terms of them. It has been shown that in theory small individual level behavioral differences can amplify such to produce large population level ones (Dickens and Flynn, 2001); more specifically, population level differences involve not just the direct effects of individual level ones but they also involve the indirect effects of these, thus allowing for a population level amplification (Gordon, 1997). As such, there is no inconsistency between small individual level 
differences and large population level ones. This point was made by the prominent early 20th century psychologist William McDougall. In 1920, he noted, "The principle is that, though differences of racial mental qualities are relatively small, so small as to be indistinguishable with certainty in individuals, they are yet of great importance for the life of nations, because they exert throughout many generations a constant bias upon the development of their culture and their institutions" (Lamb, 1999). Ninety-four years later, after discussing a number of societal and civilizational differences in light of human biodiversity, Wade (2014) concluded much the same:"[T] hese minor differences, for the most part invisible in an individual, have major consequences at the level of a society."

Some racialists have argued that biological race and culture are deeply entwined. For example, Sam Francis - quoted in Swain (2002) - argued:

The civilization that we as whites created in Europe and America could not have developed apart from the genetic endowments of the creating people, nor is there any reason to believe that the civilization can be successfully transmitted to a different people. If the people or race who created and sustained the civilization of the West should die, then the civilization also will die.

While we certainly agree that biological differences are not unrelated to cultural ones, the degree of entwinement is, in our opinion, somewhat less than that envisioned by Mr. Francis. Readers can judge for themselves, though. Exploration of the association between genetic, neurological, and culture differences is being conducted in cultural neuroscience (see: Chiao (2009)) and related fields. Regarding cultural neuroscience, while discussion typically focuses on differences between "cultural" groups, the biological racial aspect is implicitly recognized; hence, Chiao and Ambady (2010) note that they "prefer to discuss population variation in the genome in terms of culture rather than race" but then go on to discuss groups which correspond with races (e.g., ethnic Europeans and ethnic East Asians) or with nations which either can be clustered roughly into biological races or can be described in terms of degrees of (e.g., continental) racial admixture. Other research which deals with cultural differences and population genetics is being conducted in differential psychology and is being published in journals such as Intelligence (e.g., Woodley, Rindermann, Bell, Stratford, and Piffer (2014)). Still other research is being conducted in the field of evolutionary psychology; for an introduction to this line of investigation, specifically that regarding gene-culture co-evolution, readers are referred to Laland, OdlingSmee, and Myles (2010) and Penke (2010).

Regarding results, researchers have found that frequency differences in specific behaviorally associated alleles can (statistically) explain some of a number of interesting national, regional, and ethnic sociocultural differences, ${ }^{90}$ including the following: collectivism (Way and Lieberman, 2010; Luo and Han, 2014; Kitayama et al., 2014), life history (Minkov and Bond, 2015), moral looseness (Mrazek, Chiao, Blizinsky, Lun, and Gelfand, 2013), self-expression (LeClair, Janusonis, and Kim, 2014), academic achievement and cognitive ability (Piffer, 2015a; Piffer, 2015b; Minkov, Blagoev, and Bond, 2014), corporate leadership style (Kong, 2014), longterm orientation (Minkov and Bond, 2015), and life satisfaction (Inglehart et al., 2014; Kashima,

\footnotetext{
${ }^{90}$ The effect sizes of the alleles themselves explain little; but the patterns of frequency differences can explain a substantial portion of the phenotypic ones in the sense that the squared correlation between allelic scores based on multiple alleles and phenotypic scores is often moderate to high for some traits.
} 
Kent, and Kashima, 2015). Others have found that genetic similarity can (statistically) explain national differences in cognitive ability (for example: Rodriguez-Arana, 2010; Rindermann, Woodley, and Stratford, 2012), happiness (Proto and Oswald, 2014), and risk preference (Becker, Dohmen, Enke, and Falk, 2014). The above mentioned findings are tentative and in need of both replication and extension. They do, though, provide some population genetic evidence for interesting behavioral genetic differences. Regarding heritable behavioral differences, additional possibilities have been discussed by Anthropologist Peter Frost in his 2011 article "Human nature or human natures?" These include average ethnic and racial differences in visual word form processing, reproductive strategy, and propensity towards violence. Harvey (2011) has also suggested a genetic basis for the following documented phenotypic differences: route memory (between Aborigines and Europeans), holistic perception (between East Asians and Europeans), and trust (globally).

In general, some culturally related differences are undoubtedly genetically conditioned. To the extent that they can be said to be causally genetic, the pathways are likely largely indirect. ${ }^{91}$ Time will tell, though. This area of research is still in its infancy and there is much that is opaque. In terms of our overall understanding of behavioral genetic differences between races not a whole lot seems to have changed since Darwin (1876) wrote:

\begin{abstract}
Although the existing races of man differ in many respects, as in colour, hair, shape of skull, proportions of the body, etc., yet if their whole organization be taken into consideration they are found to resemble each other closely in a multitude of points... The same remark holds good with equal or greater force with respect to the numerous points of mental similarity between the most distinct races of man. The American aborigines, Negroes and Europeans differ as much from each other in mind as any three races that can be named; yet I was incessantly struck, whilst living with the Fuegians on board the "Beagle," with the many little traits of character, shewing how similar their minds were to ours; and so it was with a full-blooded negro with whom I happened once to be intimate.
\end{abstract}

\title{
IV-M. Race and Intelligence
}

We will not delve deeply into the topic of race and intelligence, as doing so would require an essay twice the current's length. We will simply note that this issue is of grave importance to many opponents of biological race - and then provide a brief outline of the hereditarian position. With regards to the issue's importance, Pigliucci (2013) tells us:

Of course, anyone who has seriously looked into this endless debate knows very well that here is where the stakes really lie: it is not about small genetic differences that may or may not help build a more individualized medicine; it is not about forensic anthropologists and how well they do their work; it is about claims that one race has superior or inferior intellectual capabilities than other one.

While we disagree with Pigliucci (2013) regarding his claim that this issue represents the true essence of the debate, as it is a very important concern for him and his colleagues and as it has relevance to moral arguments against biological race, we will discuss the matter, though as economically as possible.

\footnotetext{
${ }^{91}$ Readers are referred to Sesardic's (1993) lucid discussion of “direct” versus "indirect” genetic causation.
} 
The existence of substantial interracial and international differences in cognitive ability have long been suspected (for example: Jefferson, 1781; Galton, 1869; Baker, 1974). The last thirty years have vindicated such speculations. ${ }^{92}$ The volumes of research on this topic will not be reviewed here. Instead, readers are referred to Rindermann (2007) and Lynn and Vanhanen (2012) for recent estimates of intelligence by nation and continental race. These estimates are based on IQ and international achievement tests, exams which have been shown to be highly predictive of success both within and between nations and regions. ${ }^{93}$ As Baten and Juif (2013) note, the international cognitive ability differences are not new and they precede the event of mass schooling. As such, Baten and Sohn (2013) found that Korea, China and Japan had high numeracy levels in the 1600s; Juif and Baten (2013) found that Spanish and Portuguese had higher numeracy levels than Amerindian Incans in the 1500s. Juif and Baten (2013) also found that 1820 cohort ethnic/national cognitive ability levels predicted 21 st century national levels.

Generally speaking, global variance in intelligence exhibits a north-south clinal pattern for indigenous populations. This pattern does not hold when it comes to recent (post-1500) global migrants (e.g., Europeans in Australia, N.E. Asians in Brazil, and S.S. Africans in North America). Since there is a high correlation between skin color/reflectance and measured ability (typically around 0.9), the distribution of the two traits can be thought of similarly (i.e., both are clinal). Some published estimates which take into account various environmental factors are shown below in Table 4.13 .

There are four reasons for suspecting a genetic basis for some of the global differences ${ }^{94}$. Firstly, genes explain a large portion of intelligence differences between individuals within nations and

\footnotetext{
${ }^{92}$ A note about terminology: In psychometrics, the dominant model of intelligence has three stratums of cognitive abilities with a general factor situated at the apex. In the literature, sometimes the assortment of cognitive abilities (narrow, broad, and general) taken together is called intelligence and sometimes only the general factor is. In practice, full scale scores from cognitive batteries, such as IQ tests, index general cognitive ability (also called general intelligence) differences; as such, in context to inter-individual differences, the terms "IQ" (a measure), "cognitive ability" (an inclusive description of abilities), and "general intelligence" (stratum III in the dominant model of intelligence) are used synonymously. Here, we will use the terms "intelligence" and "cognitive ability" synonymously and to refer to the assortment of correlating cognitive abilities indexed by achievement, IQ, cognitive ability, and other tests. While the differences in intelligence which we are discussing almost certainly index ones in general intelligence, as no studies have established this, we will not call them "general intelligence" differences.

${ }^{93}$ See, for example, Malloy (2008) regarding within nation correlations; for the numerous economic, political, demographic, sociological, epidemiological, and geographic correlates, readers are referred to Lynn and Vanhanen (2012).

${ }^{94}$ As for the potential origin of congenital regional differences, a number of models have been offered. A few examples are as follows: Miller (2010) and Gottfredson (2007) proposed gene-culture co-evolution models; Cochran and Harpending (2009) suggested that beneficial alleles could have been differentially acquired through adaptive introgression; to account for the global north-south cognitive ability cline, Lynn (2006) and others have proposed a model of cold weather climatic selection (see also: Gottfredson (2007)). The last model has interesting theoretical and empirical support. Regarding theory, in (at least some) non-human species, climate is associated with between population variation in cognition, brain size, and heritable neural functioning (see, for example: Roth et al., 2010; Roth et al., 2012; Roth et al., 2013); cold evolved populations are, apparently, sharper. For humans, models which assume a simple relationship between selection conditioned on cognitive ability and climatic harshness over the last 60,000 years reasonably predict current global cognitive capital (see: Hart, 2007; relatedly: Grall, 2012). Regarding empirical findings, climate by way of cranial size explains a non-trivial portion of the National IQ variance (see:
} 
racial groups. ${ }^{95}$ Across Eurasia, Australia, and North America, by adulthood, $60-80 \%$ of the variance in ability is accounted for, directly and indirectly, by genes. This sets the behavioral genetic default.

\section{Table 4.13. Regional differences in measured intelligence relative to Europeans; scaled with a standard deviation of 15}

\section{Continental Race}

Mongoloid

Caucasoid

Amerindian

Negroid

\section{Region}

North East Asian

South East Asian

European

North African/ South Asian

Amerindian

S.S. Africa

\author{
Approximate Difference \\ 8.5 \\ $-9.5$ \\ (Reference) \\ $-11.5$ \\ $-15$ \\ $-18.7$
}

(Based on Christainsen's (2013) Table 2 regression results. The following were controlled for:

per capita GDP, under five mortality rate, average years of schooling, and malnutrition.)

Secondly, national and continental racial differences are associated with numerous historic, biological, genetic, and evolutionary variables. Some of these are shown below in Table 4.14. The evolutionary and genetic correlates of these differences imply that either genetic differences are directly causing the phenotypic differences, that genetic differences are doing so indirectly by way of environmental factors, ${ }^{96}$ or that the global genetic-intelligence covariance is a product of some third, unidentified, set of factors. Whatever the case, there is for races and nations a robust association between cognitive ability and genes; hence, there is good reason for suspecting that differences have a genetic etiology. Third, frequency differences in specific cognitively associated alleles have been shown to predict aggregate national and racial IQ differences (Piffer, 2015a; Piffer, 2015b; Minkov et al., 2014). ${ }^{97}$

\footnotetext{
Meisenberg and Woodley, 2013). Generally, cognitive and cognitively related somatic differences are in agreement with the cold weather model; this model is also in agreement with the literature regarding other species.

${ }^{95}$ It has been suggested that the heritability of cognitive ability varies across ethnic and racial groups, but Fuerst and Dalliard (2014) found no consistent meta-analytic evidence of this at least in the U.S.

${ }^{96}$ See, for example, the models of León and Burga-León (2015) and Fedderke, Klitgaard, MacMurray, and Napolioni (2014).

${ }^{97}$ These alleles are not necessarily general cognitive ability associated ones. For example, Minkov et al. (2014) note that: "The literature reviews and analyses by Dobson and Brent (2013) and Holmberg and Lesch (2011) suggest that S-allele carriers outperform L-allele carriers on a variety of cognitive tasks, such as financial decision making, probably because of their hyper vigilant decision-making style... The serotonin-transporter gene is not an IQ gene, however." The frequency differences nonetheless evidence historic selection pressure on cognitively related traits in general; if there generally was such selection pressure, it would likely, though not necessarily, have acted also on general cognitive ability. The alleles discussed by Piffer (2015a) have been shown to be reliably associated with educational attainment, educational achievement test, and intelligence test scores.
} 


\section{Table 4.14. Historic, biological, genetic, and evolutionary variables associated with national and regional racial differences in measures of cognitive ability}

IQ and edu. attainment associated SNP frequencies

Cognitive functioning associated SNP frequencies

Genomic racial admixture (across the Americas)

Racial classifications (based on genetic clusters)

Genetic proximity

Genetic proximity

Genetic distance from native South Africans

Genetic distance from the U.S. and the U.K.

Spatial proximity of nations to each other

Haplogroups

Haplogroups

Cranial capacity

Nasal Index

Time since the origin of agriculture

Technological development in 1000 B.C.

Skin color

Skin reflectance

GDP 1500s

19th century age heaping (measure of numeracy)

Temperature: annual mean

Average winter temperature

Latitude
Piffer $(2013 ; 2015)$

Minkov et al. (2014)

Fuerst and Kirkegaard (2015)

Christainsen (2013)

Becker and Rindermann (2014)

Piffer and Kirkegaard (2015)

León and Burga-León (2015)

Kodila-Tedika and Asongu (2015)

Gelade (2008)

Rindermann et al. (2012)

Rodriguez-Arana (2010)

Meisenberg and Woodley (2013)

Templer and Stephens (2014)

Meisenberg and Woodley (2013)

Lynn (2012)

Templer and Arikawa (2006)

Templer (2008)

Lynn and Vanhanen (2012)

Baten and Juif (2013)

Vanhanen (2009)

Meisenberg and Woodley (2013)

Dama (2011)

The fourth reason is that the cognitive ability scores of international migrants tend to correlate with the cognitive ability scores of those from the regions of origin. That is, to some extent, contemporaneous migrants carry their region of origin abilities with them and the differences brought persist at least until the second or third generation (Carabaña, 2011; De Philippis, 2013; Fuerst, 2014; Kirkegaard, 2015). For an explicit discussion of contemporaneous differences between races in twenty-three multiracial societies, readers are cautiously referred to Lynn (2008) (cautiously because the work is badly in need of updating ${ }^{98}$ ). ${ }^{99}$

\footnotetext{
${ }^{98}$ We make this claim based on our own investigation of the data.

${ }^{99}$ It will be noted that the existence of a robust association between migrant and region of origin performance is fairly crucial to a hereditarian (additive genetic) model. That said, and as discussed in the prior section, large hereditarian differences are not needed to account for large causal genetic differences on the level of populations. The matter, of course, is complicated by migrant selectivity, ethnic identification attrition, differential breeding patterns, non-trivial environmental influence on measures, and so on. Yet, were a racial hereditarian position correct, one would expect to find, when looking across numerous countries, a robust statistical association between region of origin scores and migrant scores.
} 
From a more historical perspective, based on an analysis of 123 countries, 54 of which were European colonies, Prayon and Baten (2010) found a European colonial migrant human capital effect. European migrants to Africa, South Asia, Oceania, and the Americas had to begin with higher levels of developed cognitive ability (as indexed by age heaping) than the peoples indigenous to those regions. The authors found that the contemporaneous benefits of the historic human capital infusion, resulting from European migration to these areas, varied as a function of the ratio of European migrants to non-European natives. The implication is that historic European migrants brought their region of origin abilities with them and that this historic migrant effect persists still today. ${ }^{100}$ As one might expect from the above discussion, genomic racial ancestry, which varies extensively in the Americas due to historic migrant waves, predicts cognitive and/or cognitive related outcomes across the Americas, between nations, between regions within nations, and between individuals within national ethnic groups (Fuerst and Kirkegaard, 2015).

This all said, are there reasons to be skeptical about the existence of a genetic basis for such differences? Firstly, the psychometric nature of the measured differences is not well investigated; simply, it is not clear to what extent they are psychometrically unbiased in the sense of having the same meaning as those differences, ones which are known to have a substantial genetic basis, within nations and regions. In principle, international differences could be akin to the wellknown secular ones (Flynn Effect), which are due to some mix of psychometric bias and (presumably) environmental factors. Secondly, the migrant and intranational data, while generally consistent with a non-trivial hereditarian hypothesis, is not compelling; groups which one would expect to do poorly not infrequently fair well (e.g., Fuerst (2014)). Thirdly, the more direct population genetic evidence (Piffer, 2015a; Piffer, 2015b; Minkov et al., 2014) is tentative. In short, the true model is necessarily more complicated than a simple hereditarian one and the issue is still undetermined; but, then, no one is arguing for a simple hereditarian model; instead, many are arguing for a simple and implausible purely environmental one. ${ }^{101}$ Our point here, though, is not to argue the case for average congenital biological racial differences in intelligence or other behavioral traits. It is simply to note that the issue is presently undetermined. This has bearing on some of the argument leveled against the biological race concept.

\footnotetext{
${ }^{100}$ Putterman and Weil (2008) also found a historic migrant effect on international economic inequality. They used a more inclusive set of countries and ethnic groups. They also found that region of origin explained outcome variance within countries.

${ }^{101}$ It will be noted that in a 2014 letter to the editor by a group of 143 population geneticist, it was claimed that: "We are in full agreement that there is no support from the field of population genetics for Wade's conjectures [that recent natural selection has led to worldwide differences in I.Q. test results, political institutions and economic development]" (Coop et al., 2014). We have no idea what the signatories meant by "no support." Either they were unaware of the evidence mentioned above or they do not consider it to constitute "population genetic" "support" in some sense. Whatever the case, the support mentioned is "support" in the sense that it is consistent with a partial natural selection model and not consistent with some environmental models. Of course, were it inconsistent with all environmental models and were it robust enough it would be called "proof."
} 
Philosophers (and others) have too long tried to destroy the scientific notion of race in different ways; the point, however, is to understand it. - Sesardic (2010)

\section{Critique of Anti-Biological Race Arguments}

\section{V-A. Anti-Biological Arguments}

Having clarified the (natural division) race concept, it is worth briefly reviewing the current state of the debate. Generally, discussion of race in the philosophy of biology and in anthropology is dominated by vocal and passionate racial constructionists, anti-realists, anti-naturalists, and eliminativists, many of whose agenda is to deconstruct race and to re-engineer social perception for the sake of social justice. ${ }^{102}$ Their motivations are often not in the least concealed. Appiah (1985) tells us that the concept of race is malign:

If we can now hope to understand the concept embodied in this system of oppositions, we are nowhere near finding referents for it. The truth is that there are no races: there is nothing in the world that can do all we ask "race" to do for us. The evil that is done is done by the concept and by easy - yet impossible - assumptions as to its application. What we miss through our obsession with the structure of relations of concepts is, simply, reality.

According to Gutmann (in Appiah and Gutmann, 1998), the idea of race is dangerous because it perpetuates injustices:

Another common usage of race - which I shall call "color" - refers only to superficial features such as skin color and facial characteristics, and occasionally also to ancestry. Were this all that race meant today, then it would not be a morally dangerous fiction. Nor would race be a very significant social or scientific category, around which some of the most vexing political problems of our time revolve....

But, human psychology being what it is, the moral case against racial injustice is unlikely to be as effective if people continue to believe in the fiction of distinguishable human races.

Kaszycka et al. (2009) urge us to struggle against the concept of race because the term is "so loaded with misconceptions, misunderstanding, fallacy, prejudice, and bigotry." They tell us:

Is it even possible to study races? Is the word "race" so loaded with misconceptions, misunderstanding, fallacy, prejudice, and bigotry that the term itself should be changed and its study limited?" (1991:195). We are well aware that dispensing with the term altogether has proved difficult. One of the reasons is an attachment to paradigms (we might call it "tradition"), but there is also a second factor: convenience. Hence, the struggle against the concept of "race" - in all of its connotations - is bound still to be long and arduous. Nonetheless, it is one eminently worthwhile to continue to undertake.

One can list innumerable similar opinions. As a result of this moral zeal, biological concepts of race have not been dispassionately evaluated and rejected on logical and empirical grounds;

\footnotetext{
${ }^{102}$ Kelly et al (2010) notes: "In sum, both eliminativist and conservationist agendas include, often tacitly, goals of psychological reformation. In particular: Eliminativists' Goal: A reduction of racial categorization in thought and behavior... But many eliminativists (including a variety of liberal thinkers) have something much more sweeping in mind, and suggest reform extending from large-scale features of social organization all the way to individual habits of thought and action."
} 
rather, they have been attacked for the sake of certain visions of egalitarianism, social justice, inclusiveness, and, at times, some estimates of "Cui bono?" As we see it, such extra-scientific intents are not, with regards to evaluating positions, problematic per se; such motives are only so insofar as they lead one to accept unsound arguments or as they dispose one towards intellectual dishonesty. As such, we are uninterested in exposing moralism and 'scientific Marxism' on the part of such authors. Our focus here is exclusively on the merits of the arguments. We do not pretend to be purely passive voices of science ourselves.

As for arguments against biological races, most are riddled with fallacies. The authors of many try their best to obscure and confuse; some, though, seem to be presented in good faith. Since many find these arguments compelling, we will consider the most often stated and/or most interesting ones.

\section{V-B. Biological Scientific Arguments}

Biological arguments work from within the biological sciences and attempt to show that human races, or, at times, races in general, do not exist given some strictly natural scientific considerations. These can be subdivided into human subspecies, panmixia, population structure, bio-statistical, cluster discordance, and folk-race biological-race mismatch arguments.

\section{Subspecies Arguments}

Subspecies arguments equate race with taxa subspecies and then try to show that human populations do not qualify as races in this sense. They generally utilize the following strategy: first, establish that biological race is synonymous with taxa subspecies; second, establish the qualifying criteria for taxa subspecies; third, establish that no human populations qualify as subspecies in the said sense.

Templeton (1998; 2013)

Templeton $(1998 ; 2013)$ employs a four step strategy to disqualify biological human races: (a) first, he contends that "biological race" should refer to taxa subspecies, (b) second, he argues that the taxonomic category subspecies should be interpreted from either, basically, a cladistic or an evolutionary taxonomic perspective, (c) third, he argues that, for formal race recognition, evolutionary taxonomy requires divisions to have a Fst value greater than 0.25 and that cladism requires a very high degree of branchedness, (d) fourth, he points out that the Fst value between human populations is lower than 0.25 and that human populations have experienced a good deal of intermixing and, as such, do not meet a strict branching criterion. There are two problems with his argument. First, the concept of biological race is not now nor ever was consistently equated with the concept of taxa subspecies. Indeed, as discussed in sections I and II, race, as such, originally found no place in traditional systematics; originally, "race" was not a taxonomic category and races were not treated as taxa. While race has since found some place, constituting taxa subspecies when formally recognized, it is generally appreciated that the concept of race is broader than that of taxa subspecies. Hence, for example, Mayr and Ashlock (1969) state: "A race that is not formally designated as a subspecies is not recognized in the taxonomic hierarchy. However, the terms subspecies and geographic race are frequently used interchangeably by 
taxonomists working with mammals, birds, and insects. Other taxonomists apply the word race to local populations within subspecies." Moreover, the evolutionary taxonomist's taxa subspecies need not necessarily even be races, as can be the case with the so-called "polytypic subspecies." The two concepts, then, overlap but do not equate. Thus, even if we were to arbitrarily set our criteria for formal taxonomic recognition such that no sets of human natural divisions met them, we would still be left with non-formal races. As discussed prior, this distinction between biological race as a taxonomic category and a taxa and as a more general type of classification goes back to Immanuel Kant; it is hardly new. All in all, Templeton's initial premise is untenable.

Second, his supposed standard subspecies recognition criteria are either, in the case of evolutionary taxonomy, non-existent or, in the case of cladism, not obviously non-idiosyncratic. Regarding the evolutionary taxonomy perspective, Templeton's said subspecies qualifying criterion is based on a misrepresentation of his cited source, Smith et al. (1997). ${ }^{103}$ The cited authors do not discuss magnitudes of genetic differentiation but rather the ambiguous $75 \%$ rule of thumb, a rule which was discussed in section IV-I. As noted in that section, by at least some contemporaneous interpretations of this rule, including Smith et al.'s own multivariate one, traditional human races (THRs) clearly meet the said criterion. Regarding the cladistic perspective, as discussed in section I-I, the general conventions regarding intraspecific classifications are unclear.

\section{$\operatorname{Lahr}(1996)$}

Lahr (1996) identifies biological race with subspecies in the category sense and then tries to disqualify human subspecies on the basis of the 75\% rule. Lahr (1996) argues: "Modern human regional populations may be very discrete in some characteristics which could comply with the $75 \%$ rule, but not in their combined biological parameters." Lahr's (1996) argument suffers from the previously noted problem of equating biological race with taxa subspecies. Additionally, Lahr's understanding of the evolutionary taxonomist's $75 \%$ qualifying rule of thumb is

problematic. First, there are no formal criteria for formal taxonomic racial recognition. To verify this point, readers can check the International Code for Zoological Nomenclature. No formal criteria are set because it is well recognized that "no non arbitrary criterion is available to define the category subspecies" (Mayr and Ashlock, 1969). Moreover, with regards to the 75\% rule of thumb, there seems to be no interpretative standard which stipulates that differences are in "combined biological parameters." Further, this combined parameter critique makes no sense with respect to a multivariate approach. In a multivariate analysis, differences would necessarily be in combined biological parameters.

\section{Pigliucci and Kaplan (2003)}

Pigliucci and Kaplan (2003) use a strategy similar to that of Templeton $(1998 ; 2013)$ except that they do not invoke non-existent or idiosyncratic criteria. They seem to simply argue that there should be such criteria in the case of humans due to possible social ramifications of the usage of the race concept. Discussing one extra-zoological criterion, they note:

\footnotetext{
${ }^{103}$ Alan Templeton was contacted by email on December $4^{\text {th }} 2014$. He was unable to provide any other reference in support of his claim.
} 
Before addressing those questions, it is worth taking a short detour to consider why so many authors writing about the (non)existence of human races have made use of such a strong definition of race (i.e., assumed that biologically significant races must be populations separated from other populations by serious barriers to gene flow). Part of the reason undoubtedly has to do with the history of the term "race" as it is applied to humans. Insofar as one is asking a question not about the existence of biologically significant races (of the sort that exist in certain species of Drosophila, for example) but rather about the existence of a biological justification for the "ordinary" language racial categories, the concept of race appealed to will have to be quite strong.

Admittedly, the authors' statement is ambiguous. While their argument might be a consequentialist one, as we suppose, an alternative interpretation would be that they are arguing that there should be such a criterion in the case of humans because historically human races unlike, say, tulip races - were thought to be deeply discontinuous. If so, this type of argument would represent a no-true-race one (critiqued in section V-G). We will assume that the authors intended to make a social consequentialist argument. Assuming so, this argument represents a variant of the so-called moralistic fallacy (Davis, 1978), which is discussed in section VI. The specific problem with the argument is that the race (dis)qualifying criterion is not grounded in biological taxonomic practices; rather, it is in socio-moral concerns. Thus, we are no longer dealing with biological races and biological scientific arguments against them. We are dealing with folk moral-philosopher ones.

Seemingly inconsistently, the authors acknowledge that human ecotypes legitimately can be called ecotypic races or ecotypic subspecies. They do not impose extra-ecological criteria to rule out the possibility of such races and subspecies. We presume that this is because they hope to employ an ecotypic concept to release the pressure built up from all out biological race denial without, at the same time, giving biological legitimacy to traditional classifications. As such, while they allow for human ecological races and ecological subspecies, they argue that such races do not correspond with traditionally recognized ones such as the THRs. As Pigliucci (2013) notes:

Pigliucci and Kaplan (2003) have therefore proposed that human races... could be thought of from a biological perspective as ecotypes. There are several implications to this proposal, the most fundamental being... (b) ecotypes (and hence races) are only superficially different from each other because they are usually selected for only a relatively small number of traits that are advantageous in certain environments. This means that races are nothing like phylogenetically divergent subspecies, and that racial differences are literally skin deep... [This account] shows that Sesardic-like [population genetic] accounts of race are ill-informed scientifically.[Italics added]

The argument seems to be that the THRs and regional divisions such as Europeans and East Asians can not be ecotypes because ecotypes (a) are only superficially different and (b) are selected for only a relatively small number of traits. Pigliucci (2013) and Pigliucci and Kaplan (2003) additionally argue that (c) ecotypes are locally adapted to a specific ecological range. They imply that since broad natural divisions span many ecological ranges, these can not form one ecotype. This case can only be made by narrowly understanding the ecotype concept. In their hurry to dismiss 'Sesardic-like' races (which correspond with our continental-level natural division ones), they miss a broader understanding of the ecotypic concept, one which does not exclude "phylogenetically divergent subspecies" and which does not have a problem with 
expansive "geographic races" being differentially adapted as wholes. ${ }^{104}$ There has been a long history of such usage. To give some examples:

[Ecotypes] parallel, but are not nearly always identical with, the geographic subspecies... As in ecospecies, it is sometimes necessary to include more than one ecotype in a subspecies, stating that it consists of certain ecotypes that appear ecologically important but are morphologically indistinguishable. The objective is to have limits of subspecies (a morphologic term) correspond to the limits of one or a group of several ecotypes (an experimental term). (Clausen, Keck, and Hiesey, 1939).

The ecotype as defined by Turesson is any assemblage of organisms which genotypically reflects the selective action of environment, and may represent anything from a small colonial community to a large regional race ... The term ecotype is therefore a general one covering assemblages of very different taxonomic significance. (Gregor, 1944)

Ecotype: "subdivision of an ecospecies, comparable to a subspecies or geographic race and consisting of an isolated population selectively adapted to a particular set of environmental conditions." (ecotype. (n.d.). The American Heritage Science Dictionary)

Although subspecific names are usually given to geographical races and hence are based on differences in morphology and distribution, geographical races not only occupy different areas but also live in different environments so that these races must also vary ecologically to some extent. Thus, geographical races and ecotypes merely represent different ways of viewing the same biological entities, the natural populations that comprise species..." (Merrell, 1994)

In any case, the ground finch lineage seems to represent, on at least some islands and at least some times, ecological races rather than species (Zink 2002)... We usually do not class these ecotypes or races as species... Nonetheless, while most actual ecological races probably never reach the status of species, some ecological races are likely to speciate as they already maintain the linkage disequilibria needed to evolve further speciation-related traits (Felsenstein 1981), leading to assortative mating. It does not seem unlikely that speciation via this route is the source of most new and successful species. (Mallet, 2008)

Races of animals (also called "subspecies" or "ecotypes") are morphologically distinguishable populations that live in allopatry (i.e., are geographically separated). (Coyne, 2012)

The gist is that the three concepts of concern - ecotypes, taxa subspecies, and non-taxa races overlap. Thus, Clausen et al.'s ecotypes can correspond with taxa subspecies, Gregor's ecotypes can be regional races, Mallet's ecological races can be lineages which can speciate, and Coyne's human divisions are both subspecies and ecotypes. Not all ecotypes are races (that is, genealogybased divisions), let alone formally recognized ones. Yet, taxonomic subspecies and large regional races can be - and arguably always are (e.g., Mayr (1970)) - ecotypes.

\footnotetext{
${ }^{104}$ Understood broadly, all sets of differently ecologically adapted geographic races can qualify as ecotypes. This follows from the fact that ecotypes, broadly understood, can characterize differentially adapted aggregate populations (ones which differ as wholes) and not merely differentially adapted local populations (between which members more or less uniformly differ in the adapted traits in question). Thus, there is no logical problem with large geographic races cutting across numerous ecological zones and still being ecotypes.
} 
Granted, some have argued that ecotypes "are not taxonomic units" (Cronin and Mech, 2009) and "do not necessarily share common ancestry and should not be classified as taxonomic groups" (Lyon and Graves, 2014). If these authors mean that ecotypes necessarily are not genealogy-based divisions, then they are using a concept different from the original. Whatever the case, it can not be denied that the ecotype concept has a history of being interpreted such to include something "like phylogenetically divergent subspecies." So arguments against the recognition of broad geographic races as ecotypic races rest on a narrow reading of the latter concept. (And, of course, arguments which equate non-genealogical ecotypes with ecotypic races misapply, with respect to ordinary biological usage, the term race.)

Also, though it hardly needs to be said, Pigliucci's (2013) claim that ecotypic "differences are literally skin deep" (presumably, meaning non-behavioral) is yet another non sequitur. Differences between recognized ecotypes are frequently behavioral. For example, Breed and Moore (2011) compare their "Africanized" and their "European origin" honeybees. The European ecotype is said to be characterized by high honey storage, low aggression, and reproductive restraint. This description of differences sounds quite similar to "ogre naturalist" Philippe Rushton's (1995) characterization of some of the behavioral differences between his White-European and Black-African races, differences which he argued were due to ecological adaptations. The former race was said to be k-selected and the latter r-selected. Switching "race" with "ecotypic race" in this context would make no material difference. Thus Pigliucci's (2013) tactic of replacing "race" with "ecotypic race" to argue against human behavioral genetic differences fails. Indeed, as the ecotype concept might actually be preferable when it comes to studying human behavioral variation, since many of the studied differences, for example in intelligence and $\mathrm{r} / \mathrm{k}$ selection, are said to be adaptations to climatic and ecological pressures. Pigliucci (2013) simply ends up providing behavioral population geneticists an alternative conceptual tool.

In summary, these three arguments represent the prominent subspecies critiques of biological race. They are unsound because they narrowly equate biological race with taxa subspecies and because they rely on qualification conventions or interpretations of these which are not commonly used in biology or which are selectively imposed in the case of humans.

\section{Panmixia Arguments}

According to another line of argument, which appears from time to time: (a) human history was marked by extensive gene flow, (b) yet biological races require extensively restricted gene flow, (c) therefore there are no human biological races.

Before engaging this argument, it needs to be pointed out that the non-trivial differentiation between human populations indicates that there must have been significantly restricted gene flow. There is a well-known rule of thumb in biology called the One-Migrant-per-Generation Rule. According to this, populations will not genetically differentiate if there is more than one (effective) migrant per generation between them. While the actual practical number of migrants needed to prevent divergence is somewhat higher (Wang, 2004), the point stands that for the level of divergence found between THRs gene flow must have been substantially restricted. 
That noted, the basic problem with this argument is that, historically, substantial gene flow between races was always recognized; indeed, it was expected. For this reason groups were considered to be "(intraspecific) races" and not "species."

Of course, different groups show different degrees of gene flow, so one might expect "race" to denote divisions between which there is relatively little. But, in fact, there typically is and was no such requirement for race in general. Of course, a gene flow criterion does come into play when it comes to the contemporaneous formal recognition of races (i.e., in the taxonomic category sense). But to draw from this the conclusion that there is a criterion regarding race in general is to confuse races with taxa subspecies.

Even with regards to taxa subspecies conventions are ill-defined, as discussed in section I (cladism) and in section IV (evolutionary taxonomy). To repeat our position in this regards: we can not see how one could disqualify human continental races from being human taxa subspecies given liberal readings of the various rules of thumb. While human races are not as genetically differentiated as Ostrich or Elephant subspecies, as discussed in section IV-I, it is not difficult to find a number of species with unchallenged formally recognized races which are both phenotypically and genetically less differentiated than are human continental divisions.

\section{Population Structure Arguments}

Two types of population structure arguments have been made against the traditional racial classification; these were discussed in section IV-H. A more general line of argument runs: human genetic diversity is better characterized in 'non-racial' terms - where 'non-racial' means in terms of either character clines or population continua - therefore human races do not exist. Philosophically, the problem with this "better characterized" argument is that it pits a race perspective against a non-race one and ignores the possibility of seeing human variation in both 'racial' and 'non-racial' terms. It represents a false dichotomy. Empirically and theoretically, there are several problems, depending on how the argument is rendered: (a) panmixia historical did not reign (hence, among regional groups there is non-trivial genetic differentiation), (b) as discussed in section II, races as natural divisions can be cut out of a genomic continuum, and (c) the human species nonetheless shows some population structure (for a sophisticated discussion of this latter matter readers are referred to Shiao et al. (2012)).

\section{Bio-statistical Arguments}

Related to the biological arguments are statistical ones concerning the ability to accurately classify individuals into natural divisions. It has been argued that, for various reasons, individuals can not be accurately assigned to proposed biological races and therefore that biological races either can not exist or are not real or are useless, etc. The most popular version of this argument has been called the "independent trait" argument, which has been characterized by Robin Andreasen (2004) thusly:

Defenders of 'the independent variation argument' maintain that many of the traits traditionally used to define races - skin color, hair type, eye shape, blood type, propensity towards disease - vary independently (Livingstone 1964; Gould 1977; Diamond 1994). For example, a classification based on skin color may cross-classify one based on blood type. Both classifications may disagree with one 
that is based on propensity towards a certain disease. This problem is said to be compounded as more and more traits are added to the classification scheme. If one trait is used (e.g., skin color), it may be possible to provide an unambiguous classification scheme.

Again, this argument was used to support the claim that individuals could not be grouped into coherent divisions based on genetic and phenotypic characters since characters supposedly varied independently. For example, Appiah (1996) argues:

Even limiting oneself to the range of morphological criteria available to these comparative anatomists it is hard to classify people objectively into a small set of populations.

Unfortunately for this argument, it so happens that the characters of the said races, and of natural biological divisions in general, do not vary independently. Rather, characters are correlated. This allows for increasing, not decreasing, accuracy when more traits are taken into consideration. This, of course, has been known for some time but it has only recently and grudgingly been acknowledged. Hochman (2013), for example, concedes:

Sesardic argues that forensic anthropology undermines the independent variation argument by showing, contra Andreasen, that as the number of traits increases, racial classification becomes easier and easier.

Pigliucci (2013) dismisses the rebuttal to the independent variation arguments, saying:

It is a truism of multivariate statistical analysis that membership in individual clusters of pretty much any heterogeneous collection of objects can be ascertained with a fairly high degree of accuracy if one has a sufficient number of discriminatory variables to play with.

Pigliucci (2013) is of course right that individuals can often be grouped into populations so long as traits are correlated, but that this is the case does not make the "independent variation argument" less wrong. More to the point, that the traits for these biological populations are correlated evidences that we are dealing with natural, as opposed to artificial, groups. The volumes of genetic and anthropological data concerning human biological races and classifiability will not be reviewed. For discussions concerning continental-level human races and anthropometric traits, readers are referred to, among others, Baker (1974), Brues (1990), Relethford (1994), and Gill (1998).

One variant of the bio-statistical argument runs: since the level of genetic differentiation between populations is low, individuals can not accurately be assigned to natural divisions. Relethford (1994), for example, made this argument when stating:

There are several important implications from these results for both contemporary human variation and patterns of human evolution. As noted by Lewontin (1972) and subsequent studies, the low degree of among-group genetic variation relative to total species variation argues strongly against traditional typological racial classifications. While among-group variation is statistically significant in all cases, the over- all degree of among-group variation is too low to produce any substantial accuracy in racial classifications.

Likewise, Biondi, and Rickards (2002) reason: 
In the early 1970s the world of physical anthropology got acquainted with the empirical falsification of the concept of race. Indeed, it is impossible to divide humankind into biological races because genetic variation within populations is higher, around 85 percent, when compared with the distributed between populations (Lewontin 1972, 1974; Nei and Roychoudhury 1974).

This argument has been shown to be unsound. For the explanation why, readers are referred to the discussions of Mitton (1977; 1978), Risch et al. (2002), Edwards (2003), Witherspoon et al. (2007), Gao and Martin (2009), and Tal (2012). What is odd is that the idea of taking into account multiple indexes when making a racial classification is hardly new. Blumenbach in 1806 passingly noted that human racial classifications, being classifications in a natural system, should be based on "all bodily indications alike." Darwin noted that human racial classifications should be based on a full pedigree; moreover, he discussed the importance of correlated variation when it came to classification in general. In 1950, William Boyd showed how one could use multiple genetic loci to make such a classification and noted that one should use all possible genetic loci when doing so. And Lewontin (1978), in reply to Mitton (1977), agreed that it was obvious that one could divide humankind into biological races using multiple loci.

\section{Cluster Discordances Arguments}

Another type of biological argument is directed at the genomic cluster concept of race. In section IV, we discussed one presented by Barbujani et al. (2013). The reasoning is: genomic clusters at times produce discordant results, therefore no coherent racial classification can be had. As discussed in sections II and IV, the problem with such arguments is that they confuse entity with that which evinces it. Properly understood, genetic clusters (the statistical output) evince - to one degree of reliability or another, depending on the number and type of molecular markers used the presence of intraspecific natural divisions. Discordant clusters just mean that one is using imperfect data and different study samples.

\section{Folk-Race Biological-Race Mismatch Arguments}

Yet another argument is that common racial classifications - for example, the TRC - do not match up with any legitimate biological races. Kaplan (n.d.) notes:

Here is a rough summary of the main lines of argument against the biological reality of race:.. 3) the populations we identify as 'races' in contemporary social discourse do not map neatly onto any legitimate biological populations (the "mismatch" argument - see e.g. Root 2003).

One of the important functions of a biological race concept is that it allows one to determine if specific, popular (or 'folk') racial classifications match up with biological races. Regarding the TRC, this was confirmed by Rosenberg et al. (2002), who explicitly tested if "predefined "populations" matched with divisions which "reflect underlying genetic relationship" (i.e., natural divisions):

Most studies of human variation begin by sampling from predefined "populations." These populations are usually defined on the basis of culture or geography and might not reflect underlying genetic relationships (1). Because knowledge about genetic structure of modern human populations can aid in inference of human evolutionary history, we used the HGDP-CEPH Human Genome Diversity Cell Line Panel $(2,3)$ to test the correspondence of predefined groups with those inferred from individual multilocus genotypes (supporting online text). 
While Rosenberg et al. (2002) did not describe their populations as being races, the senior author reportedly noted that, to quote Wade (2014b), "the study essentially confirmed the popular notion of race." One presumes that the senior author meant "confirmed the narrow-sense biological meaningfulness of the popular continental classification."

\section{V-C. Sociological Arguments}

Sociological arguments start with the proposition that, when it comes to humans, the concept of biological race should only be used in the case of divisions for which there are "socially significant" or "large enough" or "uniform enough" or "interesting enough" or "deep enough" behavioral genetic differences. It is then argued that no such divisions exist or that any ones which do exist do not correspond with ordinary racial classifications. For example, Appiah (1996) reasons:

From Jefferson to Arnold, the idea of race has been used, in its application to humans, in such a way as to require that there be significant correlations between the biological and the moral, literary, or psychological characters of human beings; and that these be explained by the intrinsic nature [of the members of the race]... That has turned out not to be true; the recent fuss generated by The Bell Curve about the correlation of race and IQ in the United States notwithstanding.

And Andreasen (2004) notes:

Many contemporary race scholars maintain that races are biologically unreal. What they usually mean by this is that folk racial categories (such as blacks, whites, and Asians) are biologically uninteresting. They are explanatorily and predictively weak in the natural sciences - especially when it comes to explaining or predicting biologically based socially significant traits. Several arguments have been used in support of this view. Two of the most persuasive are what I call the 'independent variation argument' and the 'genetic argument'.

And Hacking (2005) argues:

About the same time that The Bell Curve was published, ogre naturalists, such as Philippe Rushton in Race, Evolution, and Behavior, made more sweeping claims to biologically grounded racial differences. They claimed that the races are distinguished by many properties rightly prized or feared for different strengths and weaknesses. If that were true, then races would exactly fit Mill's definition of a real Kind... Rushton claimed that the races are real Kinds.

There really is not much to say about these arguments. In our view, as noted in section I-L, whether biological races exist and whether there are sociologically "important" differences between them are two distinct issues.

We might be overlooking an interesting argument, though. Perhaps, Appiah (1996) et alia want to treat "biological races" contra "biological natural divisions" similar to how taxonomists treat "taxa subspecies" contra "non-taxa races." Since taxonomists impose their arbitrary standards when it comes to the formal taxonomic recognition of race, perhaps Appiah (1996) et alia are justified in imposing their arbitrary sociological standards when it comes to the recognition of race in general. Can Appiah (1996) et alia successfully make such a sociological argument? We think not. 
Let us put aside the fact that neither Appiah (1996) nor anyone else has shown that there are no "interesting" behavioral genetic differences between certain human natural divisions given the types and magnitudes of differences that Appiah (1996) et alia themselves consider to be "interesting" as inferred from their various references to the works of Rushton, Murray, and Herrnstein. Let us just focus on the logic of the argument, not the absence of supporting evidence. As for this, zoologists limit the number of formally recognized races, by imposing arbitrary standards, for the practical taxonomic reason that the number of biological races for any given species is indefinite and very large. Giving each biological race a trinomen and listing each in a catalogue would lead to taxonomic chaos. When not explicit, an implicit distinction is made between formally and not formally recognized biological races. Moreover, when not explicit, an implicit distinction is made between biological race as a taxa and biological race as a unit of analysis or as another form of classification. Opposed is the recognition of a very large and indefinite number of taxa for a very practical taxonomic reason; not opposed is the recognition of races as units of analysis or as something other than taxa.

If Appiah (1996) et alia intend to argue against the formal taxonomic recognition of certain races, they need to argue their case in zoological terms using zoological standards. If they intend to argue against the recognition of race, in general, as a pan species biological concept, then they need to couch their case in terms of evolution, zoology, ecology, population genetics, and so on. We outlined our understandings in sections I \& II. We do not see how they could make such a case. If, instead, they want to argue that certain socially recognized racial classifications do not cut out biological races, they have to make this argument using genetic data, given some generic biological, not sociological, definition of race. It is, of course, not sufficient to show that sociological races do not perfectly correspond with biological ones to show, in turn, that biological ones, themselves, do not exist. Finally, and this is the key point, if they intend to argue against the non-formal biological recognition of specific racial classifications or against the applying of the race concept to human biological variation, they need to argue this case in terms of the biological, not sociological, sciences. Otherwise, their argument succumbs to the same problem as does Kitcher's (2007) (as discussed in section I). When biological race is defined or delimited on the basis of considerations that fall outside the purview of the biological sciences, it fades as biological race. When Appiah (1996) et alia set race qualification criteria that are foreign to the biological sciences - e.g., when they require differences in "socially significant" traits they move away from biological race, a concept which applies to humans, camels, and strawberries alike.

Such sociological arguments do not address biological race as such. And they definitely do not address our biological race concept. The more these arguments appeal to extra-biological considerations, the more they cease to be arguments against human biological races as such.

\section{V-D. Unnaturalistic Arguments and the Numbers Game}

Unnaturalistic arguments maintain that human biological races are not real given that they do not meet some biologically impossible-to-fill criteria. These arguments are related to sociological ones in that they burden biological races with extra-biological criteria; the criteria imposed, though, are not sociological in the sense of "sociologically important differences." They are criteria that could not even be filled in principle given a modern understanding of biological variation. Discussing one such argument, Kaplan (n.d.) notes that one of the "main lines of 
argument against the biological reality of races" is that "what was meant by "race is biological" was a strong essentialist claim that we now know to be false, not just of human populations, but indeed of most biologically respectable populations." This argument, or at least a strongman version of it, runs something like:

(1) 'Biological race' was originally conceptualized in a "strong essentialistic" way that no longer makes sense given contemporaneous understanding

(2) We should be faithful to historic meanings

(3) When understood this way, 'biological race' can not be real

As discussed in section III, this argument, if we grant the second premise, would work against "biological species" (and "races" in that sense) - but not against "biological race" in the intraspecific sense. ${ }^{105}$ It does not seem to us that we should even grant the second premise, though. Doing so renders unreal many familiar entities like "atoms," "elements," and, of course, "species."

There are many other types of unnaturalistic arguments. Typically, they insist that the concept of race must pick out "entities worthy of special attention," where "worthy of special attention" means something like worthy in themselves independent of human concerns. Alternatively, these arguments require races to be "real natural kinds" in some implausible and biologically impossible sense. Were these arguments applied consistently, many very biological things would turn out to be biologically unreal. In section III, we criticized these types of arguments. Here, we will address another variant.

Some have turned to arguing that races are not real since there is no inherently "biologically preferable" or "fundamental" or "right" level of genetic analysis. As discussed in section II-E, one can focus on major continental-sized natural divisions or on sub-divisions of these or on subdivisions of those all the way down to the local level. This is called the "lumper and splitter" issue. It was recognized by Darwin with respect to species and varieties. In a letter, he noted: "Those who make many species are the 'splitters,' and those who make few are the 'lumpers'." This basic biological phenomenon has been turned into an argument against races:

Cavalli-Sforza, Menozzi, and Piazza (1994) state:

[A]t no level can clusters be identified with races, since every level of cluster would determine a different partition and there is no biological reason to prefer a particular one.

And Pigliucci (2013) attacks Sesardic (2010) thusly:

[O]ne can identify legitimate genetic clusters of human populations at a variety of hierarchical levels, but Sesardic offers no principled reason for identifying one such clustering as more fundamentally indicative of races.

\footnotetext{
${ }^{105}$ Race was originally understood in relation to the species realist's species - as a hereditary degeneration of the essential species type. Since these kinds of species do not exist, one might argue that race does not either. This would not be because race was conceived in a "strong essentialistic" manner, but rather because it, along with all other kinds of intraspecific biological variation, was understood in contrast to something which was.
} 
And Hochman (2013) complains:

In the Rosenberg et al. study there were five grains of analysis, each producing different clusters. How is the race naturalist to decide which is the 'right' grain of analysis, or how many races there are? Are the Kalash of northwest Pakistan, who were separated on the finest grain of analysis, supposed to be a race, for instance?

In absence of a hidden premise, this argument would apply just as well to "spatial populations," "demes," "clusters," "ecotypes," and so on. It would, by undercutting the conceptual legitimacy of that which are said to not be races, be a reductio ad absurdum. The argument maintains coherence with the implicit premise that the concept of race - unlike that of "population," "deme," "cluster," etc. - is supposed to establish a "biologically preferable" or "fundamental" or "right" level of analysis - that is to say, is supposed to allow for a "true" racial classification. But none of the above authors explain why the race concept should entail what it never could.

As it is, the concept of race has a long history of not entailing any definite level of analysis and of not allowing one to cut out one "true" racial classification (per species). Wilson and Brown (1953), for example, argued that the subspecies category was problematic given the "necessary arbitrariness of any degree of population divergence chosen as the lowest formal racial level." Accordingly, formally racial recognition was seen as problematic since there is no fundamental level of racial divergence. This argument hardly supports the position that "race" implies a "right" level of analysis. As Dobzhansky (1946) stated about races in general:

First, since all magnitudes of difference are found among populations, any specified minimum can be only arbitrary. Second, it is most important to realize that the differences between the 'major' human races are fundamentally of the same nature as the relatively minute differences between the inhabitants of adjacent towns or villages. There is no "true" subspecific level. And arguably, as noted by Darwin, there is also no true distinction between specific variation and subspecific variation as the two form a genetic continuum; even when we define a species as a genetically reproductively isolated population, the intrinsic isolation is more accidental than substantial. [Italics added]

The italicized words say it all. It is not as if lumping and splitting is a recent affair. In 1955, Garn and Coon wrote the paper, "On the Number of Races of Mankind," to explain the issue. Much earlier, Buffon, for example, wrote of the "White race," of the "European race" nested within this, and of groups as small as the "Tartar race." Blumenbach (1806) also recognized that the major races can be divided. He noted:

Each of these five principal races contain besides one or more nations which are distinguished by more or less striking structures from the rest of those of the same division. Thus Hindoos might be separated from the Caucasian; the Chinese and Japanese from the Mongolian

As the phrase "five principal races" implies, Blumenbach recognized racial sub-divisions of his principal groups, such as the "indigenous races of America" (Blumenbach, 1795). While he makes a distinction between "the races and the multifarious nations of men" (Blumenbach, 1795), this distinction is often blurred. Thus we are told, for example, that "[s]ome races of Ethiopians are found with long hair: other copper-coloured nations again with curly hair" and that "nations preserve their peculiar stature when they mingle least with the immigrants and strangers of other races" (Blumenbach, 1795). 
Now, to be fair, some used the race concept to describe only certain levels of what we would call racial differentiation. As said, Blumenbach, if ambiguously, distinguished between races and nations. Similarly, Buffon considered as "races" only groups which exhibited constant enough differences (Doron, 2011); less distinct groups were often classified as nations. Thus, many of Dobzhansky's (1946) "races" would correspond with Buffon's "nations." Some of this difference of opinion (concerning which level of variation corresponds with "race") may have been preferential. As we noted in section II-G, some employ definitions which are narrow relative to our general biological race concept e.g., Vogel and Motulsky (1986), Sarich and Miele (2004), and Pearson (2002). This is why we distinguish between general and narrow concepts.

We suspect that there is also an epistemic issue too - that Buffon, naturally enough, did not recognize that one could (e.g., using molecular character) group much further down. His nations, we suspect, were seen as something between individual variations (which did not allow for a lineage-based classification) and races (which did). Whether or not this was the case for Buffon, it definitely was for Kant. He was clear that nations did not qualify as separate races because they did not differ in characters such to allow for genealogy-based class distinctions.

It became clear in the $20^{\text {th }}$ century that one could differentiate populations all the way down to the local level. Given this situation, one could define "the" race concept such to include all intraspecific natural divisions (for example: Hartl and Clark, 1997) or to include only those that differ "enough" (where "enough" denotes some arbitrarily chosen level of differentiation). Or one could, as we sensibly do, simply distinguish between the general concept and narrow ones and recognize the narrowness of concepts of race which exclude less differentiated divisions. Our argument for why the "general concept" should be more inclusive would run along the lines of Hochman's (2013) argument for why there is no reason that "race" should describe a specific level of genetic analysis. We just draw a very different conclusion: it is (general) races all the way down - not no races at all.

But why is our argument sound? It is because, as said, there was never a claim the races described one "right" level of analysis. It has always generally been accepted that "race" described multiple nested levels. There has just been disagreement about how far down the concept extends. Hochman-like arguments work from the premise that there is no non-arbitrary reason for picking a specific level; this only works against race, in general, if race was originally understood to imply one "right" level; otherwise, it works for Dobzhansky's (1946) and our point - that the general concept should apply to all levels. Instead of ruling out races, it proliferates them!

Now Hochman (2013) anticipates this:

How is the race naturalist to decide which is the 'right' grain of analysis, or how many races there are?...

Putting aside the exaggeration of Leroi's claim - most of us would be spread across the map - the arbitrariness of a rough grain of analysis is surely a problem for racial naturalism...

Sesardic is attempting to revive race on the same definition: "the basic meaning of "race" seems to imply that, due to a common ancestry, members of a given race A will display increased genetic similarity, which will make them in some way genetically different from individuals belonging to 
another race, B" (Sesardic 2010, 144). This definition is too weak to revive what Sesardic calls "common-sense" racial classification because any groups (including neighbouring towns, socioeconomic groups, etc.) that have reduced gene-flow could be racialised. It is going to be hard to convince scientists, philosophers, laypeople - anyone really - that this definition of 'race' should be adopted.

However he jumbles two questions: "How should we define race?" and "Which racial classifications are worth focusing on?" Were we to try to rewrite the argument in coherent fashion, we would have:

(a) There is no principle reason to limit the concept of race (as natural division) to one intraspecific grain of analysis.

(b) Thus, we can make racial classifications along any valid grain.

(c) As a result of (a), we could make them on very fine grains.

(d) We do not typically do (c).

Therefore...?

Any attempt to disqualify a specific classification along this line leads to a nonsequitor. At best, one can argue that there is no good (biological scientific) reason to focus on (e.g., a continentallevel) classification. This is a world apart from arguing that our classifications do not pick out biological races. Or that biological races do not exist. And there is a simple rebuttal. The reason that certain grains of analysis are focused on was explained by Leroi as quoted by Hochman (2013):

[T] here is nothing very fundamental about the concept of the major continental races; they're just the easiest way to divide things up[.] [Italics added]

Dobzhansky (1951) said much the same:

Obviously it would not be convenient to give names to racial inhabitants of the different counties of England or of the different departments of France. But everyone will agree that the Negroes, the Europeans, and the American Indians are clearly distinct.

From a practical perspective, the "common sense" race naturalist merely needs to establish the narrow biological meaningfulness of the traditional human racial classification (i.e., establish that this delineation is one of a number of possible valid racial delineations). Human psychology will take care of the rest. This is why we recognize 4-7 continents and not tens of thousands!

Of course, it will be argued that focusing on this biological racial classification is "socially driven" in some sense. We would not argue otherwise. We would just note, though, that often pragmatic considerations (e.g., human memory span) and natural curiosities, not nefarious forces, condition this. As Hochman (2013) suggests, major races correspond to the degree of differentiation that well-meaning "scientists, philosophers, laypeople - anyone really" are interested in. 


\section{V-E. Onto-epistemology Arguments}

Instead of arguing that race is not real because it does not fulfill some unnaturalistic criteria, Winther and Kaplan (2013) argue that the existence of race can not be biologically determined because the parameters of the concept itself can not:

\footnotetext{
Indeed, racial ontologies are constructed conventionally, rather than discovered... Choices and conventions must always be made in identifying particular kinds of groups...

The broad belief is that genomics will eventually establish the existence or not of biological races... We think not. On the contrary, we argue that... human genomic data and models map in multiple ways to racial ontology...That is, genomics cannot transparently speak to whether biogenomic races exist, or even what they would be should they exist.
}

Apparently, race's existence is underdetermined because the "kinds of populations we care to identify" must, instead, be determined by social convention. HoSang (2014) makes a similar argument: "Ultimately the observer and not the observed declares which differences constitute a racial group and which do not... The researcher must still apply an a priori definition of race to the patterns of genetic variation estimated by population inference analysis." This line of argument could be applied just as well to other scientific groupings. Indeed, Stanford (1995) applied a version of it to species. It is tempting to try to dissect the implied onto-epistemology, but instead we will just reformulate the matter in a more sensible way.

We grant that biology can not determine a concept. We agree with Kant (1788) that one must start with a biological concept and then determine whether there is something in nature that is referenced by it. If so, we say that the thing, meaning that referenced as understood in accords with the concept, exists. From this perspective, nature can never determine a concept; it can never specify, for example, that "species" entails this and not that. In that narrow sense, we agree with Winther and Kaplan (2013) and HoSang (2014). We would just express ourselves differently. We would say that the concept is undetermined by nature - it is not a platonic form that we grasp from out of the manifold of experience, but a conceptual tool that we create and use to make sense of this manifold. We would treat this as the normal state of affairs. Our critique of Winther and Kaplan's and HoSang's position, with regards to the race concept, then would parallel Marc Ereshefsky's (1998) critique of Stanford (1995) with regards to the species concept. As Ereshefsky put it: "[The] argument is that it is too global. We would like to know why the existence of species is particularly problematic beyond the general claim that the reference of theoretical terms depends on our interests."

If we start out this way - not expecting nature to determine something she never can, but asking if our understanding reflects how she is - by inspecting nature, we can determine if our concept references something out there. We can ask, for example, if the species realist's species exist. In the case of race, the question would be something like: do intraspecific natural divisions describe a kind of biological variation? Were the Linnaean perspective - as characterized by, for example, Müller-Wille (2007) and Ratcliff (2007) - correct, the answer would be "No." But an examination of nature shows that this perspective, which made no room for race as an entity in natural history, is untenable. Understood this way, the existence of biological race - that is, the fact that the concept of race picks out some type of thing in nature - is biologically determined. 
We might, of course, wonder why we should - given that nature does not hand us the concept think of $i t$ this particular way. Why not, for example, conceptualize "race" just as we conceptualize "morph"? This line of inquiry mistakenly reifies the term "race." "Race", here, is the concept. To think of it differently is to think of a different concept. We might more properly ask, though: why think of this particular concept? The obvious reason is that there is something out there - not well captured by other concepts - that we would like to describe.

\section{V-F. Semantic Arguments}

Semantic arguments are frequently leveled against biological race concepts. Discussing biological race, Malik (2012), for example, writes:

\footnotetext{
'Geographical origins do not in themselves constitute races', the philosopher Naomi Zack points out. 'If all the people identified as white had ancestors alive in Europe at the same time that the people who are identified as black had ancestors alive in Africa, to say that these are racial ancestral differences adds no new information to the data on time and place. ... Race realists might argue that a Continental group is a race - that is how a race is defined. But this is to say something trivial about which there could be no debate.
}

Malik feels that race must mean something in addition to geographic ancestry and that there is no justification for calling mere "continental groups" races. Given our concept of biological race, a reply to Malik is ready on hand: "geographic ancestry," let alone "continentally delineated group" is not, in fact, synonymous with biological race. Only when individuals from roughly the same geographic region descend from the same natural division do they belong to the same race; hence, the geographically defined sociological race of "Asians" in the US does not correspond to any biological one.

The discord between geographically defined populations and races has been pointed out by others. For example, criticizing Neil Risch's continental racial classification, Condit (2007) notes: "Indeed, none of the groups claimed to be delineated as 'continental' groupings are actually very closely coterminous with a continent as the term is otherwise understood" (HoSang, 2014). Of course, what Risch and others refer to are not continentally defined populations but intraspecific natural divisions - races - on the continental-level of genetic analysis.

We might follow Malik's line of reasoning, though, and ask: why should "intraspecific natural divisions" be called "races"? Indeed, some argue that these divisions should be called by another name because the term race is 'loaded.' We agree that it is - with information. Our argument for the retention of the term is as follows:

Firstly, since we are interested in making connections, it helps to name concepts consistently. For example, we might start calling a "plant" a "tnalp" but doing so would have the effect of impeding our understanding, as we access our plant schemata largely using words. It is simply easier to better connect the modern concept of race with past ones used in context to biology and anthropology when using the term "race" instead of, say, "ecar". For example, we can better 
recognize the connection between Buffon's and Darwin's usage and Coon's and Baker's and Sesardic's and Spencer's.

One might argue that the concept has evolved such that the use of the same term is misleading; we fail to see this. For example, Kant's and Darwin's characterization of race seem to be pretty similar to modern ones. More generally, "race" in the intraspecific sense originally described genealogically understood constant varieties. Such varieties not only correspond with natural divisions but they were often thought of being these at least in some sense (for example, by Kant, the later Blumenbach, and Darwin). As it has been pointed out, those who contemporaneously employ the "race" concept in biology generally end up conceiving races as natural divisions (as discussed in section II-B) and those philosophers of biology who defend the concept end up doing likewise (as discussed in section III-A). ${ }^{106}$ Thus we have a reasonably good crosshistorical agreement in term usage.

Secondly, there presently is no good substitute term in biology. "Population" can not be used as an alternative since as noted above the term frequently refers either to spatially defined groups or to groups defined in terms of the probability of sharing descendants (i.e., demes). The latter, as noted above, is also called a "genetic population." We considered the term "natural population" to get around this issue, but it turned out that this term is often used as a synonym for "wild population" which is, of course, not what we wished to refer to. 107 "Population" simply will not do. Polymorphs, clines, and clusters also do not describe the entities of interest. Here, we suggest "natural divisions" as a neutral term, since races have been characterized as being these, but we have to append "intraspecific" for clarity's sake, making a mouthful. That said, we are not term mongers; were all applicable past usages of the term "race" (in context to biology and biological anthropology) translated as "intraspecific natural divisions" (or e.g., "ecar") and were the public educated about the meaning change, we would seriously consider dropping the term "race." This project has yet to be done, though.

The third reason is that many people argue against the coherence of race-like biological concepts and/or the existence of human biological races. We do not see how we or anyone else can well address these arguments unless the term "race" is employed to describe some type of biological division. Fourthly, when euphemisms are used, critics of the race concept often protest that the concept is just being called by another name. Thus, Silverstein (2015) complains that the population geneticists' "biogeographic ancestry" is "just race in a phony moustache and glasses." The problem for these critics is not that the race concept is called "race" but rather that it is not being called this - and that this semantic shift allows the concept to be employed in research, despite pressure against biological "race"-related research. A word game with the race concept then, to quote Silverstein (2015), "only takes us in a circle."

\footnotetext{
${ }^{106}$ It is sometimes, incorrectly, claimed the race (as subspecies) referred to unchangeable and immutable groups. For example Stolley (1999) claimed that, "Blumenbach stressed the unchanging and immutable nature of the races, apparently assuming that intermarriage never occurred." But the groups which Blumenbach discussed were said to have insensibly ran together due to intermixing!

${ }^{107}$ See, for example, Winther et al. (2014).
} 
Generally, arguments against the use of the term race are frequently transparent attempts to impede clear thinking. The typical 'loaded term' arguments are seemingly never applied to clearly politically-socially constructed sociological "races." The reason is obvious: the problem some have is not with 'loaded terms' but with biological "race-thinking."

\section{V-G. No-True-Race Arguments}

Another line of argument, discussed in section III, runs: (a) once upon a time "race" referred to $x$ type of (human) divisions, (b) we now know that $x$ type of (human) divisions do not exist, (c) we must be rigidly faithful to historic terminological usage and understand race now exactly as it once upon a time was, (d) therefore no (human) races exist.

The first problem with this line of argumentation is that scientific concepts often involve evolving and shifting meanings. For example, what we now call elements (metals, metalloids, and non-metals) do not much resemble what were once called elements (earth, water, air, and fire). The term "element" is yet currently sensibly employed to describe what it does because, as in the past, the referenced are basic units of substance that share similar properties. Likewise, the atom of today, being divisible, is in an important respect unlike Democritus' atom. Yet there is a family resemblance between the past and the contemporaneous concepts - both of which refer to small basic units of matter - and this resemblance makes it sensible to refer to our modern atoms as "atoms" and insensible to say that "atoms do not exist" (on account of being divisible). As with "elements" and "atoms," so with "species" and "races."

The second problem is that the "true" historical meanings of the term race are frequently fabricated. In section III, we discussed the case of the missing racial essences. Here we will briefly comment on three other claimed "true" historic meanings:

1. Historically races referred to taxa subspecies; we must not think of them otherwise. Enter: subspecies arguments.

Milford Wolpoff (2009) tells us:

In the earlier literature race was used synonymously with subspecies, and this is still largely the case in the biological literature. A taxonomic division [of variation] equates race with the concept of a subspecies, a division of a species into distinct and distinguishable types... The dismissal of human races as an organizing structure for human biology was for many reasons, including political reasons, but there is a firm biological basis for it in the distribution of genetic variation (Templeton, 1998), that to some extent is reflected in the distribution of anatomical variation...

Extant human anatomical variation does not attain the subspecies level; populations are neither different enough, nor separated enough, for a subspecies interpretation of their variation to be valid.

The ratio of within group to between group variance is very high in humans.

There is no treeness for human groups (Templeton,1998).”

Milford Wolpoff plays a neat game. Race is said to have been equated with "subspecies" which then is equated with "taxa subspecies" understood as it now is - that is, as referring to groups 
which represent the major divisions of a species and which are felt to differ enough to be deserving of trinomina. Let us grant that early researchers could have been so prescient that they could have known late 20th century views concerning taxonomic significance with regards to formal racial recognition. And let us ignore early subspecies concepts, such as Ehrhart's according to which subspecies were "often so similar to each other that an inexperienced person has trouble in separating them." That is, let us ignore the dissimilarity between early subspecies concepts and modern taxa subspecies ones.

Why is it that early races seem so different? For example, if races were thought to be only taxa subspecies in the current sense, nested racial classifications could not exist since taxonomic subspecies describe "the major patterns of variation found within a species" (Turtle Taxonomy Working Group, 2007). Why, if this is the case, do we have to dig through Buffon's catalogue of races to find his major divisions? Why, as noted by Caspari (2009), was race, in the early 1900s, used "to refer to geographic divisions of the human species, but also to smaller categories that could correspond to nationality and even smaller social groups." That is, whence the many nested racial classifications and why were many groups which were thought to differ from one another to a minor degree considered to be intraspecific races? Clearly, "race" was not historically equated with "taxa subspecies" as we now often understand the latter.

In short, Milford Wolpoff presents us with a fabricated history of the race concept: once upon a time race was used to mean what we now mean - and have since the mid-1900s - by taxa subspecies. His narrative allows for his version of the no-true-race argument - one which falls apart when actual historical usage is pointed out and when words and concepts are distinguished. Yes, frequently the words "race" and "subspecies" were and are used as synonyms or shorthand for something akin to "taxa subspecies." And yet frequently they were and are not. This is not a problem because words are not concepts.

2. Races were classically understood to represent sharply discontinuous populations.

According to Zack (2002), since historic conceptions held that "race is sharply discontinuous," et cetera, races do not exist in the human species. One can find innumerable reiterations of this version of the no-true-race argument. Yet if this was how races were historically conceptualized, why, for example, did Darwin (1871) note:

But the most weighty of all the arguments against treating the races of man as distinct species, is that they graduate into each other, independently in many cases, as far as we can judge, of their having intercrossed... This diversity of judgment does not prove that the races ought not to be ranked as species, but it shews that they graduate into each other, and that it is hardly possible to discover clear distinctive characters between them.

Or, earlier, Blumenbach (1806):

Neither must we take merely one pair of the races of man which stand strikingly in opposition to each other, and put these against the other, omitting all the intermediate races, which make up the connection between them. We must never forget that there is not a single one of the bodily differences in any one variety of man, which does not run into some of the others by such endless shades of all sorts, that the naturalist or physiologist has yet to be born, who can with any grounds of certainty attempt to lay down any fixed bounds between these shades, and consequently between their two extremes. 
Zack (2002) confuses race as species with intraspecific race. Discontinuities were said, for example, by Prichard, to evince that races were species; many of those who argued that human groups were not different species but were intraspecific races, emphasized the continuous aspect of the variation.

More generally, one wonders when biological races, in the intraspecific sense, were in general considered to be sharply discontinuous. Did Dobzhansky and Boyd conceptualize them as such? Did Mayr conceptualize his microgeographical races so? Did Blumenbach, Buffon, or Thomas Huxley with his Melanochroi that "pass by innumerable graduations into the Australoid type of the Dkhab, while in Europe they shade off by endless varieties of intermixture into the Xanthochroi (1870)"? Nope. What about the many early 20th century anthropologists who equated ethnic groups with races? Not generally. What about races understood as the "mere" or "accidental" varieties of the 18th and 19th century (see: Stamos (2012))? Nope. Hooton is said to have been a typologist. Maybe his types were sharply discontinuous. In Method of Racial Analysis (1926), he tells us:

\footnotetext{
A primary race is one which has been modified only by operation of evolutionary factors ... A secondary or composite race is one in which a characteristic and stabilized combination of morphological and metrical features has been effected by a long continuous intermixture of two or more primary races within an area of relative isolation ... it is apparent that the present population of the world consists for the most part of secondary races ... for man has been a migratory animal from proto-human times down to the present and the contact of races has always resulted in race mixture ... Races are great groups and any analysis of racial elements must be primarily an analysis of groups, not of separate individuals. One must conceive of race not as the combination of features which gives to each person his individual appearance, but rather as a vague physical background, usually more or less obscured or overlaid by individual variations in single subjects, and realized best in a composite picture.
}

How one can construe such a formulation as being one of sharply discontinuous divisions is beyond us. But maybe we can look elsewhere? We imagine that if we looked hard enough, we might find someone who formulated intraspecific race as Naomi Zack tells us the concept was. But this is the point: this was not how biological race, broadly conceptualized, was typically understood.

3. Races were classically understood as being homogeneous groups.

A number of critics of the race concept have implied that races were historically conceptualized as homogeneous groups. Thus, many members of the AAA reject the race concept - but oddly not the species one - on the grounds that there are no genetically homogeneous populations. As discussed in section II-A and III-B, in the Linnaean paradigm, species were thought to be homogeneous by nature. Races were contrasted with these, on the one hand, and with inconstant varieties, on the other. Races could not have been thought of as being homogeneous in characters, since if they were, inconstant varieties and individual variations, which races were understood, in part, in contrast to, could not have existed.

\section{V.H. Teleological Argument: The Future of Race}


Let us consider one final issue: the future of human biological races. Not infrequently is it pronounced, and at times with unconcealed glee, that races are on their way out, finished; and sometimes this conviction is cleverly weaved into a teleological argument, of sorts, one with a detectable eschatological flavor. This runs: since sooner than later they will not exist, we should treat biological races now as if they do not. This position is, unfortunately for its proponents, dated. Of course, human races, broadly understood, will continue to be begotten and to expire. But the cessation of these races that come and go like mayflies are not what is being spoken of, rather it is the expiration of the most distinctive varieties of man, varieties shaped and molded over thousands of years of relative isolation. Were it not for the advances in synthetic biology we might concur; globalization would eventually lead to the de-racialization of the conspicuous varieties of mankind. If it were not. But neo-eugenics and genetic engineering loom on the horizon. It is already transforming conservation biology (Biello, 2013). In our estimate, it will liberate individuals and populations thereof to birth races of a type never seen before. Will no peoples take up this chance to recreate themselves in the image of their desire? Critics of human biological race claim that the divisions of man are superficial, trivial, and insignificant. We imagine that they will be compared to some of those to come. Perhaps anti-biological racialism will recreate itself, too, in the future - somewhat ironically into a form of bioconservatism.

\section{V.I. Can a Good Argument be Made Against (the) Race (concept)?}

One might wonder if a sound argument against the concept of race could be developed. Such an argument seems to be about as likely to appear as does one against either the species concept or the morph concept. Biologically, there is something to be described and what it is has a strong claim to the name "race." Thus it is time to move on from debating whether or not race is and what race is and start asking: To what extent do such and such divisions correspond with biological races, generally understood? To what extent do they correspond with this or that narrow conception of race? What is the cause of such and such differences between these races?

In the West, thinking in terms of human natural divisions is stigmatized. And it is frequently argued that picking out such divisions is "unscientific" or "illogical." We have made clear the vapidity of this position and its many supporting arguments. Yet these arguments continue to be advanced. This is largely because there is a sociomoral dimension to this issue, one yet to be discussed. This will be addressed next. 
No, my friend, if moralists begin from a false theory, it is truly their fault when their edifice totters and falls completely apart like a house of cards. - Forster (1786, in reply to Kant)

\section{A Troublesome Inheritance?}

\section{VI-A. The Social Destruction of a Biological Reality}

If our analysis is correct, there are no sound logical or scientific reasons for rejecting the biological concept of race here characterized. There is something in nature to be described; other biological concepts do not well describe it; the concept of intraspecific natural division does; given historic usage, this concept can reasonably be called "race"; thus race is 'real' in the ordinary sense. Theoretically, reality need not have been this way. Race need not have been; and it was not always thought to have. The Linnaean perspective could have been correct; all members of a species could have been identical by descent in nature and varied due to the direct effects of the environment. In this case, there would be no races. However, it was recognized that this perspective was incorrect. The existence of intraspecific hereditary variation and, more specifically, race was recognized.

Many racial eliminativists, constructionists, anti-realists, and anti-naturalists would have us unrecognize this discovered reality. To this end, they attempt a social destruction of reality, an obscuring and concealing of that which is. Not all; some have simply argued against certain erroneous conceptions in general or as applied to our species. But a great many, as testified by their persistent loading of the concept with specious, historically unjustified requirements - deep discontinuities, privileged levels, a lack of within groups variability, taxonomic category status, few in number, etc. - have been out to deconstruct the very concept, not to clarify it. Why? This could be a case of clever sillies, of intellectuals playing word games and stretching the bounds of reason to show off their aptitude; yet, unfailing passionate advocacy argues against a clever silly hypothesis (Charlton, 2012). ${ }^{108}$ What else? The early race debate sheds light on the matter.

The position that different human groups represented different species (that is, did not share a common ancestral origin) was deemed heretical and considered to be a dangerous idea; it was thought to undermine the moral and spiritual unity of man. The concept of race, in the intraspecific sense, was advanced to defend the dogma that all humans formed but one species (Doron, 2011; Doron, 2012). It was offered as an alternative to the species or inconstant varieties dichotomy and it provided the monogenist position with an empirically plausible model of human biological variation. The moral aspect of the early race debates is readily apparent. For example, in reply to Kant, Georg Forster (1786) defends his position, much as we might ours, from moral-egalitarian criticisms:

To be sure, Kant fears ... that with the assumption that there was more than one pair either war must immediately spring up or nature leastwise could not escape the reproach <that> it did not make preparations for all the arrangements <needed > for sociability... Let me rather ask if the thought that

\footnotetext{
${ }^{108}$ Charlton, (2012) notes: "I assumed they were Clever Sillies:abstracting and systematising intellectuals who translated everything into a world of ideals and possibilities, detached from common sense and experience ... But Clever Sillies would not be so strategic; would not maintain such an aggressive and long-term (decades, even centuries long) attack on Good things, would not systematically seek-out and try to destroy truth, beauty and virtue."
} 
blacks are our brothers has ever, anywhere, even once, caused the raised whip of the slave driver to be lowered? ... Where is the bond, however strong it might be, that can hinder the decadent Europeans from ruling over their white fellow human beings equally as despotically as <they rule> over Negroes? How, therefore, are we supposed to believe that an unprovable dogma could be the sole support for our system of duties when <it> has not prevented a single act of ignominy throughout all time in which it has been accepted.

According to Forster, a belief in common ancestry is not needed for people to behave justly; for one can, through reason, recognize that one should. He argued also that history failed to support the view that a belief in shared lineage leads to human decency as within lines of descent cruelly abounds. Kinship, Forster noted, did not stop the fabled Cain from killing Abel. A fear similar to that which, in part, motivated Kant and others to oppose polygenism and to assert that human groups represented intraspecific races, not species, seems to motivate many contemporaneous intellectuals to insist that the same or similar groups represent not races but some other variety of biological variation or nothing at all. It is feared by them that the understanding of groups as being other in ancestry will lead and leads to "otherization" and inequitable treatment. Correspondingly, it is frequently felt that abolishing the term "race," the biological concept of race, and even, perhaps, human races themselves is a good way of reducing inequality and conflict. Discussing the French ideology of metissage, Yee (2003) notes that "the mere mixing of racial gene pools" is seen to "offer 'l'espoir d'une redemption', and metissage is held up as a new utopia that will bring an end to the problems of racism and ethnic conflict." In France, the term and concept of "race" have been deemed inadmissible to aid in achieving this utopian end.

When it is not argued that the biological concept of race should be either undermined, destroyed, or deemed conceptio non grata, commentators, like Kitcher (2007), maintain that the concept should only be recognized if it can be sufficiently socially justified given the "potential damage caused by deploying this concept."

Others take aim at an outlandish notion of race. After admitting that there are zoological races of mankind, Ashley Montagu (1942) tells us that race is a myth, where he means, for example, something that is the "prime determiner of all the important traits of body and soul." We would, of course, agree that race in this sense is a myth; and that so is, for example, racism in the sense of the "prime determiner of all the important social inequalities." But that says very little. Nonetheless, these critiques against unwonted notions manage to get transformed into moralbased ones against sensible biological concepts. Thus, philosopher John Hodge, in his 2013 letter to the New York Times explains why we must "destroy" and "eliminate" the idea of race:

Why do we keep talking and living as though biological "races" exist? ... The myth of "race" has supported the horrors of slavery, apartheid, segregation, eugenics and the Holocaust. It continues to support racism. We cannot simply ignore the harm this myth has caused and pretend that the myth never existed ... The scientific, democratic and ethical goal should be to eliminate the false idea of "race" completely. But how do we both destroy the myth and remedy the harm it has caused?

It seems to have not occurred to Hodge that there are both biologically valid and invalid concepts of race; this obliviousness allows his moral sensibilities to stay out of conflict with his logical and empirical ones. Thus he does not have to commit himself to an explicit social destruction of reality in the way that Kitcher would have to. He can, without having to engage in "Science for the People" type reasoning, argue that "race" is unscientific. Providing intellectual and empirical 
cover for Hodgean moral attacks, seems to us to be an important impetus for the dogged purportedly logical and empirical-based critiques of the modern race concept. It allows morally driven opponents to not commit themselves to scientific moralism. Whether this is, in fact, the case, we need not determine. What is important is that critiques of the race concept are, when not moral, often morally motivated. It is not just critiques of the concept but also of research related to race. Thus critics not infrequently make thinly veiled demands for intellectual and scientific censorship. For example, Pigliucci (2013) makes the case for a sort of soft censorship:

\begin{abstract}
Point (a) is actually not in play at all, since as I mentioned I do not think anyone - and certainly not the editors of Nature - is suggesting that academics should be prohibited from doing research on race and IQ. That said, of course, the entire academic research system is based on multiple levels of peer review (both of articles before publication, and of grant proposals before funding), one main object of which is precisely to determine whether a given research program is worth the effort and resources (be they printed pages in a journal or dollars from a granting agency).
\end{abstract}

The editors of Nature to whom Pigliucci (2013) refers seemed to have followed his advice and deemed the nexus between race and behavioral genetics to be an unacceptable area of exploration. In the 2013 editorial, "Dangerous work. Behavioural geneticists must tread carefully to prevent their research being misinterpreted," we are told:

Scientists have a responsibility to do what they can to prevent abuses of their work, including the way it is communicated. Here are some pointers ... Second: be accurate. Researchers should design studies on the basis of sound scientific reasoning. For instance, in light of increasing evidence that race is biologically meaningless, research into genetic traits that underlie differences in intelligence between races, or that predispose some races to act more aggressively than others, will produce little.

Kitcher (2007) makes an argument quite similar to that of Pigliucci (2013). Like Pigliucci (2013), Kitcher (2007) opposes "hard" or formal censorship, but argues that the softer type might be warranted.

Getting back to the main issue, we do not want to imply that the race concept is only critiqued for moral reasons. The lively debate in the philosophy of biology on the social construction and existence of species suggest that moral concerns are not the only drivers of the discourse. Without such moral concerns, the semiotics and ontology of race would be debated with as much ferocity as are the semiotics and ontology of species and spatial population. But this is the point! Outside of biological philosophy most have no idea that, in some technical senses, the reality of species or the meaningfulness of the species concept is called into question. Inside, the debate is tame and balanced. And no one inside pontificates to those outside that species are unreal, let alone misleads them with equivocal usages of terms like 'real.' Moreover, in context to the species debate, no one calls for the policing of dangerous ideas, advocates for the soft censorship of research, levels vicious ad hominems against their opponents, describes opposing ideas a "repugnant" and "offensive," recounts the supposed past evils of the opposed positions (e.g., species and slavery by way of polygenism), and so on. For all of these reasons, we can conclude that the race debate is quite unlike others concerning generic biological entities. It is morally infused and more akin to human socio-politically relevant debates such as on the heritability of intelligence than to ones concerning the definition of "species" and "population."

\title{
VI-B. The Moral Critiques
}


Scientific moralists have not limited their attack to the biological concept of race. Many of the same charges leveled against the race concept have been issued against research on and concepts related to the genetic underpinnings of behavioral traits. As cognitive scientist and popular science author Steve Pinker has noted, "In recent decades, the standard response to claims of genetic differences has been to deny the existence of intelligence, to deny the existence of races and other genetic groupings, and to subject proponents to vilification, censorship, and at times physical intimidation" (Pinker, 2006). In 1978, Bernard Davis characterized attempts to prevent dangerous knowledge by "blocking off an area of inquiry on moral grounds" as constituting a "moralistic fallacy." Strictly speaking, such attempts, and the consequentialist arguments in defense of them, are not fallacies. We could, nonetheless, dismiss such arguments on "scientific fundamentalist" grounds, ones on which social pieties have no standing. The controversial evolutionary psychologist Satoshi Kanazawa (2008) forcefully expressed this position: "No other criteria besides the truth should matter or be applied in evaluating scientific theories or conclusions... The only responsibility that scientists have is to the truth, nothing else."

While we feel that scientific and philosophical fundamentalism is often the appropriate stance for knowledge seekers to adopt, we appreciate that our moralists see things otherwise. Cofnas (2015) has offered additional arguments, both pragmatic and communitarian, against scientific moralism. While these are reasonable, we will not rest our defense on them. The problem for us is not just that scientific moralism, as such, is epistemically problematic and also, by way of this, socially so, but that the attack on the race concept is impugnable given what we take to be common sense morality. We grant, of course, that a biological concept of race can enable many modes of thought that our scientific moralists disdain. Let us consider four general perceived troubles.

For Kitcher (2007), the biological race concept leads to stereotyping and with it racial discrimination and, as a result, unjust inequalities:

In fact the practice [of stereotyping] is even more hideous that I have represented it as being, for a better explanation of the correlations involved past applications of racial concept ... So at the root of the causal story are past practices of identifying some people by superficial characteristics, viewing them as belonging to a separate race, and, in consequence, cramping and confining their aspirations and their lives. Crude essentialist notions of race, often committed to prejudiced speculations about the "biological basis" of various cognitive and behavioral traits, have played crucial roles in these practices. Application of the notion of race is thus ultimately responsible for the correlations adduced to "defend" the current practices of stereotyping.

For Hudson (1996), the concept of biological race problematically allows for classifications and with them negative evaluations:

Before these authors, "racism" could exist as little more than a visceral distrust of physical difference, crudely expressed in degrading images and outbursts of disgust. Only with the rise of racial science could "racism" take the form of an "objective" and self-conscious conviction in the radical inferiority of certain visibly different groups ... Yet we have still not freed ourselves completely from the disruptive and deluding legacy of Enlightenment racial science. The question remains, indeed, whether Buffon's recoinage of "race" should be finally relegated to the dustbin of dangerous and useless terms. 
For Appiah (1989), biological race (or at least "racialism") supports "intrinsic racism," the practice of personally valuing members differently solely on account of racial affinity:

Racialism is not, in itself a doctrine that must be dangerous, even if the racial essence is thought to entail moral and intellectual dispositions... Racialism is, however, a presupposition of other doctrines that have been called "racism," and these other doctrines have been in the last few centuries, the basis of a great deal of moral error and the source of a great deal of human suffering...

Intrinsic racists, in my definition, are people who differentiate morally between members of different races, because they believe that each race has a different moral status ... Just as, for example, many people assume that the fact that they are related to another person - a brother, an aunt, a cousin - gives a moral interest in that person, so an intrinsic racist holds that the bare fact of being of the same races is a reason for preferring one person to another.

For HoSang (2014), the concept is used to construct oppressive social structures and to legitimize racial injustice:

A cursory review of Sesardic's (2010) [defense of the biological race concept] makes clear that Sesardic advances this argument in large part to recover and legitimate the work of scholars affiliated with the Pioneer Fund, a group founded by American Nazis and Eugenicists in 1937 that has supported some of the most infamous white supremacist research in the twentieth century: studies by Richard Herrnstein and Charles Murray, Arthur Jensen, William Shockley, Linda Gottfredson, and Phillipe Rushton (Tucker 2002) ... Sesardic develops the "genomic challenge" thesis in order to recover and legitimate intellectual claims for white supremacy. ..

As the case of Hsu and Sesardic make clear, the invocation of race as a scientific category has always been linked to the production and naturalization of a social hierarchy. The very substance and rationale of their inquiry is only cognizable within this implicit framework of white supremacy.

There are more charges, but these seem to be the major coherent ones. Before we can defend the race concept we must situate it in a moral system. In some, for example a Marxist one where practically anything- such as: aptitude exams, national borders, and stereotypes (accurate or not) - which promotes social inequality is subject to indictment, it would be difficult to make a solid apologia, as least when concepts are held maximally liable for all social uses. We can put this point another way: there can be no doubt that the biological concept of race is dangerous to some ideological systems and societal ideals. For example, the concept can support the perception that members of an individual's division are more valuable than are members of other ones. This is as one would expect since race is an extended family based concept and since many are partisan with respect to family. Moreover, this perception can be justified, to some extent, as the genetic affinity between members of the same race relative to the global population can be commensurate with that between members of an extended family (e.g., between parents and grandchildren) relative to the local population (Harpending, 2002; Salter, 2003). Granting this, the race concept possesses a clear threat to Appiah's (1989) anti-“intrinsic racism" project; to maintain it, he would have to throw garden variety kin favoritism under the moral steamroller. Doing so, though, would render his position out of sync with ordinary morality - by which having a "moral interest" in one's biological family is seen as normal.

That is, we can not discuss the moral aspects of race-based social perceptions in a vacuum. We have to situate such a discussion in a meta-ethical system and in context to accepted moral customs. As for a meta-ethical system, we assume a sort of Hobbesian framework. By this, 
people are by nature selfish. Ethics, in practice, represents a set of rules created to limit the deleterious consequences of selfishness in excess. This set of rules is largely a modus vivendi made to allow individuals to maximize their particular goods. Since good maximization is not a zero sum game, individuals can profit from restrictions on how they and others achieve their ends. It is recognized that there may be natural laws and moral principles evident to the light of reason but since no one has established any, as evidenced by the continual disagreement in moral and political philosophy, a political realistic stance is adopted. When it comes to moral negotiations, participants agree to allow for disagreement as to what constitutes the good. Instead of seeking a capital-T true moral system a fair one is sought. An ethical system is fair when the rules of the game or morals are applied equally to all participants. This is sought not because fairness is deemed to be objectively good, but because it is something that self-interested parties can agree on as a basis for negotiations. The customs and morals we live by at a given time represent the product of these ethical negotiations. They are subject to change with changing interests. Since this is what we have, it is our starting point for moral evaluations.

Now, there is another point to be made. To some extent our negotiated morals vary by region, just as by time. What is acceptable here may be less so there. Since our concern is with race as a scientific concept and since science is a global enterprise, not particular to this or that region, the body of moral jurisprudence which we adopt to judge the concept needs to be as global and generally accepted as possible. We propose the following general considerations which, as best we can tell, are consistent with global mores:

(a) There is nothing intrinsically problematic with classifying and evaluating individuals. However, classifications which pick out groups for the purpose of picking on them may be morally problematic if the picking on is both unjust and egregious.

(b) The permissibility of social opinions about different racial groups is to be evaluated based on the norms used to judge the permissibility of opinions regarding comparable classes (e.g., religious, subcultural, and look-based).

(c) In-group-favoritism, broadly constructed, is common and morally permissible to a degree. Ethnic favoritism is not a special case; it should be evaluated based on norms used to assess comparable tendencies e.g., subcultural and kin favoritism. Ethnic and kin preferentialism is natural, in the sense of being partially genetically conditioned and in the sense of being evolutionarily rational (Salter, 2003). The moral acceptability of such preferencing is not contingent on its naturalness, though; it is on the principle that each should be free to seek out and work toward their own good.

(d) National, ethnic, religious, and racial groups have a right to be and a right to self-determination; the right to be entails some right to their own institutions, communities, and lifestyles.

(e) Racial discrimination, conditioned on race, is not inherently unjust. It is though when:

(e1) it does not promote an accepted institutional good, in which case it is capricious with respect to the institution; for example, if racial diversity/homogeneity is not a primary good of a state, discrimination conditioned on race would be unjust.

(e2) it does not promote an accepted individual good in a forum where such discrimination is accepted in a given region; for example, racial discrimination in the marriage and friendship market is seen as an acceptable forum for discrimination in the U.S. 
(f) The preservation and advancement of a racial group can be a legitimate institutional good (if that is what the institution is agreed to be for) just as that of cultural, religious, etc. groups can be.

(g) Inequality between groups, racial or otherwise, is not morally problematic, per se. Excessive inequality might be, circumstances depending. Inequality due to injustice is problematic, where "injustice" is understood consistent with how it is in context to individuals and other comparable classes.

(h) The above noted, if a social formation or practice is so destructive to the social good of a particular sovereign state, suppressing it is generally seen as justified by members of that state. Different nations identify as subversive different social formations e.g., homosexuality in Russia and certain religions in China (e.g., Falun Gong). This consideration stands in tension with many of the ones discussed above.

We take the above to be the ordinary moral backdrop. This is not to say that it is one endorsed by most contemporaneous Western moral philosophers - just that it is one consistent with common moral sensibilities, sensibilities which can become warped in context to thinking about race and certain other classes (see, for example: Tetlock, 2000; 2003). It will be noted that the moral ideal of inclusiveness, in the sense discussed by Kalb (2013), which "requires that persons of every race, ethnicity, religious background, sex, disability status, and sexual orientation participate equally in all major social activities, with nearly proportional presence and success" and which "presents a vision of unity in the world without outsiders and without borders" is not recognized as a general moral custom, despite its seeming adoption by certain intelligentsia in certain Western countries. This would be a parochial societal good and concerns about it would fall under consideration (h). This leads us to another point: many race related behaviors which are not seen as morally problematic given the considerations above would be deemed to be wicked by not a few moralists and perhaps by the publics of certain countries. It is for this reason that we specify a general moral framework.

\section{VI-C. The Moral Critiques: Arguments based on Outcome Differences}

We now find ourselves situated to evaluate the moral criticisms. Given the considerations outlined, under what circumstances would these hold water? They would on the following conditions: (1) the race concept underwrites social practices which are particularly destructive to the social good relative to those practices underwritten by similar accepted concepts; (2) the destructiveness is such to outweigh the benefits gained from using the concept; (3) the social destructiveness is general enough to allow for an argument against an inherently cosmopolitan scientific concept.

It might seem as if we are setting up insurmountable standards to dismiss moral arguments, but the moral arguments against race often purport to show the above. For example, Ashley Montagu (1942) argued that "race" was man's most dangerous myth - not that it was "one of many potentially dangerous concepts in the West." Of course, if one assumes from the start - as is often done (e.g., Hudson (1996); Hodge (2013)) - that the concept has no scientific validity, such arguments becomes much easier to make, since one already has epistemic justification for aborting the concept. It is only because this is not the case that moral arguments against the biological concept become rather difficult. But let us consider these with an open mind. 
For Kitcher (2007), the biological concept of race leads to unjust inequalities. It is said to work its nefarious deeds through a couple of different routes. Mainly, the concept is said to encourage the view that socially relevant racial-group differences have a non-trivial genetic etiology. Let us call this view "racial hereditarianism." ${ }^{109}$ According to Kitcher, this racial hereditarian view is problematic because it conditions inaccurate stereotypes, which, in turn, condition unjust discrimination. Worse, racial hereditarianism allows for the rationalization of the unjust states of affair (e.g., socioeconomic inequalities) produced by such discrimination. They are, naturally enough, said to be the products of hereditary racial differences in ability and behavior. Kaplan (2014) further articulates the problem that racial hereditarianism - and, with it, biological race is seen as posing:

This is why the hereditarian claim... is so dangerous. Because it *would* I think have at least some real implications. One of these would be that statistically significant differences in outcomes pursuing certain life goals could no longer be taken as prima facie evidence for differences in socially important inputs; where these inputs are a matter of justice, being able to ignore them matters to the real harms people suffer.

For Kaplan (2014), if racial hereditarianism is thought to be true, one can not justifiably, as is the common practice in sociology, presume that socioeconomic inequalities between sociological races are the product of unjust discrimination. For example, one could not presume that the relatively poor socioeconomic performance of Aborigines in Australia is due to White racism, past or present. As a results, one could not then as easily justify compensatory policies such as reverse discrimination, which could be used to equalize groups. And one could not elicit as much moral outrage about the existent differences.

Neither Kitcher (2007) nor Kaplan (2014) seem to see any ethical problem with the presumption the group differences are due to unjust discrimination. It seems to us, though, that one should not presume racial injustice - which is to say accuse some of this - unless one actually rules out plausible alternative models such as a differential ability one (Dalliard, 2014)."Why?" hardly needs to be explained and so we will not belabor the point. Readers are, instead, referred to Levin (1997) and Sesardic and De Clercq (2014) for an exposition of the reasoning in context to, respectively, race and sex differences. Generally, the default position should be "We do not know." And if one wants to make the case that differences are due to discrimination, a case which entails an accusation of injustice, the burden should be on those making it to rule out alternative models.

It might be supposed that this ruling out was already done - and that only curmudgeons would disagree. Kitcher (2007) seems to think so. But as we showed in section IV, the argument offered by Kitcher (2007) was patently specious - the argument, in fact, lends itself to the opposite

\footnotetext{
${ }^{109}$ Kitcher (2007) does not use the phrase; he just speaks of the perception of genetic differences and of the "ogre naturalist" project, which refers to the work of Rushton, a well-known racial hereditarian. Also, technically, according to "racial hereditarianism" group differences are due to hereditary (or additive genetic) factors. However, the term is being used here in a more inclusive sense, such to include also active indirect genetic models of group differences. By an active indirect model, differences can represent extended phenotypes. They can be mediated by environmental factors that are under the individual's or population's control. In contrast, by a reactive (indirect) model, differences are mediated by environmental factors which are imposed from the outside. An example of a reactive (indirect) model would be discrimination based on race indexing phenotype.
} 
conclusion. Lest it be thought that a racial hereditarian position, say with respect to intelligence and in regards to the U.S., is a fringe one, it will be noted that, according to a 2013 survey, the majority of responding intelligence researchers concurred with some form of it. These results, shown in Table 6.1, mirror those from the last major survey on the topic.

\section{Table 6.1. Surveys of researchers concerning the source of Black-White differences in the} U.S.

A. 2013 Survey of Intelligence Researchers: Source of the U.S, black-white differences in IQ (Rindermann, Coyle, and Becker, ISIR 13, 14-XII 13, Expert Survey)

$\begin{array}{lll} & & \% \text { of responding experts } \\ 0 \% . & \text { of difference due to genes: } & 17 \% \\ 0-40 \% . & \text { of difference due to genes: } & 42 \% \\ 50 \% . & \text { of difference due to genes: } & 18 \% \\ 60-100 \% . & \text { of difference due to genes: } & 39 \% \\ 100 \% . & \text { of difference due to genes: } & 5 \%\end{array}$

B. 1984 Survey of 1020 experts in psychology, etc.

(Snyderman and Rothman (1987))

$\begin{array}{ll}\text { No response } & 15 \% \\ \text { Insufficient evidence to answer } & 24 \% \\ \text { entirely environmental } & 15 \% \\ \text { Environmental and genetic } & 45 \% \\ \text { entirely genetic } & 1 \%\end{array}$

The point here is not that the existence of congenital ability differences is beyond doubt or is even probable but that the issue is unsettled. The known (sociological) race differences in ability might well turn out to be like the known class differences, substantially genetically conditioned (Rowe et al., 1998; Trzaskowski, 2014), or they might turn out to be only trivially so (as argued by Kaplan (2014)). What is known is that genomic ancestry can statistically explain some socioeconomic differences within groups such as African Americans. ${ }^{110}$ For example, Gower, Fernández, Beasley, Shriver, and Goran (2003) found a -0.13 correlation between SES and African genomic ancestry in the African American population. And Ruiz-Linares et al. (2014) reported a 0.12 correlation between European genomic ancestry and both wealth and education in a cross-national Latin American sample; in this study, it was found that the genomic-outcome association was not substantially mediated by ethnic identity. These magnitudes of association

\footnotetext{
${ }^{110}$ Fuerst and Kirkegaard (2015) presented results from their review of admixture studies conducted between 2004 and 2014. 46 studies from across the Americas were found which provided data on the relation between educational and SES indexes and genomically indexed European, African, and Amerindian ancestry in admixed populations (e.g., Trinidadian Blacks). 100\% gave results in the direction predicted by a racial hereditarian hypothesis; $87 \%$ showed a statistically significant association. Generally speaking, the associations reported above are robust.
} 
within groups can scale up to explain substantial between ethnic group differences. ${ }^{111}$ This genomic ancestry-outcome association, of course, is simply taken by some as just more prima facie evidence of racial discrimination.

Nonetheless, it is consistent with a racial hereditarian hypothesis, which proposes that behavioral characteristics, not racial discrimination, mediates the ancestry-outcome association. Could such a hypothesis be tested? It could to some extent in the same way that hypotheses concerning racial differences in disease propensities are e.g., admixture mapping (Malloy, 2013; Dalliard, 2014). If it could be, why has it not been? In 2012, political scientist James Flynn, well known for his arguments against racial hereditarianism, noted:

[I]f universities have their way, the necessary research will never be done. They fund the most mundane research projects, but never seem to have funds to test for genetic differences between races. I tell US academics I can only assume that they believe that racial IQ differences have a genetic component, and fear what they might find. They never admit that the politics of races affects their research priorities. It is always just far more important to establish whether squirrel enjoy The Magic Flute. (Flynn, 2012)

Simply, there is political pressure against doing so. And this has led to the kind of soft censorship advocated by Kitcher (2007) and Pigliucci (2013). This situation sets up the problem we have with the argument made by Kitcher (2007) and others. To start: if a hereditarian explanation for racial differences is largely correct, a biologic concept of race can not be "guilty" of nefariously inducing them. But this consideration works backwards. If Kitcher is incorrect about his causal model, then racial environmentalism - and, by way of, race denial - might be the true moral monster, one akin to a modern-day Lysenkoism. As a result of the ongoing "anti-racist" hysteria in the West, members of some ethnoracial groups are the beneficiaries of discrimination to compensate for Kitcher's perceived injustices; other groups are defamed and deconstructed on the same account. In the U.S., paranoid sociologists see ubiquitous racial discrimination by Whites against Blacks:

Drawing on a systems perspective, I show that race discrimination is a system whose emergent properties reinforce the effects of their components. The emergent property of a system of race-linked disparities is über discrimination - a meta-level phenomenon that shapes our culture, cognitions, and institutions, thereby distorting whether and how we perceive and make sense of racial disparities. Viewing within-domain disparities as part of a discrimination system requires better-specified analytic models. While the existence of an emergent system of über discrimination increases the difficulty of eliminating racial disparities, a systems perspective points to strategies to attack that system. (Reskin, 2012)

In Australia, Europeans (Whites) are admonished and shamed on account of the poor outcomes of Aborigines:

\footnotetext{
${ }^{111}$ To put the figures in perspective, among adult U.S. African Americans, the standard deviation of African admixture is about $15 \%$ and the average African admixture is about $80 \%$ (Zakharia, et al. 2009). So average African Americans and hypothetical African Americans with $95 \%$ European ancestry would differ in about 5 standard deviations of African admixture. This would suggest a difference of $0.13 \times 5=0.65$ standard deviations in SES between the two groups on account of average individual genomic ancestry alone (i.e., no population-level effects). This is more or less commensurate with the magnitudes of differences between U.S. Blacks and Whites in both income and education.
} 
When Aboriginal and Torres Strait Islander children ... take their places as doctors and scientists, when it is no longer remarked that members of parliament and cabinet ministers are indigenous, and above all when there is no social or economic indicator that shows a lower standard for Aborigines and Torres Strait Islanders, only then will Australia be able to hold up its head because a "fair go" will have become reality. (Economist Helen Hughes, Quotes in Rothwell, 2013)

The U.S. Supreme Court justices justify open racial discrimination on the grounds that historical (that is, no longer occurring) injustices are the cause of outcomes differences:

I have several times explained why government actors, including state universities, need not be blind to the lingering effects of "an overtly discriminatory past," the legacy of "centuries of law-sanctioned inequality." Id, at 298 (dissenting opinion). See also Adarand Constructors, Inc.v. Peña, 515 U. S. 200, 272-274 (1995) (dissenting opinion). Among constitutionally permissible options, I remain convinced, "those that candidly disclose their consideration of race [are] preferable to those that conceal it."

(Ginsburg, 2013)

Generally, in this regards, we have four possibilities:

(1) True environmentalism: differences are thought to be environmentally conditioned and are.

(2) False environmentalism: differences are thought to be environmentally conditioned but are by genes.

(3) True hereditarianism: differences are thought to be genetically conditioned and are.

(4) False hereditarianism: differences are thought to be genetically conditioned but are by the environment.

Those who make moral arguments from inequality believe that the concept of biological race encourages option (4), which creates unjust outcome differences. Some concede that it is not known for certain whether environmentalism or hereditarianism is actually the case, but argue that or go about as if this does not matter since false environmentalism (3) can have no negative externalities. But the actual effect of (3) is a perverted form of justice in which unjust treatment is dished out for the sake of attempting to equalize unequal groups and in which groups are ethnocided for the sake of preventing differences not unjustly caused.

To even begin to make moral arguments that rest on group inequality, proponents of these need to establish: (a) that the relevant differences are not, in fact, genetically - or somehow other conditioned, (b) that these differences are the product of injustice, and (c) that a biological concept of race enables this injustice. We think that the moral import of the causal uncertainty of the said differences is underappreciated - or maybe not, maybe it is well understood. The uncertainty does not just undermine arguments against biological race, it impugns them. Antibiological race arguments, insofar as they are used to obstruct the determination of the cause of group differences and with it, in many people's opinion, a correct assessment of culpability, represent an obstruction of justice whether or not a hereditarian position is substantially correct. Insofar as they hinder an empirical determination of the cause of the said differences, they represent an affront to justice.

True hereditarianism would do more still. It would complicate many historical narratives. Time constraints preclude us from elaborating on this latter point. Instead of attempting a condensed discussion of this complex matter, for some alternative perspectives that emerge from genetic realism about race differences, we refer readers to philosopher Gedaliah Braun's controversial work, "Racism, Guilt, Self-Hatred, and Self-Deceit" - specifically to, for example, the following 
sections: "The Pros and Cons of Apartheid," "African States Not Fit to Govern Themselves," "The Paradox of Integration," and "School Segregation in America."

What is particularly ethically problematic about the moral arguments, given the causal uncertainty, is that the conclusions of these are used to underwrite the claims about moral wrongdoing. For example, Sapp (2012) tells us:

Although race is void of biological foundation, it has a profound social reality. All too apparent are disparities in health and welfare. Despite all the evidence indicating that "race" has no biological or evolutionary meaning, the biological-race concept continues to gain strength today in science and society [.]

These underwritten claims are then inputted back as premises in the moral arguments: while the race concept is not really devoid of "biological or evolutionary meaning" it might be best to communicate the idea that it is because of the "disparities in health and welfare" that the concept leads to - disparities which we know are due to unjust discrimination and not to genes because, after all, race is devoid of "biological or evolutionary" meaning. Now, it might be the case that group differences are primarily due to unjust discrimination - but this needs to be determined. A trial needs to take place before the court of empirical data - not a lynching based on the assertions of social activists in academia.

Our conclusion in this regards then is the reverse of Kitcher's. Now, if it is determined that there are no relevant congenital differences, we agree that the elimination of the false belief in these would be the scientific and ethical thing to do - just as would be the elimination of the false belief in racism insofar as it is found that outcome differences could be accounted for by genetic or other factors. If the former proved impossible, then it would be reasonable to explore the extent to which the biological scientific concept of race contributes to the misperception of differences. If it is found to contribute, nontrivially, we can begin to discuss if it would be reasonable, given how we handle other concepts, and given international context, to rename or unrecognize the race concept - assuming a scientific moralistic frame. Finally we can weigh whether scientific moralism is itself a good idea. This would then put us in a position to make an argument.

\section{VI-D. The Moral Critiques: Arguments based on Racial Classification and Identity}

Hudson (1996) argued that the concept of race is morally problematic because it allows for the degrading treatment of individuals by permitting them to be grouped into classes which can be thought of as "radically inferior." While, of course, the concept has been used to cut out human divisions and while it can not be denied that members of some divisions have considered members of others, on account of their class membership, to be of less value, the claim that "race" allowed for a view of "radical inferiority" strikes us as curious.

As has been noted, the concept of (intraspecific) race was developed to explain the "constant varieties" of both plant and animal species. Hudson, oddly interpreting Linnaeus' variety category as one which gives "little indication that there is any room for change," seemed to have missed the inconstant varieties versus species dichotomy, which set the backdrop for the introduction of the race concept. 
As noted prior, the intraspecific race concept was frequently employed to support the monogenist dogma, according to which human groups were lineages of the same species and thus not radically different either ontologically, morally, or physiologically. Insofar as objective moral worth was grounded in natural law and insofar as humans were said to share a common nature as a birthright (the biblical view at the time of the concept's development), this race concept precluded an "objective' and self-conscious conviction" of "radical inferiority." The species concept, on the other hand, did allow for this - and it was, at times, employed by some polygenists, for example Josiah Nott, to justify social hierarchies. This is not to say that the intraspecific concept of race was not employed to justify racial inequality. It is to clarify, rather, that the concept was not originally employed to support the belief in "radical" differences.

But what about allowing for some notion of difference and inferiority? Sure, but the concept of race is not particular in this regards. Such seems to be a generic property of human social categories. That which is conceptualized as "divinity," allows for delineations according to belief - e.g., "orthodox," "heretic," "pagan." "Social class" allows for arrangements based on social status - e.g., "high class" and "low class." "Family" and "kin" allow for groupings based on pedigree - e.g., "kin" and "non-kin"; "Political position" allows for categories based on sociopolitical orientation - e.g., "communist," "fascist," and "capitalist." All of these classes and many more can be and have been differentially evaluated, valued, and treated; and many great evils have been perpetrated against members as members of these classes. If such an argument, one based on the social uses and abuses of and related to groupings, is to be leveled against one concept, it only makes sense to do so across the board. Unless unprincipled exceptions are made or unless there are justified reasons for exceptionalism in the case of race, this type of argument against the acknowledgment of the concept reduces to absurdity. To see this, one can just apply the same line of argumentation to other social formations and the concepts which underwrite them. We can rephrase Hodge's (2013) polemic. Regarding the concept of "family":

The myth of "family" has supported the horrors of child abuse, incest, domestic violence, nepotism and the Mafia. It continues to support favoritism for one's own so-called "family members" over socalled "strangers." Yet scientists have found no evidence of a "Smith gene" that distinguishes "Smith family members" from "Jones family members." We cannot simply ignore the harm this myth has caused and pretend that the myth never existed! The scientific, democratic and ethical goal should be to eliminate the false anthropological concept of "family" completely! Any time someone mentions "family," they perpetuate this evil lie.

Regarding the concept of "religion":

Scientists have found no evidence to support the idea of "religion". Therefore, religion is a myth. Religion supported wars, witch-hunts, slavery (e.g., Islamic slave trade), segregation, genocides, et cetera. Not only are certain religions flawed, as suggested by the practice of some of worshiping an elephant deity, but the very idea of "religion" is. The scientific, democratic and ethical goal should be to eliminate the false idea completely. To start, we must condition others to understand that when they discourse about religion they are talking about an arbitrary and harmful social custom constructed based on a continuum of psychosocial experiences.

These represent silly arguments against concepts. The argument against the race concept on the grounds that it allows for potentially abusive classifications, then, seems to generalize to absurdity. One could, though, restructure the argument. One could say that the race concept 
underwrites a very pernicious social formation i.e., racial identitarianism. And that this social formation needs to be abolished.

One could and this all has been done regarding family and religion as social formations. The attacks on these social structures - against family (e.g., Plato and Abiezer Coppe) and religion (e.g., Marx and Richard Dawkins) are almost invariably grounded in a communistic or universalistic ideology. Thus, twentieth century Russian novelist William Gerhardie denounces family, that "ungodly unit of pernicious preferential loyalty" (Mount, 2010), while sociobiologist E. O. Wilson tells us that we should eliminate religious faiths for the "sake of human progress" because they are tribal, which is bad as "every tribe, no matter how generous, benign, loving and charitable, nonetheless looks down on all other tribes" (Osborne, 2015).

While some academics and intellectuals see these forms of social organization and identity as despicable engines of social disharmony, this is not how ordinary people typically view them. The same holds with regards to ethnicity - granted, in the West, anti-racial elitist sentiments have percolated down deep into the popular consciousness, so the same might not hold, in some regions, with regards to racial identity, as such. Nonetheless, by the lived-morality of ordinary people, the destruction of racial and ethnic groups as cultural groups - ethnocide as defined by UNESCO (Schabas, 2000) ${ }^{112}$ - is generally seen as a morally offensive act. This notion of the wrongness of eliminating racial groups as groups or identities was embedded in the original concept of "genocide" as developed by Raphael Lemkin:

Generally speaking, genocide... is intended rather to signify a coordinated plan of different actions aiming at the destruction of essential foundations of the life of national groups, with the aim of annihilating the groups themselves. The objectives of such a plan would be the disintegration of the political and social institutions, of culture, language, national feelings, religion, and the economic existence of national groups, and the destruction of the personal security, liberty, health, dignity, and even the lives of the individuals belonging to such groups... Genocide has two phases: one, destruction of the national pattern of the oppressed group [called: denationalization]; the other, the imposition of the national pattern of the oppressor. (Axis Rule in Occupied Europe, 1944)

Of course, genocide as denationalization is the very thing that many of our racial eliminativists aim for. To them, one can only note that the same "dangerous idea" logic applies to their inclusive, universalist outlook. To phrase this in Hodgean terms:

The myth of "equality" and "universality" has supported the horrors of the Jacobinism, Leninism, Stalinism, Maoism, and the Holodomor - ultimately the greatest democides of the 20th century. It continues to support totalitarian humanism around the world. We cannot simply ignore the harm this myth has caused and pretend that the myth never existed. The scientific, democratic and ethical goal should be to eliminate the false concepts of "equality" and "universality" completely.

Returning to our main point, as E. O. Wilson noted, every tribe, religious or otherwise, evaluates and differently values other ones. For ordinary people, this, when not in excess, is an acceptable

\footnotetext{
${ }^{112}$ In UNESCO's "Declaration of San Jose," ethnocide is when "an ethnic group is denied the right to enjoy, develop and transmit its own culture and its own language, whether collectively or individually. This involves an extreme form of massive violation of human rights and, in particular, the right of ethnic groups to respect for their cultural identity."
} 
state of affairs. Only for some universalistically inclined intellectuals is it not, often except in the case of their own moral tribe (see: Haidt, 2012). ${ }^{113}$ Generally, since evaluating is what tribes kinship-based, religious, cultural, and moral - do, to single out racial tribes one has to offer a justification.

To make such an argument against the race concept in particular, one has to make the argument that racial identitarianism is particularly dangerous, as compared to other forms of social identity, and is so much so to overcome the moral problem with e.g., ethnocide. We will consider a major justification, expressed by racial eliminativists (Kelly, Machery, and Mallon, 2010). It is argued that racial identity and association is particularly invidious because, first, historically biological racial-based associations - as opposed to family, political, cultural, and religious-based ones have been excessively destructive and because, second, contemporaneously they still are. The first piece of supporting evidence is dismissible on historical grounds. Those who make it conveniently fail to mention the scale of historic atrocities made based on religious and political social associations or in the name of the family. Regarding the second piece of evidence, it is either based on social inequality between said racial groups (e.g., Blacks and Whites in the U.S.) or on the prevalence of ethnic group conflicts. We discussed the problem with arguments based on inequality prior.

The problem with those based on "ethnic conflicts" is that "ethnic groups" are often not organized around a biological race concept. As such, arguments which point to ethnic conflicts work against other concepts like "ethnicity," "religion," "tribe," "nation," "people" and so on not against "biological race," as such. Politicized ethnicity has a deep history (Gat, 2012). It long preceded the event of the race concept. Moreover contemporaneous "ethnic conflicts" (see: Vanhanen (2012)) exist regardless of whether groups are called "races" or are thought of as representing biological scientific divisions. The conflict between Kurds and Muslims in Iraq, between Sunni and Shia Muslims in Bahrain, between Flemings and Walloons in Belgium, and many others would not be attenuated by somehow discrediting biological racial-based identifications or by censoring the term "race" because the groups do not conceptualize themselves in terms of biological race. Of course this does not mean that "race," in the social form, is not particularly problematic in some regions. One might, then, argue that the concept of "race" should be rejected locally in, say, the Americas. Likewise, perhaps in the Middle East, we could deem that "religion" does not exist; in the Korean peninsula that "political ideology" does not; in Sub-Saharan Africa that "tribes" do not. But this would produce a rather unwieldy scientific epistemology.

Again, we run into an absurdity.

Still we might persist. Perhaps there is something particularly invidious about racial identity, as compared to, say, "ethnic identity," that might incline us to dispose solely with the race concept

\footnotetext{
${ }^{113}$ There is an oddity. Universalists such as E. O. Wilson must recognize that many are congenitally disposed to "tribalism"; there is a rich literature in behavioral genetics on the heritability of such tendencies. Universalists must then recognize that particularists can not accept the "supernatural elements" inherent in the anti-particularistic, universalistic belief system. And that this leads to the particularists being sneered at as "bigots" by the universalists. But, for Wilson, it is on the account of looking down on and excluding that tribes are said to be bad in the first place. This should imply that Wilson's universalistic moral tribe is likewise indictable. What explains the failure to recognize this? In group-bias, one might suppose.
} 
so to undercut this identity. A case for this could be made. Anthropologist Pierre Van Den Berghe argued that with race "because the markers themselves are largely immutable, ascribed at birth and genetically inherited, societies that use primarily phenotypes as ethnic markers are characterized by more rigid and invidious intergroup relations that societies using cultural makers." Whether this is so is an empirical question that deserves to be explored. It can be, for example, in part with the ethnic conflict data set developed by Vanhanen (2012). Showing that, on the global level, societies which use phenotypes as ethnic markers exhibit more invidious intergroup relations would not allow for a consequentialist argument against the concept of race by itself. One would additionally have to show that the rigidity and destructiveness of such social formations were mediated by the belief that groups represented genealogical divisions - after all, this is what the concept of race adds to the picture. That is, one would have to establish, not assume, that the conceiving of groups as biological scientific races (that is, as different intraspecific lineages) preconditions more "invidious intergroup relations." As Forster noted to Kant in regards to thinking of groups as different species lineages, it is not obvious that it does.

The considerations above situate us to develop a more robust argument. Perhaps race is a dangerously explosive concept, not because it purports to mark out "radically inferior" groups or because it is made up - because races are myths constructed willy-nilly for economic ends - but rather because it does exactly what it purports to do: identifies genealogical divisions. This identifying could be socially dangerous because people, indeed all organisms, have evolved to be genetically selfish and, accordingly, have evolved tendencies to discriminate, sometimes wantonly so, on the basis of indexes of genetic propinquity (Eibl-Eibesfeldt, 1973; van den Berghe, 1981; Rushton, 1989; Salter and Harpending, 2013). ${ }^{114}$ Race would be a dangerous idea because it would let people think about and recognize lineage differences. In this regards, a passage from Wolfe's "Back to Blood (2012)" comes to mind:

So, my people, that leaves only our blood, the bloodlines that course through our very bodies and unite us. "La Raza!" as the Puerto Ricans cry out. "The race!" cries the whole world. The Muslims? Their jihad? Their Islam? All that is nothing but a screen, a cover story. What they are, is ... Arabs! Forget the rest of it! Arabs! - once the rulers of all Asia and half of Europe! Once the world's reigning intelligentsia - and now left behind in the dust of modern history! Back to blood, muhajeen! They, like all people, all people everywhere, have but one last thing on their minds - Back to blood!" All people, everywhere, you have no choice but - Back to blood!

In practice, the concept of race would enable the construction of particularist social identities built around phenotypic indexes of ancestry. It would tie these identities to a generally held to be sacred phenomenon (family). Being an extended-kinship concept, it would allow for the justification of racial nepotism by way of kinship analogies - as kin favoritism is tolerated to a degree. As an evolutionary concept, it would allow for the justification of the same based on evolutionary theory (specifically, inclusive fitness theory). And this is roughly the role that race

\footnotetext{
${ }^{114}$ Members of the same ethnic groups relative to the global population can often be as related as kin relative to the local population (Salter, 2003; Salter and Harpending, 2013), so mechanisms similar to those that condition kin discrimination (both in the sense of detection and favoritism) can plausibly scale up. This could be represented as a serendipitous "misfiring" of kin-favoritism (Tooby and Cosmides, 1989; Kurzban et al. 2001) or as the result of group selection (Salter and Harpending, 2013). How the dispositions evolved - as byproducts or as co-adaptations does not matter for the point being made.
} 
seems to play for modern racial identitarians and nationalists (e.g., Salter, 2003; MacDonald, 2005; Taylor, 2011).

To be clear, according to such an argument, the race concept would be problematic because it would (a) underwrite the construction of social identities based on visible, immutable characteristics (and thus potentially allow for more invidious discrimination relative to culturalbased identities), because it would (b) relate these social identities to interest in lineage, ancestry, blood, and family (and thus tend to encourage a more passionate identification with the identities), and because it would (c) allow for the justification/rationalization of, at times excessive, in-group favoritism.

Our problem with such a line of argument is that insofar as the race concept - as opposed to say the morph one - could do or does do this, it can because a non-trivial number of people do in fact value kinship in both the close and extended form and because the justifications for both racial identification and racial favoritism are plausible given this value. Insofar as race as kinship is valued, this is reason to not obscure the concept. The same point can be made with regards to religion. Presumably, religion taps into something which does or can move people. The concept "religion" allows one to think about this something and to differentiate between interpretations of it. The recognition of differences in conjunction with the emotionally charged nature of that considered lead to, at times, violent conflicts precisely because something is seen as worth fighting over. How does it make sense to deprive people of this valued thing - or the seeing of it - for the sake of other values e.g., equality and inclusive? This consideration brings us back to the point that many people see ethnocide as a bad thing and see racial identity not as a bad thing. So arguments against the race concept on the grounds that it underwrites racial identity do not seem to have much traction given what we take to be ordinary moral sensibilities.

\section{VI-E. The Moral Critiques: Arguments based on Racial Favoritism}

This brings us to our next criticism. For Appiah (1989) the problem is with "intrinsic racism," the preferencing of members of one's own race over members of others. Why this is seen as intrinsically more morally problematic than either intrinsic familyism or what we might call intrinsic self-ism, the preferencing of oneself over others, is left unclarified. The utilitarian philosopher Peter Singer has recognized the connection between the two. In "The Expanding Circle (2013)" he notes that:

\footnotetext{
Within the groups, other distinctions are similarly not ethically relevant. That someone is related to me rather than to you, or lives in my village among the dozen villages that make up our community, is not an ethical justification for special favoritism... Once I have come to see my interests and those of my kin and neighbors as no more important, from an ethical point of view, than those of my society, the next step is to ask why the interests of my society shall be more important than the interests of other societies.
}

Singer cleverly (and sophistically) reasons from the position that sound ethical principles are ones that apply equally to all moral actors (moral universalism) to the position that behaviors, insofar as they are moral, are ones that maximize the desires of all, with no special consideration given to one's self and own (utilitarianism). We obviously reject utilitarianism. But our argument 
does not hinge on this dismissal. It does on the lack of popular acceptance for this ethical system, as testified by the actual behaviors of people, even the proponents of utilitarianism themselves. ${ }^{115}$

One might, in contrast, posit an adaptive-based ethics, where the good is maximizing one's inclusive fitness. Thus, defending one's race's genetic integrity and securing its global representativity would be an inherent good (for example: Salter, 2003). Obviously, if we assumed such an ethics, consequentialist arguments against racial favoritism and race-thinking could not get off the ground. But, like (preference) utilitarianism, this ethical system does not currently have much currency. It does not then put us in a situation to well evaluate viable consequentialist arguments (for or) against our cosmopolitan concept of race. Again, we must reason about the matter, to the extent we do, from a general ethical frame, such as outlined earlier.

With respect to this general frame, as we understand it, some degree of "intrinsic racism" is acceptable just as some degree of intrinsic self-ism and intrinsic family-ism is. Just as family 'nepotism' is tolerated to a lesser extent than is self 'nepotism,' racial 'nepotism' is tolerated to a lesser extent than is family 'nepotism.' To the extent that there is a problem with such favoritism, it is one of degree not kind. That is, there is no categorical rejection of racial favoritism, since the above kinds of favoritism fall on the same continuum. Those who oppose racial favoritism need to explain why, given a general ethical frame, this kind of favoritism is specifically problematic. Generally, from the perspective of lived-morality, Singer's utilitarian conclusion represents the moral absurdity that Appiah's position reduces to. One might frown on genealogical partisanship in general, by what are the grounds for claiming that such is worse than partisanship along other lines?

It might be questioned why anyone would be inclined to be partial with respect to race. But the answer is obvious. Many people seem to have a genetic disposition for (ethno) racial favoritism (Lewis and Bates, 2010; Weber, Johnson, and Arceneaux, 2011; Orey and Park, 2012). Some people (correctly) analogize biological race to kinship and apply the same moral logic (e.g., Salter, 2003). Others simply identify racially and are partial to those they identify with. Also, many people tend to identify with and prefer other people who are more phenotypically similar to themselves (for example: Mackinnon, Jordan, and Wilson, 2011; McPherson, Smith-Lovin, and Cook, 2001) and, owing to genomic similarity, members of the same biological race happen to be, on average, more phenotypically similar to each other than they are to members of other races.

It could be reasoned that for the sake of the social good, despite some people valuing it, racial identity - and with it favoritism - should be suppressed. In a similar manner, some argue that gay identity should be suppressed on the grounds that it is socially corrosive. And maybe for this end the concept of "homosexuality" needs to be deemed scientifically invalid. This logic makes sense. But the burden is on those who make such an argument first to make a strong enough case, given ordinary ethics, that racial identity and social formations are particularly destructive such to outweigh the value of these and to justify, basically, ethnocide (our consideration $\mathrm{h}$ versus, for

\footnotetext{
${ }^{115}$ See, for example, Liberalbiorealist's (2010) discussion of Peter Singer's behaviors in relation to utilitarianism.
} 
example, $\mathrm{c}, \mathrm{d}$, and f. $)^{116}$ Second, the burden is on them to extend the argument to one against the race concept, given the treatment of other concepts. A persuasive argument along these lines seems unlikely.

\section{VI-F. The Moral Critiques: Arguments based on the "Racial Worldview"}

All three concerns - social inequality, classifying and evaluating, and exclusive favoritism - are central to HoSang's (2014) line of critique. According to this, the race concept does not just allow for individuals to be classed and degraded, but it was created for this very purpose. Thus HoSang (2014) tells us that the race concept, one of "naturally occurring categories or classes" emerged "as an effort to link human variation to explanations for hierarchy and inequality" and was "developed explicitly to situate the groups it identified within a colonial worldview."

If so, we wonder, why was the race concept developed not by conquistadors and explorers from the two colonial superpowers of the era, Spain and Britain, but instead by German and French naturalists and philosophers. Why was it employed so frequently to describe the varieties of plants and animals? Why was it used to argue against polygenism, a position which could have actually provided a theological basis for "hierarchy and inequality." And, we wonder, why was the traditional human classification scheme developed and popularized largely by Linnaeus (1735) and Blumenbach (1775) based on the variety concept, one which was explicitly said to cut out arbitrary, not natural, classifications?

One need not commit oneself to HoSang's (2014) untenable position, however. The American Anthropological Association (AAA), for example, simply maintains that "race" underwrites the "racial worldview" which is bad because it "was invented to assign some groups to perpetual low status, while others were permitted access to privilege, power, and wealth." The AAA, in this statement, conveniently makes no distinction between "race" in the specific and intraspecific senses - and leaves unsaid the egalitarian employment of the intraspecific race concept. While neither concept - species nor subspecies - was "invented" to create social hierarchies, the AAA does not commit itself to this position. Rather it does to the position that the "racial worldview" was. The race concept, in turn, is guilty of aiding and abetting this view. The phrase "the racial worldview" seems to refer to Smedley's (1998) concept, which is characterized as (to paraphrase):

1. Peoples can be classed into biologically separate, discrete, and exclusive divisions.

2. Phenotypic differences index racial identity and status.

3. Each races has a unique sociobiological traits profile.

4. Races are unequal. They both can and ought to be ranked and ordered.

5. Racial characters, morphological and psychological, are hereditary.

6. Distinct races "should be segregated and allowed to create their own institutions, communities, and lifestyles, separate from those of other races."

The critique against the biological race concept would be that it is material with which the racial worldview is constructed. In a similar way, the biological concept of "sex" (as in sexual

\footnotetext{
${ }^{116}$ For a defense of the race concept along the lines that it allows for racial identity, which is a good thing, see Outlaw (1996).
} 
dimorph) could be critiqued on the grounds that it is used in the construction of the "patriarchal worldview" Let us analyze this "racial worldview" to see if the AAA's indictment has any merit. The "race concept" is more or less captured by points (1), (2), and (5) jointly. As with any scientific concept, it was "invented" to describe natural phenomena. Point (3) is a claim about certain human racial classifications. The AAA concerns itself with the TRC - which, it turns out, happened to more or less cut out biological natural divisions. Moreover, the cause of the differences discussed by the AAA - socioeconomic ones in the Americas - is still undetermined and these differences have been shown to be correlated with genomic racial admixture both within and between ethnic populations (Fuerst and Kierkegaard, 2015). So some version of claim (3) is not now and was not prior empirically unreasonable. Point (4), sans "ought" and insofar as the same sense of "unequal" is applied to other classes and to individuals within these, is just to treat racial classes like other ones (e.g., social class) - alternatively, it is to not indulge in late $20^{\text {th }}$ and early $21^{\text {st }}$ century sensitivities. Point (6), describes an actual political position. Sans "should be segregated" this is consistent with UNESCO's declaration that ethnic groups should not be deconstructed; correspondingly, the right to self-segregation seems to be more or less consistent with the international principle of national self-determination. It seems that it is at least not crazy to support something like point (6). Most of the "racial worldview," then, seems reasonable.

The AAA's indictment of it rests on perceived unjust discrimination. They reason that "presentday inequalities [in the Americans] between so-called "racial" groups are not a consequence of their biological inheritance but products of historical and contemporary social, economic, educational, and political circumstances." Based on this determination, one for which they provide no proof, they conclude that racial classifications were "invented" for the sake of class exploitation. Now we can juxtapose "the racial worldview" with what might be called the "antiracial worldview" as outlined by van den Berghe (1981):

1. All humans are members of a single species and there are no biologically meaningful subspecies within it. "Races" are social constructs corresponding to no biological reality.

2. Differences between human populations are smaller than within them, and such differences as exist (e.g., in I.Q. tests performance) are largely if not entirely the product of the social environment.

3. Racism and ethnocentrism are irrational, dysfunctional attitudes. If not downright aberrations, to which certain rigid authoritarian types of personality are especially prone. Such attitudes must be combatted though social therapy promoting equal status contact groups.

To parallel Smedley's "racial worldview” we can add a fourth claim:

4. These "races" should be integrated and not "allowed to create their own institutions, communities, and lifestyles, separate from those of other races."

This would be the position that the "no race" view enables and which the AAA seems to adopt. As for it, point (1) is a falsehood. The first part of point (2) is true on average, but the second part is, as noted above, undetermined. And the claim that group differences are the product of exogenous factors underwrites accusations of iniquitous behavior, which are morally problematic for the reasons discussed prior. Regarding point (3), the second part now seems to be false since such behaviors - to some extent - appear to be rooted in evolved psychology. ${ }^{117}$ The other parts are defensible under ordinary morality only if "racism" and "ethnocentrism" are taken to mean

${ }^{117}$ Though, see Kelly et al. (2010). 
"unreasonable racial preferentialism" or "unjustified discrimination." But the terms are often used expansively to mean "racial identitarianism" and "preference for and interest in one's race." Insofar as the latter is meant, "combatt[ing]" such attitudes through "social therapy" is an affront to ordinary moral sensibilities (e.g., our (c)). Point (4) offends these sensibilities (e.g., our (d)) at least by our reading of them.

Granting the veracity of the considerations above, it is not clear that the "the racial worldview" is more morally suspect than the "the anti-racial worldview" and it is clear that the former is more epistemologically sound than the latter. An argument against the "race concept" on account of supporting the "the racial worldview" then can just as easily, if not more so, be turned into an argument for the concept on account of not supporting the opposite.

To review, arguments against the race concept are largely morally driven. Since race is a coherent, meaningful biological concept, arguments that are grounded in logic and empirics flounder. Thus, potentially sound arguments have to be grounded in morality. This entails scientific moralism. There are general epistemic and social problems with such scientific activism. Moreover, there are moral problems with the scientific moralists' arguments themselves. According to these arguments, the concept of race enables unjust inequality and exclusion. It does this by encouraging stereotypes and hereditarian speculations (Kitcher, 2007), by underwriting classifications which allow for degradation (Hudson, 1996), by underwriting racial identification which can be nepotistic (Appiah, 1989), and by underwriting the "racial worldview" (HoSang (2014) and the AAA). There are a number of problems with these arguments. First, the causes of the said group differences are not established; they could be due to evolved genetic propensities. Insofar as denial of biological race obscures this possibility, it obstructs justice, which requires an accurate determination of the causes of differences, not wild assertions regarding these. Second, the race concept is not unique in allowing for classifications which can lead to degradation. And there seems to be no sustainable justification for singling out the race concept. Third, given ordinary moral standards, there is nothing obviously morally wrong with racial identification and with some degree of racial favoritism. In contrast, there is with the destruction of racial cultural identities (ethnocide). Thus, arguments against the race concept based on its underwriting racial identity are unsustainable. Moreover, race denialism, insofar as it aids in the destruction of racial identity, is impeachable. All of these reasons taken together, in conjunction with others, undercut the argument against the race concept by way of that against the "racial worldview." Indeed, they reverse the thrust of it. 


\section{Conclusion}

In the West, at least, thinking in terms of human natural divisions or biological races is stigmatized. It is frequently held that recognizing such divisions is "unscientific" or "illogical." In this essay, it has been shown that this position is untenable. It has been demonstrated that there is a coherent, operationalizable concept of race which has been remarkably stable across time and which underlies and integrates a plethora of local definitions. Today, this concept makes sense of a type of biological variation not made sense of by other common biological scientific ones and so plays an epistemic role akin to that it played when it was developed in the 1700s.

The numerous logical and empirical critiques of the race concept and of specific racial classifications were patiently dissected. Most were found to be void of content; none were found to be even remotely compelling. The critiques were largely grounded in misreadings of the concept and of the literature elaborating it. Ultimately, such arguments represent social destructions, since, the Linnaean perspective being false, there is in fact something in nature which "race" describes.

It was noted that critiques of the race concept are largely motivated by moral-egalitarian concerns. Despite the socially and epistemically problematic dimension of scientific moralism, arguments grounded in it were entertained. These were found to be troubled, given ordinary moral sensibilities. More generally, what was dubbed the "anti-racial worldview" was also found to be morally problematic.

And yet such arguments are incessantly made and put forth with great zeal. This suggests that deep sociopolitical factors might be promoting them. Indeed, a number of anthropologists who have studied the topic have deduced the same; they have just interpreted such kinds of factors as underwriting the construction not destruction of the concept. If the analysis here is correct, the politics of the destruction of the race concept would be a fruitful area of exploration. Specifically, the degree to which criticism of the race concept is promoted by macro-sociopolitical agendas related to the multicultural and international projects needs to be explored in depth. 


\section{References}

A'Hearn, B., Baten, J., \& Crayen, D. (2009). Quantifying quantitative literacy: Age heaping and the history of human capital. The Journal of Economic History, 69(03), 783-808.

Albrecht, G. H., Gelvin, B. R., \& Miller, J. M. (2003). The hierarchy of intraspecific craniometric variation in gorillas: a population-thinking approach with implications for fossil species recognition studies. Gorilla biology: a multidisciplinary perspective, 62-103. Allaby, M. (Ed.). (2010). A dictionary of ecology. Oxford University Press. Alland, A. (2004). Race in mind: Race, IQ, and other racisms. Macmillan. Alpers, D. L., van Vuuren, B. J., Arctander, P., \& Robinson, T. J. (2004). Population genetics of the roan antelope (Hippotragus equinus) with suggestions for conservation. Molecular ecology, 13(7), 1771-1784.

Amadon, D. 1949. The seventy-five percent rule for subspecies. Condor 51:250-258. Andreasen, R. O. (1998). A new perspective on the race debate. The British journal for the philosophy of science, 49(2), 199-225.

Andreasen, R. O. (2000). Race: biological reality or social construct?. Philosophy of Science, S653-S666.

Andreasen, R. O. (2004). The cladistic race concept: a defense. Biology and Philosophy, 19(3), 425-442.

Andreasen, R. O. (2005). The meaning of 'race': Folk conceptions and the new biology of race. The Journal of philosophy, 102(2), 94-106.

Andreasen, R. O. (2007). Biological conceptions of race. Philosophy of Biology, 455-481.

Appiah, A. (1985). The uncompleted argument: Du Bois and the illusion of race. Critical inquiry, 12(1), 21-37.

Appiah, K. A. (1989, April). The Conservation of" Race". In Black American Literature Forum (pp. 37-60). Indiana State University.

Appiah, K. A. (1996). Race, culture, identity: Misunderstood connections. Tanner Lectures on Human Values, 17, 51-136.

Appiah, K. A., \& Gutmann, A. (1998). Color conscious: The political morality of race. Princeton University Press.

Archer, M. E. (1988). The subspecies problem as applied to Vespa (Hymenoptera: Vespidae). The College, Lord Mayors Walk, York Y03 7EX, England.

Ashlock, P. D. (1974). The uses of cladistics. Annual Review of Ecology and Systematics, 81-99. Aulchenko, Y. S. (2010). Effects of population structure in genome-wide association studies.

Analysis of Complex Disease association Studies: A Practical Guide, 123.

Baker, J. R. (1974). Race Oxford: Oxford University Press.

Bamshad, M. J., Wooding, S., Watkins, W. S., Ostler, C. T., Batzer, M. A., \& Jorde, L. B. (2003). Human population genetic structure and inference of group membership. The American Journal of Human Genetics, 72(3), 578-589.

Barbujani, G., \& Colonna, V. (2010). Human genome diversity: frequently asked questions. Trends in Genetics, 26(7), 285-295.

Barbujani, G., Ghirotto, S., \& Tassi, F. (2013). Nine things to remember about human genome diversity. Tissue antigens, 82(3), 155-164.

Barbujani, G., Magagni, A., Minch, E., \& Cavalli-Sforza, L. L. (1997). An apportionment of human DNA diversity. Proceedings of the National Academy of Sciences, 94(9), 4516-4519. 
Barreiro, L. B., Laval, G., Quach, H., Patin, E., \& Quintana-Murci, L. (2008). Natural selection has driven population differentiation in modern humans. Nature genetics, 40(3), 340-345.

Baten, J., \& Juif, D. (2013). A story of large landowners and math skills: Inequality and human capital formation in long-run development, 1820-2000. Journal of Comparative Economics. Baten, J., \& Sohn, K. (2013). Back to the 'normal' level of human-capital driven growth? A note on early numeracy in Korea, China and Japan, 1550-1800 (No. 52). University of Tübingen Working Papers in economics and finance.

Becker, A., Dohmen, T., Enke, B., \& Falk, A. (2014). The Ancient Origins of the Cross-Country Heterogeneity in Risk Preferences.

Becker, D. \& Rindermann, H. (2014). Genetic distances and IQ-differences: A cross-national study. Talk at 12. December 2014 at the 15th Conference of ISIR in Graz, Austria.

Becquet, C., Patterson, N., Stone, A. C., Przeworski, M., \& Reich, D. (2007). Genetic structure of chimpanzee populations. PLoS Genetics, 3(4), e66.

Bernasconi, R., \& Lott, T. L. (Eds.). (2000). The idea of race. Hackett Publishing. Bernier François (1684). Nouvelle Division de la Terre, par les differentes Espèces ou Races d'hommes qui l'habitent. Journal des Sçavans 12, 148-55.

Biello, D. (2013, March). Efforts to Resuscitate Extinct Species May Spawn a New Era of the Hybrid. Scientific America. Retrieved from:

http://www.scientificamerican.com/article.cfm?id=lost-species-revived-from-dna-and-restoredto-nature.

Bliss, C. (2012). Race decoded: The genomic fight for social justice. Stanford University Press. Blyth, E. (1835). An attempt to classify the "varieties" of animals, with observations on the marked seasonal and other changes which naturally take place in various British species, and which do not constitute varieties. Magazine of natural history, 8, 40-53.

Bhatia, G., Patterson, N., Sankararaman, S., \& Price, A. L. (2013). Estimating and interpreting

FST: The impact of rare variants. Genome research, 23(9), 1514-1521.

Bird, A. and Tobin, E. "Natural Kinds". The Stanford Encyclopedia of Philosophy (Winter 2012

Edition), Retrieved from: http://plato.stanford.edu/entries/natural-kinds/.

Blumenbach, J. F. (1795). On the natural variety of mankind. (T. Bendyshe, Trans.). London:

Longman, Green, Longman \& Roberts, 1865.

Blumenbach, J. F. (1806). Contributions to Natural History. Part 1 (1865). (T. Bendyshe, Trans.). Anthropological Society of London.

Biondi, G., \& Rickards, O. (2002). The scientific fallacy of the human biological concept of race. Mankind Quarterly, 42(4), 355-388.

Bird, C. E., Karl, S. A., Smouse, P. E., \& Toonen, R. J. (2011). Detecting and measuring genetic differentiation. Phylogeography and population genetics in Crustacea, 19, 31-55.

Inglehart, R. F., Borinskaya, S., Cotter, A., Harro, J., Inglehart, R. C., Ponarin, E., \& Welzel, C. (2014). Genetic factors, cultural predispositions, happiness and gender equality. Journal of Research in Gender Studies, 4(1), 32-100

Boas, F. (1974). A Franz Boas Reader. The Shaping of American Anthropology, 1883-1911, G.W. Stocking Jr. (ed.), Chicago: The University of Chicago Press.

Bowcock, A. M., Kidd, J. R., Mountain, J. L., Hebert, J. M., Carotenuto, L., Kidd, K. K., \& Cavalli-Sforza, L. L. (1991). Drift, admixture, and selection in human evolution: a study with DNA polymorphisms. Proceedings of the National Academy of Sciences, 88(3), 839-843. 
Bowcock, A. M., Ruiz-Linares, A., Tomfohrde, J., Minch, E., Kidd, J. R., \& Cavalli-Sforza, L. L. (1994). High resolution of human evolutionary trees with polymorphic microsatellites. Nature, 368(6470), 455-457.

Boyd, W. C. (1950). Genetics and the Races of Man (p. 453). Blackwell. Edward N. Zalta (ed.). Brace, C. L. (1999). An anthropological perspective on "race" and intelligence: the non-clinal nature of human cognitive capabilities. Journal of anthropological research, 245-264.

Braby, M. F., Eastwood, R., \& Murray, N. (2012). The subspecies concept in butterflies: has its application in taxonomy and conservation biology outlived its usefulness?. Biological Journal of the Linnean Society, 106(4), 699-716.

Braun, G. (2007). Racism, Guilt and Self-Deceit, (Self-Published).

Breed, M. D., \& Moore, J. (2011). Animal behavior. Academic Press.

Britton, N. L., \& Brown, A. (1913). An Illustrated Flora of the northern United States, Canada and the British possessions: from Newfoundland to the parallel of the southern boundary of Virginia, and from the Atlantic Ocean westward to the 102d meridian (Vol. 1). C. Scribner's sons. Brody, H., \& Hunt, L. M. BiDil: Assessing a Race-Based Pharmaceutical. Ann Fam Med 2006 4: 556-560; doi: 10.1370/afm. 582.

Brown, D. M., Brenneman, R. A., Koepfli, K. P., Pollinger, J. P., Milá, B., Georgiadis, N. J., ... \& Wayne, R. K. (2007). Extensive population genetic structure in the giraffe. BMC biology, 5(1), 57.

Brown, R. A., \& Armelagos, G. J. (2001). Apportionment of racial diversity: a review.

Evolutionary Anthropology, 10(1), 34-40.

Brues, A. M. (1990). The once and future diagnosis of race. Skeletal Attribution of Race Methods for Forensic Anthropology Maxwell Museum of Anthropology: University of New Mexico, 1-9.

Buffon. Natural History: General and Particular. (W. Smellie, Trans.). T. Cadell and W. Davies, 1781. Moran's online copy accessed at: faculty.njcu.edu/fmoran/buffonhome.htm. Also here: http://www.oocities.org/mandyandsnoopyoochies1438/buffon/1varieties.htm Buffon, G. L. L. (1778). Les Époques de la nature: 1778. Paleo.

Burg, T. M., Trites, A. W., \& Smith, M. J. (1999). Mitochondrial and microsatellite DNA analyses of harbour seal population structure in the northeast Pacific Ocean. Canadian Journal of Zoology, 77(6), 930-943.

Cahan, S., \& Gamliel, E. (2011). First among others? Cohen's d vs. alternative standardized mean group difference measures. Practical Assessment, Research and Evaluation, 16(10), 1-6. Calafell, F., Shuster, A., Speed, W. C., Kidd, J. R., \& Kidd, K. K. (1998). Short tandem repeat polymorphism evolution in humans. European Journal of Human Genetics, 6(1), 38-49.

Campbell, M. C., \& Tishkoff, S. A. (2008). African genetic diversity: implications for human demographic history, modern human origins, and complex disease mapping. Annual review of genomics and human genetics, 9, 403.

Campbell, M. C., \& Tishkoff, S. A. (2010). The evolution of human genetic and phenotypic variation in Africa. Current biology, 20(4), R166-R173.

Camus, P. A., \& De Ciencias, F. (2002). Populations, metapopulations, and the open-closed dilemma: the conflict between operational and natural population concepts. Oikos, 97(3), 433438.

Carabaña, J. (2011). Why Do the Results of Immigrant Students Depend So Much on Their Country of Origin and so Little on Their Country of Destination?. In Pisa Under Examination (pp. 207-221). Sense Publishers. 
Caspari, R. (2009). 1918: Three perspectives on race and human variation. American journal of physical anthropology, 139(1), 5-15.

Cavalli-Sforza, L. L., and Bodmer, W. (1976). The Genetics of Human Populations. San

Francisco: Freeman.

Cavalli-Sforza, L. L., Menozzi, P., \& Piazza, A. (1994). The history and geography of human genes. Princeton university press.

Chandler, D., \& Munday, R. (2011). A dictionary of media and communication. Oxford

University Press.

Charlton, B. (2012, April 20). The ruling Leftist intellectual elite: well-meaning fools, corrupt

careerists, clever sillies or evil madmen? Retrieved from:

http://charltonteaching.blogspot.com/2012/04/ruling-leftist-intellectual-elite-well.html.

Chater, A. O., Brummitt, R. K., \& Ehrhart, F. (1966). Subspecies in the works of Friedrich

Ehrhart. Taxon, 95-106.

Chollett, D. L. (2011). Reflections on reflections: dialectical commentaries on gender and class in NTAE production. Dialectical anthropology, 35(2), 187-194.

Cheng, C. Y., Reich, D., Haiman, C. A., Tandon, A., Patterson, N., Elizabeth, S., ... \& Kao, W. L. (2012). African ancestry and its correlation to type 2 diabetes in African Americans: a genetic admixture analysis in three US population cohorts. PloS one, 7(3), e32840.

Chiao, J. Y. (2009). Cultural neuroscience: a once and future discipline. Progress in brain research, 178, 287-304.

Chiao, J. Y., \& Ambady, N. (2010). Cultural neuroscience. Handbook of cultural psychology.

Christainsen, G. B. (2013). IQ and the wealth of nations: How much reverse causality?.

Intelligence, 41(5), 688-698.

Clausen, J., Keck, D. D., \& Hiesey, W. M. (1939). The concept of species based on experiment. American Journal of Botany, 26(2), 103-106.

Cochran, G., \& Harpending, H. (2009). The 10,000 year explosion: How civilization accelerated human evolution. Basic Books.

Cofnas, N. (2015). Science Is Not Always "Self-Correcting”. Foundations of Science, 1-16.

Cohen, J. (1988). Statistical power analysis for the behavioral sciences (2nd ed.). Hillsdale, NJ:

Lawrence Erlbaum.

Cole, K., Felsenstein, J., and Lewontin, R. (1986). Population differences in quantitative characters as opposed to gene frequencies. The American Naturalist, 127(5), 729-734.

Conley, D., Fletcher, J., \& Dawes, C. (2014). The Emergence of Socio-Genomics. Contemporary Sociology: A Journal of Reviews, 43(4), 458-467.

Coon, C. S. (1962). The origin of races. Oxford, England: Knopf.

Cracraft, J. (1997). Species concepts in systematics and conservation biology-an ornithological viewpoint. Systematics Association Special Volume, 54, 325-340.

Cronin, M. A., MacNeil, M. D., \& Patton, J. C. (2005). Variation in mitochondrial DNA and microsatellite DNA in caribou (Rangifer tarandus) in North America. Journal of Mammalogy,86(3), 495-505.

Cronin, M. A., MacNeil, M. D., Vu, N., Leesburg, V., Blackburn, H. D., \& Derr, J. N. (2013).

Genetic Variation and Differentiation of Bison (Bison bison) Subspecies and Cattle (Bos taurus)

Breeds and Subspecies. Journal of Heredity, 104(4), 500-509.

Cronin, M. A., \& Mech, L. D. (2009). Problems with the claim of ecotype and taxon status of the wolf in the Great Lakes region. Molecular Ecology, 18(24), 4991-4993. 
Coop, Graham; Eisen, Michael; Nielsen, Rasmus; Przeworski, Molly; Rosenberg, Noah (8 August 2014). "Letter to the Editor of the New York Times Book Review (Letter from Population Geneticists)". Retrieved 25 September 2014 Coyne, J. (2012, February 28). Are there human races? Retrieved from: http://whyevolutionistrue.wordpress.com/2012/02/28/are-there-human-races/. Coyne, J. (2014a, May 14). New book on race by Nicholas Wade: Professor Ceiling Cat says paws down. Retrieved from: https://whyevolutionistrue.wordpress.com/2014/05/14/new-bookon-race-by-nicholas-wade-professor-ceiling-cat-says-paws-down/.

Coyne, J. (2014b, May 17). Allen Orr slams Nicholas Wade's new book? Retrieved from: https://whyevolutionistrue.wordpress.com/2014/05/17/allen-orr-slams-nicholas-wades-newbook/.

Coyne, J. A., \& Orr, H. A. (2009). Speciation: A catalogue and critique of species concepts. Philosophy of biology: An anthology, 272-292.

Crow, J. F. (2002). Unequal by nature: A geneticist's perspective on human differences.

Daedalus, 131(1), 81-88.

Culver, M., Johnson, W. E., Pecon-Slattery, J., \& O'brien, S. J. (2000). Genomic ancestry of the American puma (Puma concolor). Journal of Heredity,91(3), 186-197.

Dalliard, M. (2014). The Elusive X-Factor: A Critique of J. M. Kaplan's Model of Race and IQ. Open Differential Psychology.

Dalton, B. W. (2011). US Educational Achievement on International Assessments: The Role of Race and Ethnicity.

Dama, M. S. (2013). Cognitive ability correlates positively with son birth and predicts crosscultural variation of the offspring sex ratio. Naturwissenschaften, 1-11.

Dangerous work. Behavioural geneticists must tread carefully to prevent their research being misinterpreted [Editorial]. (2013, October, 02), Nature. pp. 5-6. Retrieved from:

https://www.madinamerica.com/2013/10/dangerous-work-behavioural-geneticists-must-treadcarefully-prevent-research-misinterpreted/.

Darwin, C. (1859). On the Origin of Species by Means of Natural Selection, or Preservation of Favoured Races in the Struggle for Life: Murray.

Darwin, C. (1862). On the various contrivances by which British and foreign orchids are fertilized. Murray, London, 365.

Darwin, C. (1903). More letters of Charles Darwin: a record of his work in a series of hitherto unpublished letters (Vol. 2). D. Appleton.

Davies, G., Tenesa, A., Payton, A., Yang, J., Harris, S. E., Liewald, D., ... \& Deary, I. J. (2011). Genome-wide association studies establish that human intelligence is highly heritable and polygenic. Molecular psychiatry, 16(10), 996-1005.

Davis, B. D. (1978). The moralistic fallacy. Nature, 272(5652), 390.

Davis, J. I., \& Nixon, K. C. (1992). Populations, genetic variation, and the delimitation of phylogenetic species. Systematic Biology, 41(4), 421-435.

De Philippis, M. (2013). Parents' Country of Origin and Intergenerational Mobility of School

Performance.

De Queiroz, K. (1999). The general lineage concept of species and the defining properties of the species category. Species: new interdisciplinary essays, 49-89.

de Queiroz, K. (2003, June). A unified concept of species and its consequences for the future of taxonomy. In Proceeding of the Symposia: Biodiversity, Past, Present and Future \& The Future 
of Taxonomy, held in the occasion of the 150TH anniversary of the California Academy of Sciences. San Francisco: California Academy of Sciences (pp. 196-215).

De Queiroz, K. (2007). Species concepts and species delimitation. Systematic biology, 56(6), 879-886.

De Queiroz, K. (2011). Branches in the lines of descent: Charles Darwin and the evolution of the species concept. Biological Journal of the Linnean Society,103(1), 19-35.

Devitt, M. (2008). Resurrecting Biological Essentialism*. Philosophy of Science, 75(3), 344382.

Diamond, J. (1994). Race without color. Discover, 15(11), 83-89.

Diamond, J. (1997). Guns, germs, and steel: the fates of human societies. NY: WW Norton \& Company, 14.

Dickens, W. T., \& Flynn, J. R. (2001). Heritability estimates versus large environmental effects: the IQ paradox resolved. Psychological review, 108(2), 346.

Dobzhansky, T. (1944). Chromosomal races in Drosophila pseudoobscura and Drosophila persimilis. Carnegie Inst. Washington Publ, 554, 47-144.

Dobzhansky, T. (1946). The genetic nature of differences among men. Yale University Press. Dobzhansky, T. (1970). Genetics of the evolutionary process (Vol. 139). New York: Columbia University Press.

Doron, C. O. (2011). Races et dégénérescence. L'émergence des savoirs sur l'homme anormal (Doctoral dissertation, Université Paris-Diderot-Paris VII).

Doron, C. O. (2012). Race and Genealogy: Buffon and the Formation of the Concept of 'Race'. Duchesne, A. N. (1766). Histoire naturelle des fraisiers. Didot le jeune.

E. Casetta \& V. Tripodi, Making Sense of Gender, Sex, Race, and the Family, Humana. Mente Journal of Philosophical Studies, 22, 75-109.

Duedahl, P. (2008, November). UNESCO Man: Changing the Concept of Race, 1950-70. Paper presented at Inclusion, Collaboration \& Engagement: American Anthropological Association, San Francisco, California.

Ecotype. (n.d.). In The American Heritage Science Dictionary. Retrieved March 23, 2015, from: http://dictionary.reference.com/cite.html?qh=ecotype\&ia=ahsd.

Edelaar, P. I. M., \& Björklund, M. (2011). If FST does not measure neutral genetic differentiation, then comparing it with QST is misleading. Or is it?.Molecular Ecology, 20(9), 1805-1812.esper

Eibl-Eibesfeldt, I. (1973). Love and hate: On the natural history of basic behaviour patterns. Aldine Transaction.

Eizirik, E., Kim, J. H., Menotti-Raymond, M., Crawshaw, J. R., Peter, G., O’Brien, S. J., \& Johnson, W. E. (2001). Phylogeography, population history and conservation genetics of jaguars (Panthera onca, Mammalia, Felidae).Molecular Ecology, 10(1), 65-79.

Elhaik, E. (2012). Empirical distributions of FST from large-scale human polymorphism data. PloS one, 7(11), e49837

Ereshefsky, M. (1998). Species pluralism and anti-realism. Philosophy of Science, 103-120. Ereshefsky, M. (2008) Systematics and taxonomy. In: Sarkar S., Plutynski A. (eds.) The Blackwell companion to the philosophy of biology. Blackwell, Oxford, pp 99-118.

Esper, E. J. C. (1782). De Varietatibus specierum in naturae productis, disquisitio philosophica. (Doctoral dissertation).

Feldman, M. (2014). Echoes of the Past: Hereditarianism and A Troublesome Inheritance. PLoS genetics, 10(12), e1004817. 
Fish, J. M. (Ed.). (2013). Race and intelligence: Separating science from myth. Routledge. Flynn, J. R. (2012). Are we getting smarter. Rising IQ in the Twenty-First Century, Cambridge. Forster, G. (1786). Something More about the Human Races. (J. Mikkelsen, Trans.). SUNY Press, 2013.

Fedderke, J. W., Klitgaard, R. E., MacMurray, J. P., \& Napolioni, V. (2014).Diagnosing Deep Roots of Development: Genetic, Disease and Environmental Factors (No. 465).

Frost, P. (2011). Human nature or human natures?. Futures, 43(8), 740-748.

Frost, P. (2015, January 3). Sometimes the consensus is phony. (Blog post). Retrieved from: http://evoandproud.blogspot.com/2015/01/sometimes-consensus-is-phony.html.

Fuchs, H. (1958). Historical remarks on the concept of subspecies In: Taxon, 7: 2. Fuentes (2000). The concept of race: To be or not to be.

Fuerst, J. (2014). Ethnic/Race Differences in Aptitude by Generation in the United States: An Exploratory Meta-analysis. Open Differential Psychology.

Fuerst, J., and Dalliard, M. (2014). Genetic and Environmental Determinants of IQ in Black, White and Hispanic Americans: A Meta-analysis and New Analysis. Open Behavioral Genetics. Fuerst, J., and Kirkegaard, E. O. W. (2015, May). Admixture in the Americas. Paper presented at the London Conference on Intelligence, London, UK. Accessible at:

https://docs.google.com/presentation/d/1hjhOiitk0MnqMHgVthyj8j7qa4qcAqPUDNaTT8rpetg/e dit?pli=1\#slide=id.p

Funk, W. C., Forsman, E. D., Mullins, T. D., \& Haig, S. M. (2008). Introgression and dispersal among spotted owl (Strix occidentalis) subspecies. Evolutionary Applications, 1(1), 161-171. Stephen T. Garnett and Les Christidis (2007). Implications of changing species definitions for conservation purposes. Bird Conservation International, 17, pp 187-195.

Gao, X., \& Martin, E. R. (2009). Using allele sharing distance for detecting human population stratification. Human heredity, 68(3), 182-191.

Garcia, J. R., MacKillop, J., Aller, E. L., Merriwether, A. M., Wilson, D. S., \& Lum, J. K. (2010). Associations between dopamine D4 receptor gene variation with both infidelity and sexual promiscuity. PLoS One, 5(11), e14162.

Garn, S. M. (1971). Human races. Thomas.

Garn, S. M., \& Coon, C. S. (1955). On the Number of Races of Mankind. American

Anthropologist, 57(5), 996-1001.

Garner, A., Rachlow, J. L., \& Waits, L. P. (2005). Genetic diversity and population divergence in fragmented habitats: conservation of Idaho ground squirrels. Conservation Genetics, 6(5), 759774.

Gat, A. (2012). Nations: the long history and deep roots of political ethnicity and nationalism.

Cambridge University Press.

Gedahlia, B. (2007). Racism, Guilt and Self-Deceit, (Self-Published).

Gelade, G. A. (2008). The geography of IQ. Intelligence, 36(6), 495-501.

Gelber, J. L. (2010). Causes and Kinds in Aristotle's Embryology.

Ghiselin, M. T. (2004). Mayr and Bock versus Darwin on genealogical classification. Journal of Zoological Systematics and Evolutionary Research, 42(2), 165-169.

Gill, G. W. (1998). Craniofacial criteria in the skeletal attribution of race. Advances in the identification of human remains, 2nd edn. Charles C. Thomas, Springfield, 293-317.

Gilmour, J.S.L. and Gregor, J.W.: 1939, 'Demes: A Suggested New Terminology', Nature 144, 333. 
Gilmour and Heslop-Harrison (1954). The Deme Terminology and the Units of Microevolutionary Change', Genetica 27, 147-16

Girtanner, C. (1976). Concerning the Kantian Principle for Natural History. (J. Mikkelsen, Trans.). SUNY Press, 2013.

Gottfredson, L. S. (2007). 17 Innovation, fatal accidents, and the evolution of general intelligence. Integrating the mind: Domain general versus domain specific processes in higher cognition, 387.

Gould, S. J. (1984). Human equality is a contingent fact of history. Natural History, 93(11), 2633.

Gordon, R. A. (1997). Everyday life as an intelligence test: Effects of intelligence and intelligence context. Intelligence, 24(1), 203-320.

Gower, B. A., Fernández, J. R., Beasley, T. M., Shriver, M. D., \& Goran, M. I. (2003). Using genetic admixture to explain racial differences in insulin-related phenotypes. Diabetes, 52(4), 1047-1051.

Grall, L. (2012). Ice Age Climate, Somatic Capital, and the Timing of the Neolithic Transition. Gregor, J. W. (1944). The ecotype. Biological Reviews, 19(1), 20-30.

Gregor, J. W., \& Lang, J. M. S. (1936). Experimental Taxonomy I. Experimental Garden Technique in Relation to the Recognition of the Small Taxonomic Units. New Phytologist, 35(4), 323-350.

Groves, C. (2004). The what, why and how of primate taxonomy. International Journal of Primatology, 25(5), 1105-1126.

Groves, C., \& Grubb, P. (2011). Ungulate taxonomy. JHU Press.

Groves, C. (2012). Species concept in primates. American journal of primatology, 74(8), 687.

Groves, C. P. (2013). The nature of species: A rejoinder to Zachos et al.Mammalian BiologyZeitschrift für Säugetierkunde, 78(1), 7-9.

Guo, J., Tan, J., Yang, Y., Zhou, H., Hu, S., Hashan, A., ... \& Tang, K. (2014). Variation and signatures of selection on the human face. Journal of human evolution, 75, 143-152.

Hacking, I. (2005). Why race still matters. Daedalus, 134(1), 102-116.

Hacking, I. (2007). Natural kinds: Rosy dawn, scholastic twilight. Royal Institute of Philosophy Supplement, 61, 203-239.

Haffer, J. (2003). Christian Ludwig Brehm (1787-1864) über Spezies und Subspezies von Vögeln. Journal für Ornithologie, 144(2), 129-147.

Haffer, J. (2007). Biological Species and Speciation - Mayr's First Synthesis. Ornithology, Evolution, and Philosophy: The Life and Science of Ernst Mayr 1904-2005, 183-241.)

Haidt, J. (2012). The righteous mind: Why good people are divided by politics and religion. Vintage.

Haig, S. M., Beever, E. A., Chambers, S. M., Draheim, H. M., Dugger, B. D., Dunham, S., ... \& Sheffield, L. M. (2006). Taxonomic considerations in listing subspecies under the US Endangered Species Act. Conservation Biology,20(6), 1584-1594.

Hamill, R. M., Doyle, D., \& Duke, E. J. (2006). Spatial patterns of genetic diversity across European subspecies of the mountain hare, Lepus timidus L.Heredity, 97(5), 355-365.

Hanihara, T. (2008). Morphological variation of major human populations based on nonmetric dental traits. American journal of physical anthropology, 136(2), 169-182.

Hardimon, M. O. (2012). The Idea of a Scientific Concept of Race. Journal of Philosophical Research, 37, 249-282. 
Hardimon, M. O. (2013). Race concepts in medicine. Journal of Medicine and Philosophy, 38(1), 6-31.

Hart, M. H. (2007). Understanding human history: An analysis including the effects of geography and differential evolution. Washington Summit Publishers.

Hartl, D. L., \& Clark, A. G. (1997). Principles of population genetics (Vol. 116). Sunderland:

Sinauer associates.

Harvey, J. (2011). Race and Equality: The Nature of the Debate. Ulster Institute.

Haslanger, S. (2008). A social constructionist analysis of race. Revisiting race in a genomic age, 56-69.

Heller, R., \& Siegismund, H. R. (2009). Relationship between three measures of genetic differentiation GST, DEST and G'ST: how wrong have we been?. Molecular Ecology, 18(10), 2080-2083.

Hennig, W. (1966). Phylogenetic systematics. Translated by D. Dwight Davis and Rainer Zangerl. Urbana, University of Illinois Press.

Henry, D. (2006). Aristotle on the Mechanisms of Inheritance. Journal of the History of Biology, 425-455.

Henry, D. (2009). Generation of animals. A Companion to Aristotle. Oxford, 368-383.

Henry, D. (2011). Aristotle's Pluralistic Realism. The Monist, 94(2), 198-222.

Herráez, D. L., Bauchet, M., Tang, K., Theunert, C., Pugach, I., Li, J., ... \& Stoneking, M.

(2009). Genetic variation and recent positive selection in worldwide human populations:

evidence from nearly 1 million SNPs. PloS one, 4(11), e7888.

Hochman, A. (2013). Racial discrimination: How not to do it. Studies in History and Philosophy of Science Part C: Studies in History and Philosophy of Biological and Biomedical Sciences. Hodge, J. (2013, July 16). Invitation to a Dialogue: The Myth of 'Race'. New York Times. Hooton, E. A. (1926). Methods of racial analysis. Science, 63(1621), 75-81.

Hörandl, E. (2007). Neglecting evolution is bad taxonomy. Taxon, 1-5.

Hörandl, E., \& Stuessy, T. F. (2010). Paraphyletic groups as natural units of biological classification. Taxon, 1641-1653.

Horsman, R. (1981). Race and manifest destiny. Harvard University Press.

HoSang, D. M. (2014). On Racial Speculation and Racial Science A Response to Shiao et al. Sociological Theory, 32(3), 228-243.

Hubbe, M., Hanihara, T., \& Harvati, K. (2009). Climate signatures in the morphological differentiation of worldwide modern human populations. The Anatomical Record, 292(11), 1720-1733.

Hubbs, C. L. (1943). Criteria for subspecies, species and genera, as determined by researches on fishes. Annals of the New York Academy of Sciences, 44(2), 109-121.

Hudson, N. (1996). From "nation" to "race": The origin of racial classification in eighteenthcentury thought. Eighteenth-Century Studies, 29(3), 247-264.

Hull, D. L. (1965). The effect of essentialism on taxonomy-two thousand years of stasis (I). The British Journal for the Philosophy of Science, 15(60), 314-326.

Hull, D. L. (2010). Science as a process: an evolutionary account of the social and conceptual development of science. University of Chicago Press.

Hulse, F. S. (1962). Race as an evolutionary episode. American Anthropologist, 64(5), 929-945. Huxley, J. S. (1939). Clines: an auxiliary method in taxonomy. Bijdr. Dierk, 27, 491-520.

Huxley, T. H. (1870). On the geographical distribution of the chief modifications of mankind. Journal of the Ethnological Society of London (1869-1870), 404-412. 
Irish, J. D. (1998). Ancestral dental traits in recent Sub-Saharan Africans and the origins of modern humans. Journal of Human Evolution, 34(1), 81-98.

Isaac, B. (2006). Proto-racism in Graeco-Roman antiquity. World archaeology, 38(1), 32-47. Jakobsson, M., Edge, M. D., \& Rosenberg, N. A. (2013). The relationship between FST and the frequency of the most frequent allele. Genetics, 193(2), 515-528.

James, Michael, "Race", The Stanford Encyclopedia of Philosophy (Winter 2012 Edition), Edward N. Zalta (ed.), Retrieved from :

http://plato.stanford.edu/archives/win2012/entries/race/\&gt;.

Jefferson, T. (1781). Notes on the State of Virginia.

Jensen, A. R. (1998). The g factor: The science of mental ability. Westport, CT: Praeger.

Johnson, K. (2012). Ordering life: Karl Jordan and the naturalist tradition. JHU Press.

Jorde, L. B., Bamshad, M., \& Rogers, A. R. (1998). Using mitochondrial and nuclear DNA

markers to reconstruct human evolution. Bioessays, 20(2), 126-136.

Jorde, L. B., Rogers, A. R., Bamshad, M., Watkins, W. S., Krakowiak, P., Sung, S., ...

\&Harpending, H. C. (1997). Microsatellite diversity and the demographic history of modern humans. Proceedings of the National Academy of Sciences, 94(7), 3100-3103.

Jorde, L. B., Watkins, W. S., Bamshad, M. J., Dixon, M. E., Ricker, C. E., Seielstad, M. T., \& Batzer, M. A. (2000). The distribution of human genetic diversity: a comparison of mitochondrial, autosomal, and Y-chromosome data. The American Journal of Human Genetics, 66(3), 979-988.

Jorde, L. B., \& Wooding, S. P. (2004). Genetic variation, classification and 'race'. Nature genetics, 36, S28-S33.

Jost, L. O. U. (2008). GST and its relatives do not measure differentiation. Molecular Ecology, 17(18), 4015-4026.

Juif, D. T., \& Baten, J. (2013). On the human capital of Inca Indios before and after the Spanish Conquest. Was there a "Pre-Colonial Legacy"?. Explorations in Economic History, 50(2), 227241.

Kalb, J. (2013). Against Inclusiveness: How the Diversity Regime is Flattening America and the West and What to Do About It. Open Road Media. Angelico Press.

Kanazawa, S. (2008, February 14). If the truth offends, it's our job to offend. Psychology Today. Retrieved from: https://www.psychologytoday.com/blog/the-scientific-fundamentalist/200802/ifthe-truth-offends-it-s-our-job-offend.

Kant, I. (1777). On the different Human Races. (J. Mikkelsen, Trans.). SUNY Press, 2013

Kant, I. (1785). Determination of the Concept of a Human Race. (J. Mikkelsen, Trans.). SUNY Press, 2013.

Kant, I. (1788). On the use of teleological principles in philosophy. (J. Mikkelsen, Trans.). SUNY Press, 2013.

Kanthaswamy, S., Kurushima, J. D., \& Smith, D. G. (2006). Inferring Pongo conservation units: a perspective based on microsatellite and mitochondrial DNA analyses. Primates, 47(4), 310321.

Kaplan, J. (n.d.). (How Much) Do the Semantics of "Race" Matter? A Note From a Parochial Perspective.

Kaplan, J. M. (2011). 'Race': What Biology Can Tell Us about a Social Construct.

Kaplan, J. M. Race, IQ, and the search for statistical signals associated with so-called "X"factors: environments, racism, and the "hereditarian hypothesis". Biology \& Philosophy, 1-17. 
Kaplan, J.M. (2014, June 5). This is why the hereditarian claim ... is so dangerous. Because it *would* I think have at least some real implications. One of these would be that statistically significant differences in outcomes pursuing certain life goals could no longer be taken as prima facie evidence for differences in socially important inputs; where these inputs are a matter of justice, being able to ignore them matters to the real harms people suffer. (Blog comment). Retrieved from: https://scientiasalon.wordpress.com/2014/05/29/on-the-biology-ofrace/comment-page-2/\#comment-3166.

Kashima, E. S., Kent, S., \& Kashima, Y. (2015). Life satisfaction in the new country: a multilevel longitudinal analysis of effects of culture and 5-HTT allele frequency distribution in country of origin. Social cognitive and affective neuroscience, 10(1), 50-54.

Kaszycka, K. A., Štrkalj, G., \& Strzałko, J. (2009). Current views of European anthropologists on race: Influence of educational and ideological background. American Anthropologist, 111(1), 43-56.

Kaszycka, K. A., \& Strzałko, J. (2003). Race: Tradition and convenience, or taxonomic reality? More on the race concept in Polish anthropology.

Keita, S. O. (1993). The subspecies concept in zoology and anthropology: A brief historical review and test of a classification scheme. Journal of Black Studies, 416-445.

Keita, S. O., \& Kittles, R. A. (1997). The persistence of racial thinking and the myth of racial divergence. American Anthropologist, 99(3), 534-544.

Keita, S. O. Y., Kittles, R. A., Royal, C. D. M., Bonney, G. E., Furbert-Harris, P., Dunston, G. M., \& Rotimi, C. N. (2004). Conceptualizing human variation. Nature genetics, 36, S17-S20. Kelly, D., Machery, E., \& Mallon, R. (2010). Race and racial cognition.

Kind. 2015. In www.collinsdictionary.com. Retrieved January 20, 2014, from: http://www.collinsdictionary.com/dictionary/english/kind?showCookiePolicy=true. King, R. C., \& Stansfield, W. D. (1990). Encyclopedic dictionary of genetics. VCH Verlagsgesellschaft $\mathrm{mbH}$.

King, R. C., Mulligan, P., \& Stansfield, W. (2013). A dictionary of genetics. Oxford University Press.

Kirkegaard, E. O. W. (2015). Immigrant GPA in Danish primary school is predictable from country-level variables. Open Differential Psychology.

Kitayama, S., King, A., Yoon, C., Tompson, S., Huff, S., \& Liberzon, I. (2014). The dopamine D4 receptor gene (DRD4) moderates cultural difference in independent versus interdependent social orientation. Psychological science,25(6), 1169-1177.

Kitcher, P. (1999). "Race, Ethnicity, Biology, Culture.” In: Racism. Edited by Leonard Harris. pp. 87-117.

Kitcher, P. (2007). Does 'race' have a future?. Philosophy \& Public Affairs, 35(4), 293-317. Kodila-Tedika, O., \& Asongu, S. (2015). Genetic Distance and Cognitive Human Capital: A Cross-National Investigation (No. 15/012).

Kong, D. T. (2014). An economic-genetic theory of corporate corruption across cultures: An interactive effect of wealth and the 5HTTLPR-SS/SL frequency on corporate corruption mediated by cultural endorsement of self-protective leadership. Personality and Individual Differences, 63, 106-111.

Kopec, M. (2014). Clines, Clusters, and Clades in the Race Debate. Kurtén, B. (1968). Pleistocene mammals of Europe. Transaction Publishers. pg. 40.

Kurzban, R., Tooby, J., \& Cosmides, L. (2001). Can race be erased? Coalitional computation and social categorization. Proceedings of the National Academy of Sciences, 98(26), 15387-15392. 
Lahr, M. M. (1996). The evolution of modern human diversity: a study of cranial variation (Vol. 18). Cambridge University Press.

Laland, K. N., Odling-Smee, J., \& Myles, S. (2010). How culture shaped the human genome: bringing genetics and the human sciences together. Nature Reviews Genetics, 11(2), 137-148. Lamb, K. (1999). Individual \& group character in the social psychology of William McDougall. Mankind quarterly, 39(3), 255.

Lange, N. (2012). Perspective: imaging autism. Nature, 491(7422), S17-S17.

Lao, O., Vallone, P. M., Coble, M. D., Diegoli, T. M., Van Oven, M., Van Der Gaag, K. J., ... \& Kayser, M. (2010). Evaluating self- declared ancestry of US Americans with autosomal, Ychromosomal and mitochondrial DNA. Human mutation, 31(12), E1875-E1893.

LeClair, J., Janusonis, S., \& Kim, H. S. (2014). Gene-culture interactions: a multi-gene approach. Culture and Brain, 2(2), 122-140.

Lee, J. J. (2010). Review of intelligence and how to get it: Why schools and cultures count, RE Nisbett, Norton, New York, NY (2009). ISBN: 9780393065053.

Leigh, A., \& Gong, X. (2009). Estimating cognitive gaps between Indigenous and nonIndigenous Australians. Education economics, 17(2), 239-261.

Leinonen, T., McCairns, R. S., O'Hara, R. B., \& Merilä, J. (2013). QST-FST comparisons: evolutionary and ecological insights from genomic heterogeneity. Nature Reviews Genetics, 14(3), 179-190.

Lennox, J. G. (2001). Aristotle's philosophy of biology: studies in the origins of life science. Cambridge University Press. P 138.

Lennox, J. G. (2009). Form, Essence, and Explanation in Aristotle's Biology. A Companion to Aristotle, 348-367.

Lenoir, T. (1980). Kant, Blumenbach, and vital materialism in German biology. Isis, 77-108.

León, F. R., \& Burga-León, A. (2015). How geography influences complex cognitive ability. Intelligence, 50, 221-227.

Leroi, A. M. (2005). A family tree in every gene. Journal of genetics, 84(1), 3-6.

Levin, M. (2002a). The race concept: a defense. Behavior and philosophy, 21-42.

Levin, M. (2002b). "Race Unreal?". The Mankind Quarterly. pp. 413-418.

Levin, M. E. (1997). Why race matters: Race differences and what they mean. Praeger Publishers/Greenwood Publishing Group.

Lewens, T. (2012a). Pheneticism reconsidered. Biology \& Philosophy, 27(2), 159-177.

Lewens, T. (2012b). Species, essence and explanation. Studies in History and Philosophy of

Science Part C: Studies in History and Philosophy of Biological and Biomedical Sciences, 43(4), 751-757.

Lewis, G. J., \& Bates, T. C. (2010). Genetic evidence for multiple biological mechanisms underlying in-group favoritism. Psychological science, 21(11), 1623-1628.

Lewontin, R. C. (1972). The apportionment of human diversity. In: Dobzhansky T, Hecht MK, Steere WC, editors. Evolutionary Biology 6. New York: Appleton-Century-Crofts (pp 381-398).

Lewontin, R. C. (1978). Single-and multiple-locus measures of genetic distance between groups. American Naturalist, 1138-1139.

Li, J. Z., Absher, D. M., Tang, H., Southwick, A. M., Casto, A. M., Ramachandran, S., .. \& Myers, R. M. (2008). Worldwide human relationships inferred from genome-wide patterns of variation. Science, 319(5866), 1100-1104.

Liberalbiorealist. (2010, April 9). More on Biological Radicalism (Blog post). Retrieved from: https://liberalbiorealism.wordpress.com/2010/04/09/more-on-biological-radicalism/. 
Lieberman, L., Hampton, R. E., Littlefield, A., \& Hallead, G. (1992). Race in biology and anthropology: a study of college texts and professors. Journal of Research in Science Teaching, 29(3), 301-321.

Lieberman, L., Kirk, R. C., \& Corcoran, M. (2003). The decline of race in American physical anthropology. Anthropological Review, 66, 3-21.

Lieberman, L., Kirk, R. C., \& Littlefield, A. (2003a). Perishing Paradigm: Race - 1931-99.

American Anthropologist, 105(1), 110-113.

Lieberman, L., Kirk, R. C., \& Littlefield, A. (2003b). The race concept in five regions: Variations without consensus. Collegium Antropol 28: 907-921.

Lieberman, L. and Rice, p. 1996. "Races or Clines?" Module \#2. General Anthropology Division Modules in Teaching Anthropology, American Anthropological Association, Arlington, VA, 1996. Lindzey, G., \& Thiessen, D.D. (1970). Contributions to behavior-genetic analysis: The mouse as a prototype. Ardent Media.

Linnaeus, C. (1964). Systema naturae 1735: facsimile of the first edition with an introduction and a first English translation of the "Observationes.". Trans. And ed. MSJ Engel-Ledeboer and H. Engel (Nieuwkoop: B. de Graaf).

Linnaeus, C. (1737). Critica botanica. Lugduni Batavorum.

Long, J. C. (2009). Update to Long and Kittles's "Hman Genetic Diversity and the Nonexistence of Biological Races" (2003): Fixation on an Index. Human biology, 81(5), 799-803.

Long, J. C., Li, J., \& Healy, M. E. (2009). Human DNA sequences: more variation and less race. American journal of physical anthropology, 139(1), 23-34.

Lorenzen, E. D., Arctander, P., \& Siegismund, H. R. (2006). Regional genetic structuring and evolutionary history of the impala Aepyceros melampus.Journal of Heredity, 97(2), 119-132. Lorenzen, E. D., Arctander, P., \& Siegismund, H. R. (2008). High variation and very low differentiation in wide ranging plains zebra (Equus quagga): insights from mtDNA and microsatellites. Molecular ecology, 17(12), 2812-2824.

Lorenzen, E. D., De Neergaard, R., Arctander, P., \& Siegismund, H. R. (2007). Phylogeography, hybridization and Pleistocene refugia of the kob antelope (Kobus kob). Molecular Ecology, 16(15), 3241-3252.

Lorenzen, E. D., Heller, R., \& Siegismund, H. R. (2012). Comparative phylogeography of African savannah ungulates1. Molecular Ecology, 21(15), 3656-3670.

Lorenzen, E. D., Simonsen, B. T., Kat, P. W., Arctander, P., \& Siegismund, H. R. (2006).

Hybridization between subspecies of waterbuck (Kobus ellipsiprymnus) in zones of overlap with limited introgression. Molecular ecology, 15(12), 3787-3799.

Luo, S., \& Han, S. (2014). The association between an oxytocin receptor gene polymorphism and cultural orientations. Culture and Brain, 1-19.

Luo, S. J., Kim, J. H., Johnson, W. E., Walt, J. V. D., Martenson, J., \& Karanth, U. K. (2004).

Phylogeography and genetic ancestry of tigers (Panthera tigris). PLoS biology, 2(12), 2275-2293. Lyell, Charles (1830).Principles of Geology 1, London: John Murray.

Lyman, R. L., \& McKern, W. C. (2003). WC McKern and the midwestern taxonomic method. University of Alabama Press.

Lynn, R. (2008). Race, I. Q., \& Worldwide, I. The Global Bell Curve.

Lynn, R. (2012). IQs predict differences in the technological development of nations from 1000

BC through 2000 AD. Intelligence, 40(5), 439-444.

Lynn, R., \& Vanhanen, T. (2012). Intelligence: A unifying construct for the social sciences.

Ulster Institute for Social Research. 
Lynn, R., \& Vanhanen, T. (2012). National IQs: A review of their educational, cognitive, economic, political, demographic, sociological, epidemiological, geographic and climatic correlates. Intelligence, 40(2), 226-234.

Lyon, T. B., \& Graves, W. N. (2014). The Real Wolf: The Science, Politics, and Economics of Co-existing with Wolves in Modern Times. Ted Lyons Publications.

MacDonald, K. Review of On Genetic Interests: Family, Ethny, and Humanity in an Age of Mass Migration, by Frank Salter (Frankfurt Am Main, Germany: Peter Lang, 2003). Human Ethology Bulletin, 20(2), 7-10, June 2005.

Mackinnon, S. P., Jordan, C. H., \& Wilson, A. E. (2011). Birds of a feather sit together: Physical similarity predicts seating choice. Personality and Social Psychology Bulletin, 37(7), 879-892.

Magnuson, K. A., \& Waldfogel, J. (2005). Early childhood care and education: Effects on ethnic and racial gaps in school readiness. The future of children, 15(1), 169-196.

Malik, K. (2012, March 4). why both sides are wrong in the race debate. (Blog post). Retrieved from: https://kenanmalik.wordpress.com/2012/03/04/why-both-sides-are-wrong-in-the-racedebate/.

Mallet, J. (1995). A species definition for the modern synthesis. Trends in Ecology \& Evolution, 10(7), 294-299.

Mallet, J. (2001). Species, concepts of. Encyclopedia of biodiversity, 5, 427-440.

Mallet, J. (2008). Hybridization, ecological races and the nature of species: empirical evidence for the ease of speciation. Philosophical Transactions of the Royal Society B: Biological Sciences, 363(1506), 2971-2986.

Malloy, J. (2008). James Watson tells the inconvenient truth: Faces the consequences. Medical Hypotheses, 70(6), 1081-1091.

Malloy, J. (2013, March 29). Cryptic Admixture, Mixed-Race Siblings, \& Social Outcomes. (Blog post). Retrieved from: http://humanvarieties.org/2013/03/29/cryptic-admixture-mixedrace-siblings-social-outcomes/.

Marakeby, H., Badr, E., Torkey, H., Song, Y., Monteil, C. L., Heath, L. S., \& Vinatzer, B. A. (2014). A system to automatically classify and name any individual genome-sequenced organism independently of current biological classification and nomenclature. PloS one, 9(2), e89142.

Marioni, R. E., Batty, G. D., Hayward, C., Kerr, S. M., Campbell, A., Hocking, L. J., ... \& Deary, I. J. (2014a). Common Genetic Variants Explain the Majority of the Correlation Between Height and Intelligence: The Generation Scotland Study. Behavior genetics, 44(2), 91-96.

Marioni, R. E., Davies, G., Hayward, C., Liewald, D., Kerr, S. M., Campbell, A., ... \& Deary, I. J. (2014b). Molecular genetic contributions to socioeconomic status and intelligence. Intelligence, 44, 26-32.

Marks, J. (1994). Black, white, other. Natural History, 103(12), 32-35. Martinez-Bakker, M. E., Sell, S. K., Swanson, B. J., Kelly, B. P., \& Tallmon, D. A. (2013). Combined Genetic and Telemetry Data Reveal High Rates of Gene Flow, Migration, and LongDistance Dispersal Potential in Arctic Ringed Seals (Pusa hispida). PloS one, 8(10), e77125. Mathews, B. (1925). The Clash of Colour. A Study in the Problem of Race. London: Edinburgh House Press.

Mayden, R. L. (1997). A hierarchy of species concepts: the denouement in the saga of the species problem.

Mayr, E. (1942). Systematics and the Origin of Species: From the Viewpoint of a Zoologist (No. 13). Harvard University Press.

Mayr, E. (1947). Ecological factors in speciation. Evolution, 263-288. 
Mayr, E. (1963). Animal species and evolution. Animal species and their evolution.

Mayr, E. (1965a). Classification and phylogeny. American Zoologist, 5(1), 165-174.

Mayr, E. (1965b). Numerical phenetics and taxonomic theory. Systematic Zoology, 73-97.

Mayr, E. (1982). The growth of biological thought: diversity, evolution and inheritance. Harvard University Press.

Mayr, E. (2002). The biology of race and the concept of equality. Daedalus, 131(1), 89-94.

Mayr, E. (2004). What makes biology unique?: considerations on the autonomy of a scientific discipline. Cambridge University Press.

Mayr, E., \& Ashlock, P. D. (1969). Principles of systematic zoology. New York, McGraw-Hill.

Mayr, E., \& Ashlock, P. D. (1991). Principles of systematic zoology. New York, McGraw-Hill.

Mayr, E., \& Bock, W. J. (2002). Classifications and other ordering systems. Journal of

Zoological Systematics and Evolutionary Research, 40(4), 169-194.

McEvoy, B. P., Lind, J. M., Wang, E. T., Moyzis, R. K., Visscher, P. M., van Holst

McPherson, M., Smith-Lovin, L., \& Cook, J. M. (2001). Birds of a feather: Homophily in social networks. Annual review of sociology, 415-444.

Meisenberg, G., \& Woodley, M. A. (2013). Global behavioral variation: A test of differential-K. Personality and Individual Differences, 55(3), 273-278.

Melnick, D. J., \& Hoelzer, G. A. (1993). What is mtDNA good for in the study of primate evolution?. Evolutionary Anthropology: Issues, News, and Reviews, 2(1), 2-10.

Meirmans, P. G., \& Hedrick, P. W. (2011). Assessing population structure: FST and related measures. Molecular Ecology Resources, 11(1), 5-18.

Meier, R. (2000). The Hennigian Species Concept Rudolf Meier and Rainer Willmann. Species concepts and phylogenetic theory: A debate, 30.

Merrell, D. J. (1994). The adaptive seascape: the mechanism of evolution. U of Minnesota Press.

Merriwether, D. A., Clark, A. G., Ballinger, S. W., Schurr, T. G., Soodyall, H., Jenkins, T., \&

Wallace, D. C. (1991). The structure of human mitochondrial DNA variation. Journal of

Molecular Evolution, 33(6), 543-555.

Miele, F. (2002). Intelligence, race, and genetics: Conversations with Arthur R. Jensen. Westview Press.

Miller, G. F. (2010). 13 Are Pleiotropic Mutations and Holocene Selective Sweeps the Only Evolutionary-genetic Processes Left for Explaining Heritable Variation in Human Psychological Miller, J. M., Hallager, S., Monfort, S. L., Newby, J., Bishop, K., Tidmus, S. A., ... \& Fleischer, R. C. (2011). Phylogeographic analysis of nuclear and mtDNA supports subspecies designations in the ostrich (Struthio camelus). Conservation Genetics, 12(2), 423-431.

Traits?. The evolution of personality and individual differences, 376.

Minkov, M., Blagoev, V., \& Bond, M. H. (2014). Improving Research in the Emerging Field of Cross-Cultural Sociogenetics The Case of Serotonin. Journal of Cross-Cultural Psychology, 0022022114563612.

Minkov, M., \& Bond, M. H. (2015). Genetic polymorphisms predict national differences in life history strategy and time orientation. Personality and Individual Differences, 76, 204-215.

Mitton, J. B. (1977). Genetic differentiation of races of man as judged by single-locus and multilocus analyses. American Naturalist, 203-212.

Mitton, J. B. (1978). Measurement of differentiation: reply to Lewontin, Powell, and Taylor. American Naturalist, 1142-1144.

Mount, F. (2010). Subversive Family. Simon and Schuster. 
Mountain, J. L., \& Risch, N. (2004). Assessing genetic contributions to phenotypic differences among 'racial' and 'ethnic' groups. Nature Genetics, 36, S48-S53.

Molnar, S. (1998). Human variation: races, types, and ethnic groups. Upper Saddle River, NJ: Prentice Hall.

Montagu, M. F. Ashley (1942). Man's Most Dangerous Myth: The Fallacy of Race. New York. Moodley, Y., \& Harley, E. H. (2005). Population structuring in mountain zebras (Equus zebra): the molecular consequences of divergent demographic histories. Conservation Genetics, 6(6), 953-968.

Morning, A. (2011). The nature of race: How scientists think and teach about human difference. University of California Pr.

Morning, A. (2014). Does Genomics Challenge the Social Construction of Race?. Sociological Theory, 32(3), 189-207.

Morrison, D. (2012, May 30). Networks of genealogy. (Blog post). Retrieved from: http://phylonetworks.blogspot.com/2012/05/networks-of-genealogy.html

Mrazek, A. J., Chiao, J. Y., Blizinsky, K. D., Lun, J., \& Gelfand, M. J. (2013). The role of culture-gene coevolution in morality judgment: examining the interplay between tightnesslooseness and allelic variation of the serotonin transporter gene. Culture and brain, 1(2-4), 100117.

Müller-Wille, S. (2002). Cabbage, Tulips, Ethiopians-“Experiments” in Early Modern Heredity. Max Planck Institute for the History of Science, 7.

Müller-Wille, S. (2007). Figures of inheritance, 1650-1850. Heredity Produced. At the Crossroads of Biology, Politics, and Culture 1500-1870.

Müller-Wille, S., \&Orel, V. (2007). From Linnaean species to Mendelian factors: Elements of hybridism, 1751-1870. Annals of Science, 64(2), 171-215.

Müller-Wille, S. (2014). Race and History: Comments from an Epistemological Point of View. Science, Technology \& Human Values, 0162243913517759.

Muwanika, V. B., Nyakaana, S., Siegismund, H. R., \& Arctander, P. (2003). Phylogeography and population structure of the common warthog (Phacochoerus africanus) inferred from variation in mitochondrial DNA sequences and microsatellite loci. Heredity, 91(4), 361-372.

Nei, M., \& Roychoudhury, A. K. (1993). Evolutionary relationships of human populations on a global scale. Molecular biology and evolution, 10(5), 927-943.

Nelson, G., \& Platnick, N. I. (1981). Systematics and biogeography: cladistics and vicariance (Vol. 214). New York: Columbia University Press.

Nisbett, R. E., Aronson, J., Blair, C., Dickens, W., Flynn, J., Halpern, D. F., \& Turkheimer, E. (2012). Intelligence: new findings and theoretical developments. American Psychologist, 67(2), 130.

Nishiyama, T., Kishino, H., Suzuki, S., Ando, R., Niimura, H., Uemura, H., ... \& Tanaka, H. (2012). Detailed Analysis of Japanese Population Substructure with a Focus on the Southwest Islands of Japan. PloS one, 7(4), e35000.

Nixon, K. C., \& Wheeler, Q. D. (1990). An amplification of the phylogenetic species concept. Cladistics, 6(3), 211-223.

O’Brien, S. J., \& Mayr, E. (1991). Bureaucratic mischief: recognizing endangered species and subspecies. Science(Washington), 251(4998), 1187-1188.

Odrowaz-Sypniewska (2009, November). Natural Kinds - What are They?. In Worldviews,

Science and Us: Studies of Analytical Metaphysics-A Selection of Topics from A Methodological Perspective-Proceedings of the 5Th Metaphysics of Science Workshop (p. 64). World Scientific. 
Okasha, S. (2002). Darwinian metaphysics: Species and the question of essentialism. Synthese, 131(2), 191-213.

Oliveira, J. D. D., Igarashi, M. L. S. D. P., Machado, T. M. M., Miretti, M. M., Ferro, J. A., \& Contel, E. P. B. (2007). Structure and genetic relationships between Brazilian naturalized and exotic purebred goat domestic goat (Capra hircus) breeds based on microsatellites. Genetics and Molecular Biology, 30(2), 356-363.

Orey, B. D. A., \& Park, H. (2012). Nature, nurture, and ethnocentrism in the Minnesota Twin Study. Twin Research and Human Genetics, 15(01), 71-73.

Orr, A. (2014, June 05). Stretch Genes. New York Review of Books.

Osborne, H. (2015, January 28). E. O. Wilson: I'm not an atheist but religion should be eliminated. International Business Times.

Ossorio, P. N. (2009). Race, genes, and intelligence.

Outlaw, L. T. (1996). On race and philosophy. Psychology Press.

Parry, W. W. T., \& Hacker, E. A. (1991). Aristotelian logic. SUNY Press.

Pearson, R. (2002). The debate on race: A problem of semantics rather than of biology. Mankind quarterly, 42(4), 419-440.

Pemberton, T. J., DeGiorgio, M., \& Rosenberg, N. A. (2013). Population structure in a comprehensive genomic data set on human microsatellite variation. G3: Genes| Genomes| Genetics, 3(5), 891-907.

Penke, L. (2010). Bridging the Gap Between Modern Evolutionary Psychology and the Study of Individual Differences. The evolution of personality and individual differences, 243.

Pérez-Lezaun, A., Calafell, F., Seielstad, M., Mateu, E., Comas, D., Bosch, E., \& Bertranpetit, J. (1997). Population genetics of Y-chromosome short tandem repeats in humans. Journal of molecular evolution, 45(3), 265-270.

Pickrell, J. K., \& Reich, D. (2014). Toward a new history and geography of human genes informed by ancient DNA. Trends in Genetics, 30(9), 377-389.

Piffer, D. (2013). Factor Analysis of Population Allele Frequencies as a Simple, Novel Method of Detecting Signals of Recent Polygenic Selection: The Example of Educational Attainment and IQ. Mankind Quarterly, 54, 168-200.

Piffer, D. (2015a). Estimating the genotypic intelligence of populations and assessing the impact of socioeconomic factors and migrations. The Winnower. DOI: 10.15200/winn.142299.93508 Piffer, D (2015b): A review of intelligence GWAS hits: their relationship to country IQ and the issue of spatial autocorrelation. Figshare. http://dx.doi.org/10.6084/m9.figshare.1393160 Piffer, D. and Dall'Olio, G. M. (2015): Using Vcftools to calculate Weir and Cockerham's variance components for 1000 Genomes phase 3 data. Figshare.

http://dx.doi.org/10.6084/m9.figshare.1450792

Piffer, D., and Kirkegaard, E. (2015). Strong negative relationship between population-level general intelligence and ADHD genetic factors inferred from allele frequencies.

Pigliucci, M. (2013). What are we to make of the concept of race?: Thoughts of a philosopherscientist. Studies in History and Philosophy of Science Part C: Studies in History and Philosophy of Biological and Biomedical Sciences.

Pigliucci, M., \& Kaplan, J. (2003). On the concept of biological race and its applicability to humans. Philosophy of Science, 70(5), 1161-1172.

Pinker, S. (2006, June 26). Groups and Genes. Retrieved from: http://www.newrepublic.com/article/77727/groups-and-genes. 
Prayon, V., \& Baten, J. (2010). Human capital, institutions, settler mortality, and economic growth in Africa, Asia and the Americas. University of Tuebingen Working Paper.

Prichard, J. C. (1836). Researches into the physical history of mankind (Vol. 1). Sherwood, Gilbert, and Piper.

Proto, E., \& Oswald, A. J. (2014). National Happiness and Genetic Distance: A Cautious Exploration.

Prüfer, K., Racimo, F., Patterson, N., Jay, F., Sankararaman, S., Sawyer, S., ... \& Pääbo, S. (2014). The complete genome sequence of a Neanderthal from the Altai Mountains. Nature, 505(7481), 43-49.

Putterman, L., \& Weil, D. N. (2008). Post-1500 population flows and the long run determinants of economic growth and inequality (No. w14448). National Bureau of Economic Research.

de Queiroz, K. (2005). Different species problems and their resolution. BioEssays, 27(12), 12631269.

Quintyn, C. B. (2010). The Existence Or Non-existence of Race?: Forensic Anthropology, Population Admixture, and the Future of Racial Classification in the US. Teneo Press.

Ramey, R. R., Liu, H. P., Epps, C. W., Carpenter, L. M., \& Wehausen, J. D. (2005). Genetic relatedness of the Preble's meadow jumping mouse (Zapus hudsonius preblei) to nearby subspecies of $Z$. hudsonius as inferred from variation in cranial morphology, mitochondrial DNA and microsatellite DNA: implications for taxonomy and conservation. Animal conservation, 8(03), 329-346.

Ratcliff, M. J. (2007). Duchesne's Strawberries: Between Growers' Practices and Academic Knowledge. Heredity Produced: At the Crossroads of Biology, Politics, and Culture, 1500-1870, 205-228.

Relethford, J. H. (1994). Craniometric variation among modern human populations. American Journal of Physical Anthropology, 95(1), 53-62.

Relethford, J. H. (2009). Race and global patterns of phenotypic variation. American journal of physical anthropology, 139(1), 16-22.

Remsen Jr, J. V. (2010). Subspecies as a meaningful taxonomic rank in avian classification.

Ornithological Monographs, 67(1), 62-78.

Reskin, B. (2012). The Race Discrimination System. Annual Review of Sociology, 38, 17-35.

Ridley, M. (1989). The Cladistic Solution to the Species Problem. Biology \& Philosophy 4: 1-

16.

Rindermann (2014, January). The Psychology Approach to Macroeconomics. Talk presented at the American Economic Association, 2014 AEA Meeting.

Rindermann, H., Woodley, M. A., \& Stratford, J. (2012). Haplogroups as evolutionary markers of cognitive ability. Intelligence, 40(4), 362-375.

Risch, N., Burchard, E., Ziv, E., \& Tang, H. (2002). Categorization of humans in biomedical research: genes, race and disease. Genome Biol, 3(7), 1-12.

Rodriguez-Arana, A. (2010). Intelligence and the Wealth of Nations: Genetics Matter but there is Still Much Room to Reduce Inequalities preliminary. In DEGIT Conference.

Rosenberg, N. A. (2011). A population-genetic perspective on the similarities and differences among worldwide human populations. Human biology, 83(6), 659.

Rosenberg, N. A., Pritchard, J. K., Weber, J. L., Cann, H. M., Kidd, K. K., Zhivotovsky, L. A., \& Feldman, M. W. (2002). Genetic structure of human populations. Science, 298(5602), 23812385 . 
Rosenberg, N. A., Mahajan, S., Ramachandran, S., Zhao, C., Pritchard, J. K., \& Feldman, M. W. (2005). Clines, clusters, and the effect of study design on the inference of human population structure. PLoS genetics, 1(6), e70.

Roth, I. I., Gallagher, C. M., LaDage, L. D., \& Pravosudov, V. V. (2012). Variation in brain regions associated with fear and learning in contrasting climates. Brain, behavior and evolution, 79(3), 181-190.

Roth, T. C., Chevalier, D. M., LaDage, L. D., \& Pravosudov, V. V. (2013). Variation in hippocampal glial cell numbers in food-caching birds from different climates. Developmental neurobiology, 73(6), 480-485.

Roth, T. C., LaDage, L. D., \& Pravosudov, V. V. (2010). Learning capabilities enhanced in harsh environments: a common garden approach. Proc. Biol. Sci. 277, 3187-3193.

Rowe, D. C., Vesterdal, W. J., \& Rodgers, J. L. (1998). Herrnstein's syllogism: Genetic and shared environmental influences on IQ, education, and income. Intelligence, 26(4), 405-423. Rowland, M. (1992). Biology. Edinburgh: Thomas Nelson and Sons.

Ruiz-García, M., Corrales, C., \& Pinedo-Castro, M. (2012). Craniometric and microsatellite genetic differentiation among putative ocelot subspecies (Leopardus pardalis) throughout Latin America. Molecular Population Genetics, Phylogenetics, Evolutionary Biology and Conservation of the Neotropical Carnivores. Hauppauge, New York: Nova Science Publishers.

Ruiz-Linares, A., Adhikari, K., Acuña-Alonzo, V., Quinto-Sanchez, M., Jaramillo, C., Arias, W., ... \& Gonzalez-José, R. (2014). Admixture in Latin America: geographic structure, phenotypic diversity and self-perception of ancestry based on 7,342 individuals. PLoS genetics, 10(9), e1004572.

Rushton, J. P. (1989). Genetic similarity, human altruism, and group selection.Behavioral and Brain sciences, 12(03), 503-518.

Rushton, J. P. (1995). Race, evolution, and behavior: A life history perspective.

Rushton, J. P., \& Jensen, A. R. (2005). Thirty years of research on race differences in cognitive ability. Psychology, public policy, and law, 11(2), 235.

Ryder, O. A. (1986). Species conservation and systematics: the dilemma of subspecies. Trends in Ecology \& Evolution, 1(1), 9-10.

Sailer, S. (1998). Making Sense of the Concept of Race: A Race Is An Extremely Extended Family. Retrieved November 20, 2013, from http://www.isteve.com/makingsense.htm.

Salter, F. (2003). On genetic interests. Family, Ethny and Humanity in an Age of Mass Migration. Peter Lang, Frankfurt am Main ua.

Salter, F. (2008). Misunderstandings of kin selection with reference to the immortality of values and the delay in quantifying ethnic kinship. Mankind Quarterly, 48(3), 311.

Salter, F., \& Harpending, H. (2013). JP Rushton's theory of ethnic nepotism. Personality and Individual Differences, 55(3), 256-260.

Sapp, J. (2012). Race Finished. American Scientists. Retrieved from:

http://www.americanscientist.org/bookshelf/pub/race-finished.

Sarich, V., \& Miele, F. (2004). Race: The reality of human differences. pg. 162-163.

Schabas, W. (2000). Genocide in international law: the crimes of crimes. Cambridge University Press.

Seielstad, M. T., Minch, E., \& Cavalli-Sforza, L. L. (1998). Genetic evidence for a higher female migration rate in humans. Nature genetics, 20(3), 278-280.

Sesardic, N. (1993). Heritability and causality. Philosophy of Science, 396-418. 
Sesardic, N. (2010). Race: a social destruction of a biological concept. Biology \& Philosophy, 25(2), 143-162.

Sesardic, N., \& De Clercq, R. (2014). Women in Philosophy: Problems with the Discrimination Hypothesis. Academic Questions, 27(4), 461-473.

Sethuraman, A. (2013). On inferring and interpreting genetic population structure-applications to conservation, and the estimation of pairwise genetic relatedness (Doctoral dissertation, Iowa State University).

Shiao, J. L., Bode, T., Beyer, A., \& Selvig, D. (2012). The genomic challenge to the social construction of race. Sociological Theory, 30(2), 67-88.

Simpson, G. G. (1961). Principles of animal taxonomy (Vol. 20). Columbia University Press.

Silverstein, J. (2015, April 13). Genes Don't Cause Racial-Health Disparities, Society Does. The Atlantic.

Sloan, P. R. (1973). The idea of racial degeneracy in Buffon's Histoire Naturelle. Racism in the eighteenth century, 3, 245-263.

Sloan, P. R. (1979). Buffon, German biology, and the historical interpretation of biological species. The British journal for the history of science, 12(02), 109-153.

Smedley, A. (1998). "Race" and the Construction of Human Identity. American Anthropologist, 100(3), 690-702.

Smith, H. M., Chiszar, D., \& Montanucci, R. R. (1997). Subspecies and classification.

Herpetological Review, 28(1), 13-17.

Smith, J. (2013, February 10). The Enlightenment's 'Race' Problem, and Ours. New York Times. Snyderman, M., \& Rothman, S. (1987). Survey of expert opinion on intelligence and aptitude testing. American Psychologist, 42(2), 137.

Sober, E. (1980). Evolution, population thinking, and essentialism. Philosophy of Science, 350383.

Spencer, Q. (2011, October). How to Be a Biological Racial Realist. Talk presented at the Philosophy Colloquium Series, California State University.

Spencer, Q. (2012). What 'biological racial realism' should mean. Philosophical studies, 159(2), 181-204.

Spencer, Q. (2014). The unnatural racial naturalism. Studies in History and Philosophy of

Science Part C: Studies in History and Philosophy of Biological and Biomedical Sciences, 46, 38-43.

Stamos, D. N. (2003). The species problem: Biological species, ontology, and the metaphysics of biology. Lexington Books.

Stamos, D. N. (2005). Pre-Darwinian Taxonomy and Essentialism-A Reply to Mary Winsor. Biology and Philosophy, 20(1), 79-96.

Stamos, D. N. (2012). Darwin and the Nature of Species. SUNY Press.

Stanford, P. K. (1995). For pluralism and against realism about species. Philosophy of Science, 70-91.

Stoneking, M., Jorde, L. B., Bhatia, K., \& Wilson, A. C. (1990). Geographic variation in human mitochondrial DNA from Papua New Guinea. Genetics, 124(3), 717-733.

Strauss, A., \& Hubbe, M. (2010). Craniometric similarities within and between human populations in comparison with neutral genetic data. Human biology, 82(3), 315-330.

Strkalj, G. (2006). Artificial classification and the study of human variation. Rivista di biologia, 99(1), 14. 
Štrkalj, G. (2007). The status of the race concept in contemporary biological anthropology: A review. Anthropologist, 9(1), 73-78.

Strkalj, G., Ramsey, S., \& Wilkinson, A. T. (2008). Anatomists' attitudes towards the concept of race. South African Medical Journal, 94(2), 90.

Stuessy, T.F. (2009a). Paradigms in biological classification (1707-2007): Has anything really changed? Taxon 58: 68-76.

Stuessy, T. F. (2009b). Plant taxonomy: the systematic evaluation of comparative data. Columbia University Press.

Sussman, R. W. (2014). The Myth of Race: The Troubling Persistence of an Unscientific Idea. Harvard University Press.

Swain, C. M. (2002). The new white nationalism in America: Its challenge to integration. Cambridge University Press.

Tal, O. (2009). From heritability to probability. Biology \& Philosophy, 24(1), 81-105.

Tal, O. (2012). Two complementary perspectives on inter-individual genetic distance.

Biosystems.

Tang, H., Quertermous, T., Rodriguez, B., Kardia, S. L., Zhu, X., Brown, A., ... \& Risch, N. J. (2005). Genetic structure, self-identified race/ethnicity, and confounding in case-control association studies. The American Journal of Human Genetics, 76(2), 268-275.

Taylor, J. (2011). White Identity: Racial Consciousness in the 21st Century. New Century Books. Templer, D. I. (2008). Correlational and factor analytic support for Rushton's differential $K$ life history theory. Personality and Individual Differences, 45(6), 440-444.

Templer, D. I., \& Arikawa, H. (2006). Temperature, skin color, per capita income, and IQ: An international perspective. Intelligence, 34(2), 121-139.

Templer, D. I., \& Stephens, J. S. (2014). The relationship between IQ and climatic variables in African and Eurasian countries. Intelligence, 46, 169-178.

Templeton, A. R. (1998). Human races: a genetic and evolutionary perspective. American Anthropologist, 100(3), 632-650.

Templeton, A. R. (2013). Biological races in humans. Studies in History and Philosophy of Science Part C: Studies in History and Philosophy of Biological and Biomedical Sciences. Tetlock, P. E. (2003). Thinking the unthinkable: Sacred values and taboo cognitions. Trends in cognitive sciences, 7(7), 320-324.

Tetlock, P. E., Kristel, O. V., Elson, S. B., Green, M. C., \& Lerner, J. S. (2000). The psychology of the unthinkable: taboo trade-offs, forbidden base rates, and heretical counterfactuals. Journal of personality and social psychology, 78(5), 853.

Tian, C., Kosoy, R., Nassir, R., Lee, A., Villoslada, P., Klareskog, L., ... \& Seldin, M. F. (2009). European population genetic substructure: further definition of ancestry informative markers for distinguishing among diverse European ethnic groups. Molecular Medicine, 15(11-12), 371. Tooby, J., \& Cosmides, L. (1989). Kin selection, genic selection, and information-dependent strategies. Behavioral and Brain Sciences, 12(03), 542-544.

Trzaskowski, M., Harlaar, N., Arden, R., Krapohl, E., Rimfeld, K., McMillan, A., ... \& Plomin, R. (2014). Genetic influence on family socioeconomic status and children's intelligence. Intelligence, 42, 83-88.

Turchin, M. C., Chiang, C. W., Palmer, C. D., Sankararaman, S., Reich, D., \& Hirschhorn, J. N. (2012). Evidence of widespread selection on standing variation in Europe at height-associated SNPs. Nature genetics, 44(9), 1015-1019. 
Turkheimer, E. (2000). Three laws of behavior genetics and what they mean.Current Directions in Psychological Science, 9(5), 160-164.

Turtle Taxonomy Working Group. (2007). Turtle taxonomy: methodology, recommendations, and guidelines. In Defining Turtle Diversity: Proceedings of a Workshop on Genetics, Ethics, and Taxonomy of Freshwater Turtles and Tortoises. Chelonian Res. Monogr (Vol. 4, pp. 73-84). Uphyrkina, O., Johnson, W. E., Quigley, H., Miquelle, D., Marker, L., Bush, M., \& O'Brien, S. J. (2001). Phylogenetics, genome diversity and origin of modern leopard, Panthera pardus.

Molecular ecology, 10(11), 2617-2633.

Van den Berghe, P. L. (1987). The ethnic phenomenon. ABC-CLIO.

Vanhanen, T. (2009). The limits of democratization: Climate, intelligence, and resource distribution. Washington Summit Publishers.

Vanhanen, T. (2012). Ethnic Conflicts. Ulster Institute for Social Research.

Velasco, J. D. (2012). The future of systematics: tree thinking without the tree. Philosophy of Science, 79(5), 624-636.

Vogel, F. (1997). Human genetics: problems and approaches (Vol. 878). Springer. pg. 610. Vogel, F. \& Motulsky, A. G. (1986). Human Genetics: Problems and Approaches. Second edition. Springer-Verlag. pg. 807.

Wade, N. (2014b, May 29). In Defense of A Troublesome Inheritance. Huff Post. Retrieved from: http://www.huffingtonpost.com/nicholas-wade/in-defense-of-a-troublesome-

inheritance_b_5413333.html.

Wade, N. (2014a). A troublesome inheritance: Genes, race and human history. Penguin.

Walsh, D. (2006). Evolutionary essentialism. The British journal for the philosophy of science, 57(2), 425-448.

Wang, C. C., Jin, L., \& Li, H. (2013). Global patterns of sex-biased migrations in humans. arXiv preprint arXiv:1310.7883.

Wang, J. (2004). Application of the one-migrant-per-generation rule to conservation and management. Conservation Biology, 18(2), 332-343.

Wang, Q., Strkalj, G., \& Sun, L. (2003). On the concept of race in Chinese biological anthropology: alive and well. Current anthropology, 44(3), 403-403.

Waples, R. S., \& Gaggiotti, O. (2006). INVITED REVIEW: What is a population? An empirical evaluation of some genetic methods for identifying the number of gene pools and their degree of connectivity. Molecular ecology, 15(6), 1419-1439.

Way, B. M., \& Lieberman, M. D. (2010). Is there a genetic contribution to cultural differences? Collectivism, individualism and genetic markers of social sensitivity. Social cognitive and affective neuroscience, 5(2-3), 203-211.

Weber, C., Johnson, M., \& Arceneaux, K. (2011). Genetics, Personality, and Group Identity. Social Science Quarterly, 92(5).

Weir, B. S., \& Cockerham, C. C. (1984). Estimating F-statistics for the analysis of population structure. evolution, 1358-1370.

Weiss, K. M., \& Fullerton, S. M. (2005). Racing around, getting nowhere. Evolutionary Anthropology: Issues, News, and Reviews, 14(5), 165-169.

Weiss, V. (2007). The population cycle drives human history-from a eugenic phase into a dysgenic phase and eventual collapse.

Wells, J. V. Richmond, M. E, Milo, E. Populations, metapopulations, and species populations: what are they and who should care?. Wildlife Society Bulletin, 1995, p. 458-462. 
Wheeler, Q. D., and Platnick, N. I. (2000). A Critique from the Wheeler and Platnick Phylogenetic Species Concept Perspective: Problems with Alternative Concepts of Species. In: Wheeler, Q. D., and Platnick, N.I (ed.). The Biological Species concept. Species concepts and phylogenetic theory: a debate, 133.

Whitlock, M. C., \& McCauley, D. E. (1999). Indirect measures of gene flow and migration: $\mathrm{FST} \neq 1 /(4 \mathrm{Nm}+1)$. Heredity, 82(2), 117-125.

Wilder, J. A., Kingan, S. B., Mobasher, Z., Pilkington, M. M., \& Hammer, M. F. (2004). Global patterns of human mitochondrial DNA and Y-chromosome structure are not influenced by higher migration rates of females versus males. Nature genetics, 36(10), 1122-1125.

Wilkins, J. (2010). How many species concepts are there. The Guardian, London. Wilkins, J. (2011, 22, April). Is Brian Blessed a monkey or an ape? Retrieved from: http://evolvingthoughts.net/2011/04/is-brian-blessed-a-monkey-or-an-ape/.

Willems, T., Gymrek, M., Highnam, G., Mittelman, D., \& Erlich, Y. (2014). The landscape of human STR variation. Genome research, 24(11), 1894-1904.

Williams, C. L., Homan, H. J., Johnston, J. J., \& Linz, G. M. (2004). Microsatellite variation in Red-winged Blackbirds (Agelaius phoeniceus). Biochemical Genetics, 42(1-2), 35-41.

Wilson, E. O., \& Brown, W. L. (1953). The subspecies concept and its taxonomic application. Systematic Zoology, 2(3), 97-111.

Winsor, M. P. (2000). Species, Demes, and the Omega Taxonomy: Gilmour and The New Systematics. Biology and Philosophy, 15(3), 349-388.

Winther, R. G., \& Kaplan, J. M. (2013). Ontologies and Politics of Biogenomic 'Race'. Theoria, 60(136), 54-80.

Winther, R. G., Giordano, R., Edge, M. D., \& Nielsen, R. (2014). The Mind, the Lab, and the Field: Three Kinds of Populations in Scientific Practice.

Wiseman, R., O'Ryan, C., \& Harley, E. H. (2000). Microsatellite analysis reveals that domestic cat (Felis catus) and southern African wild cat (F. lybica) are genetically distinct. Animal Conservation, 3(03), 221-228.

Witherspoon, D. J., Wooding, S., Rogers, A. R., Marchani, E. E., Watkins, W. S., Batzer, M. A., \& Jorde, L. B. (2007). Genetic similarities within and between human populations. Genetics, 176(1), 351-359.

Wolfe, T. (2012). Back to blood: a novel. Hachette UK.

Woodley, M.A. (2009). Is Homo sapiens polytypic? Human taxonomic diversity and its implications. Medical hypotheses, 74(1), 195-201.

Woodley, M. A., Rindermann, H., Bell, E., Stratford, J., \& Piffer, D. (2014). The relationship between Microcephalin, ASPM and intelligence: A reconsideration. Intelligence, 44, 51-63. Wright, S. (1978). Vol. 4: Variability within and among natural populations. Chicago [etc.]: University of Chicago Press.

Wu, A. D., Li, Z., \& Zumbo, B. D. (2007). Decoding the meaning of factorial invariance and updating the practice of multi-group confirmatory factor analysis: A demonstration with TIMSS data. Practical Assessment, Research and Evaluation, 12(3), 1-26.

Wu, D. D., \& Zhang, Y. P. (2011). Different level of population differentiation among human genes. BMC evolutionary biology, 11(1), 16.

Xochitl, F., Calderón-Lobato, R. D., Parra-Bracamonte, G. M., Sifuentes-Rincón, A. M., DeYoung, R. W., García-De León, F. J., \& Arellano-Vera, W. (2012). Genetic diversity and structure among subspecies of white-tailed deer in Mexico. Journal of Mammalogy, 93(4), 11581168. 
Xu, S., Huang, W., Qian, J., \& Jin, L. (2008). Analysis of genomic admixture in Uyghur and its implication in mapping strategy. The American Journal of Human Genetics, 82(4), 883-894.

Yang, J., Benyamin, B., McEvoy, B. P., Gordon, S., Henders, A. K., Nyholt, D. R., ... \& Visscher, P. M. (2010). Common SNPs explain a large proportion of the heritability for human height. Nature genetics, 42(7), 565-569.

Yee, J. (2003). Métissage in France: a postmodern fantasy and its forgotten precedents. Modern \& Contemporary France, 11(4), 411-425.

Zakharia, F., Basu, A., Absher, D., Assimes, T. L., Go, A. S., Hlatky, M. A., ... \& Tang, H. (2009). Characterizing the admixed African ancestry of African Americans. Genome Biol, 10(12), R141. Zhang, Y. (2008). Tree-guided Bayesian inference of population structures. Bioinformatics, 24(7), 965-971.

Zhang, Y. D., \& Tier, B. (2009). Population stratification, not genotype error, causes some SNPs to depart from Hardy-Weinberg Equilibrium. In Proc. Assoc. Advmt. Anim. Breed. Genet (Vol. 18, pp. 243-246).

1000 Genomes Project Consortium. (2010). A map of human genome variation from populationscale sequencing. Nature, 467(7319), 1061-1073. 